\title{
Supplementary
}

\section{Novel HIV-1 Protease Inhibitors with Morpholine as the P2 Ligand to Enhance Activity against DRV-Resistant Variants}

Mei Zhu,'Yue Dou,' Ling Ma," Biao Dong, Fan Zhang, Guoning Zhang, Juxian Wang, Jinming Zhou, ${ }^{*}$ Shan Cen, ${ }^{*}$ and Yucheng Wang ${ }^{*}$

Table of Contents:

I. ${ }^{1} \mathrm{H}$ NMR, ${ }^{13} \mathrm{C}$ NMR and HR MS Spectrums of Compounds

II. Chemistry section

III. In vitro assay for HIV-1 Protease Inhibition

IV. Converting $\mathrm{IC}_{50}$ to $\mathrm{K}_{\mathrm{i}}$ values

V. Infectivity assay on HIV-1 late stage

VI. Infectivity assay on HIV-1 early stage

VII. Construction of DRV-resistant pNL4-3-E-R- cloning (pHIV-1 $\mathrm{DRV}_{\mathrm{S}} \mathrm{R}$

VIII. Molecular modeling 


\section{I. ${ }^{1} \mathrm{H}$ NMR, ${ }^{13} \mathrm{C}$ NMR and HR MS Spectrums of Compounds}
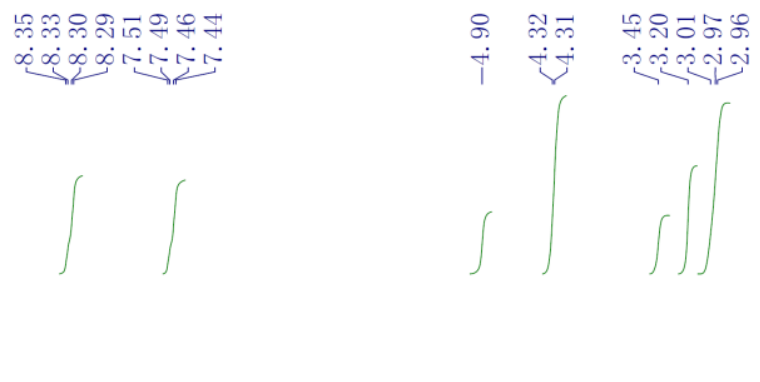

$\overbrace{\mathrm{N}}^{\mathrm{N}} \mathrm{N}_{\mathrm{O}}^{\mathrm{O}}$

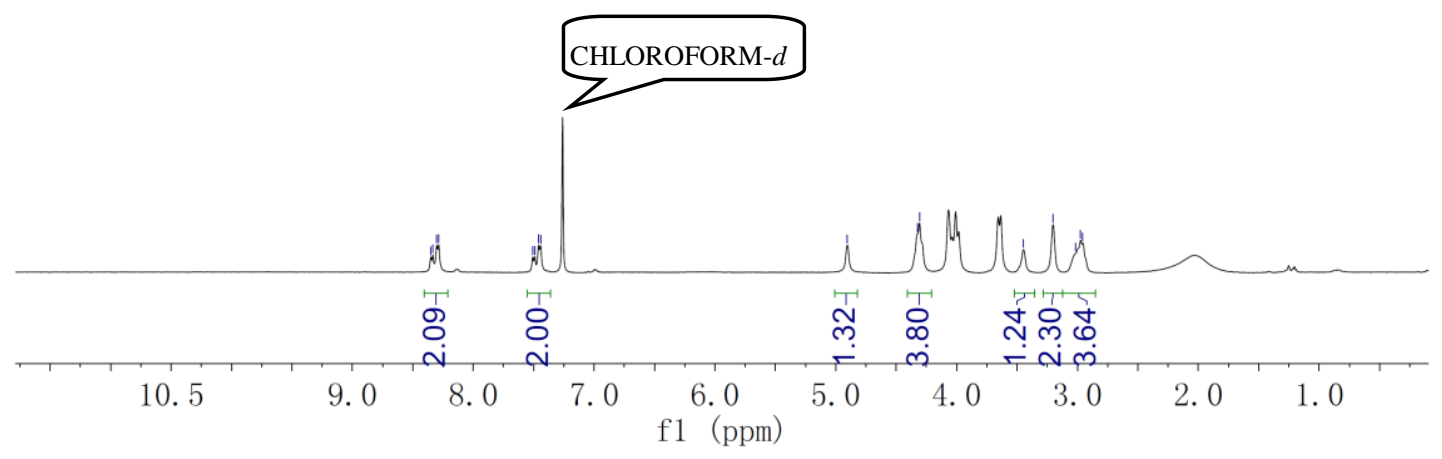

${ }^{1} \mathrm{H}$ NMR Spectrum of compound $\mathbf{1 2}$

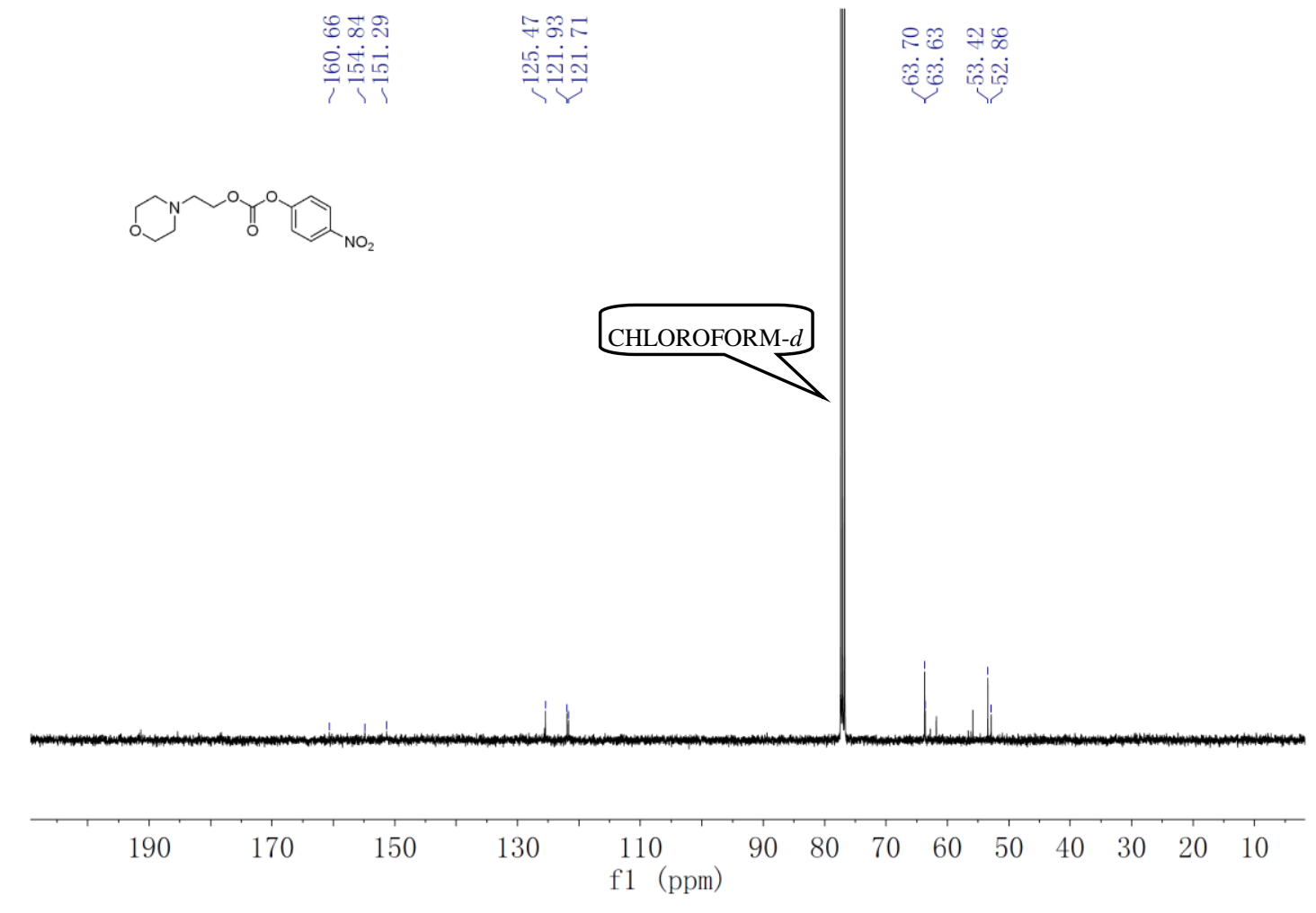

${ }^{13} \mathrm{C}$ NMR Spectrum of compound $\mathbf{1 2}$ 


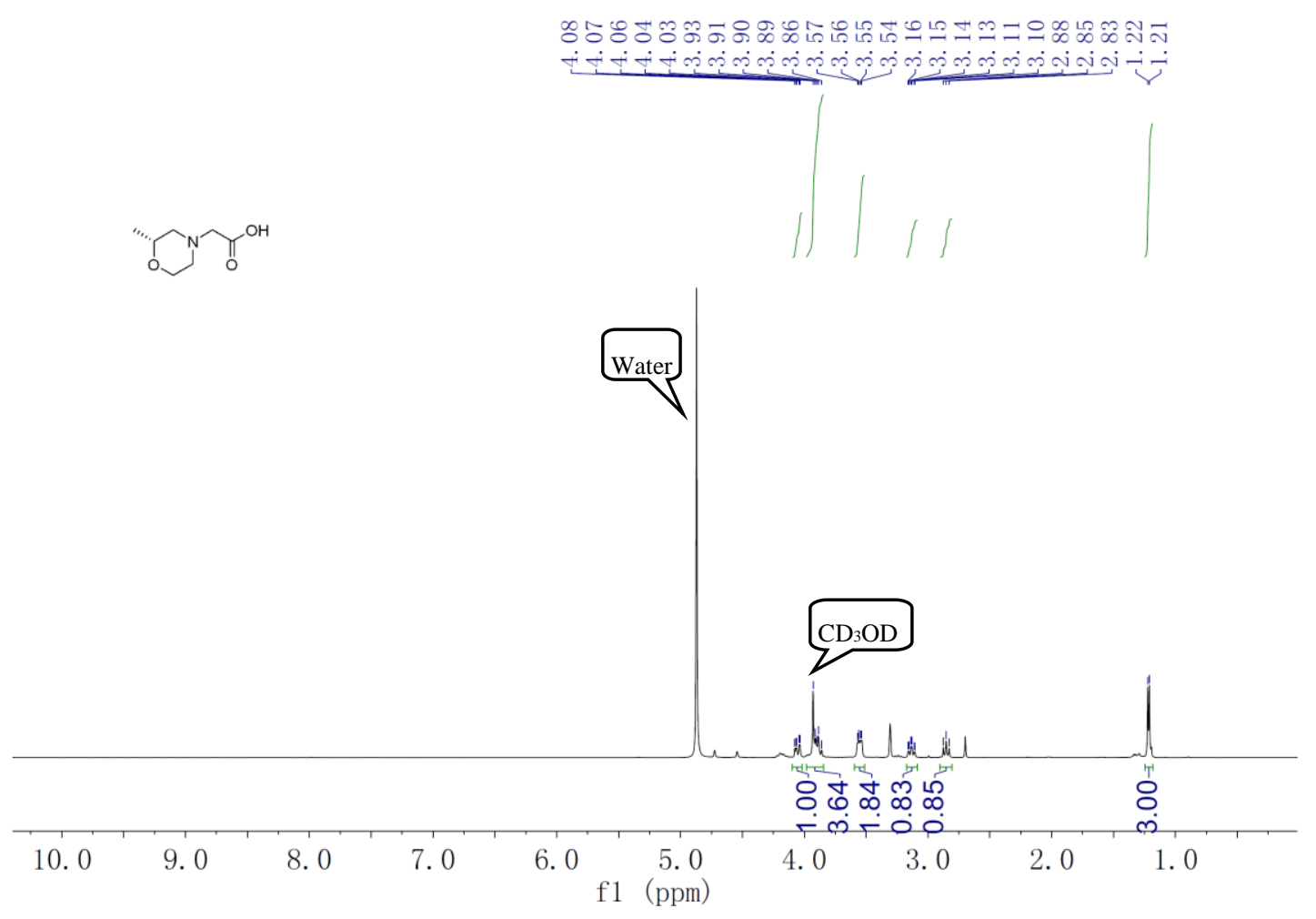

${ }^{1} \mathrm{H}$ NMR Spectrum of compound $\mathbf{1 6}$

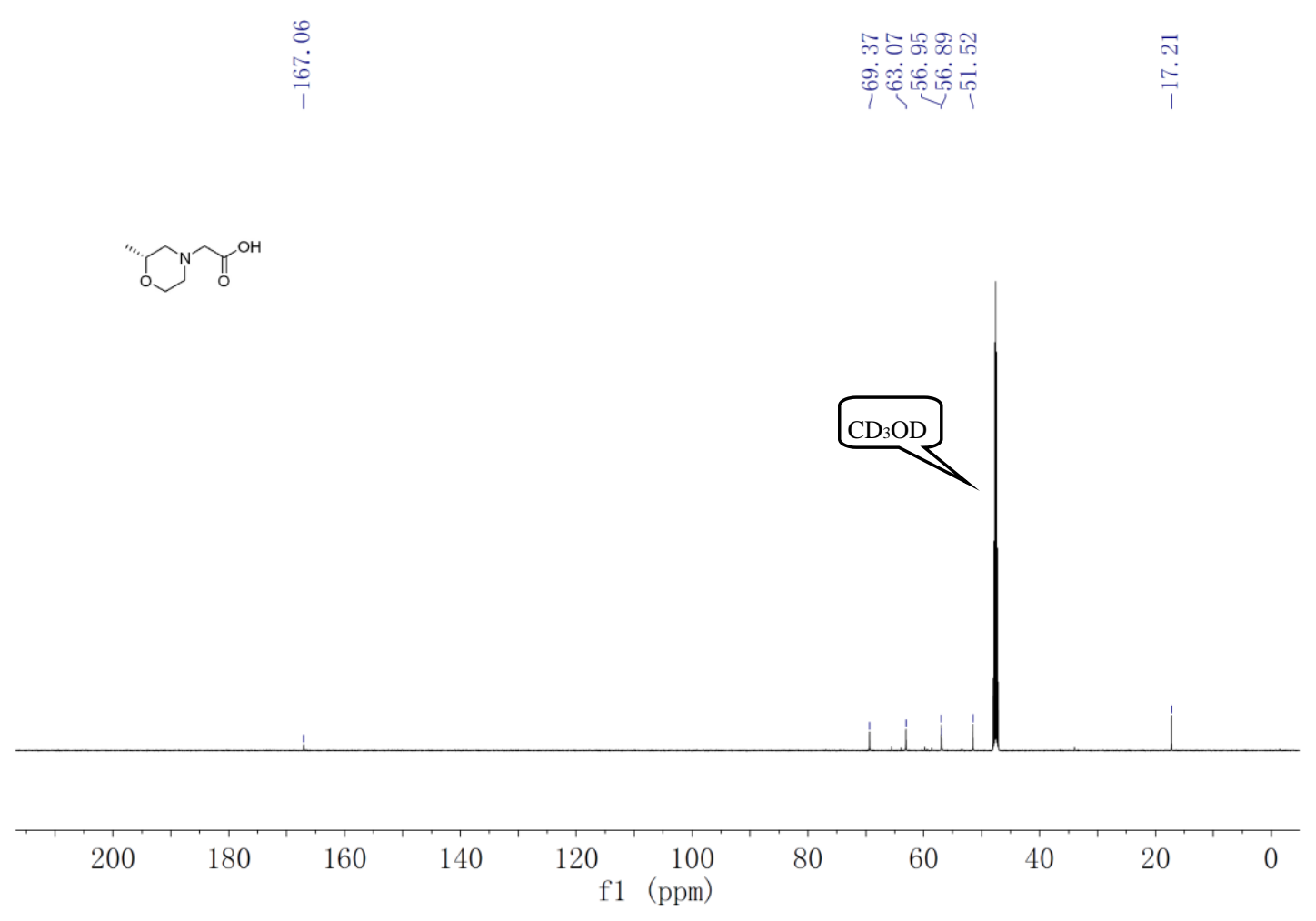

${ }^{13} \mathrm{C}$ NMR Spectrum of compound $\mathbf{1 6}$ 


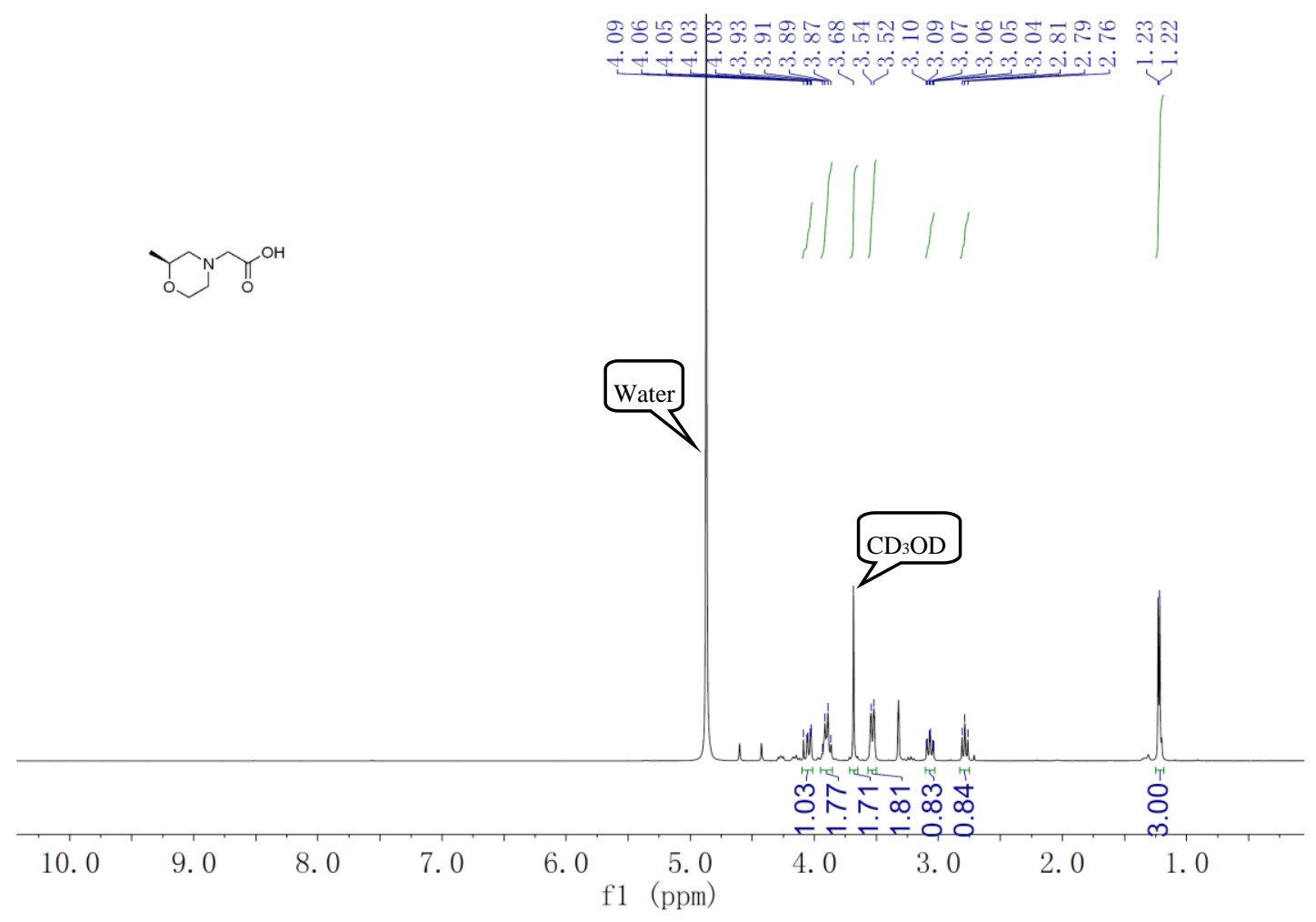

${ }^{1} \mathrm{H}$ NMR Spectrum of compound $\mathbf{1 7}$

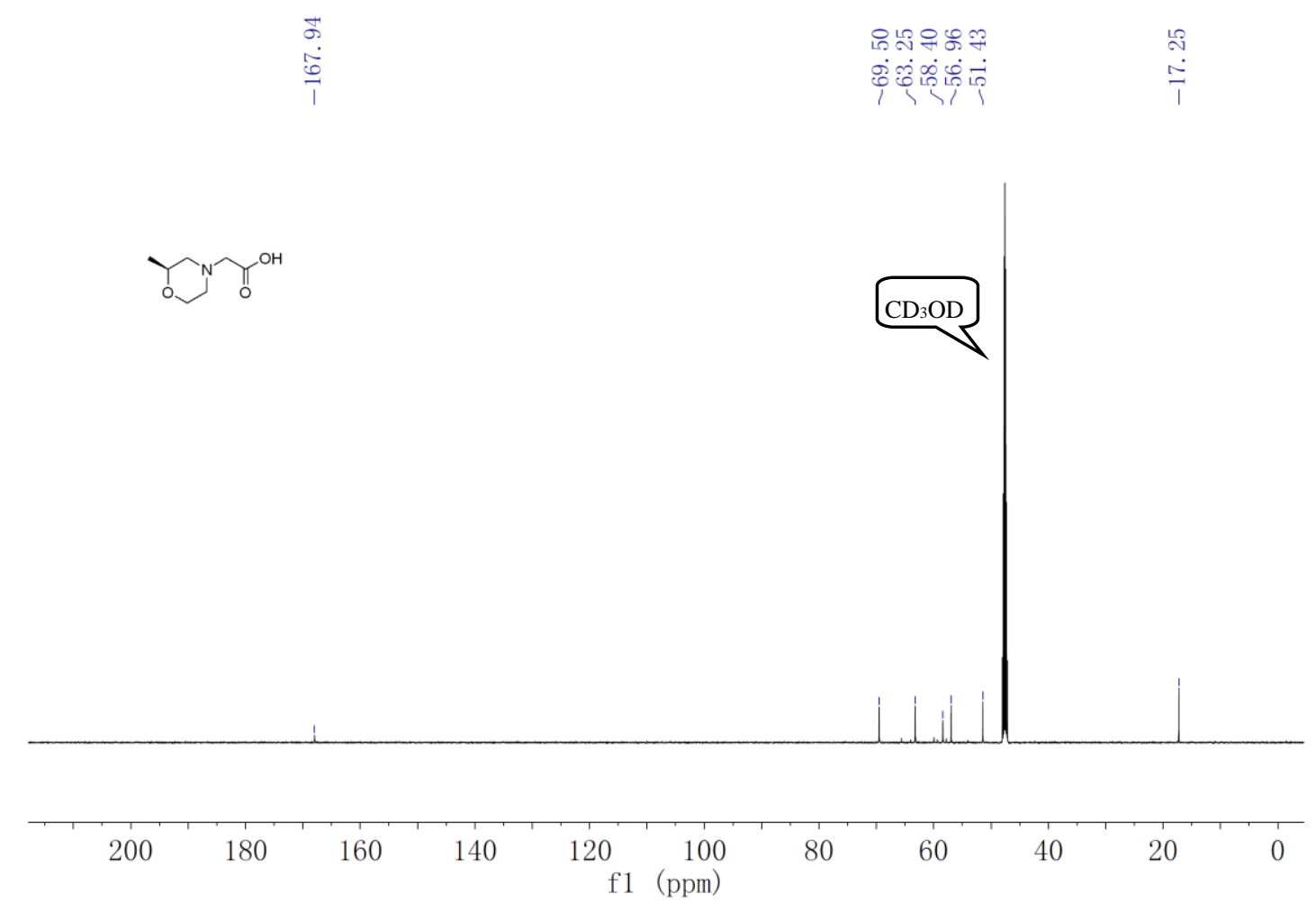

${ }^{13} \mathrm{C}$ NMR Spectrum of compound $\mathbf{1 7}$ 


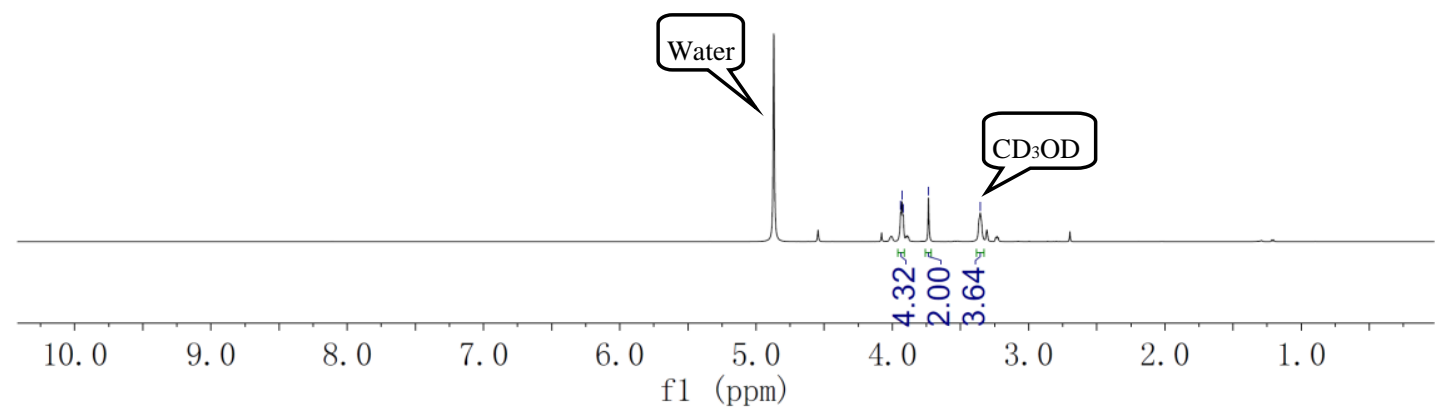

${ }^{1} \mathrm{H}$ NMR Spectrum of compound $\mathbf{1 8}$

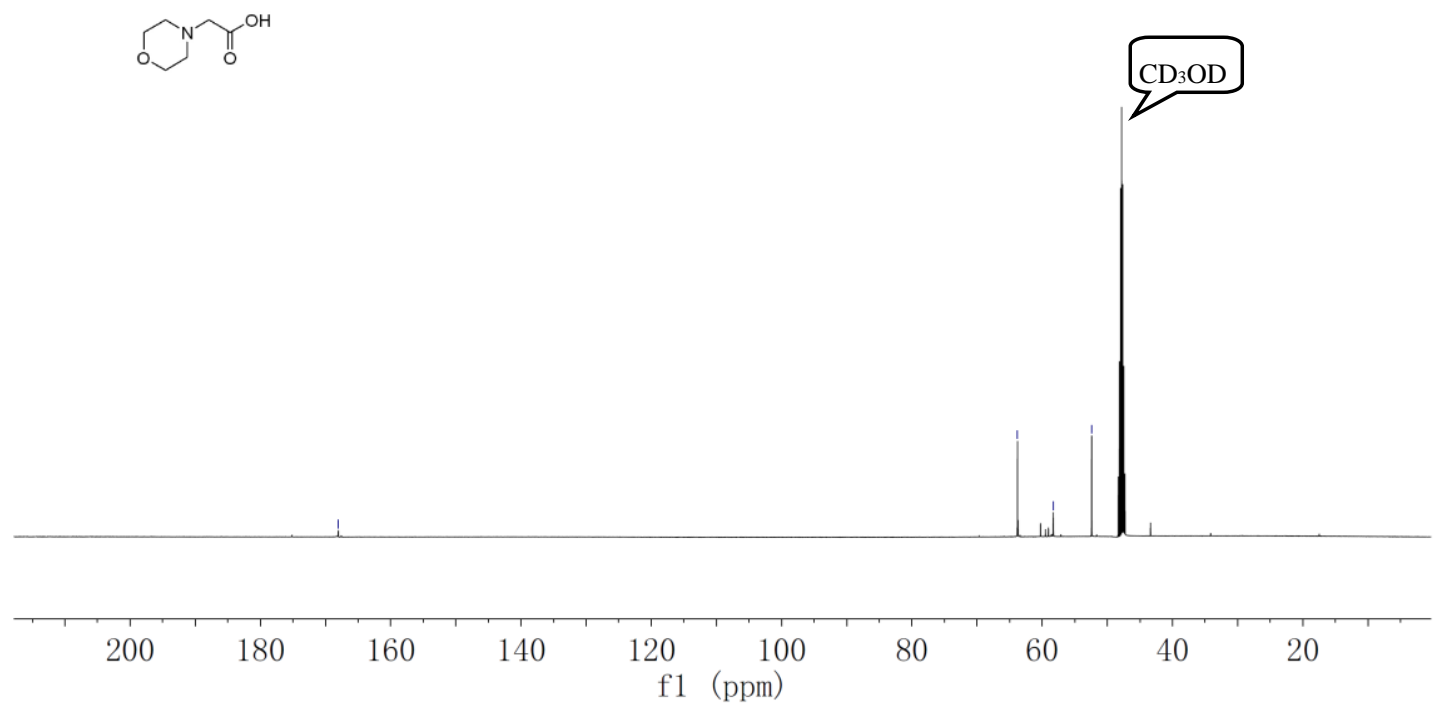

${ }^{13} \mathrm{C}$ NMR Spectrum of compound $\mathbf{1 8}$ 

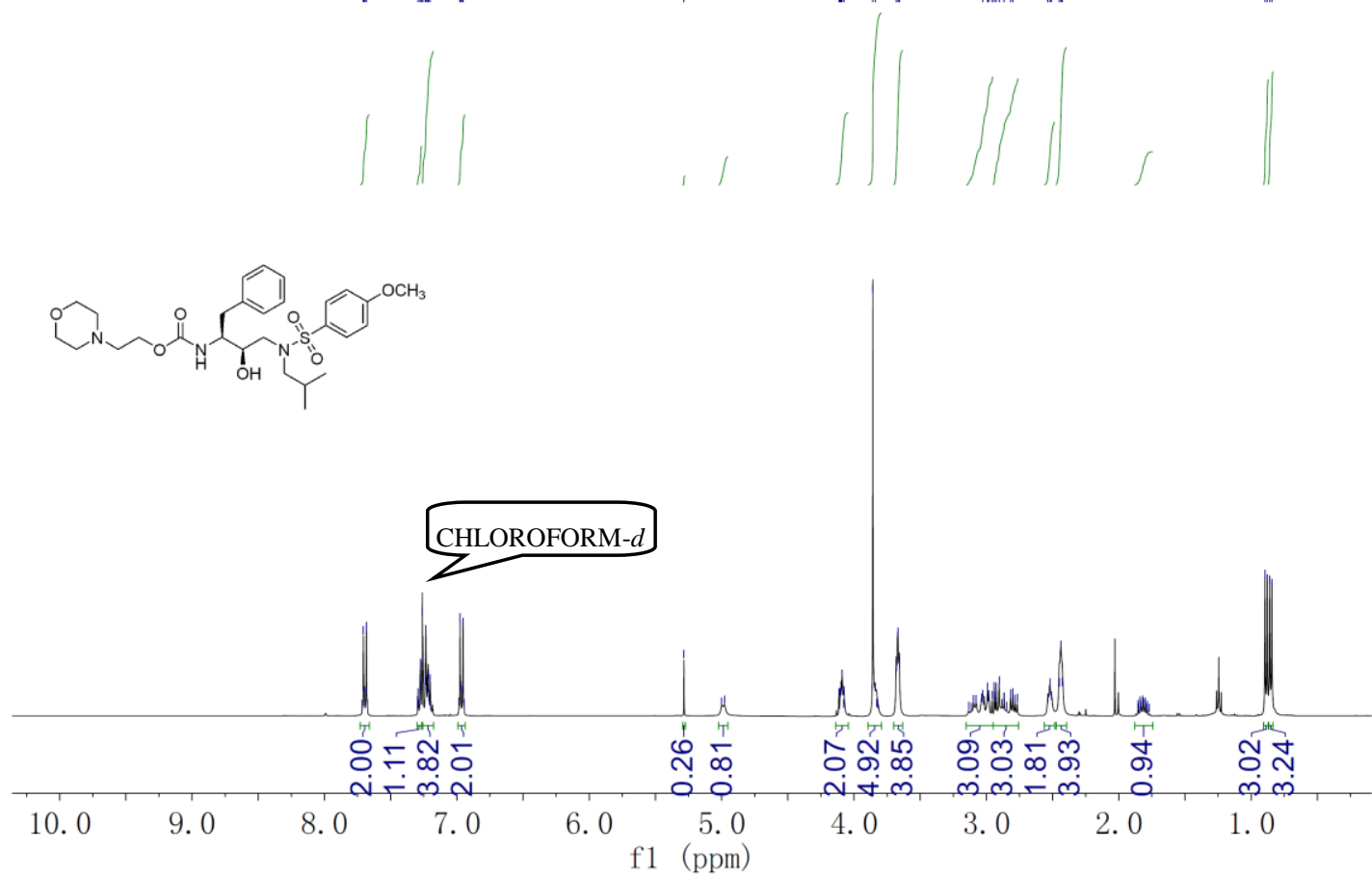

${ }^{1} \mathrm{H}$ NMR Spectrum of compound 23a
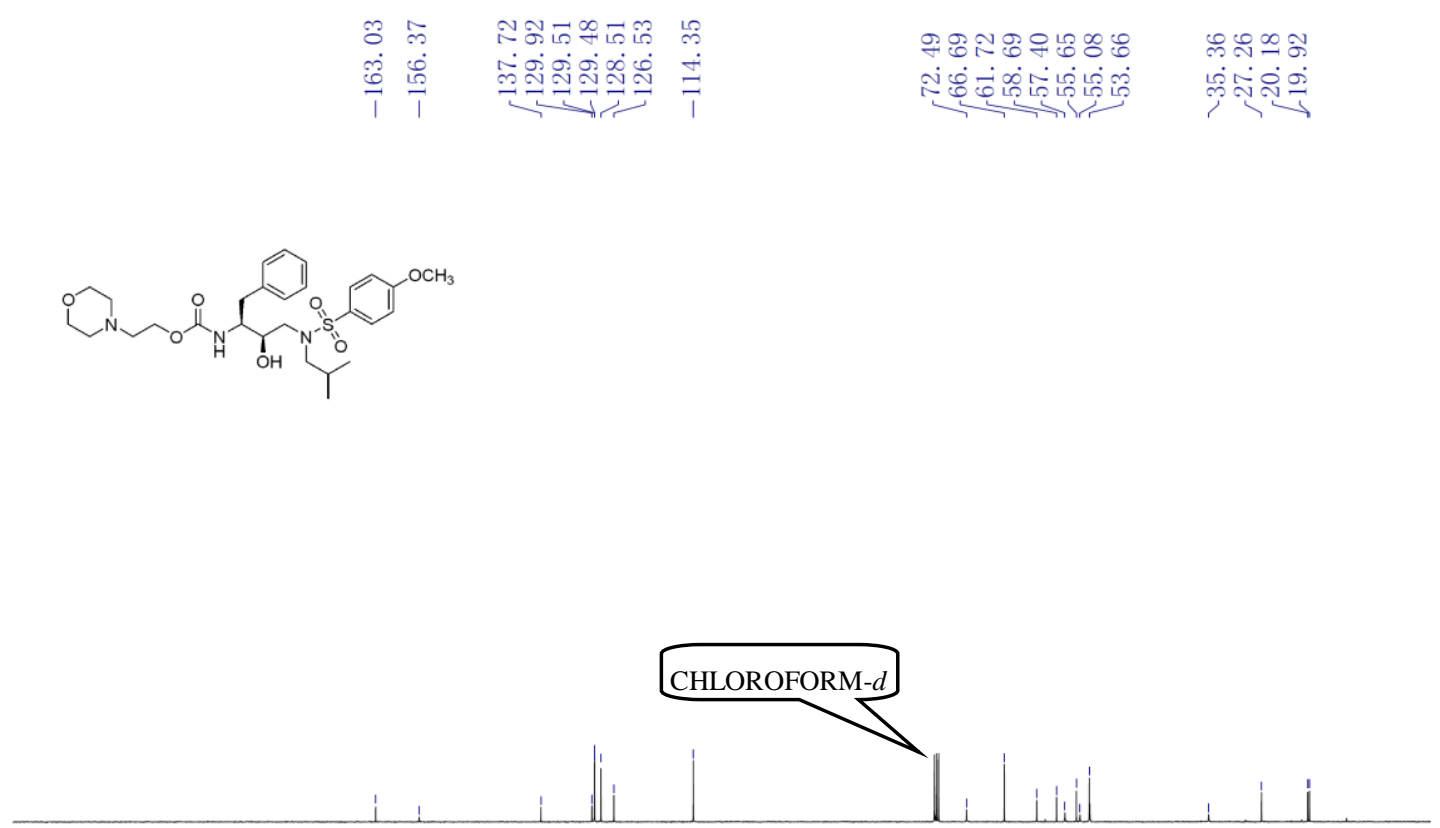


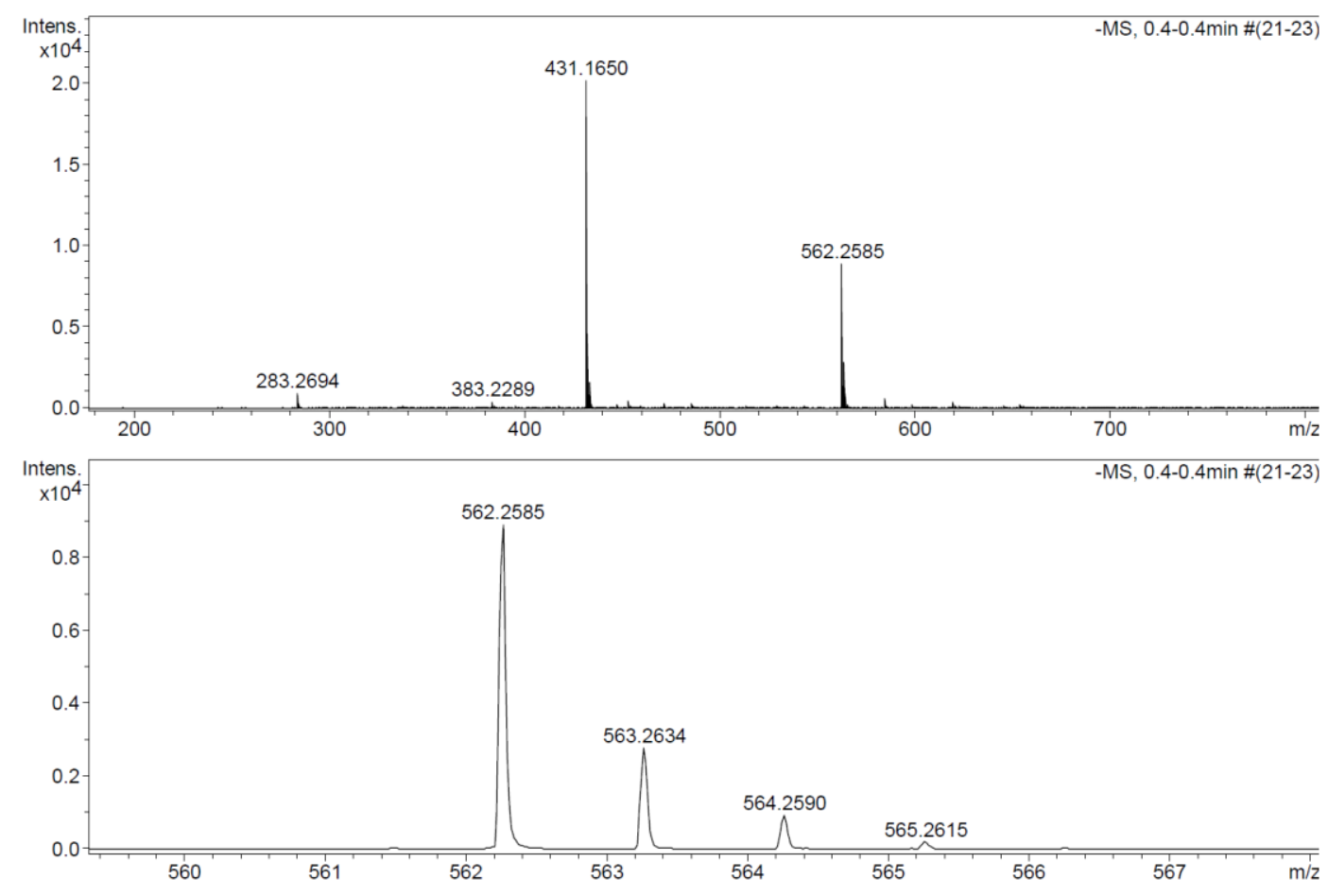

HR MS Spectrum of compound 23a

도요

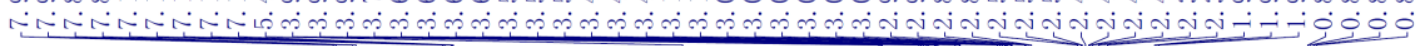

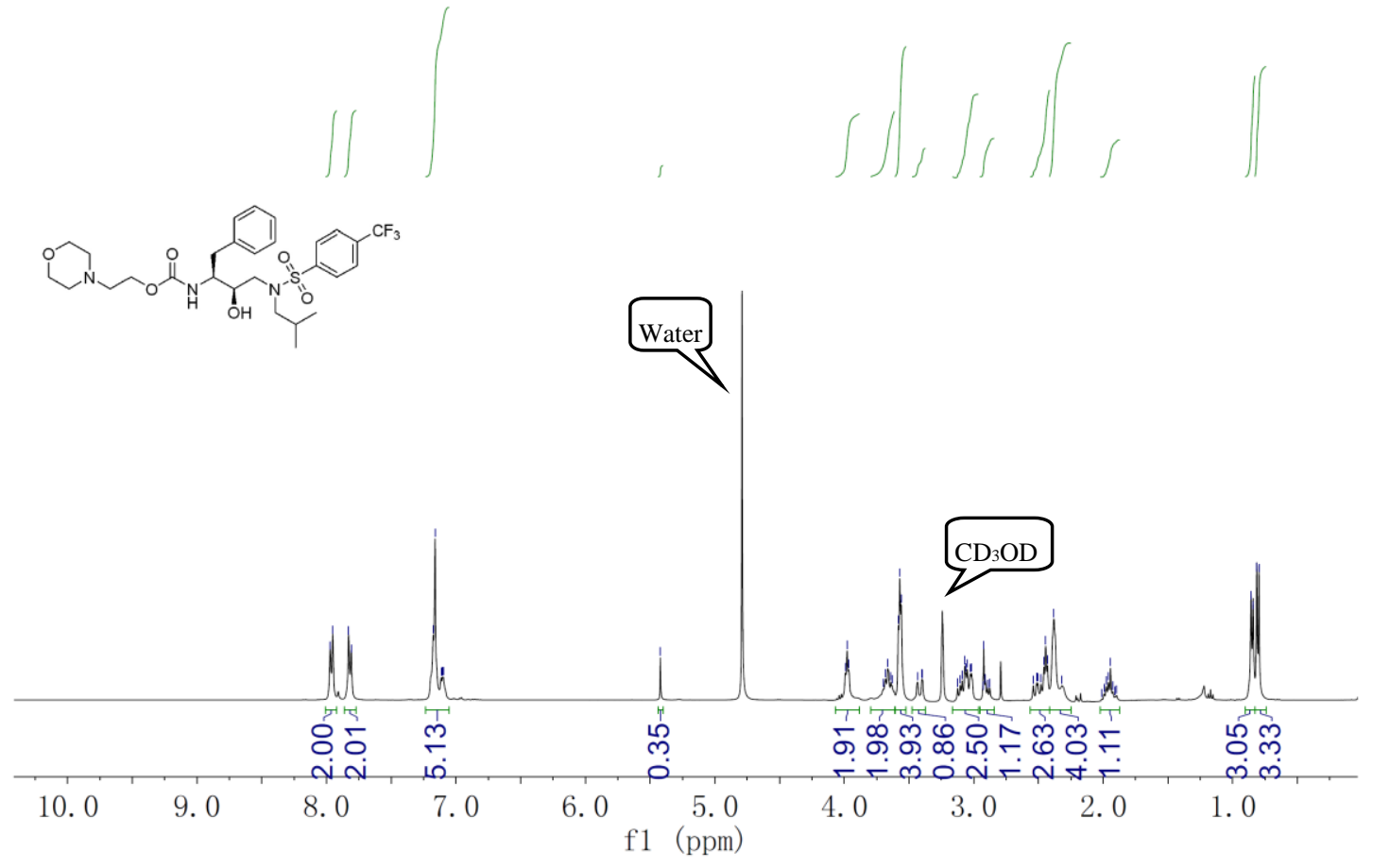

${ }^{1} \mathrm{H}$ NMR Spectrum of compound $\mathbf{2 3 b}$ 


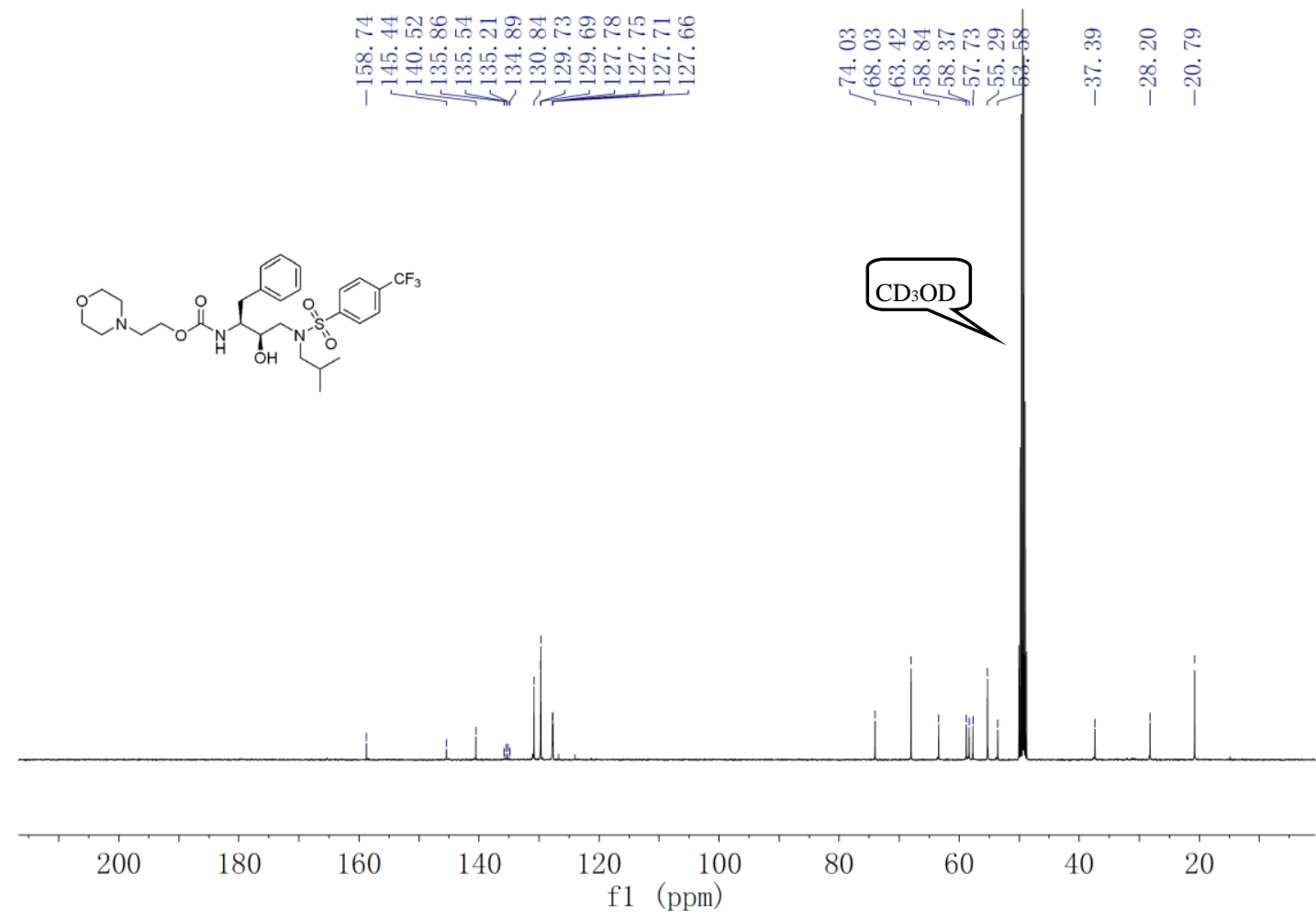

${ }^{13} \mathrm{C}$ NMR Spectrum of compound 23b

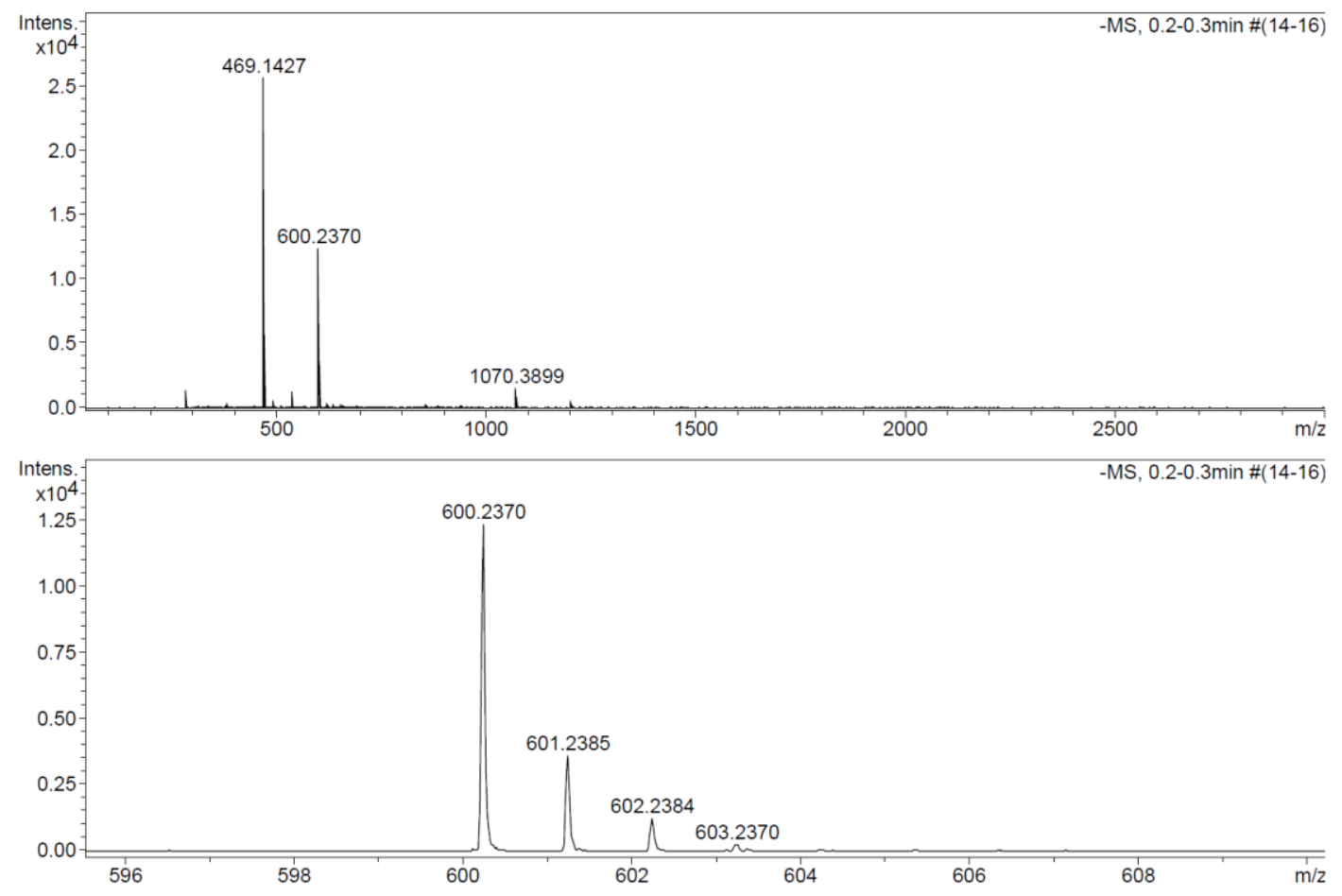

HR MS Spectrum of compound 23b 


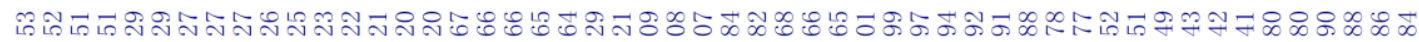

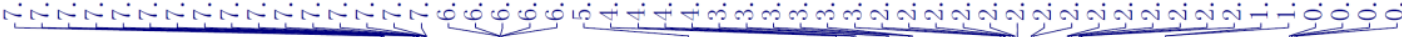
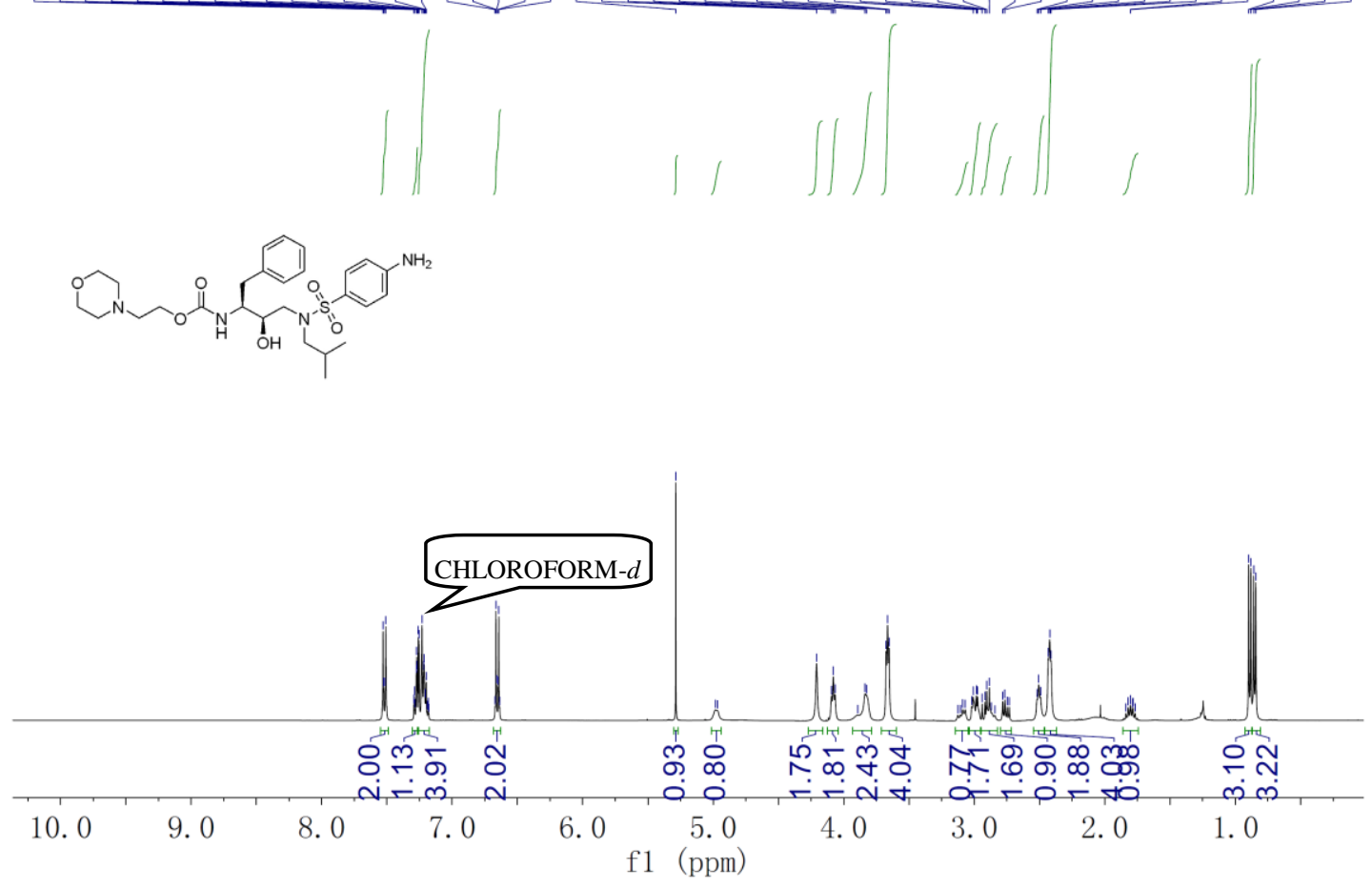

${ }^{1} \mathrm{H}$ NMR Spectrum of compound 23c

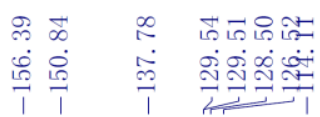

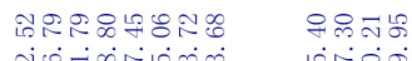

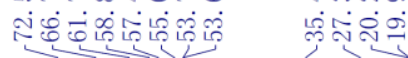
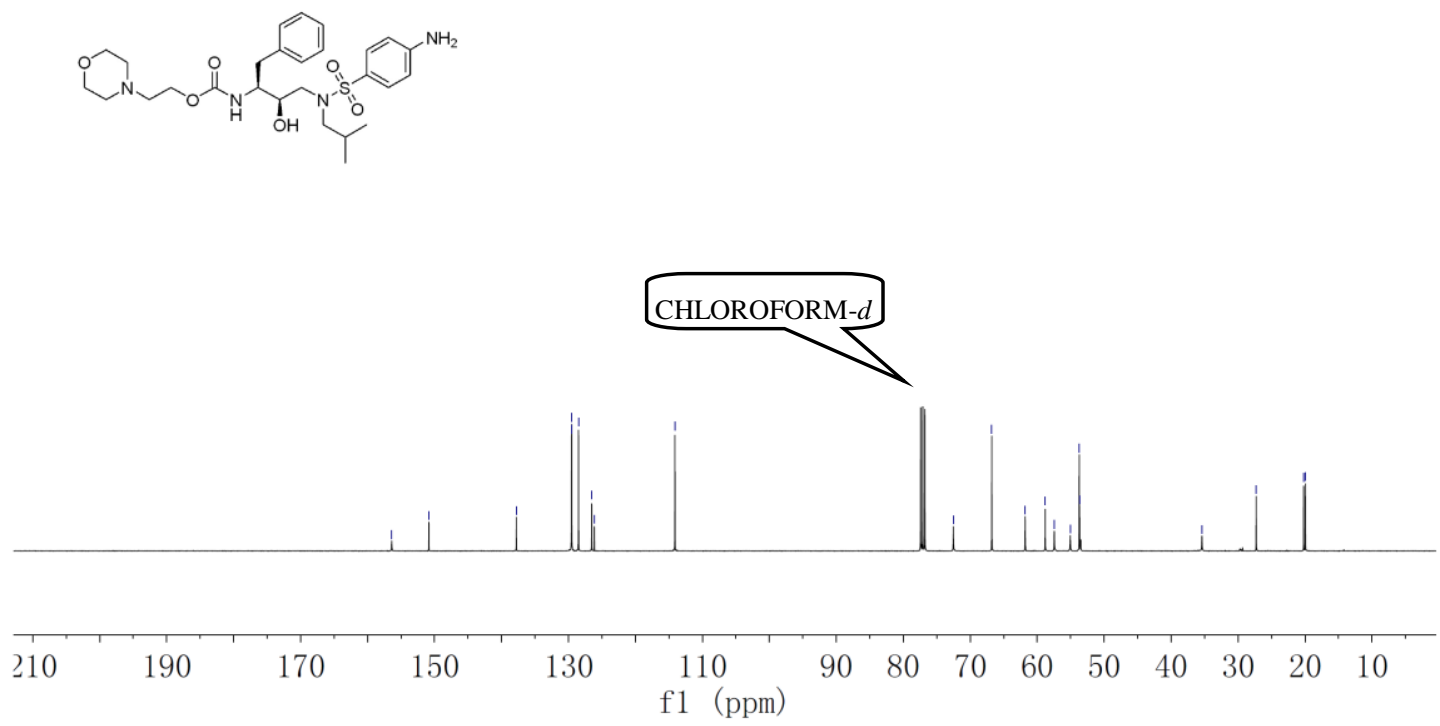

${ }^{13} \mathrm{C}$ NMR Spectrum of compound 23c 


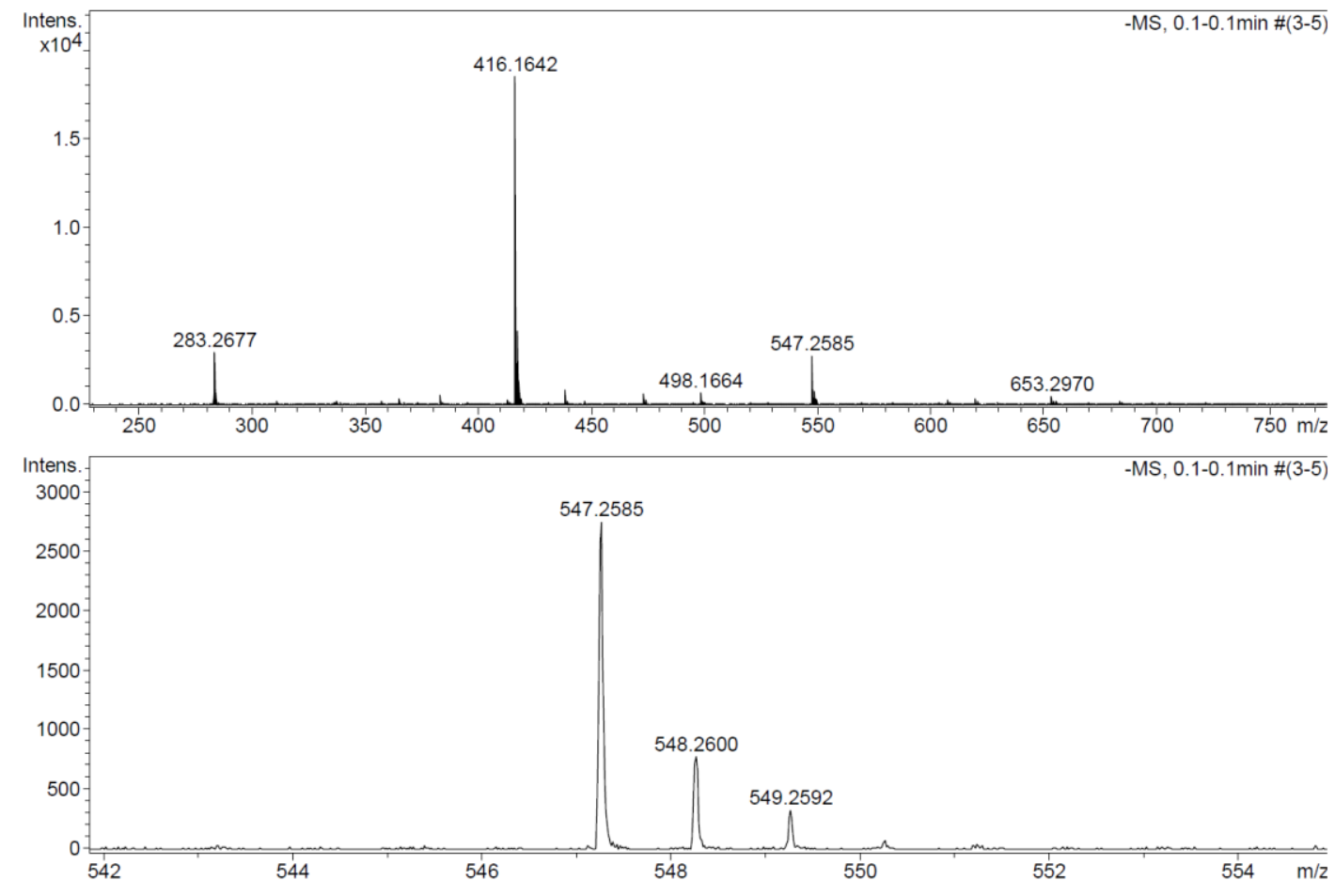

HR MS Spectrum of compound 23c

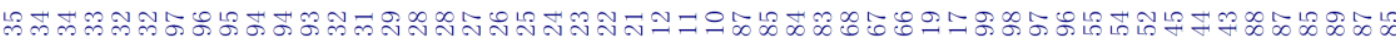

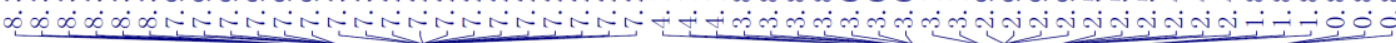<smiles>C=CC(=O)N(CC(C)C)S(=O)(=O)c1ccc([N+](=O)[O-])cc1</smiles>
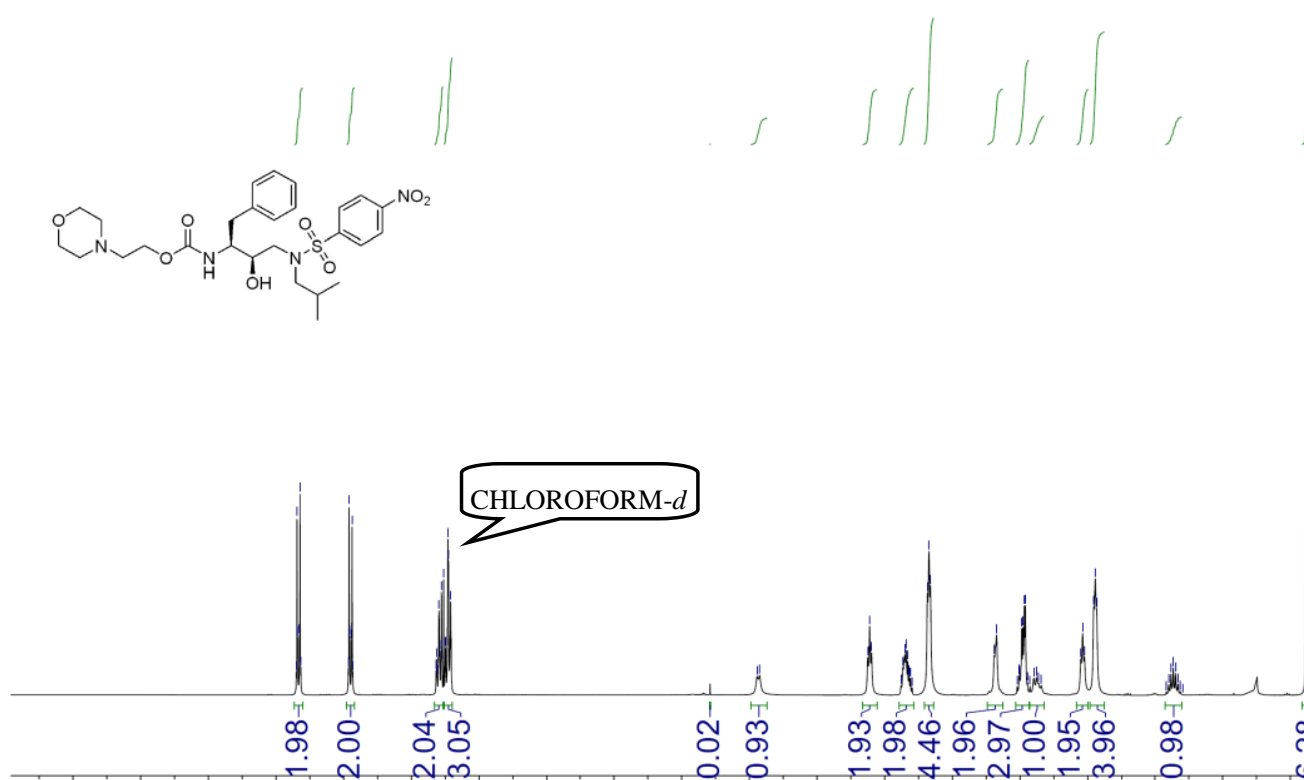

10. 0

9. 0

8. 0

7.0

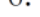

f1 (ppm)

๗ั.

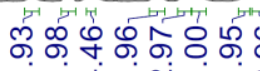

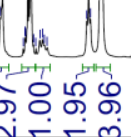

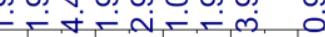

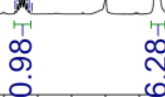

$\stackrel{\infty}{\sim}$

,

${ }^{1} \mathrm{H}$ NMR Spectrum of compound 23d 


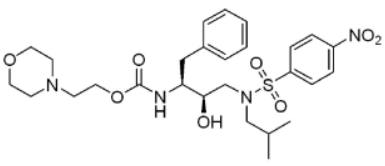

CHLOROFORM-d

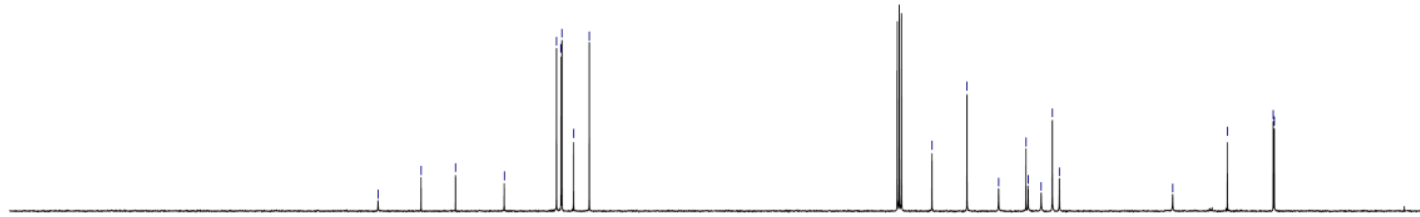

200

$180 \quad 160$

140

120

100

80

60

40

20

${ }^{13} \mathrm{C}$ NMR Spectrum of compound 23d

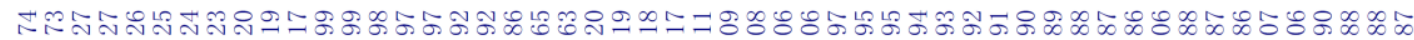

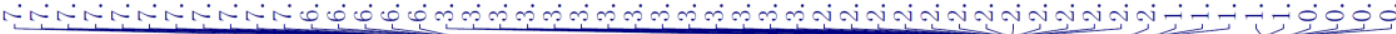

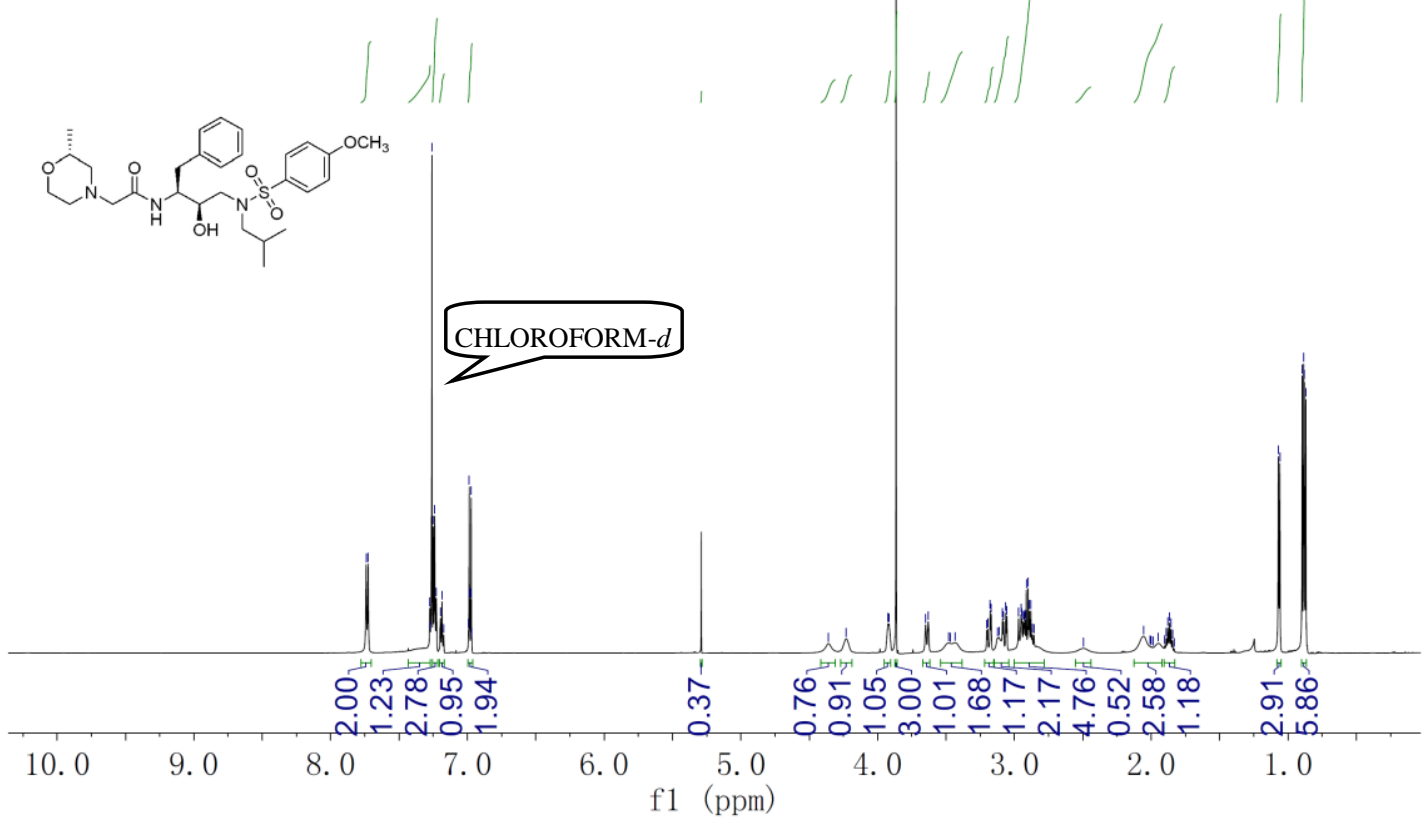

${ }^{1} \mathrm{H}$ NMR Spectrum of compound $\mathbf{2 4 a}$ 


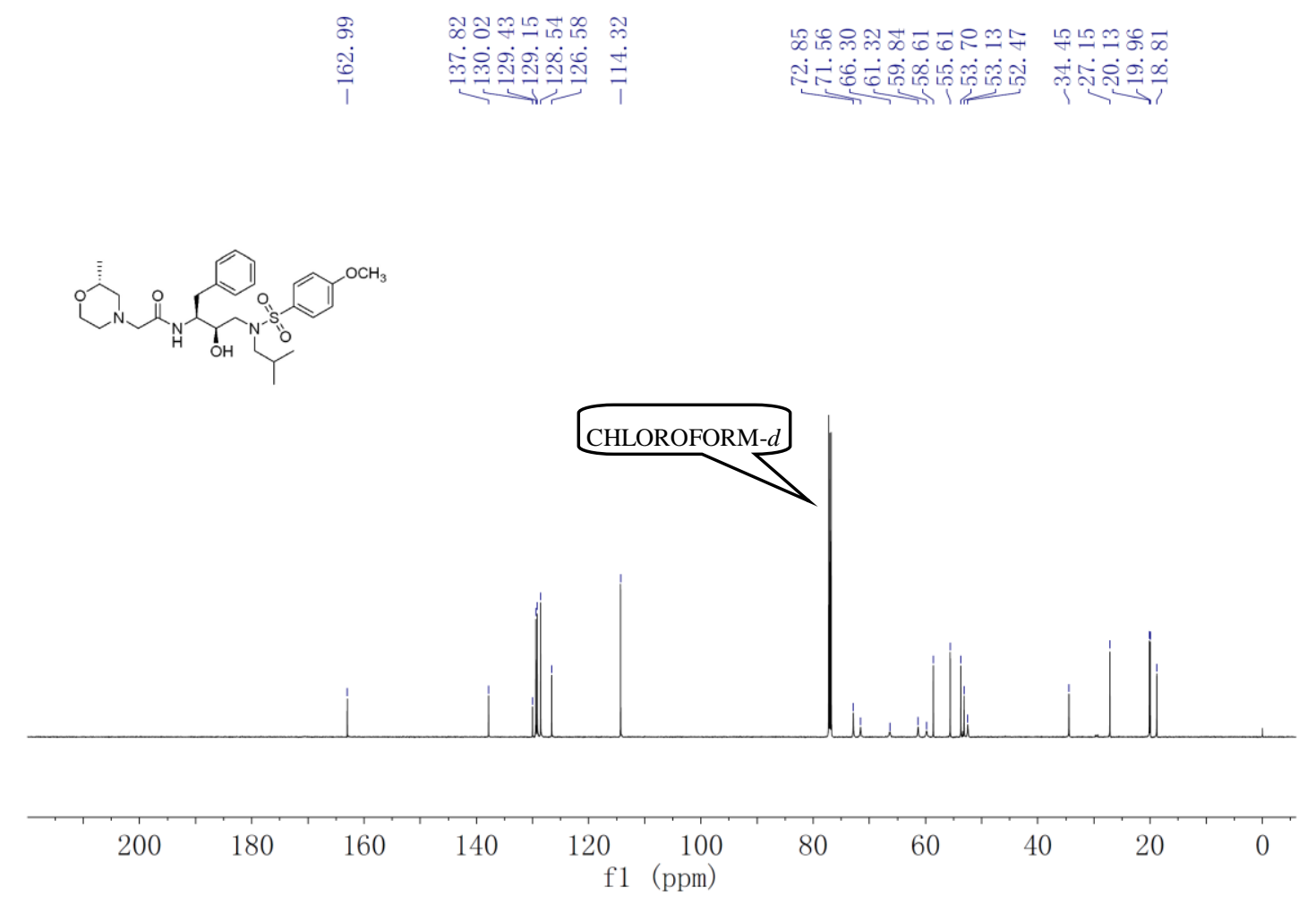

${ }^{13} \mathrm{C}$ NMR Spectrum of compound $\mathbf{2 4 a}$

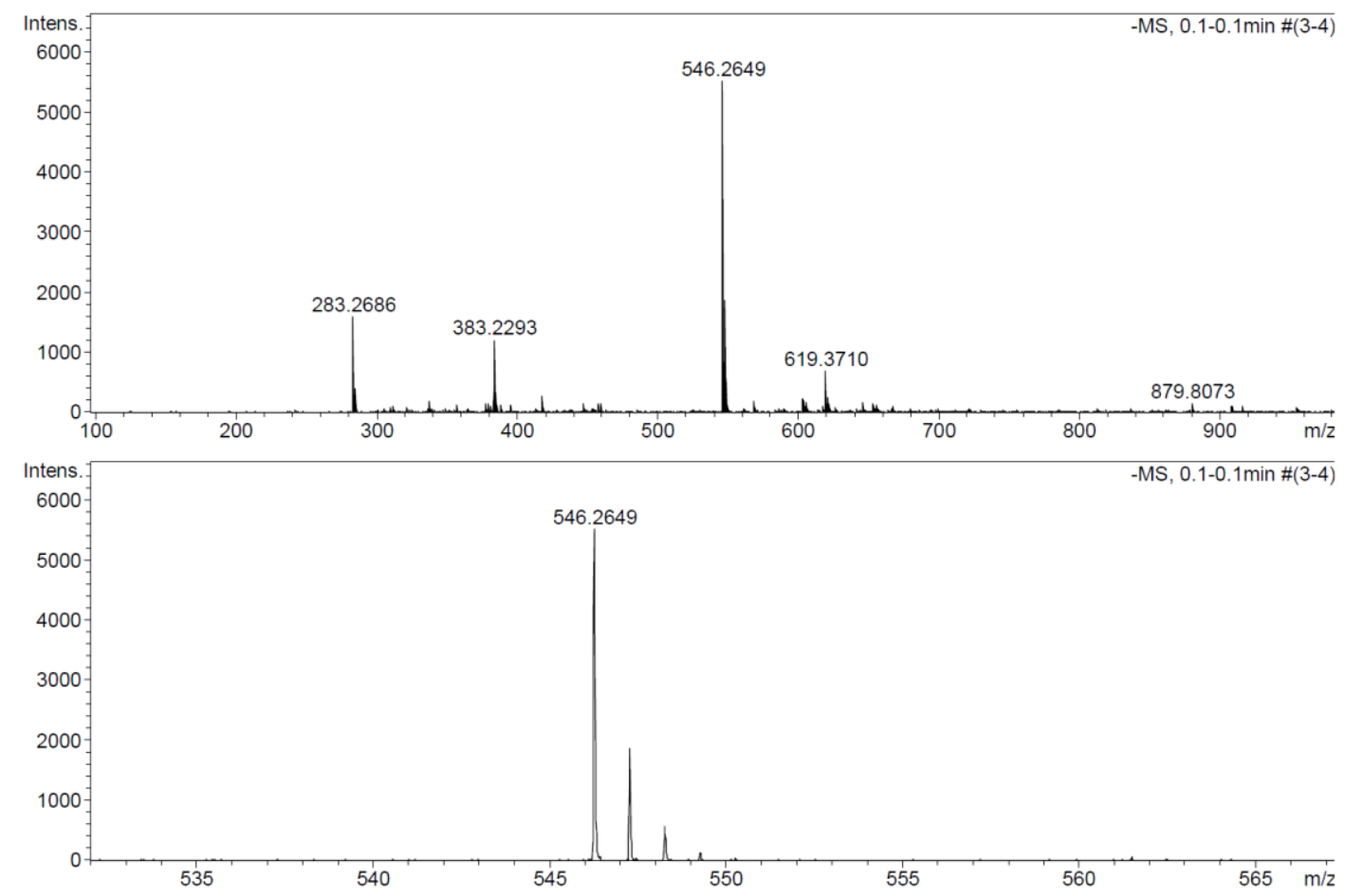

HR MS Spectrum of compound 24a 


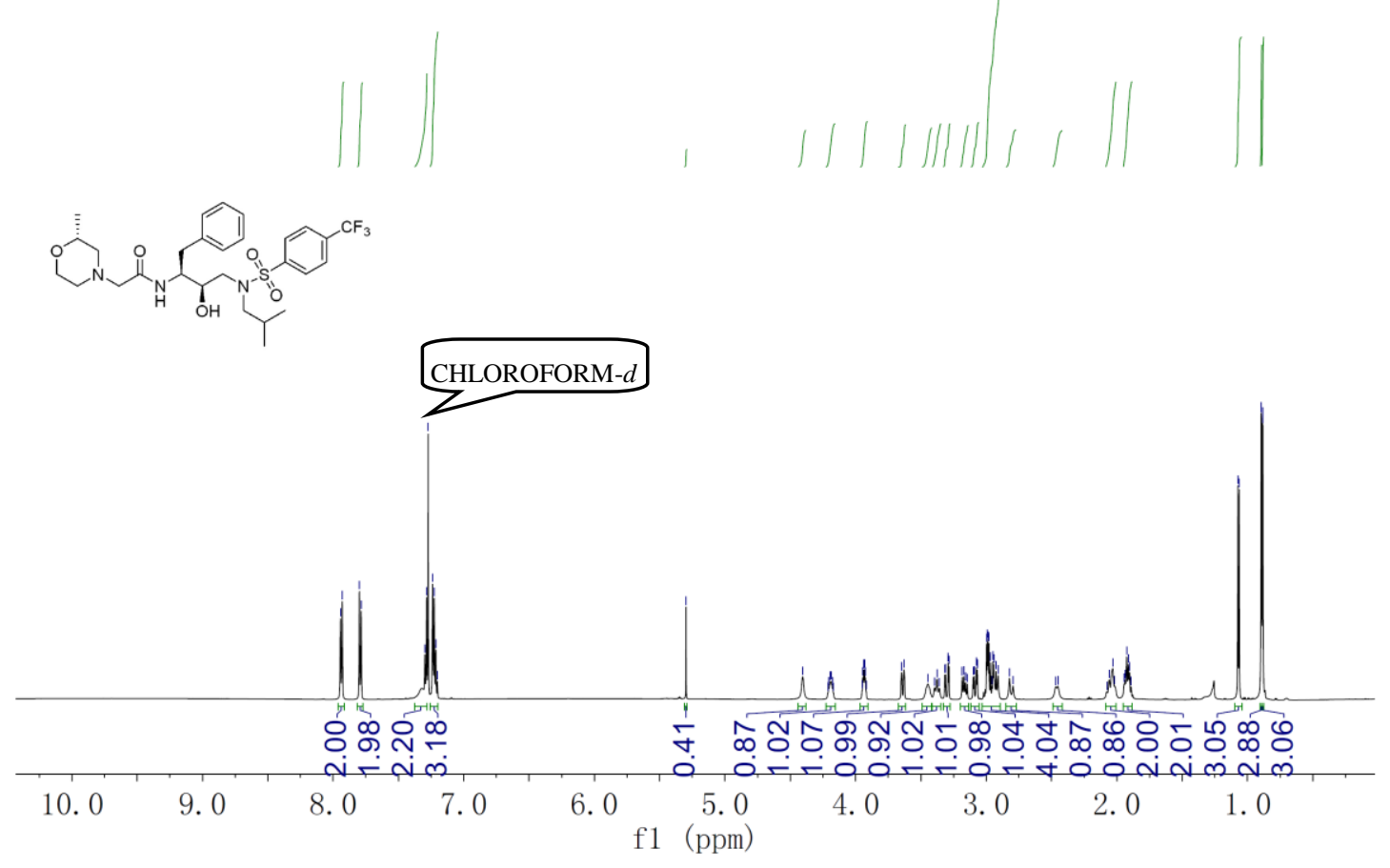

${ }^{1} \mathrm{H}$ NMR Spectrum of compound 24b

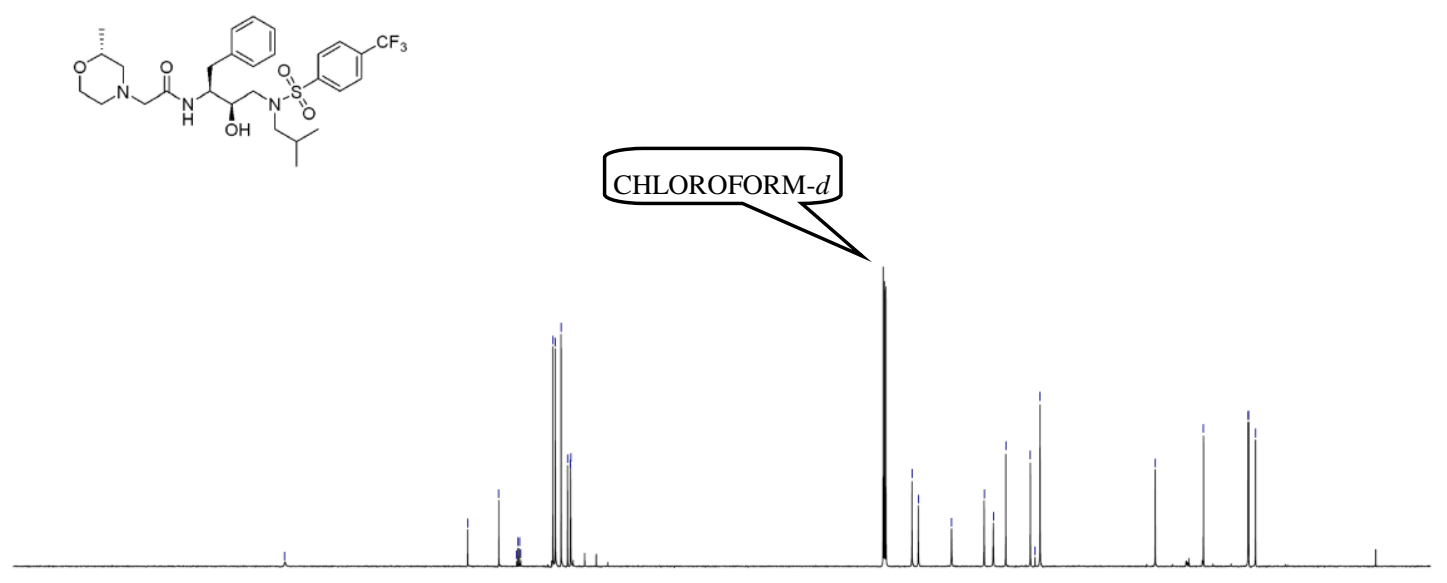

\begin{tabular}{|c|c|c|c|c|c|c|c|c|c|c|}
\hline 200 & 180 & 160 & 140 & 120 & $\begin{array}{l}100 \\
(\mathrm{ppm})\end{array}$ & 80 & 60 & 40 & 20 & 0 \\
\hline
\end{tabular}

${ }^{13} \mathrm{C}$ NMR Spectrum of compound 24b 


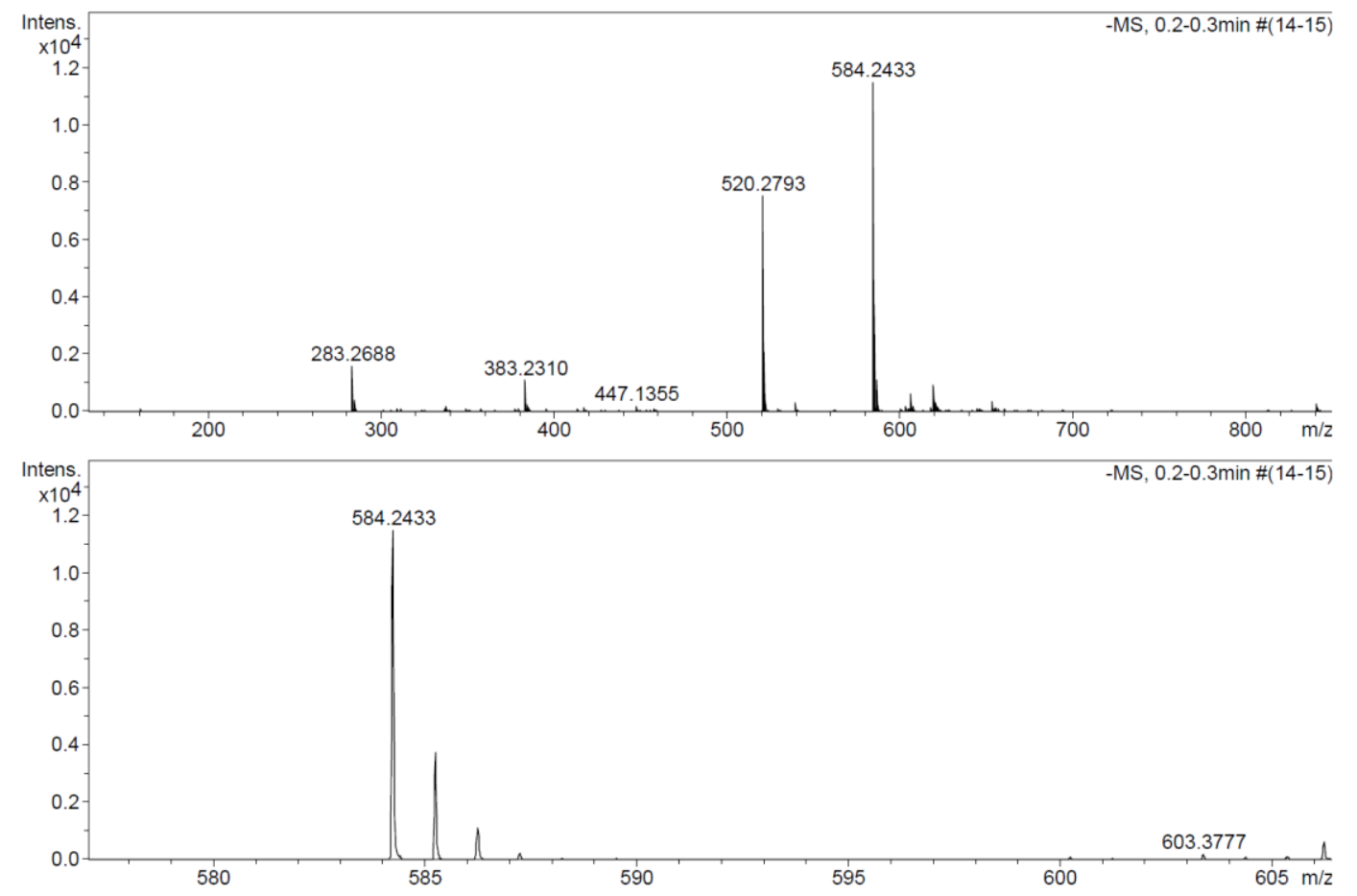

HR MS Spectrum of compound 24b

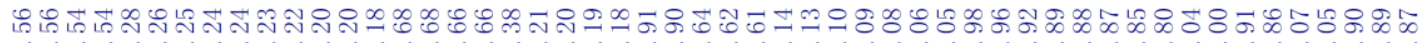

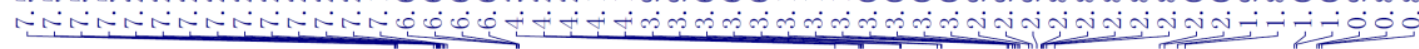

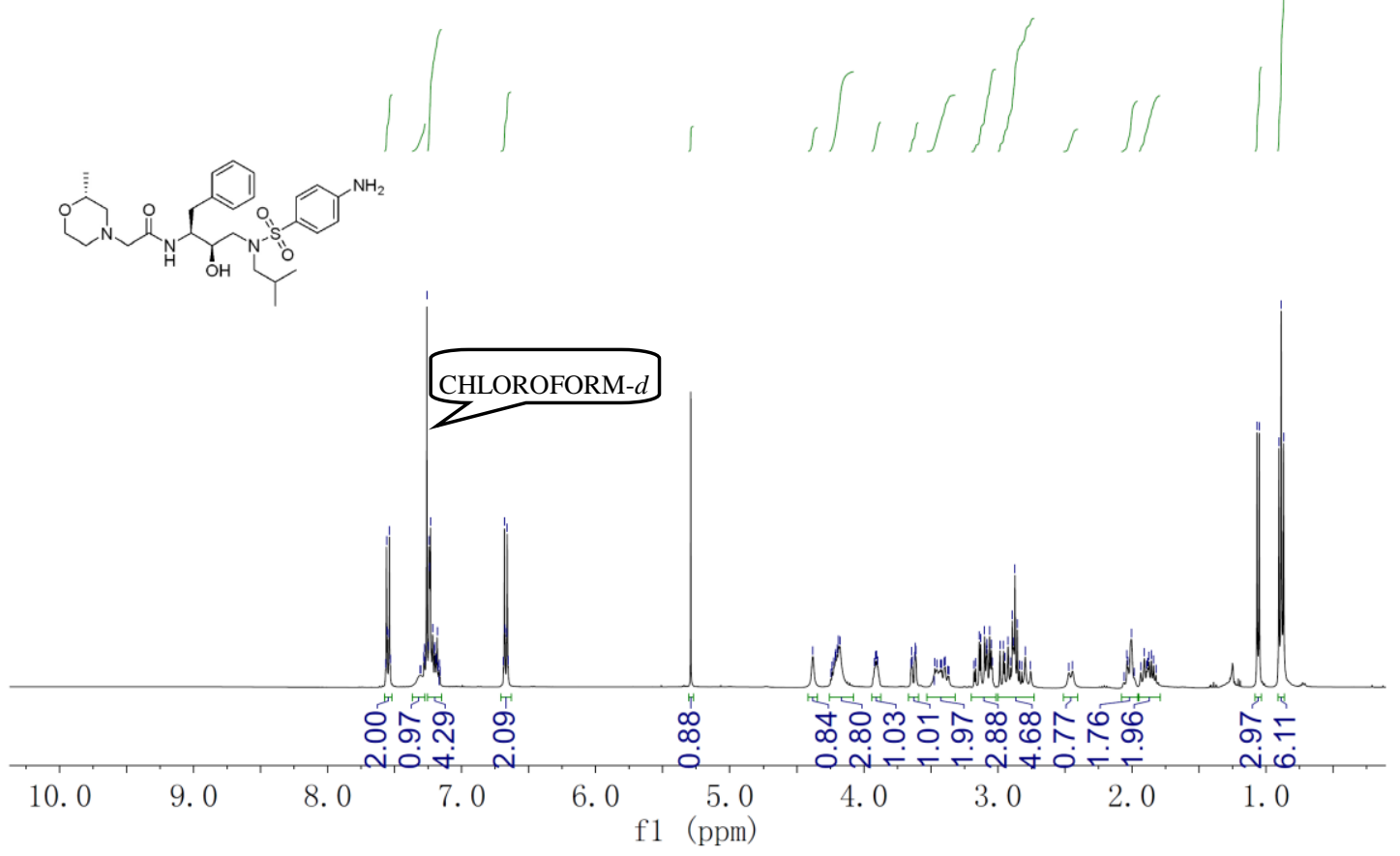

${ }^{1} \mathrm{H}$ NMR Spectrum of compound $\mathbf{2 4 c}$ 


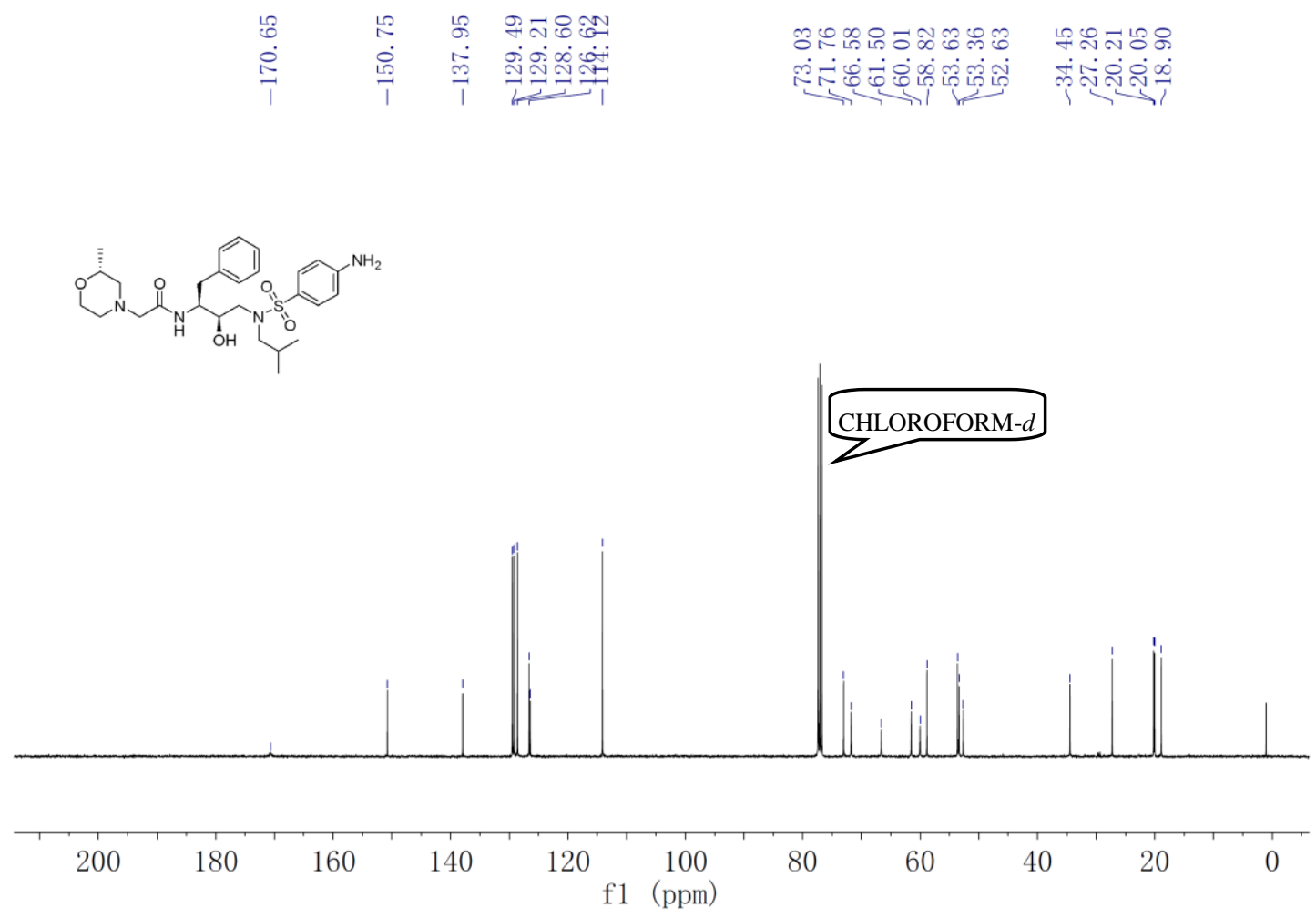

${ }^{13} \mathrm{C}$ NMR Spectrum of compound $\mathbf{2 4 c}$

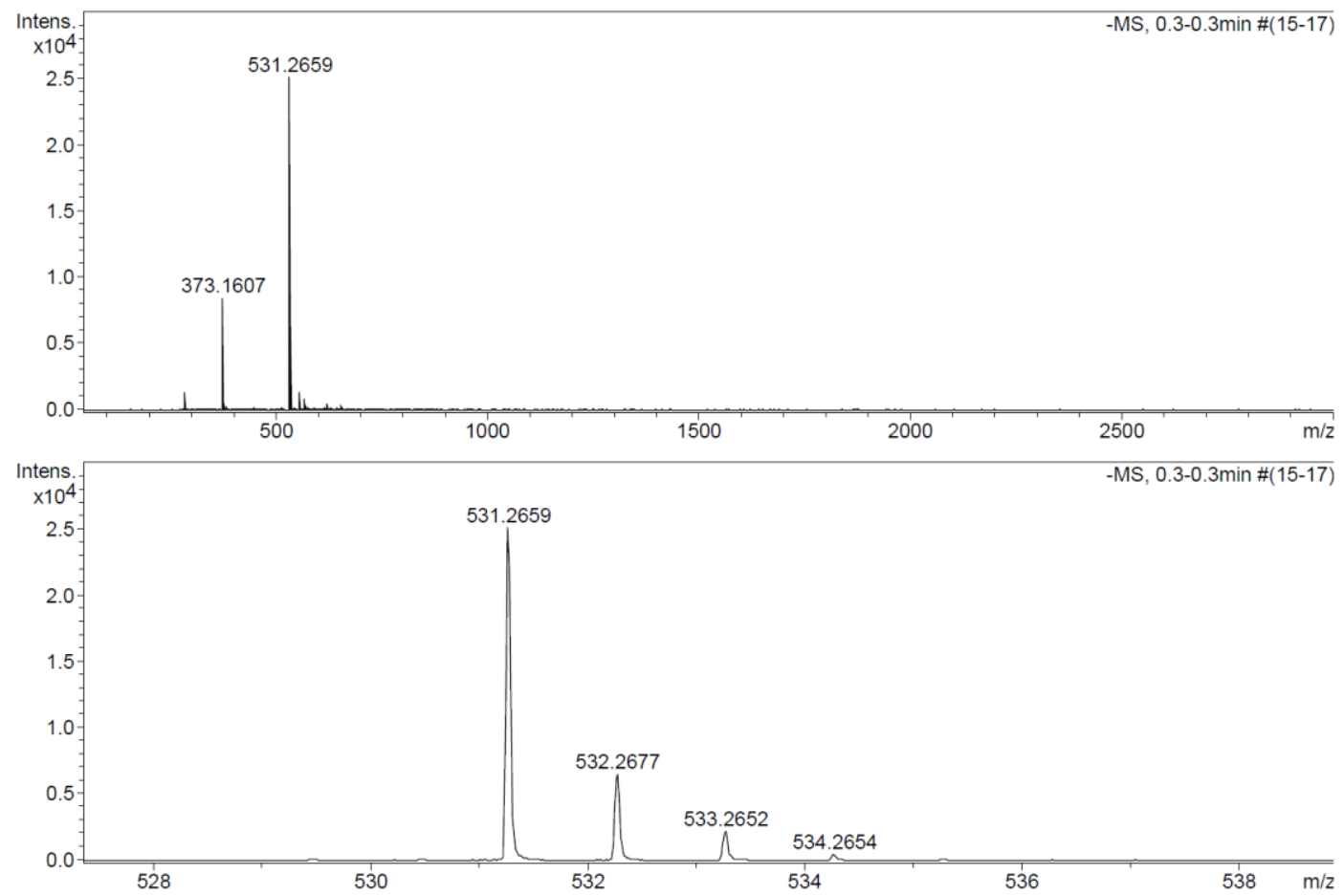

HR MS Spectrum of compound $\mathbf{2 4 c}$ 


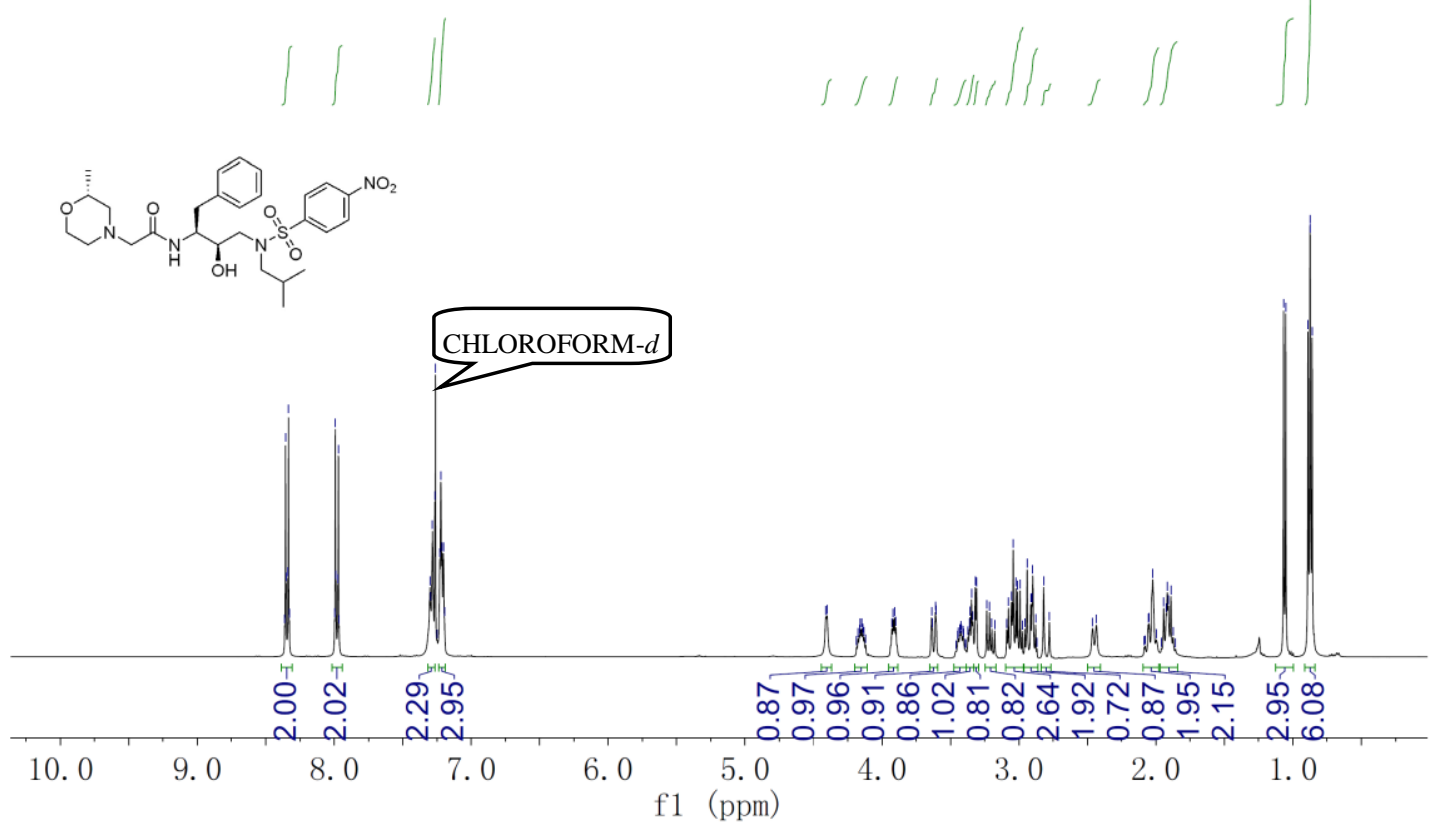

${ }^{1} \mathrm{H}$ NMR Spectrum of compound $\mathbf{2 4 d}$
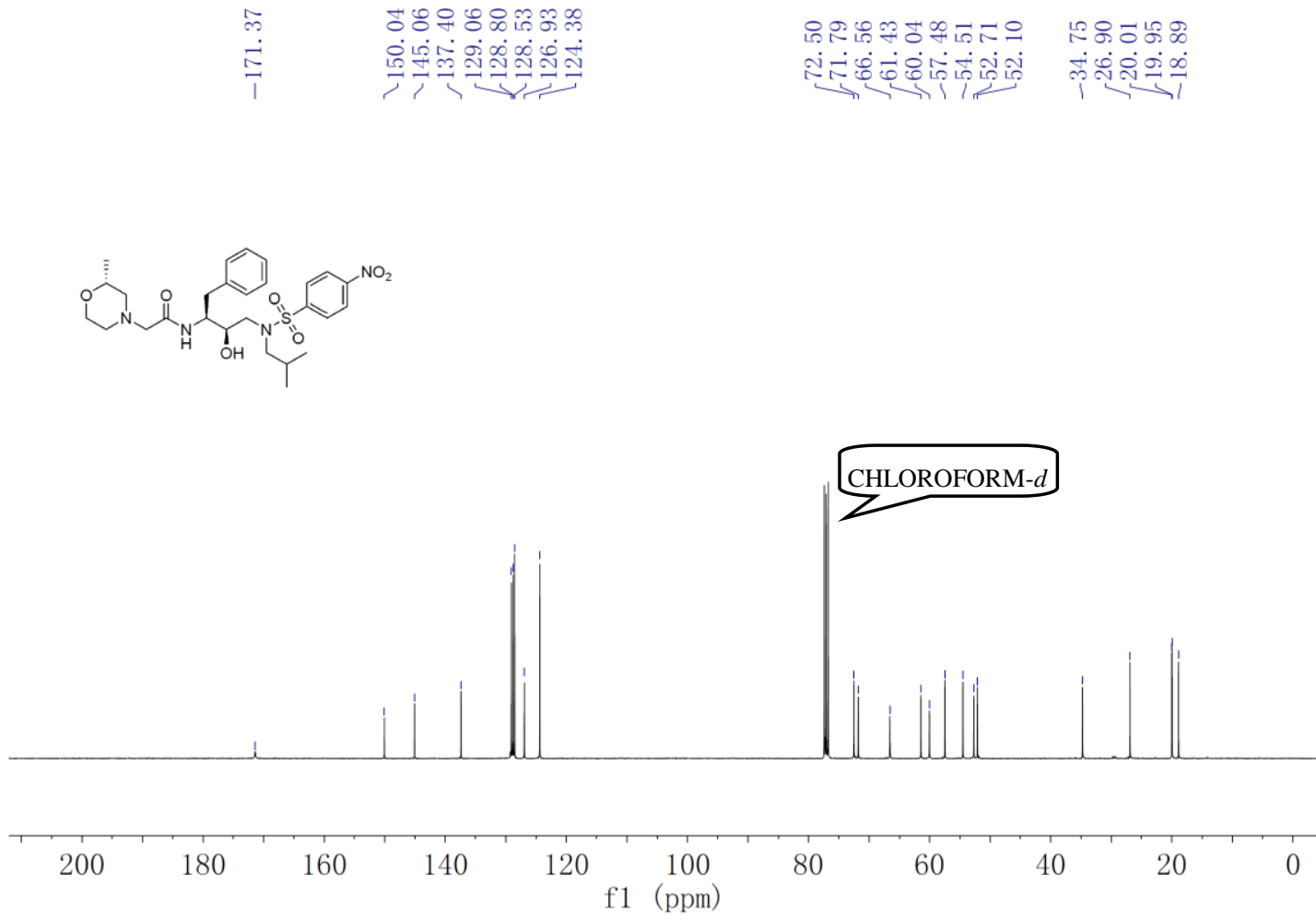

${ }^{13} \mathrm{C}$ NMR Spectrum of compound 24d 


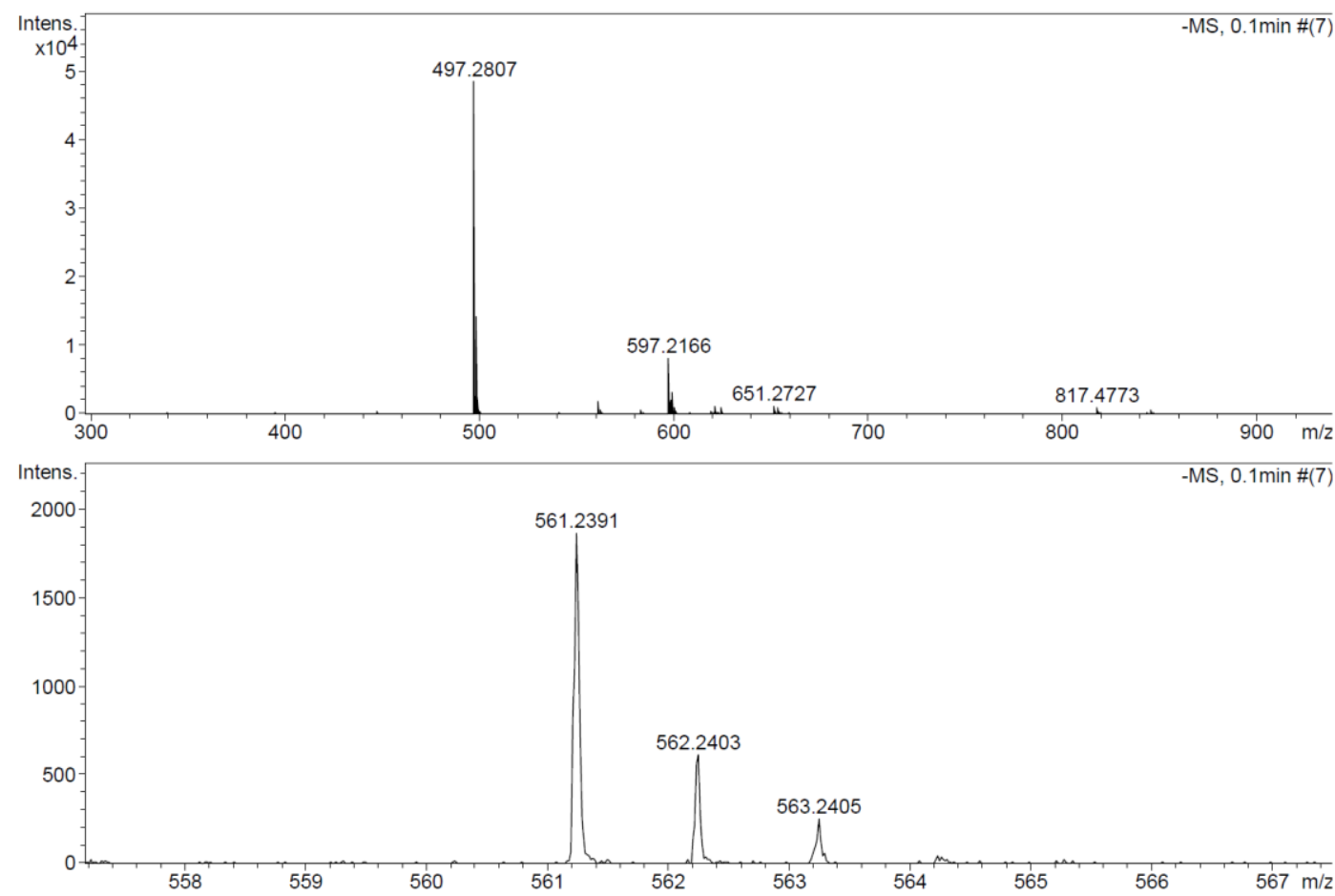

HR MS Spectrum of compound 24d

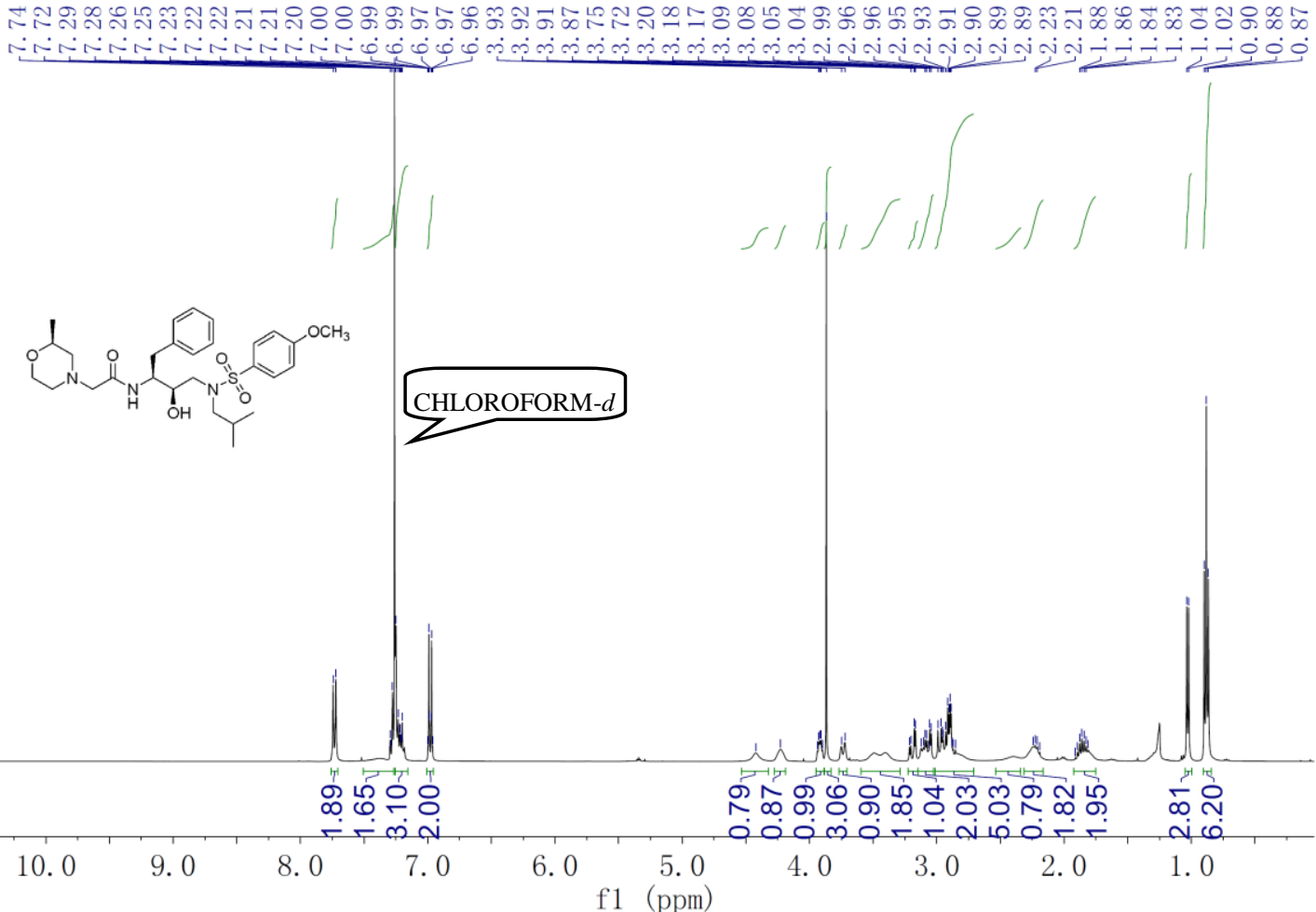

${ }^{1} \mathrm{H}$ NMR Spectrum of compound $\mathbf{2 5 a}$ 


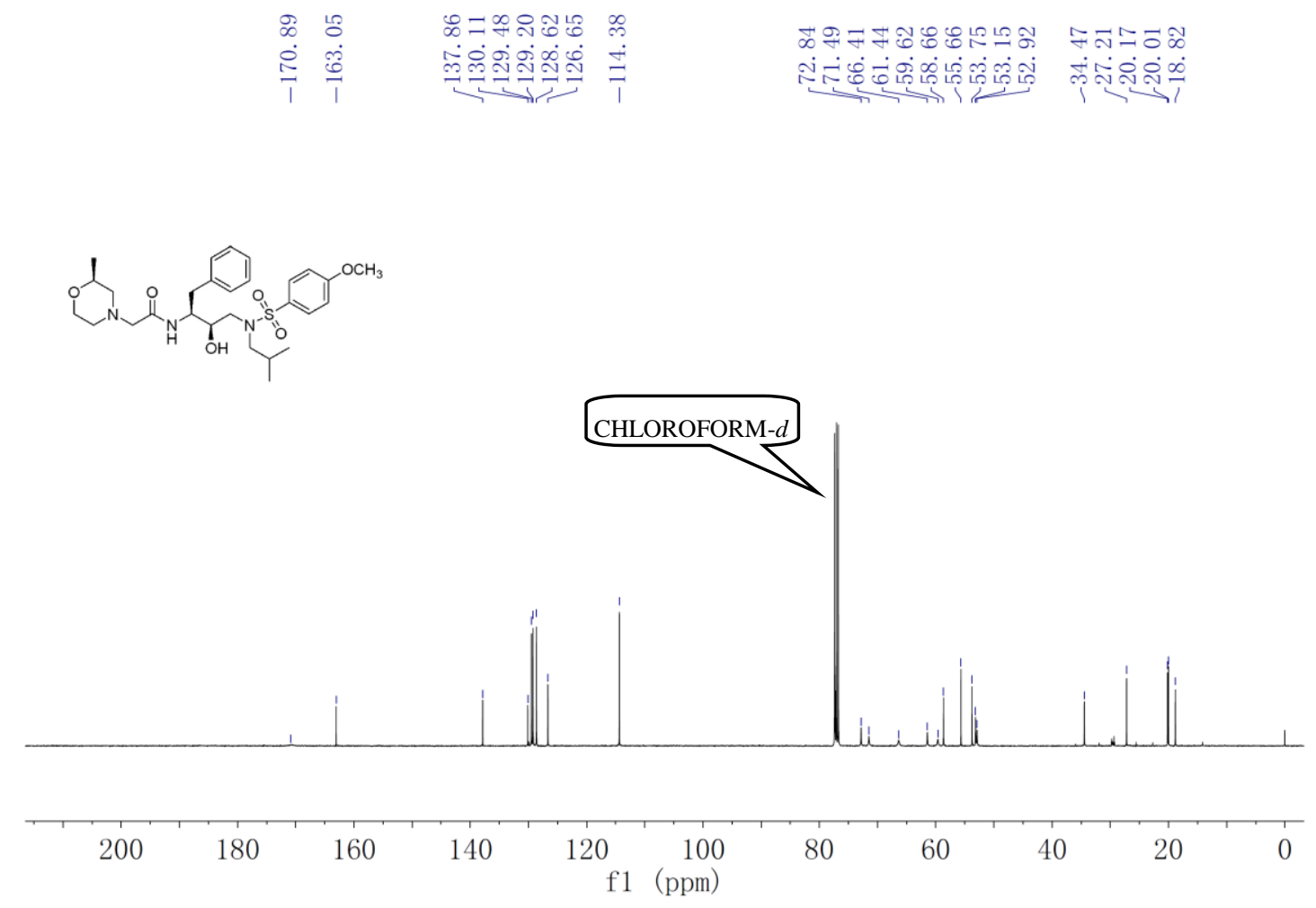

${ }^{13} \mathrm{C}$ NMR Spectrum of compound 25a

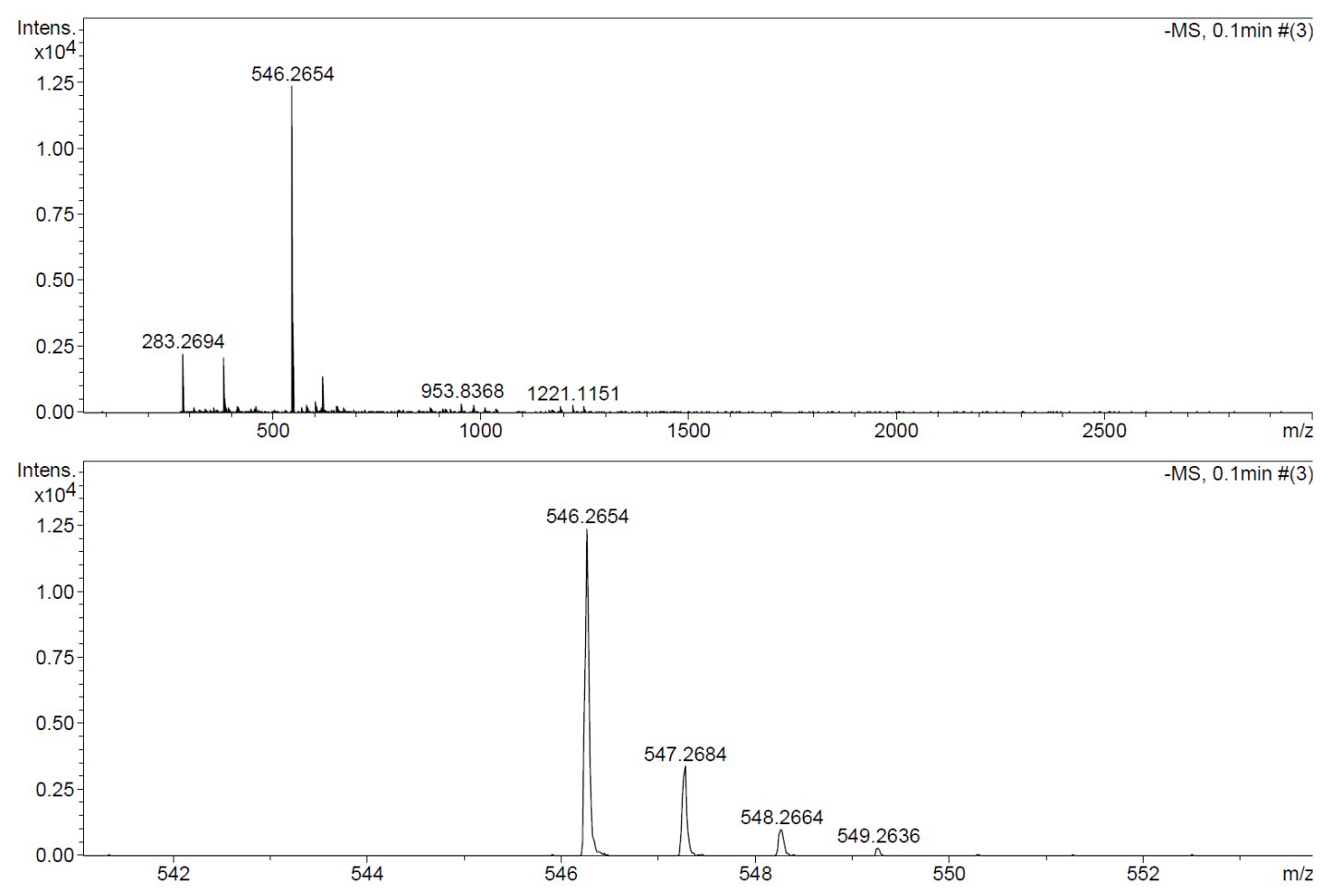

HR MS Spectrum of compound 25a 


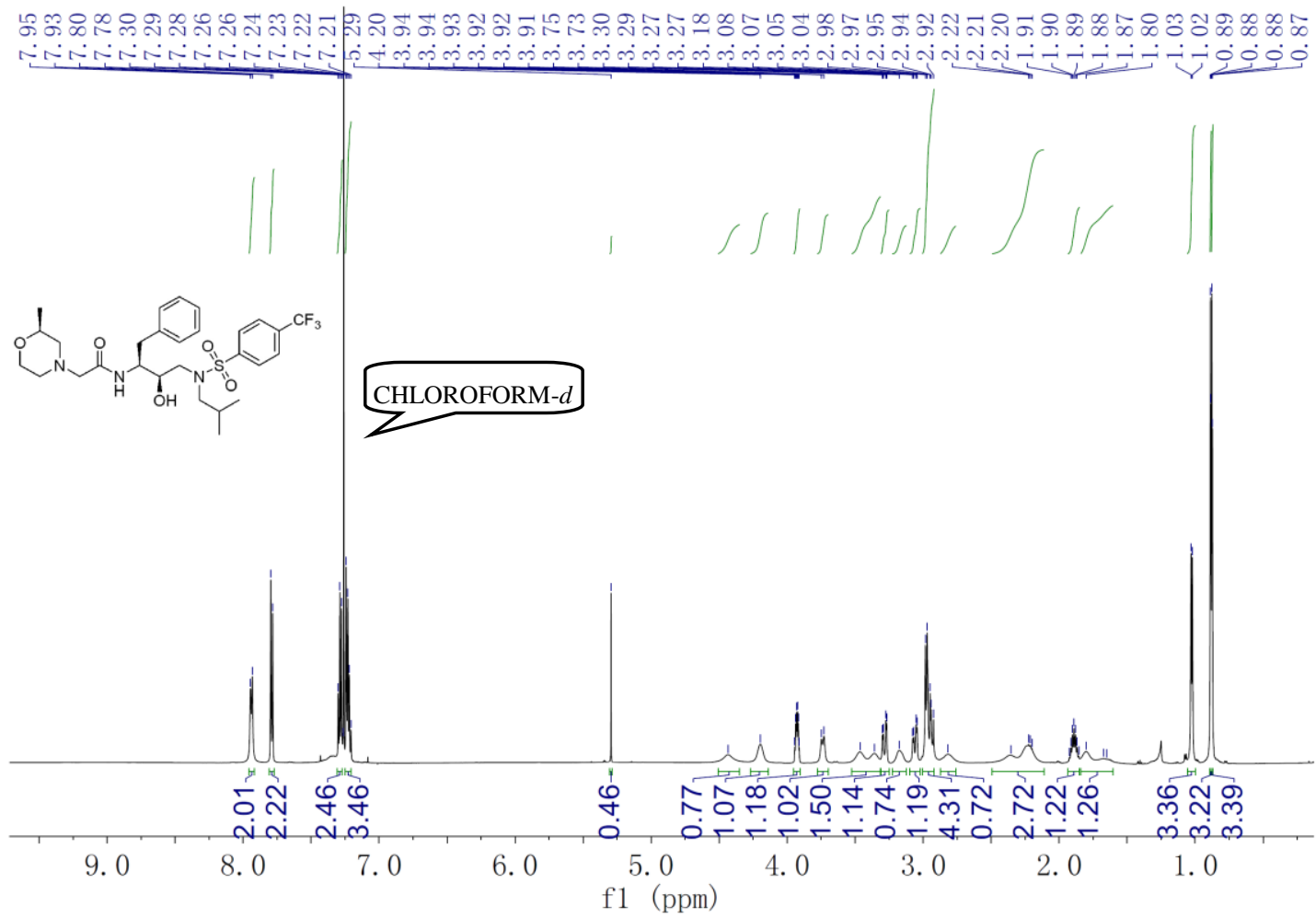

${ }^{1} \mathrm{H}$ NMR Spectrum of compound $\mathbf{2 5 b}$

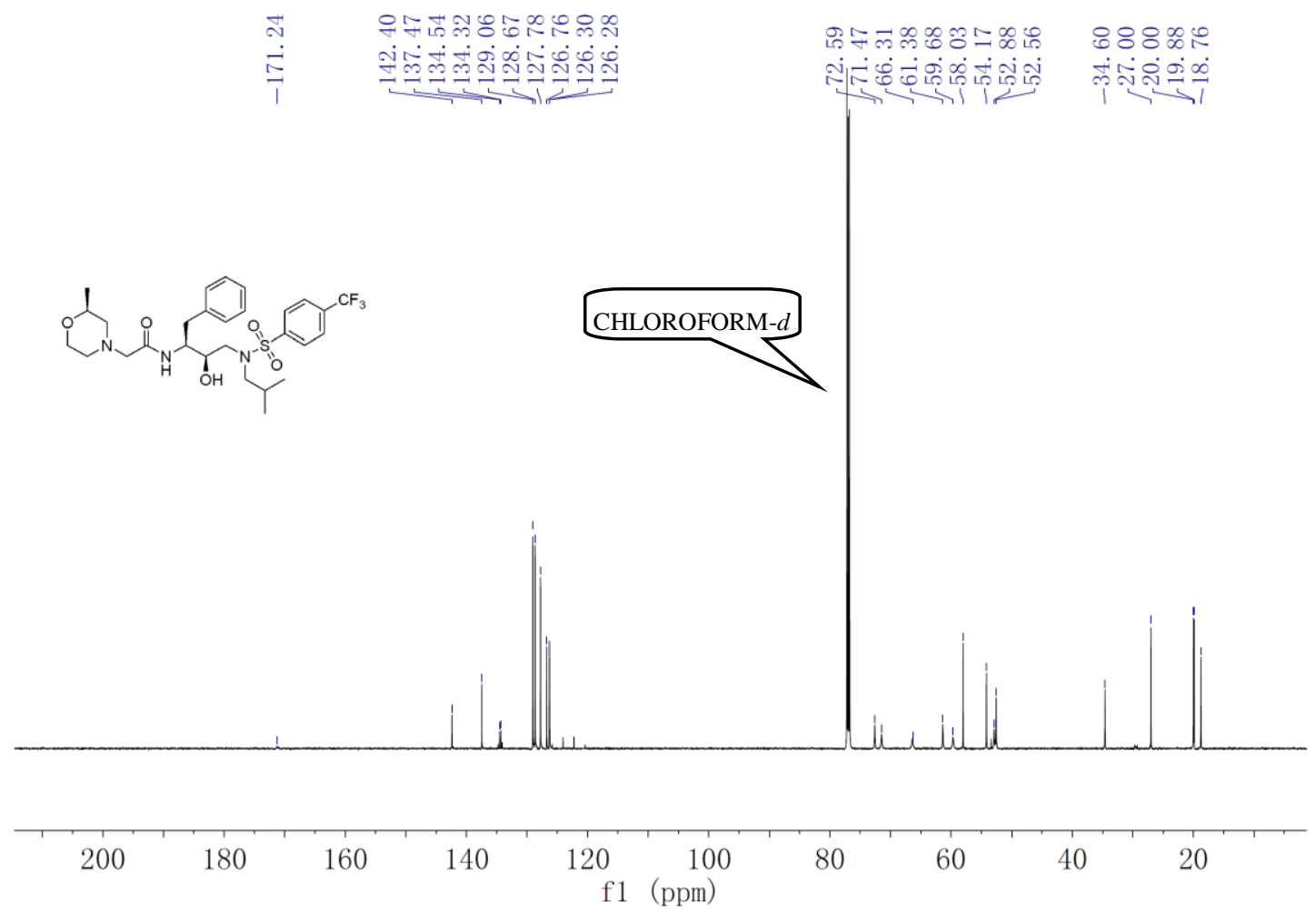

${ }^{13} \mathrm{C}$ NMR Spectrum of compound $\mathbf{2 5 b}$ 


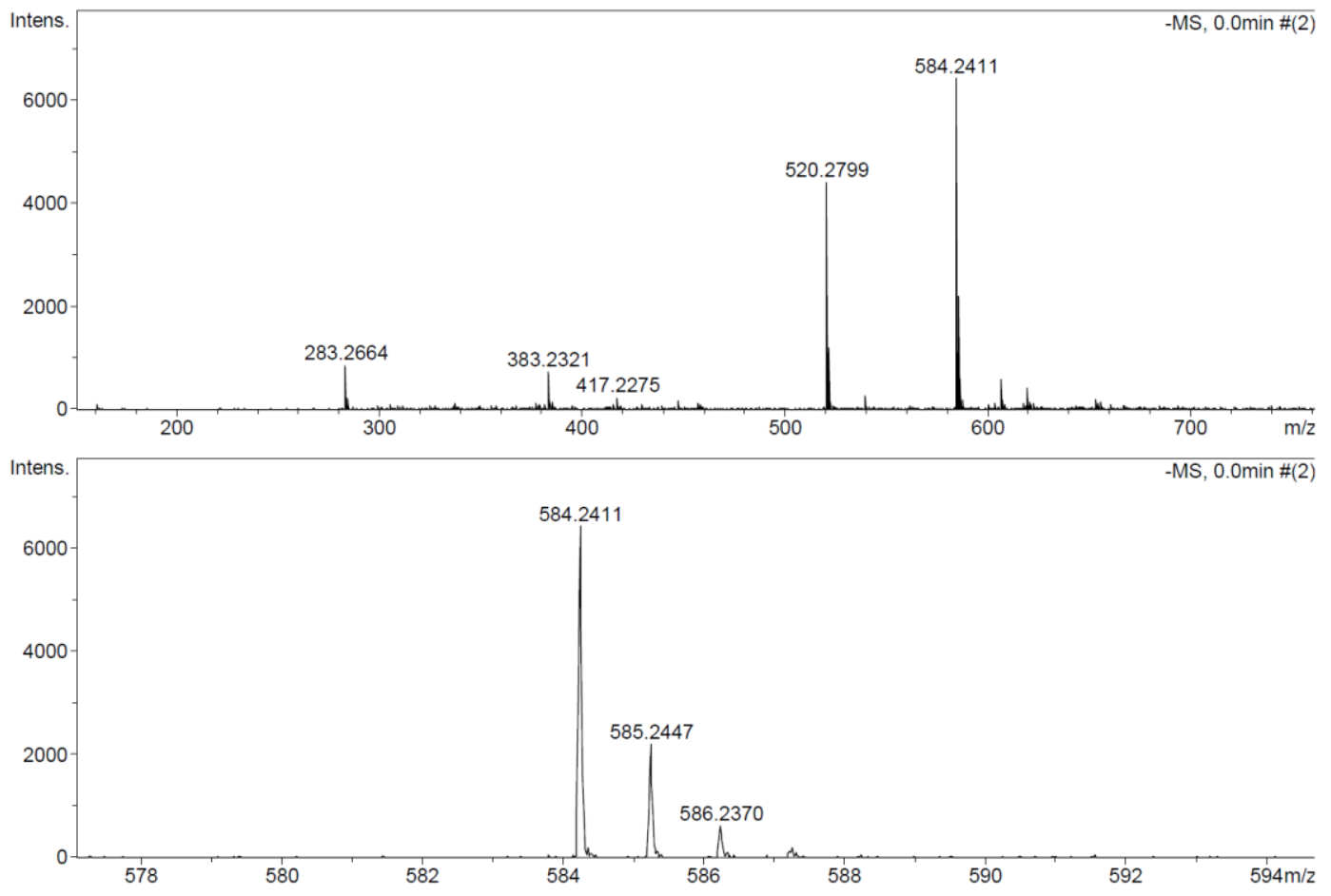

HR MS Spectrum of compound 25b

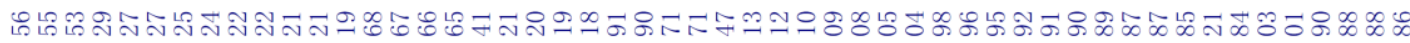

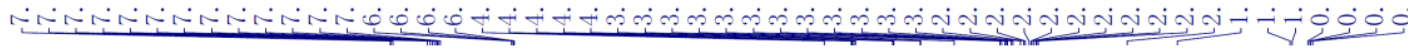
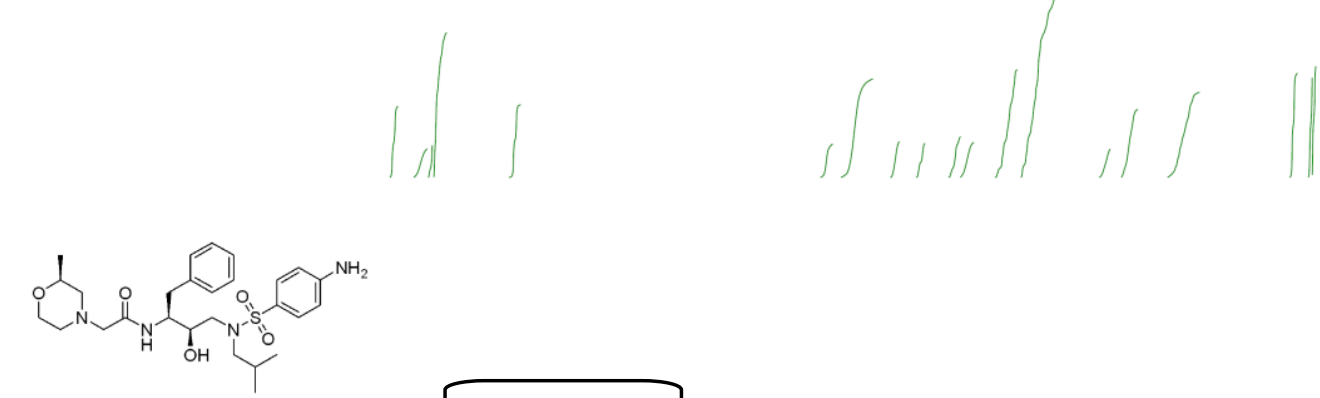

CHLOROFORM- $d$

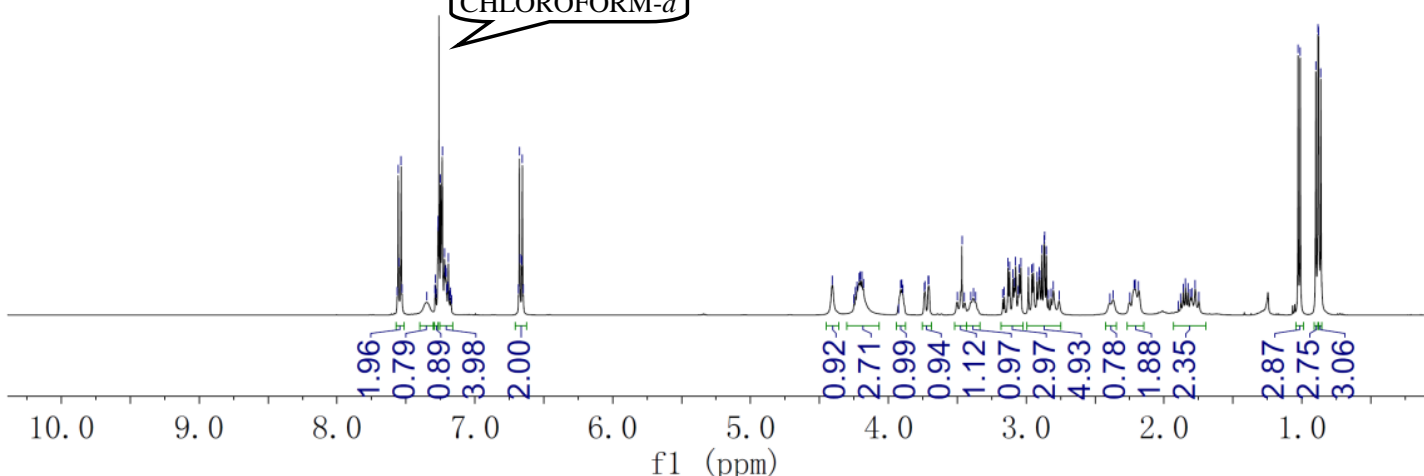

${ }^{1} \mathrm{H}$ NMR Spectrum of compound 25c 


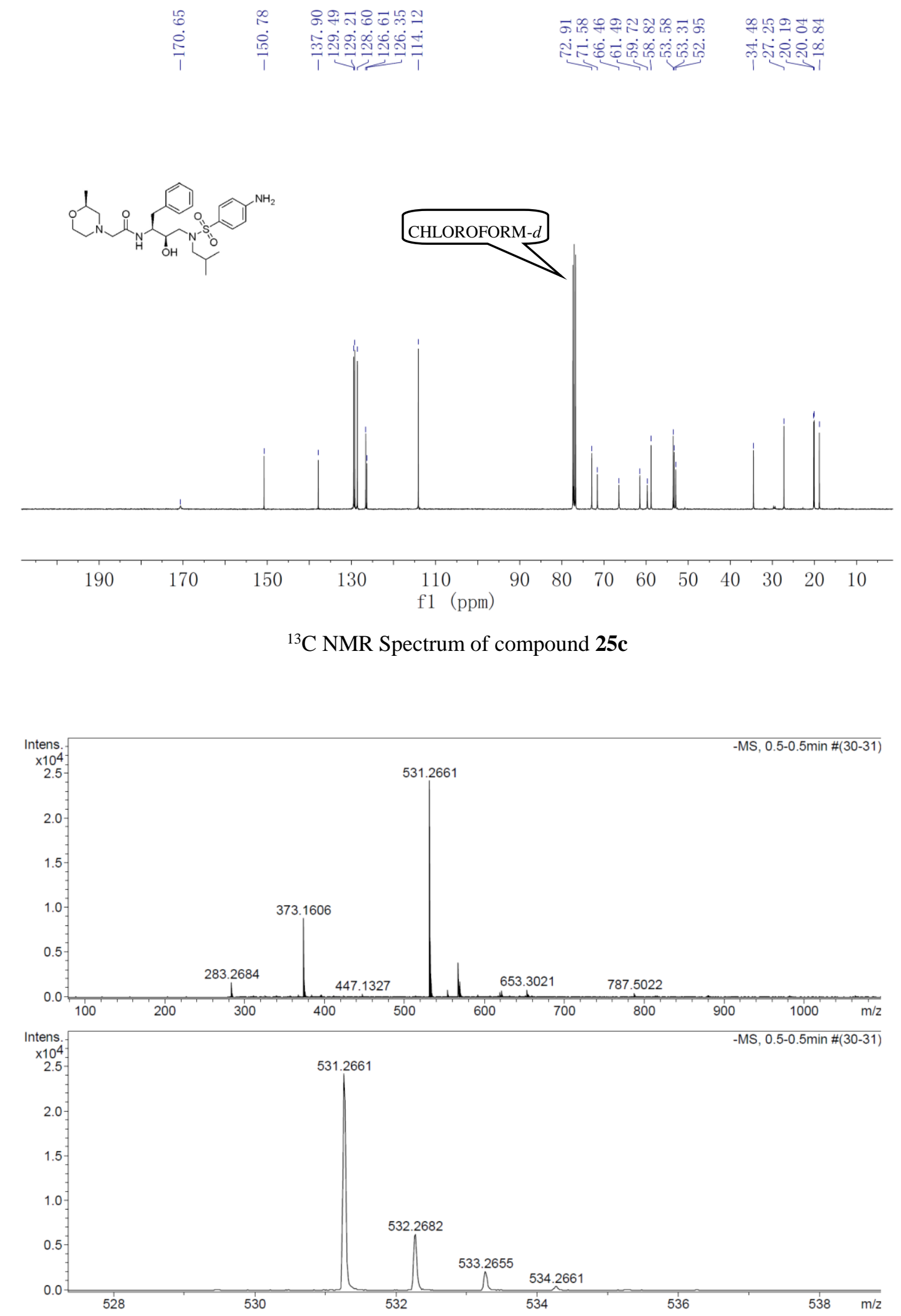

HR MS Spectrum of compound 25c 
<smiles>CCCC=CC(C)C</smiles><smiles>CC(C)CN(CC(O)C(Cc1ccccc1)NC(=O)N1CCOC(C)C1)S(=O)(=O)c1ccc([N+](=O)[O-])cc1</smiles>

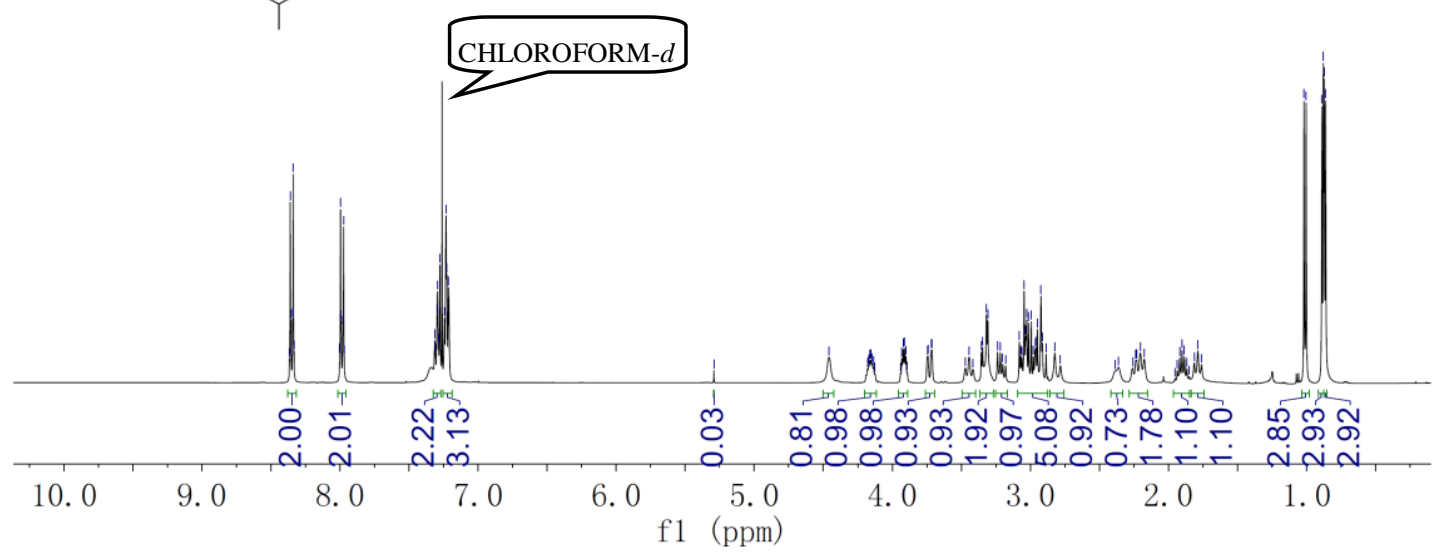

${ }^{1} \mathrm{H}$ NMR Spectrum of compound 25d

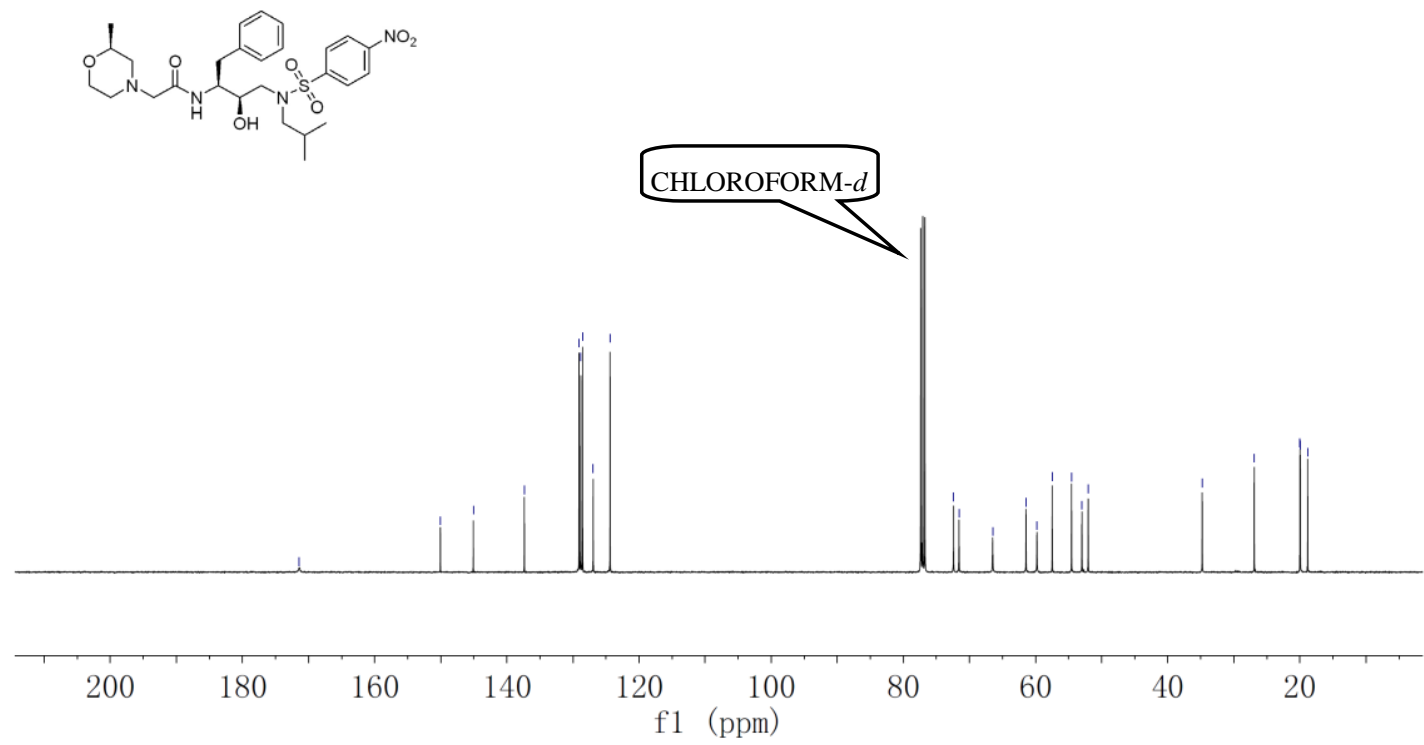

${ }^{13} \mathrm{C}$ NMR Spectrum of compound $\mathbf{2 5 d}$ 

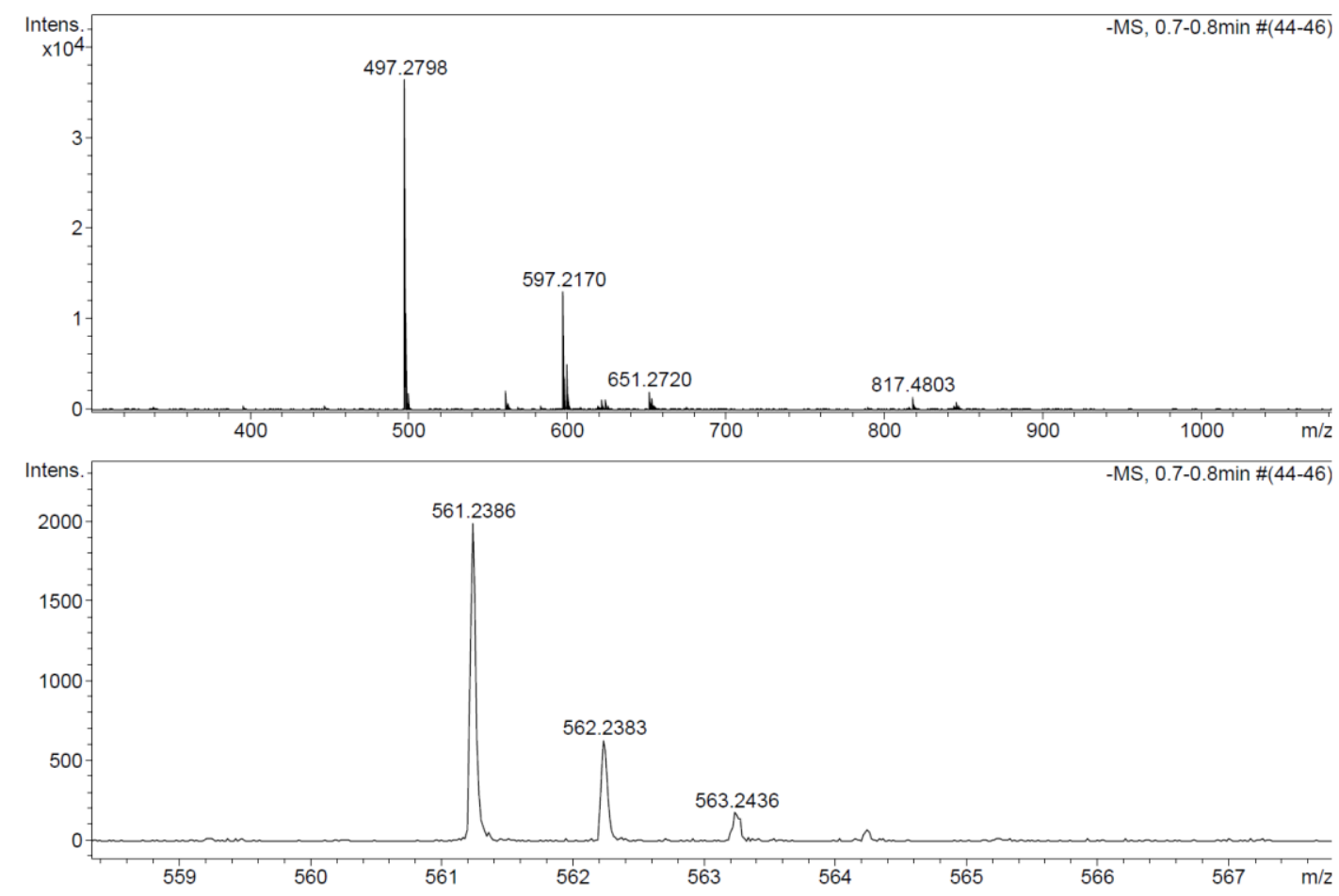

HR MS Spectrum of compound 25d

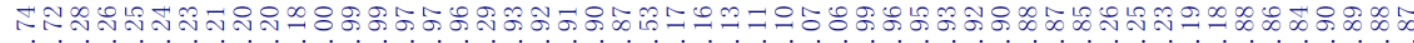

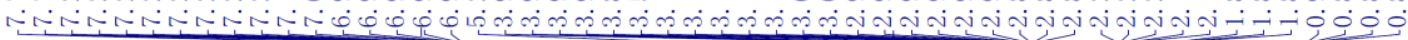

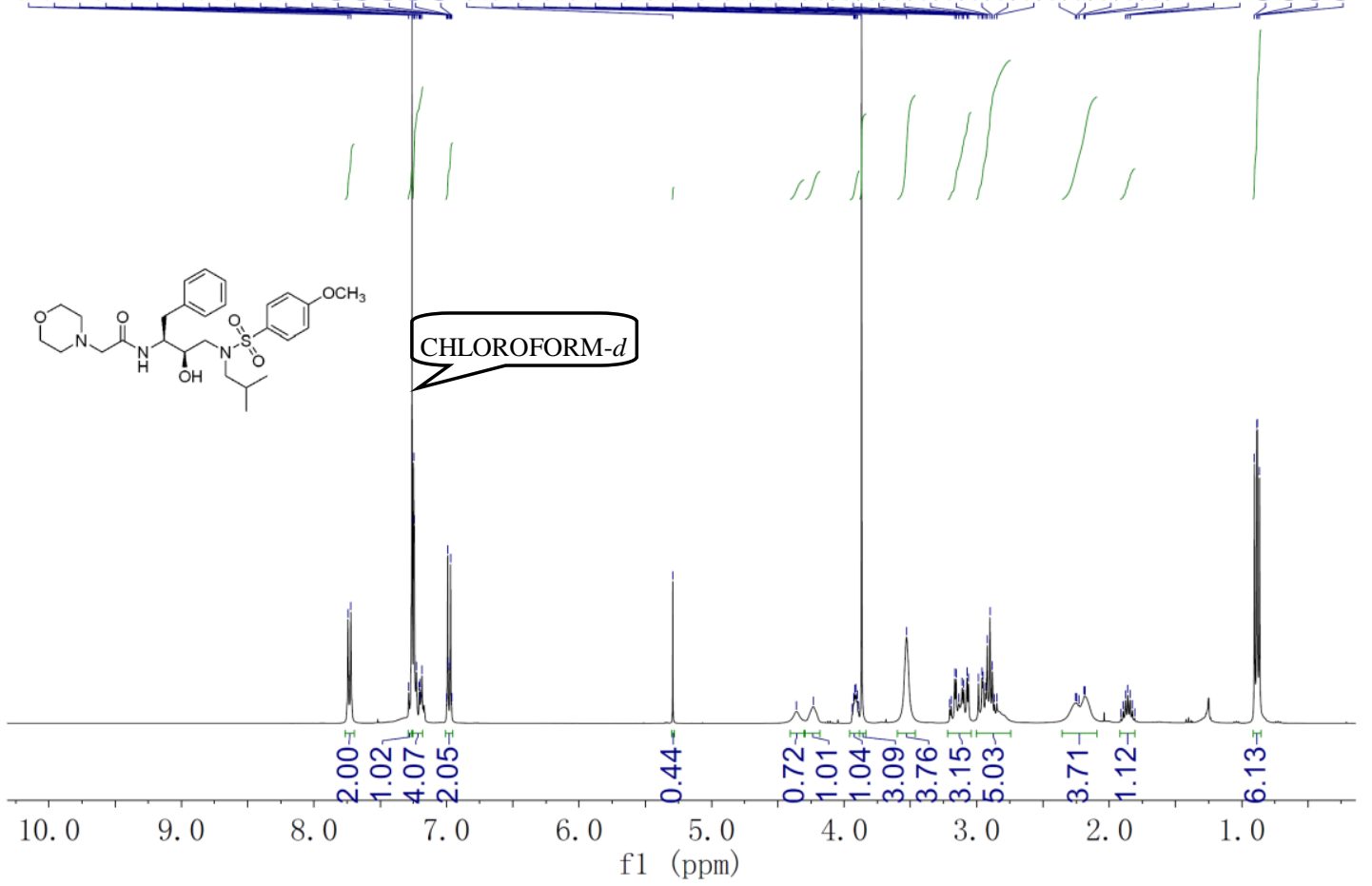

${ }^{1} \mathrm{H}$ NMR Spectrum of compound 26a 

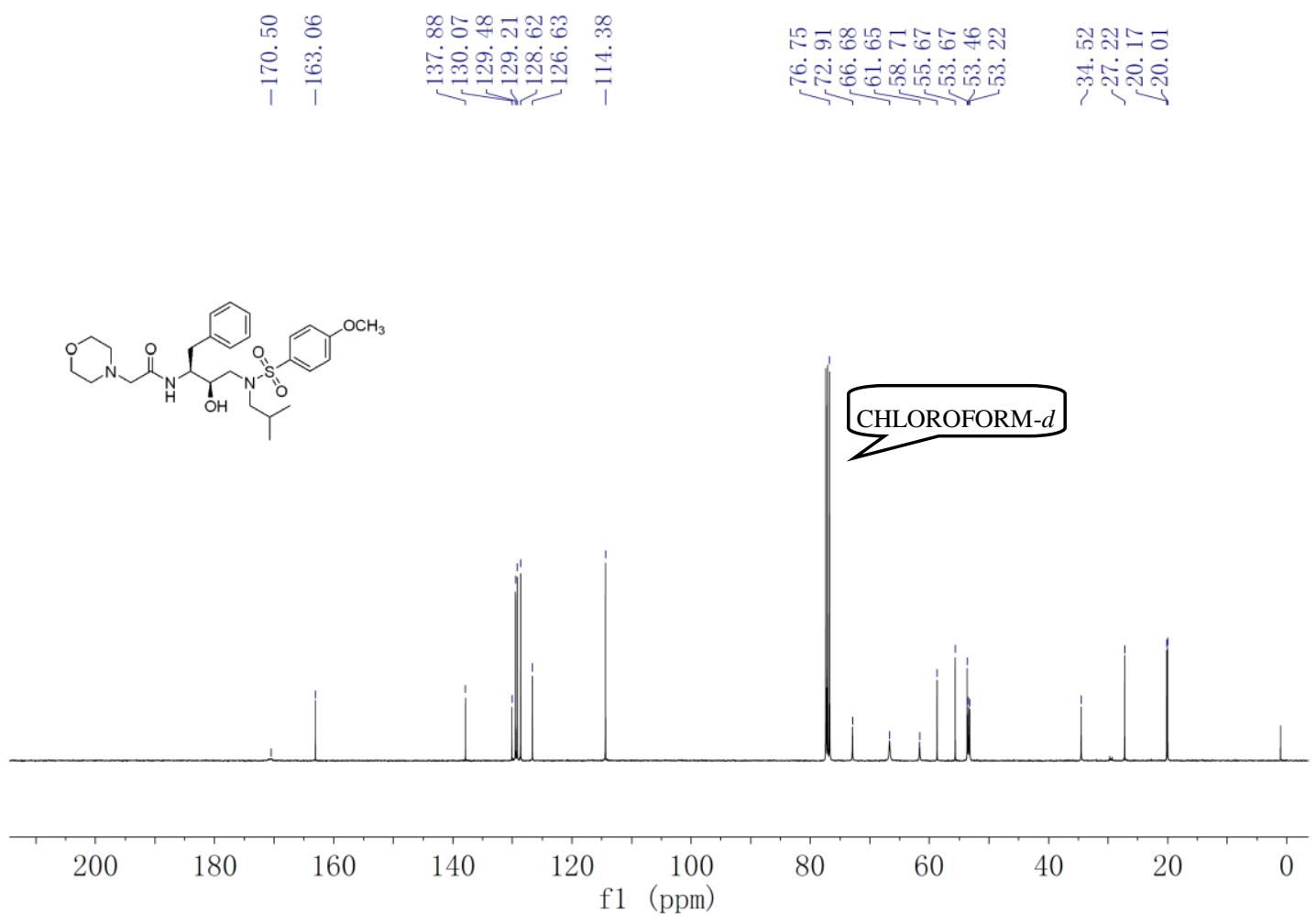

${ }^{13} \mathrm{C}$ NMR Spectrum of compound 26a
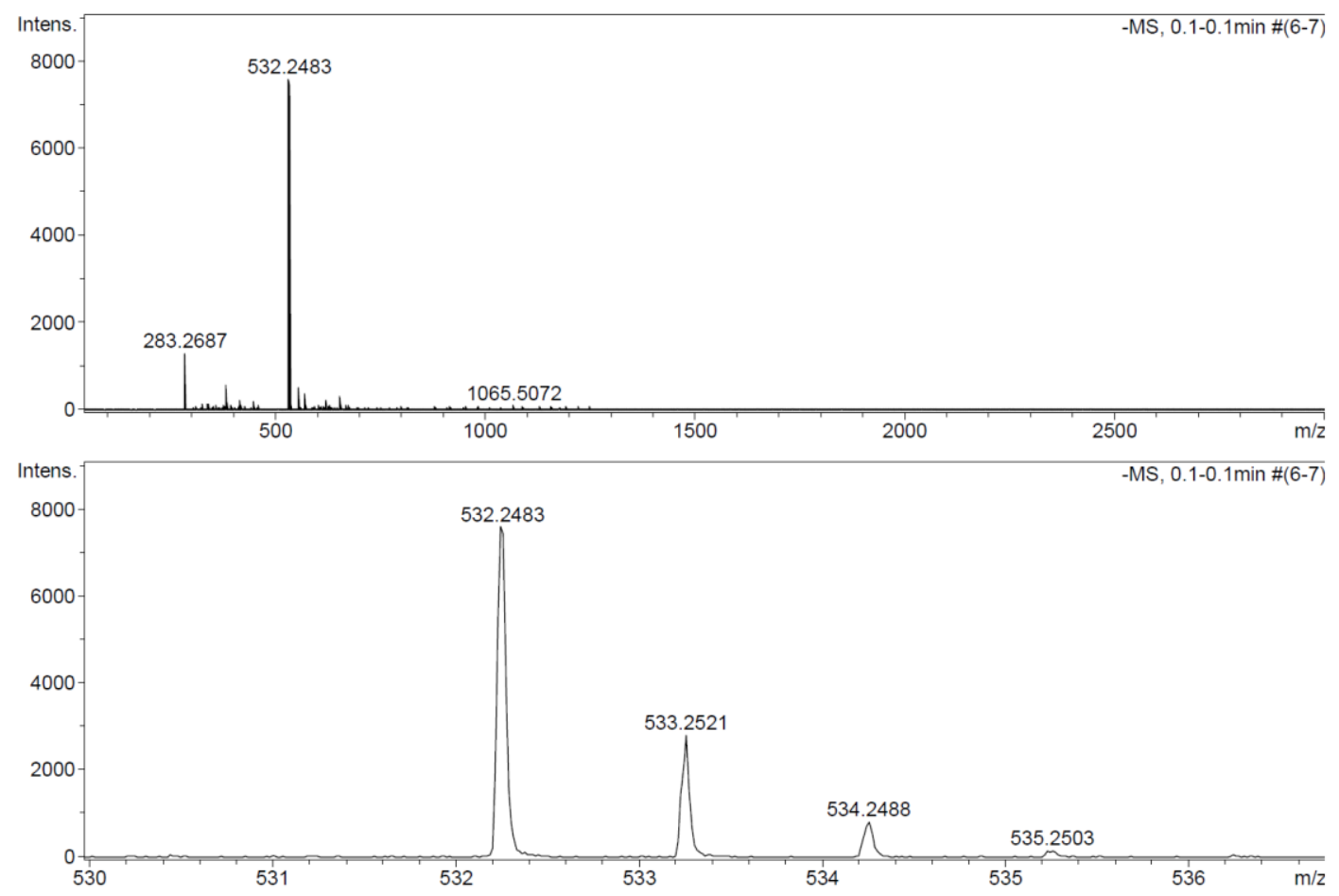

HR MS Spectrum of compound 26a 


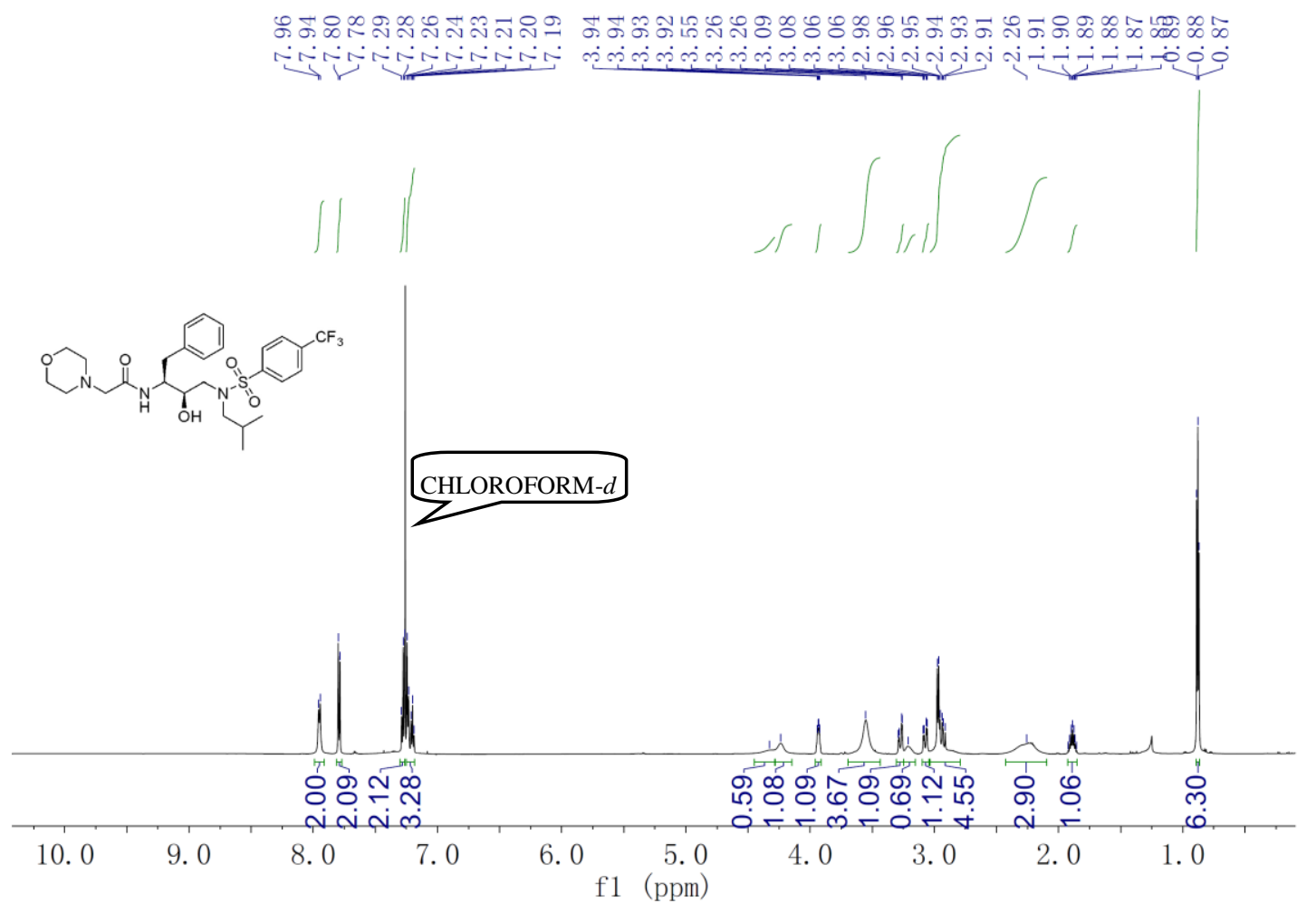

${ }^{1} \mathrm{H}$ NMR Spectrum of compound $\mathbf{2 6 \mathbf { b }}$

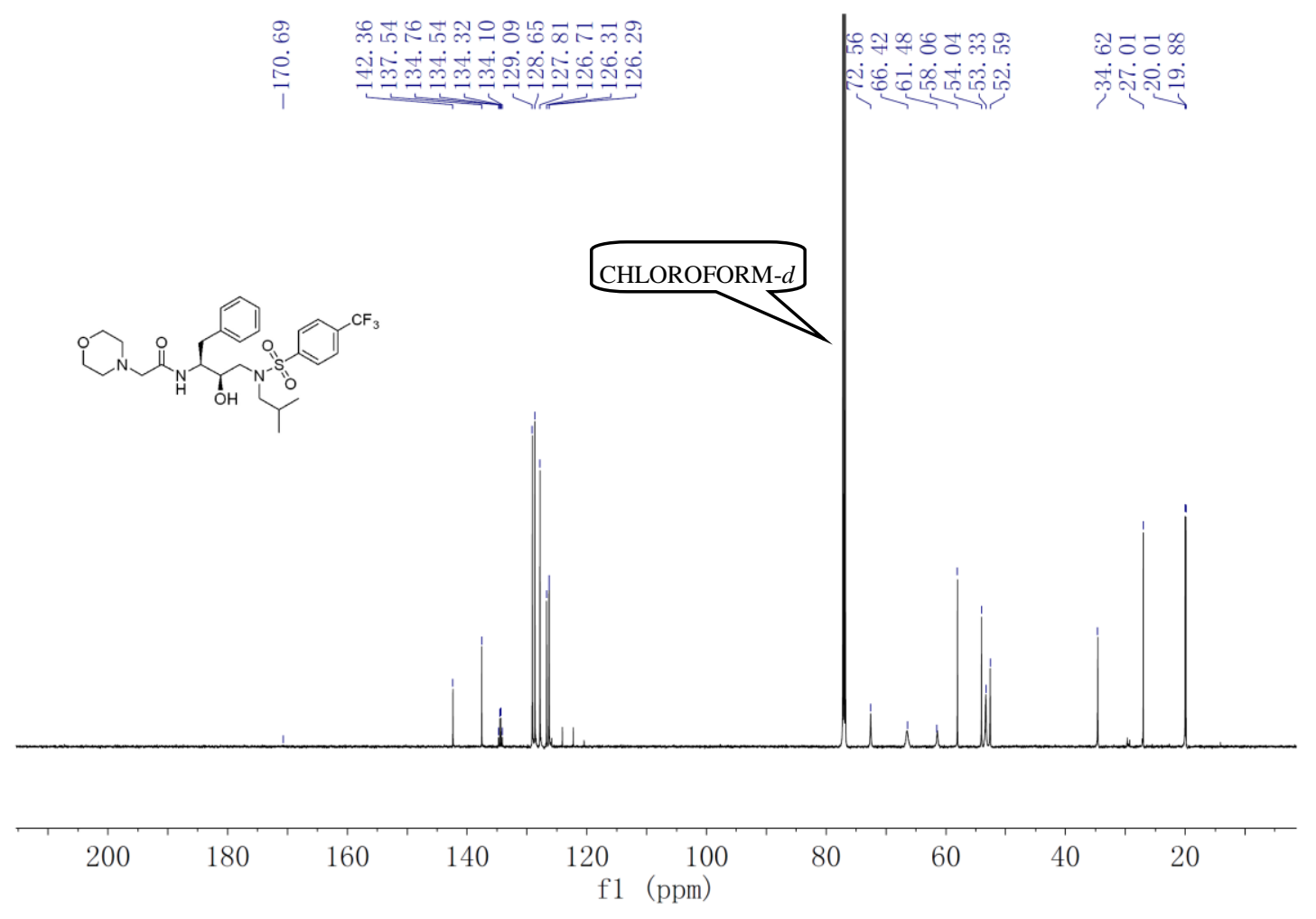

${ }^{13} \mathrm{C}$ NMR Spectrum of compound $\mathbf{2 6 \mathbf { b }}$ 

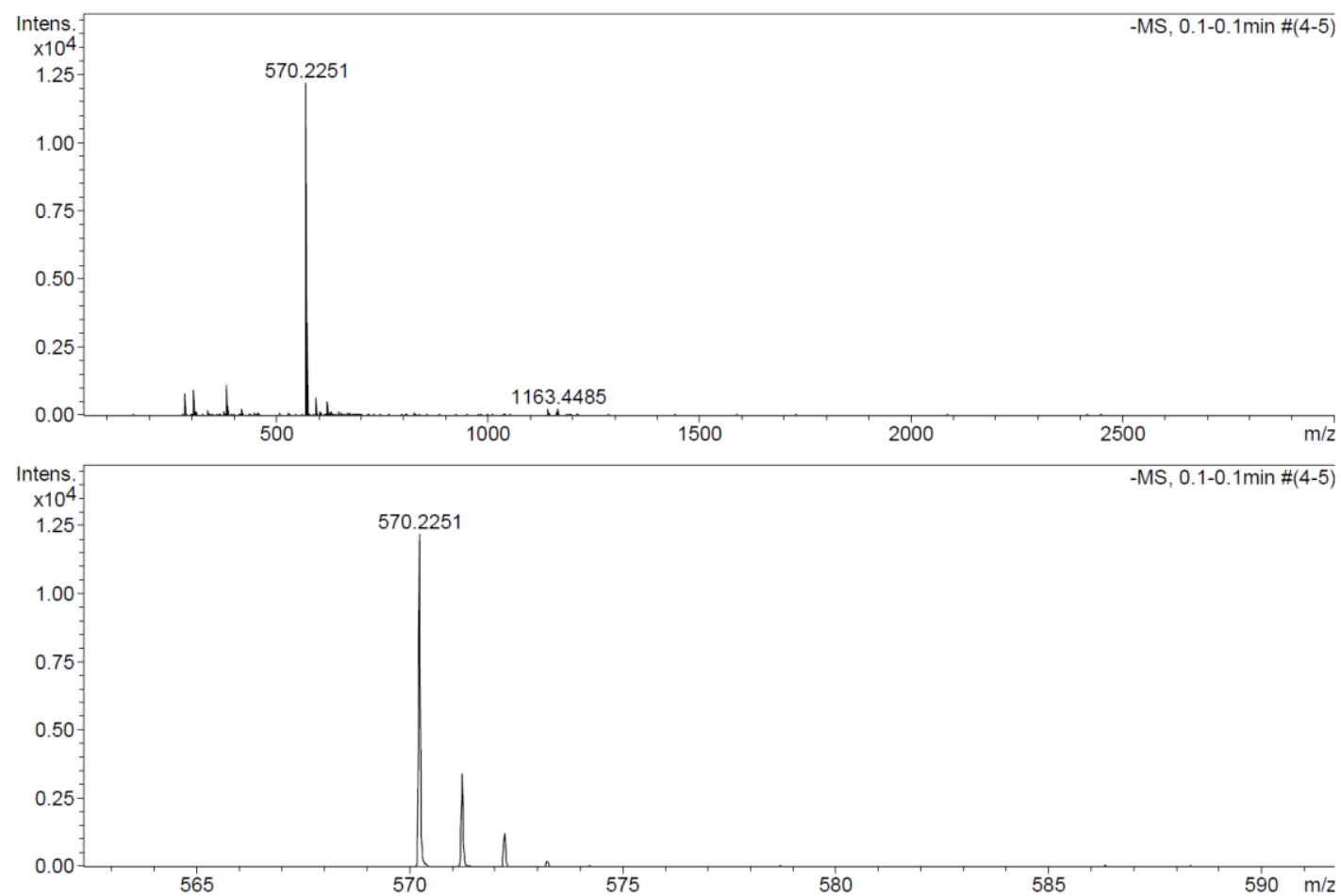

HR MS Spectrum of compound 26b

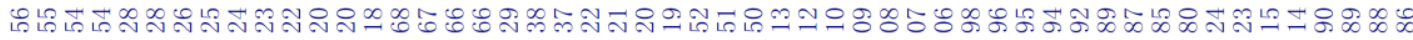

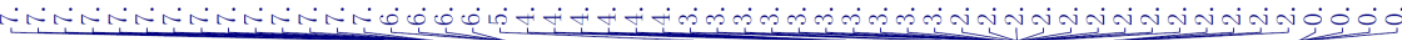
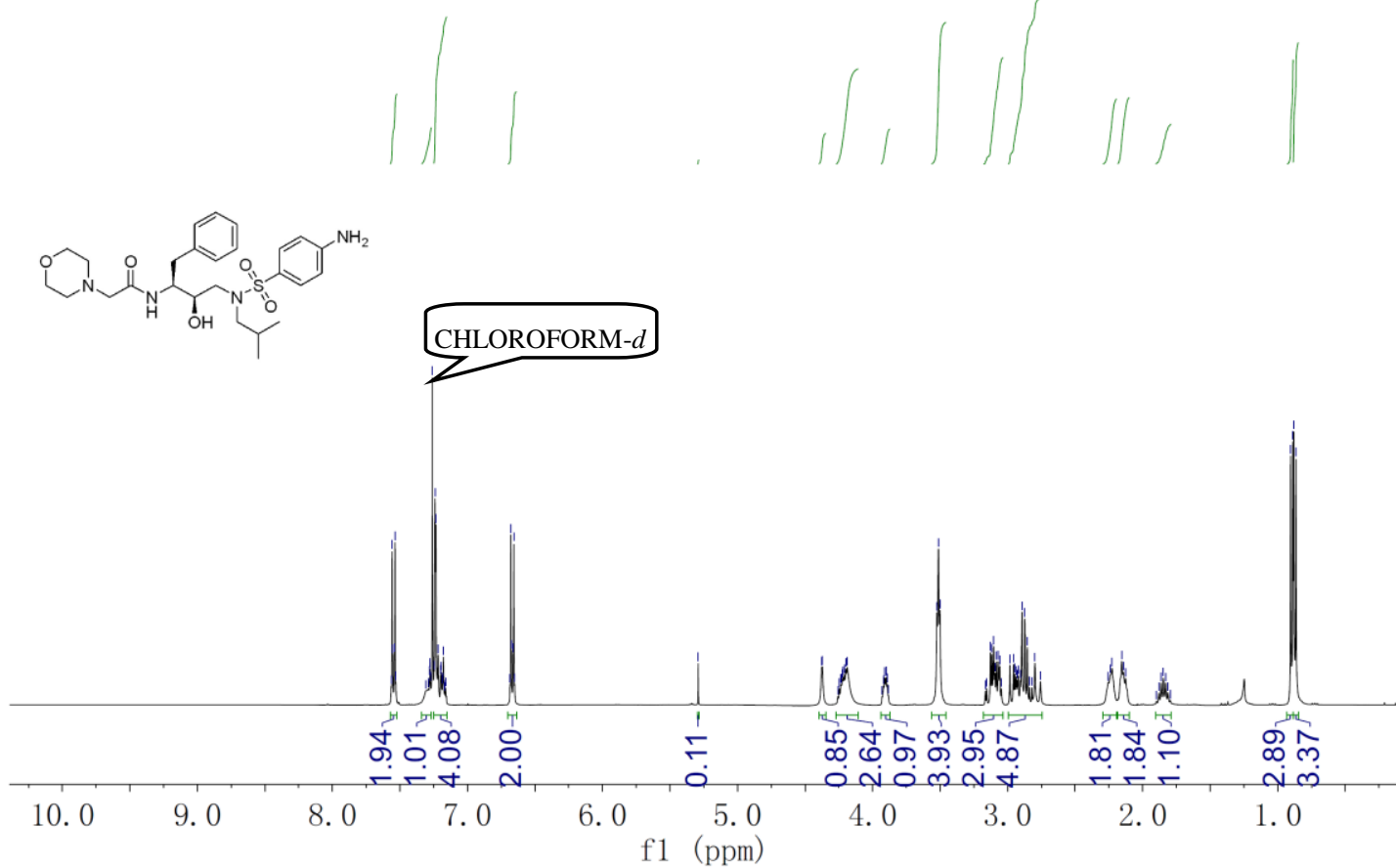

${ }^{1} \mathrm{H}$ NMR Spectrum of compound $\mathbf{2 6 c}$ 


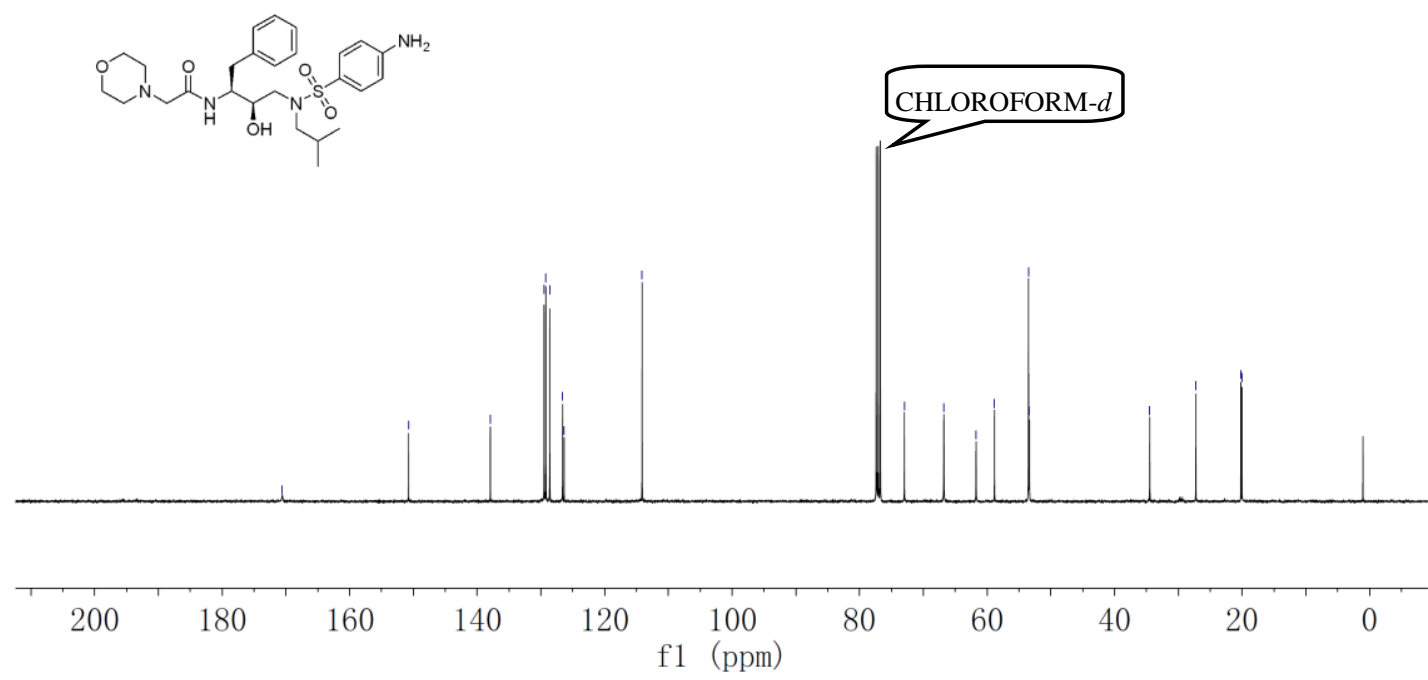

${ }^{13} \mathrm{C}$ NMR Spectrum of compound $\mathbf{2 6 c}$

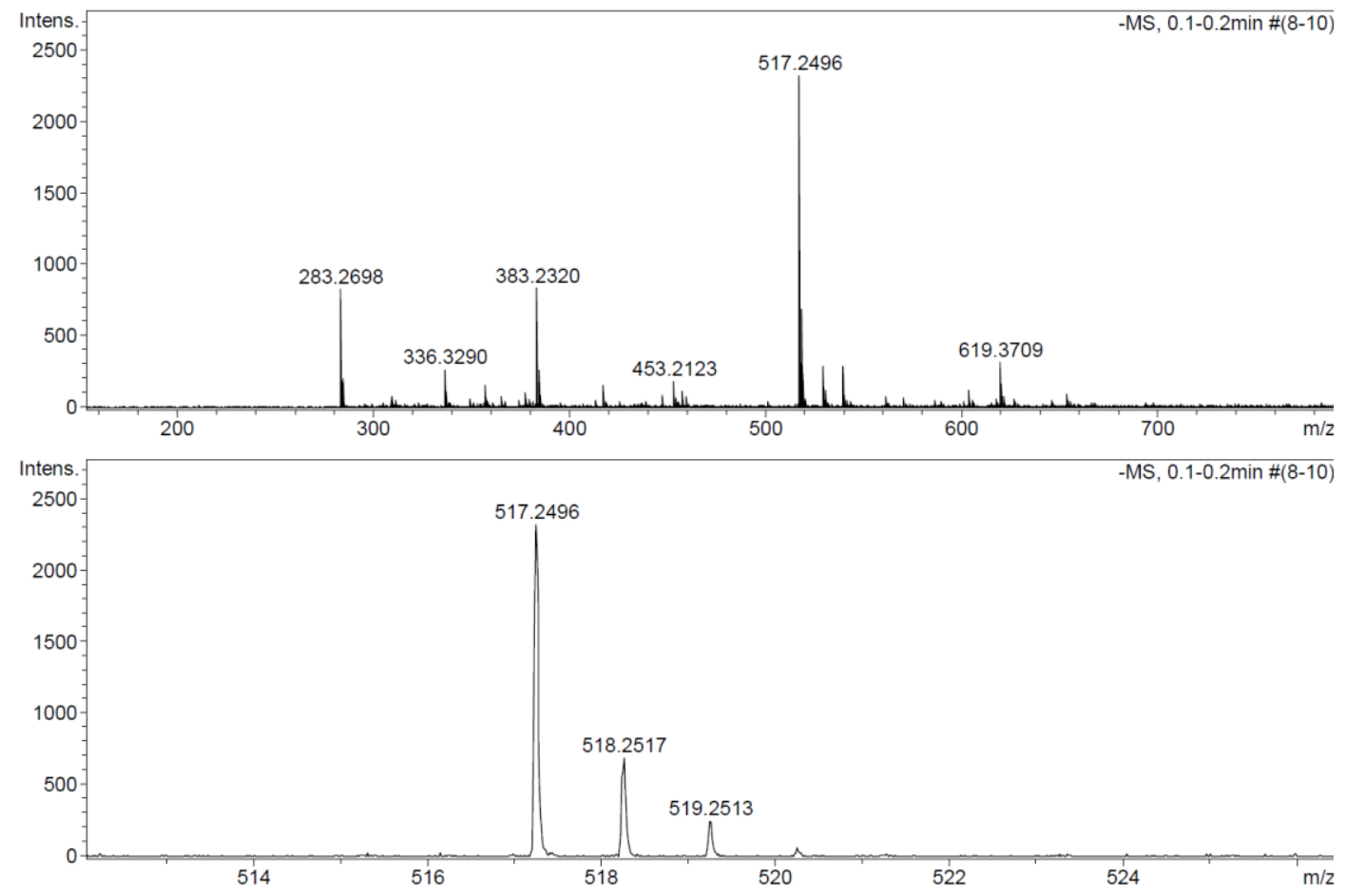

HR MS Spectrum of compound 26c 

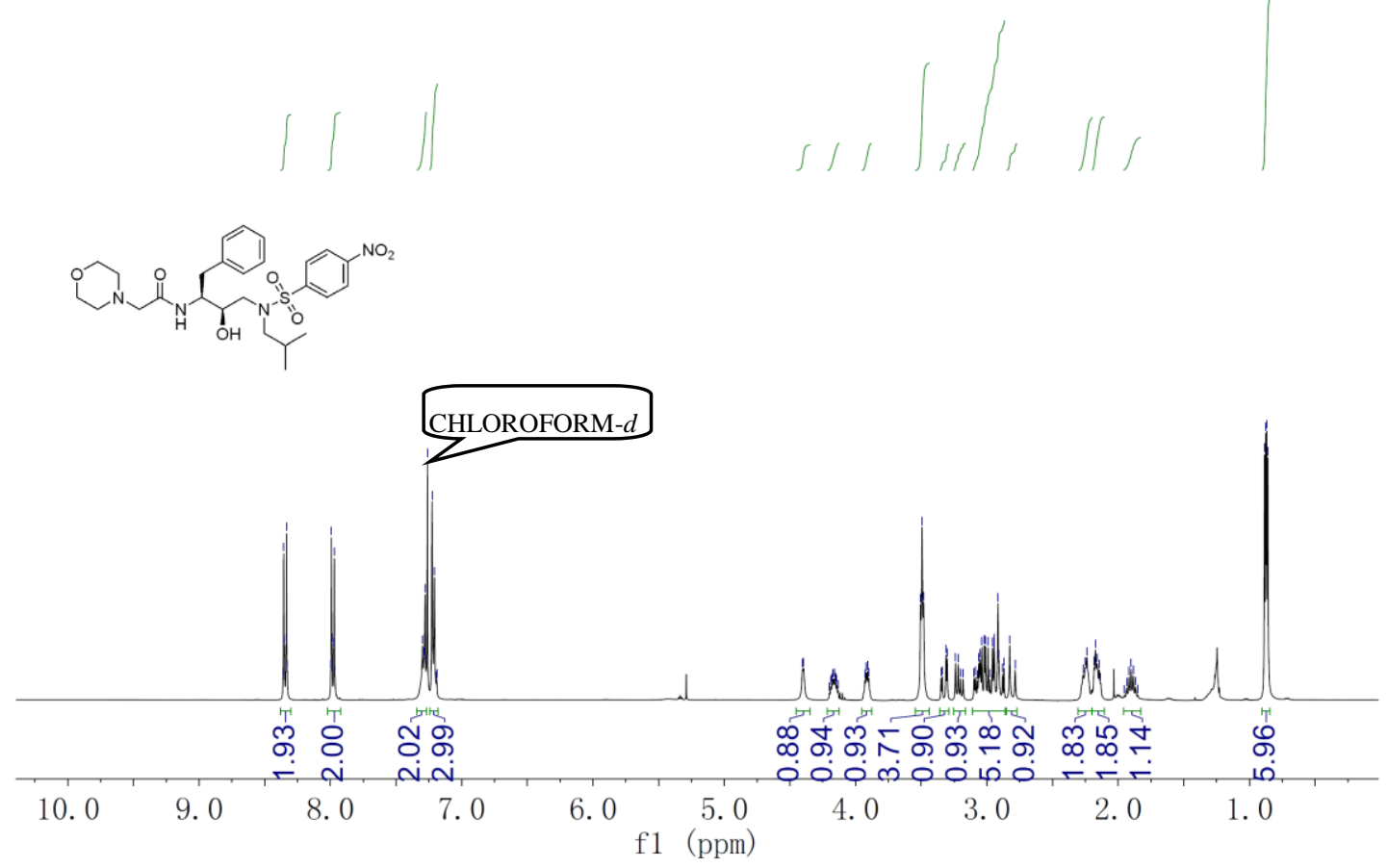

${ }^{1} \mathrm{H}$ NMR Spectrum of compound 26d
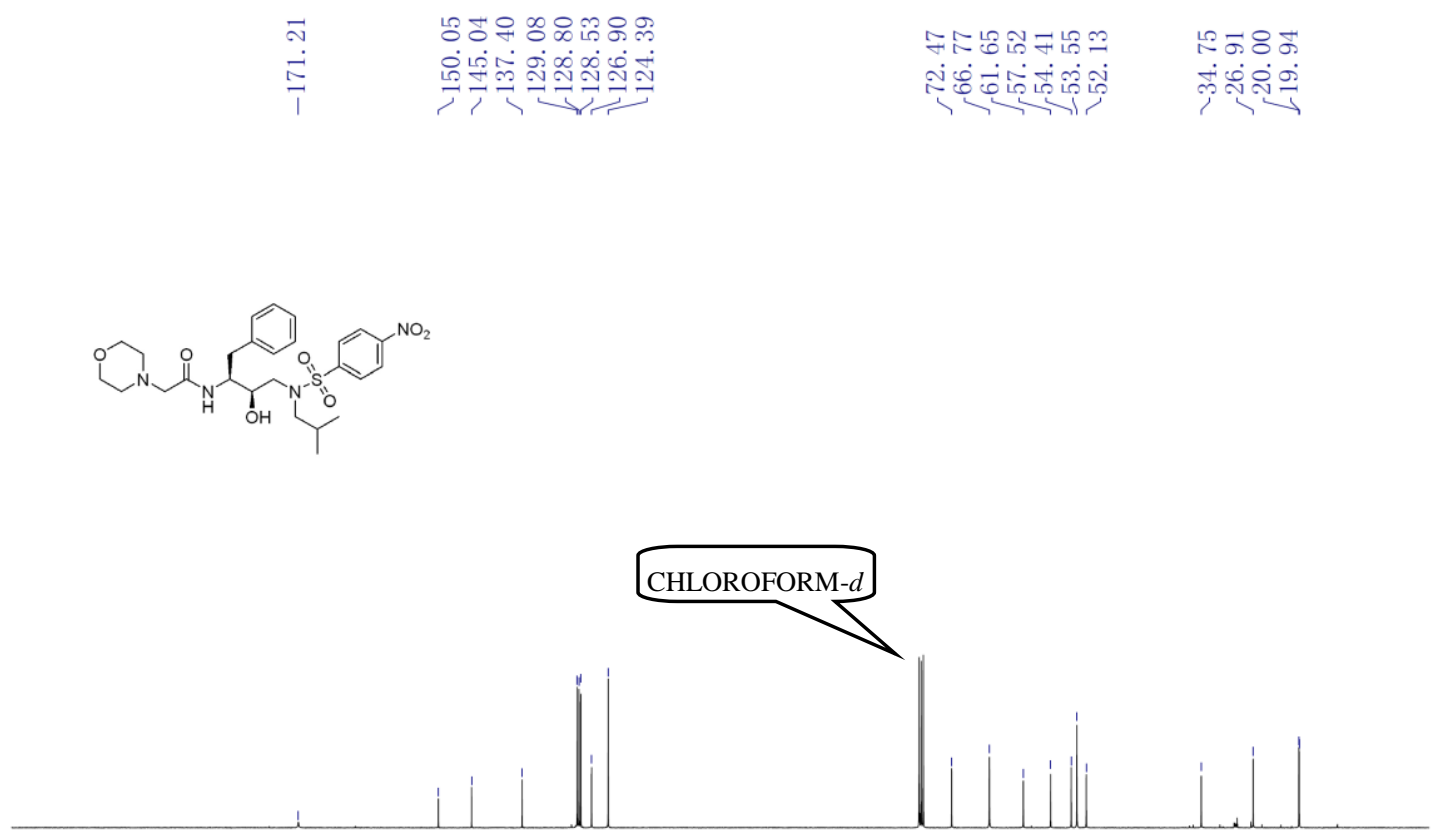

200 180 160 140 $120 \quad 100$ 80 60 40 20

${ }^{13} \mathrm{C}$ NMR Spectrum of compound 26d 

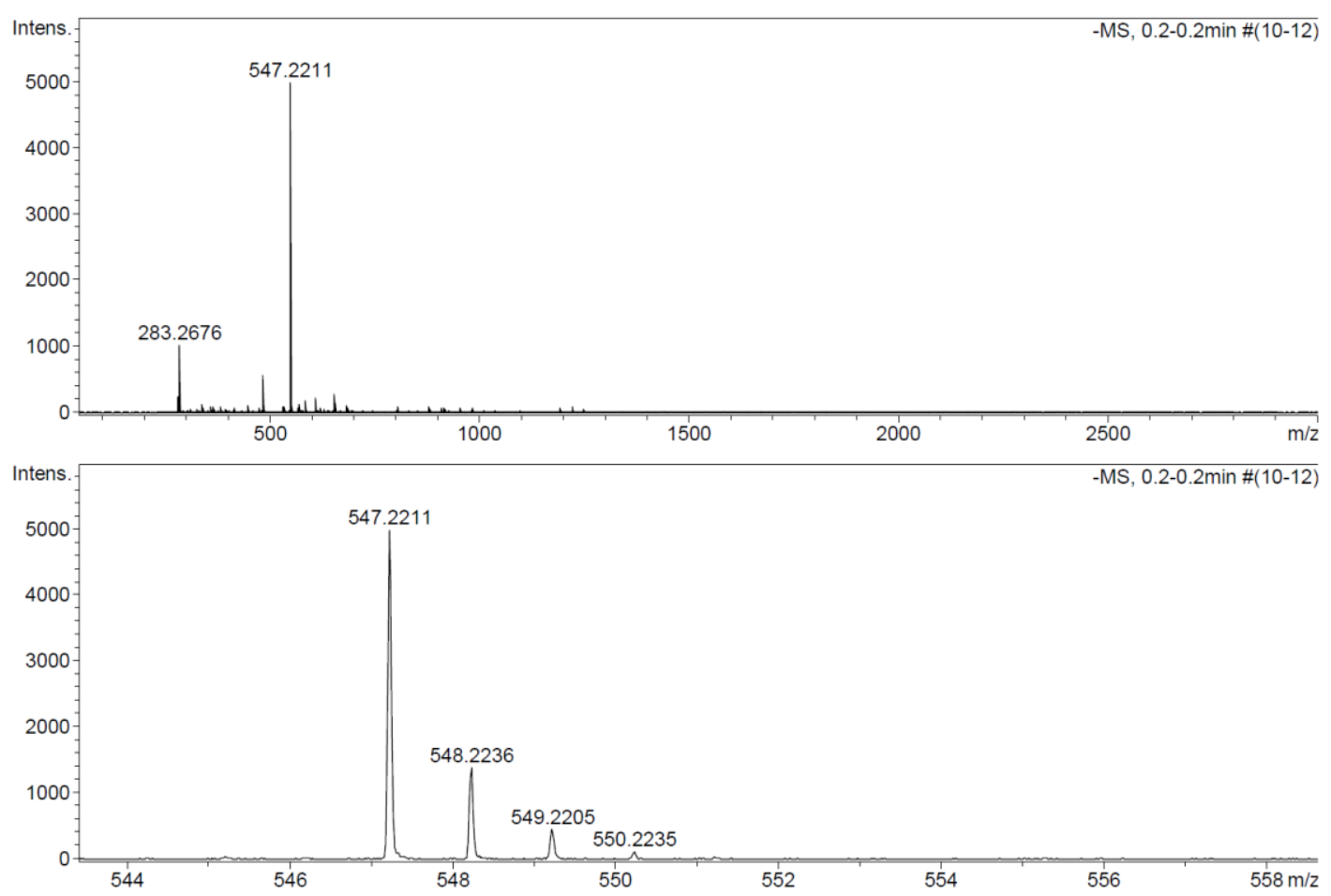

HR MS Spectrum of compound 26d

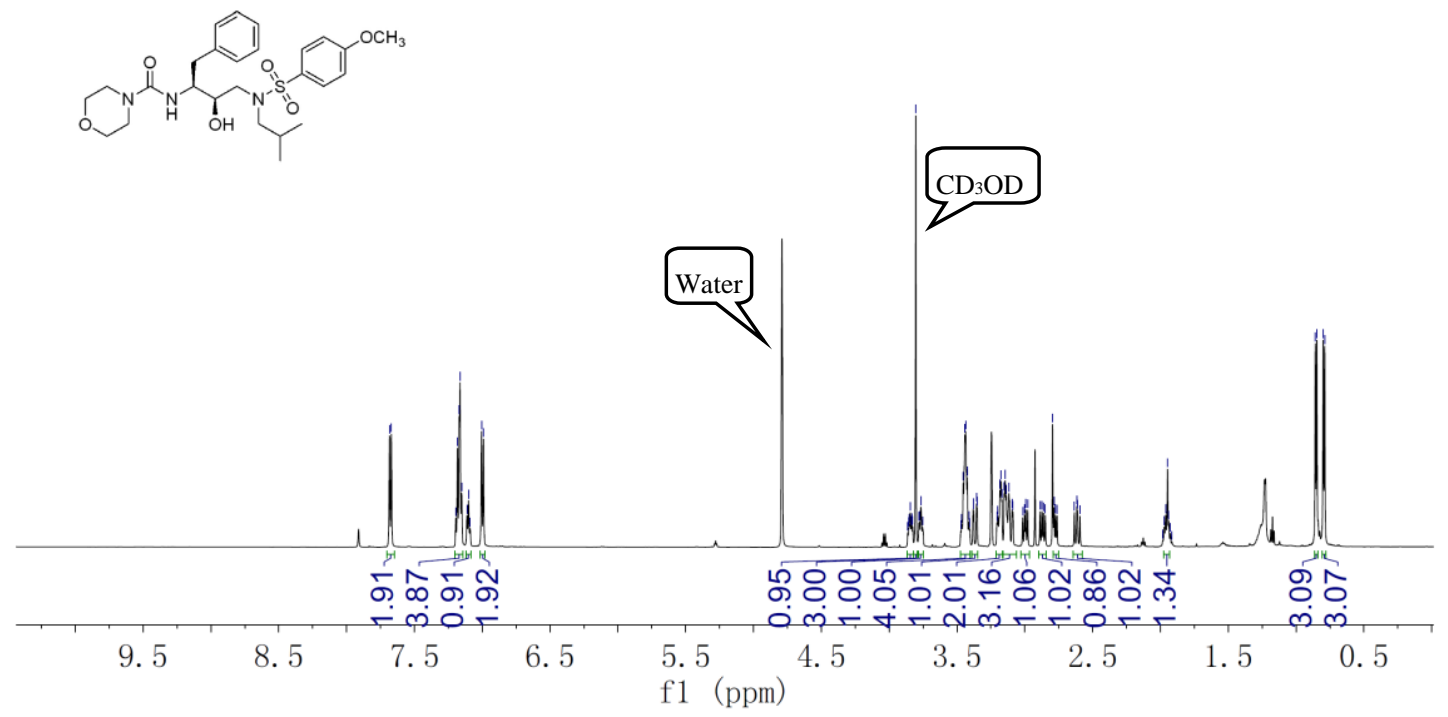

${ }^{1} \mathrm{H}$ NMR Spectrum of compound 27a 


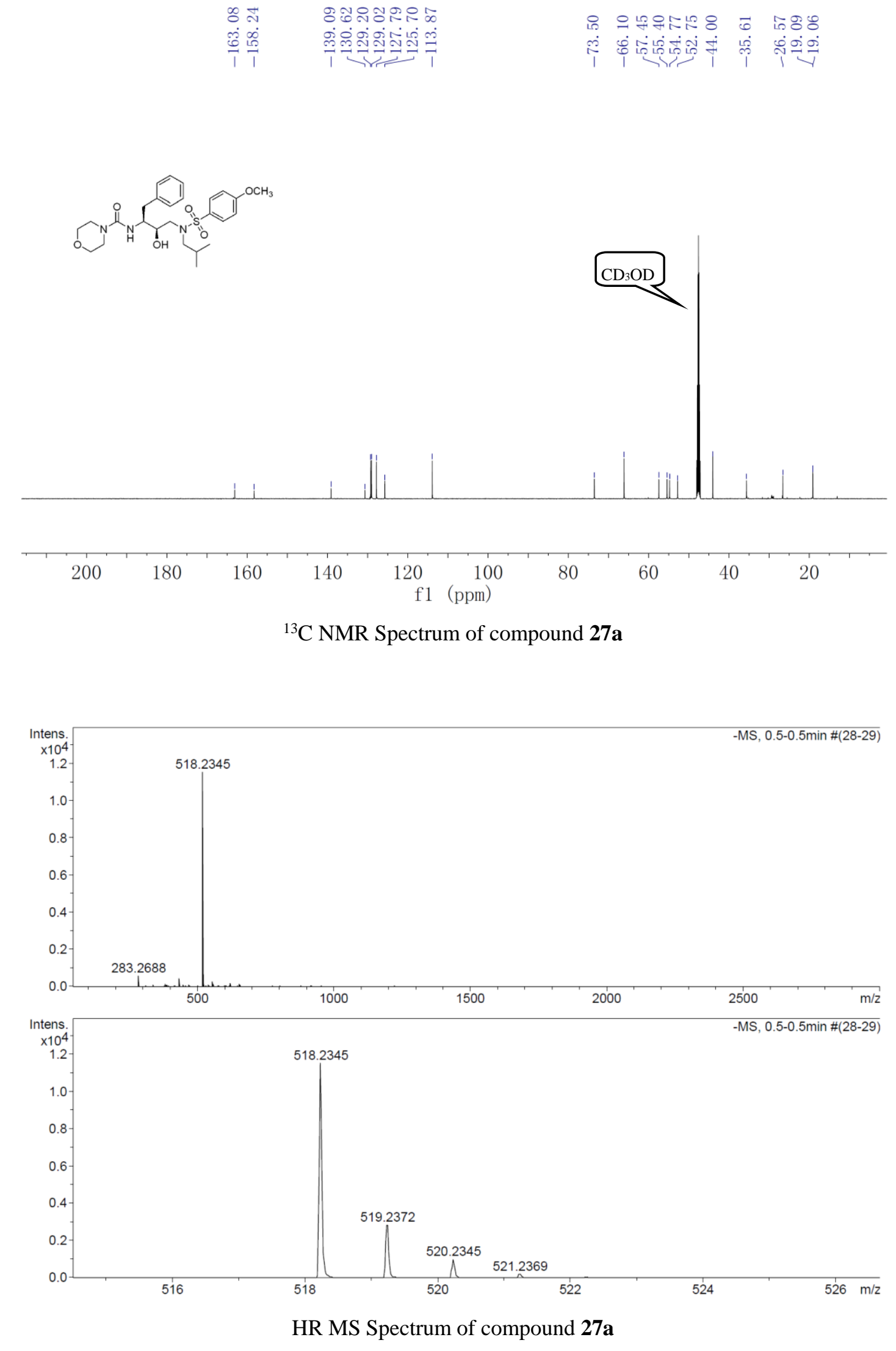




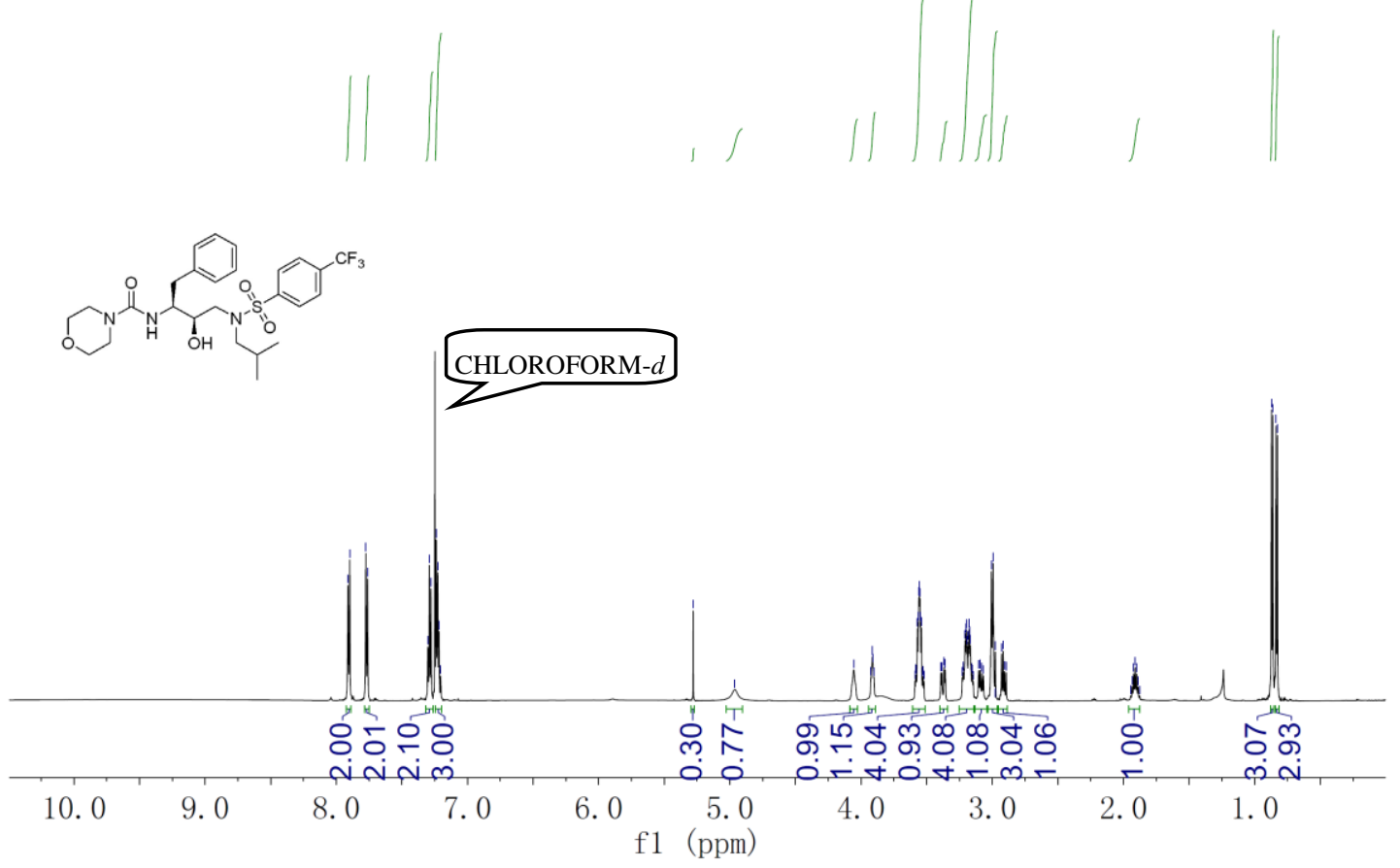

${ }^{1} \mathrm{H}$ NMR Spectrum of compound $\mathbf{2 7 b}$
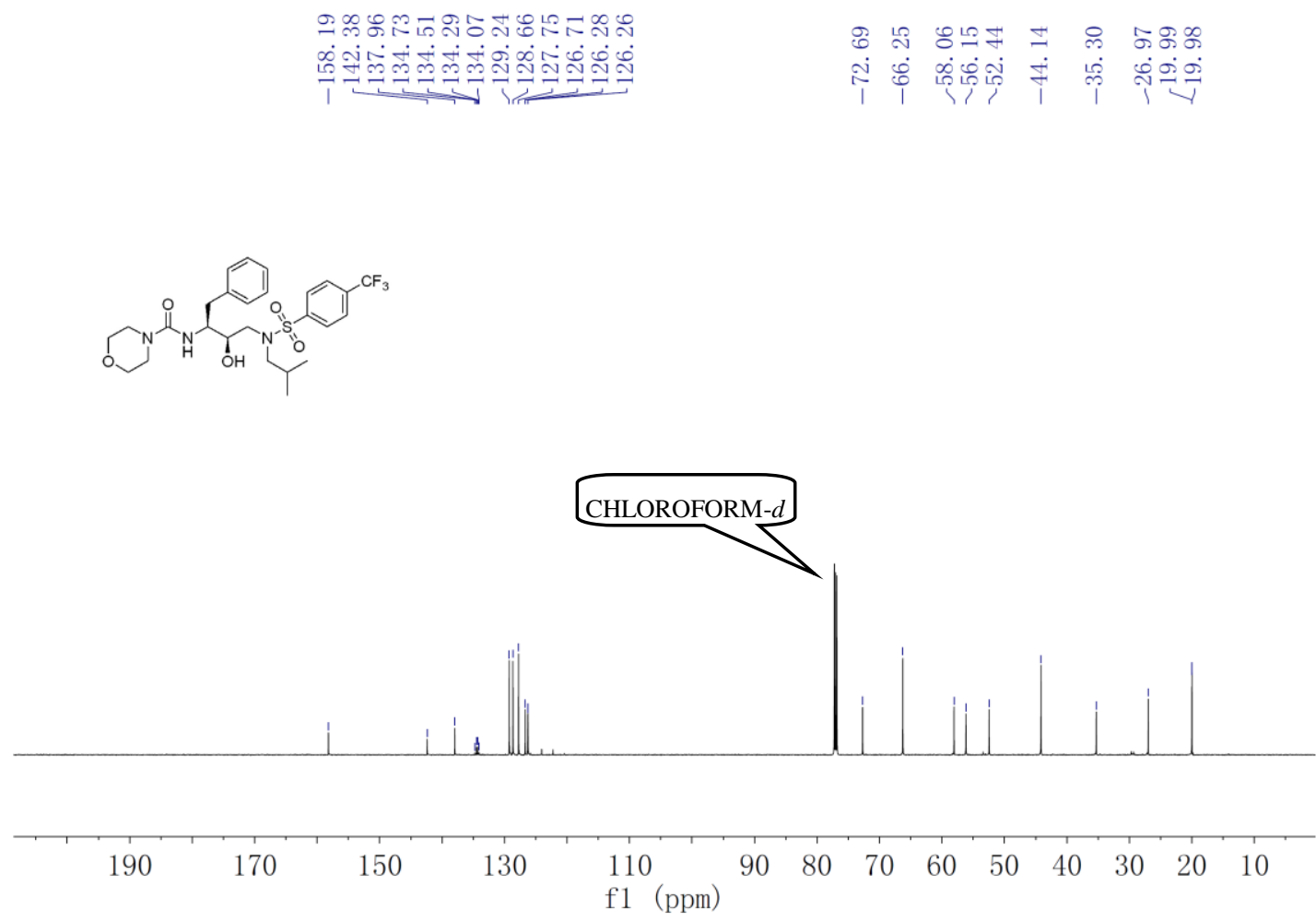

${ }^{13} \mathrm{C}$ NMR Spectrum of compound $\mathbf{2 7 b}$ 


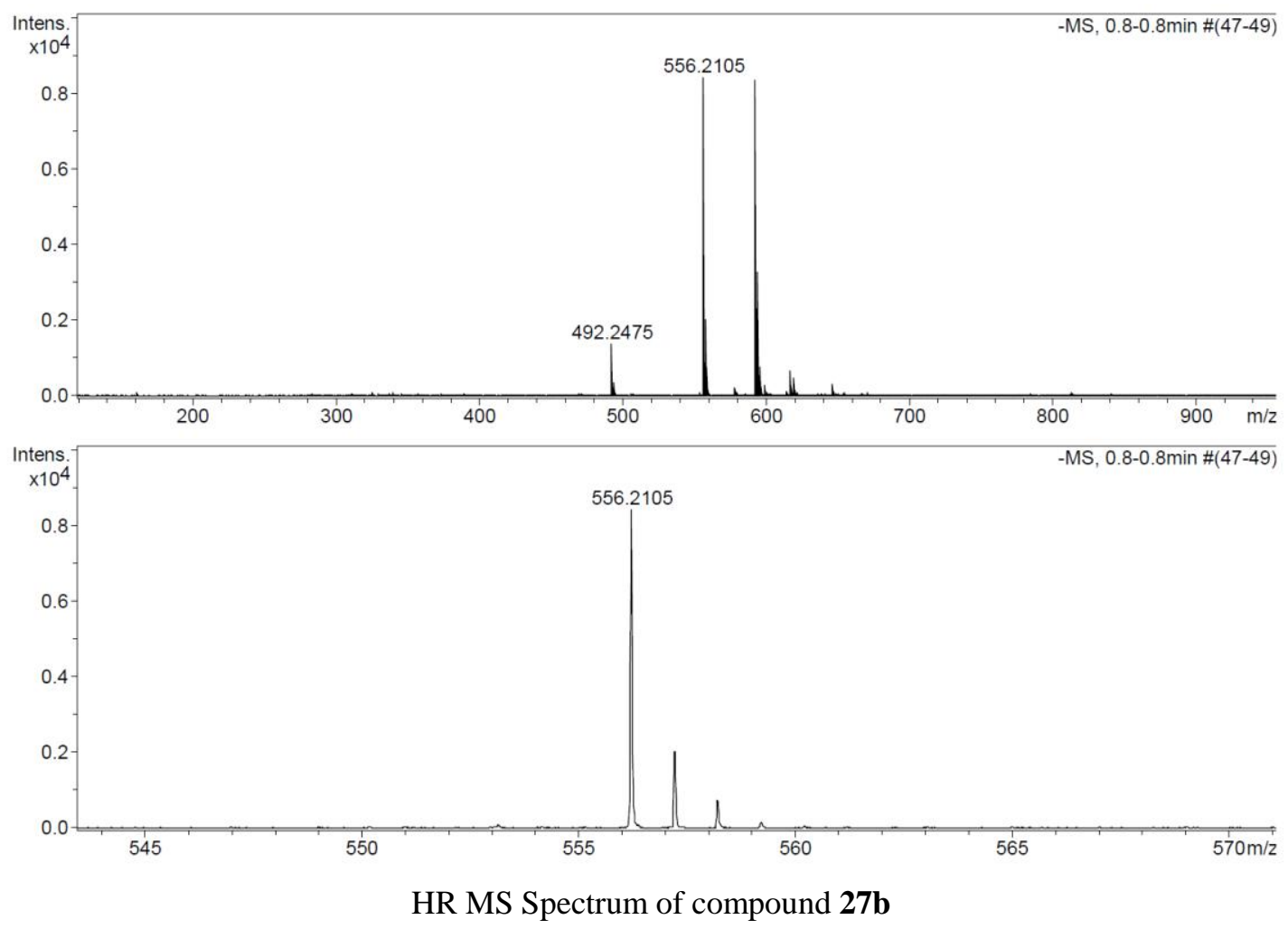

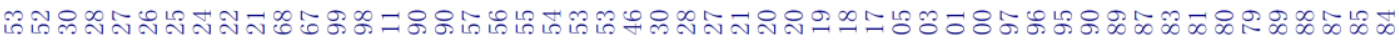

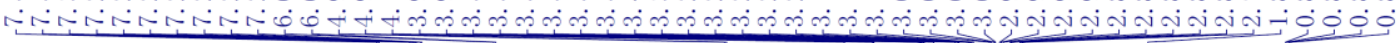
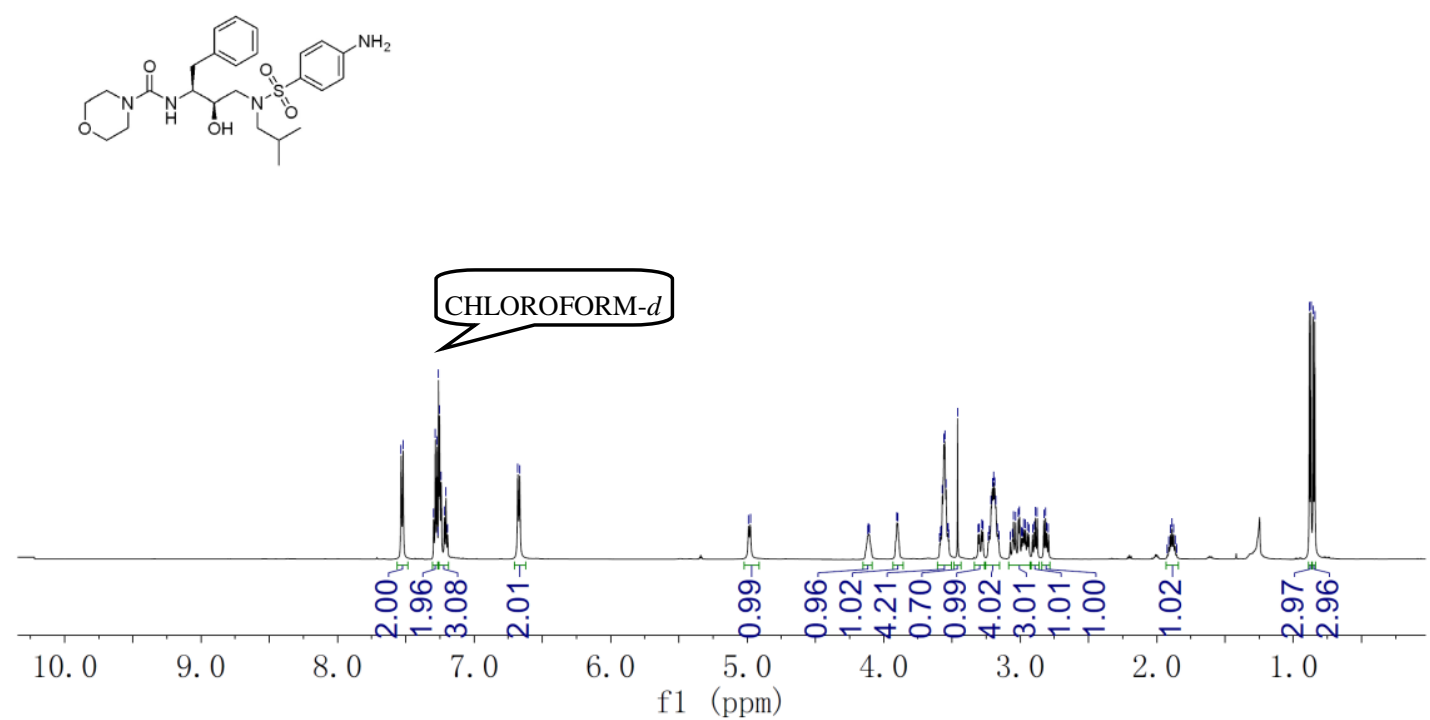

${ }^{1} \mathrm{H}$ NMR Spectrum of compound 27c 

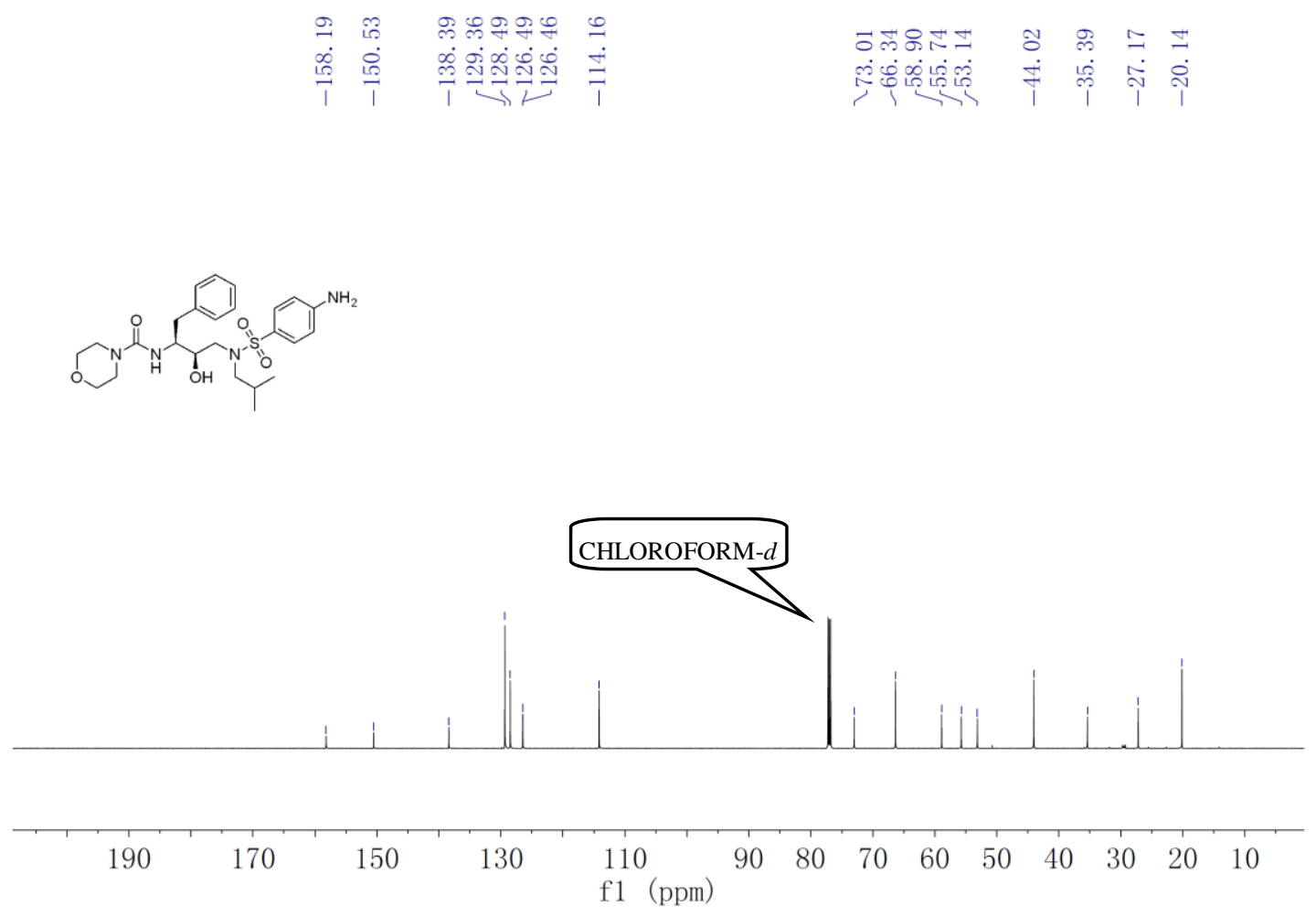

${ }^{13} \mathrm{C}$ NMR Spectrum of compound 27c
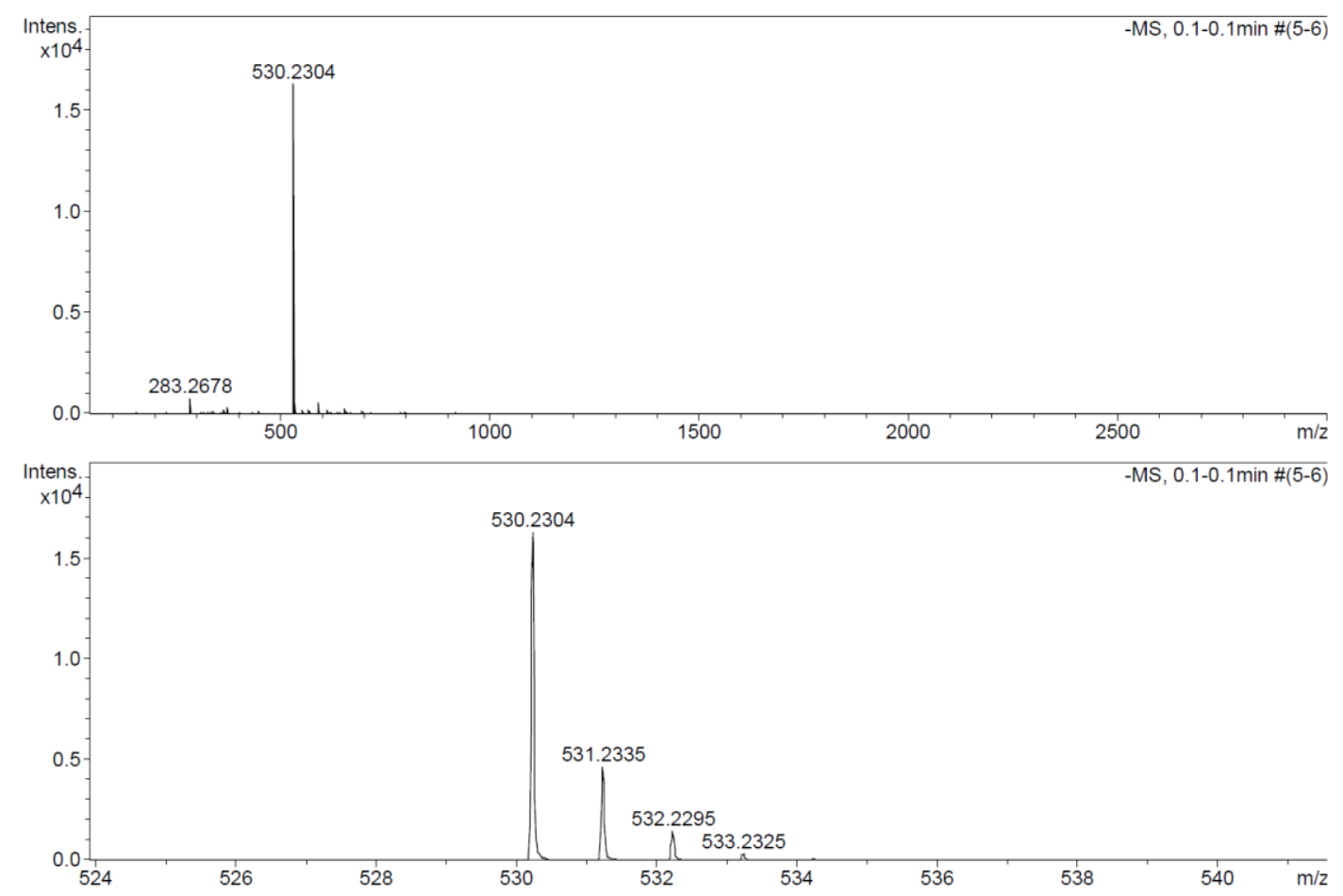

HR MS Spectrum of compound 27c 


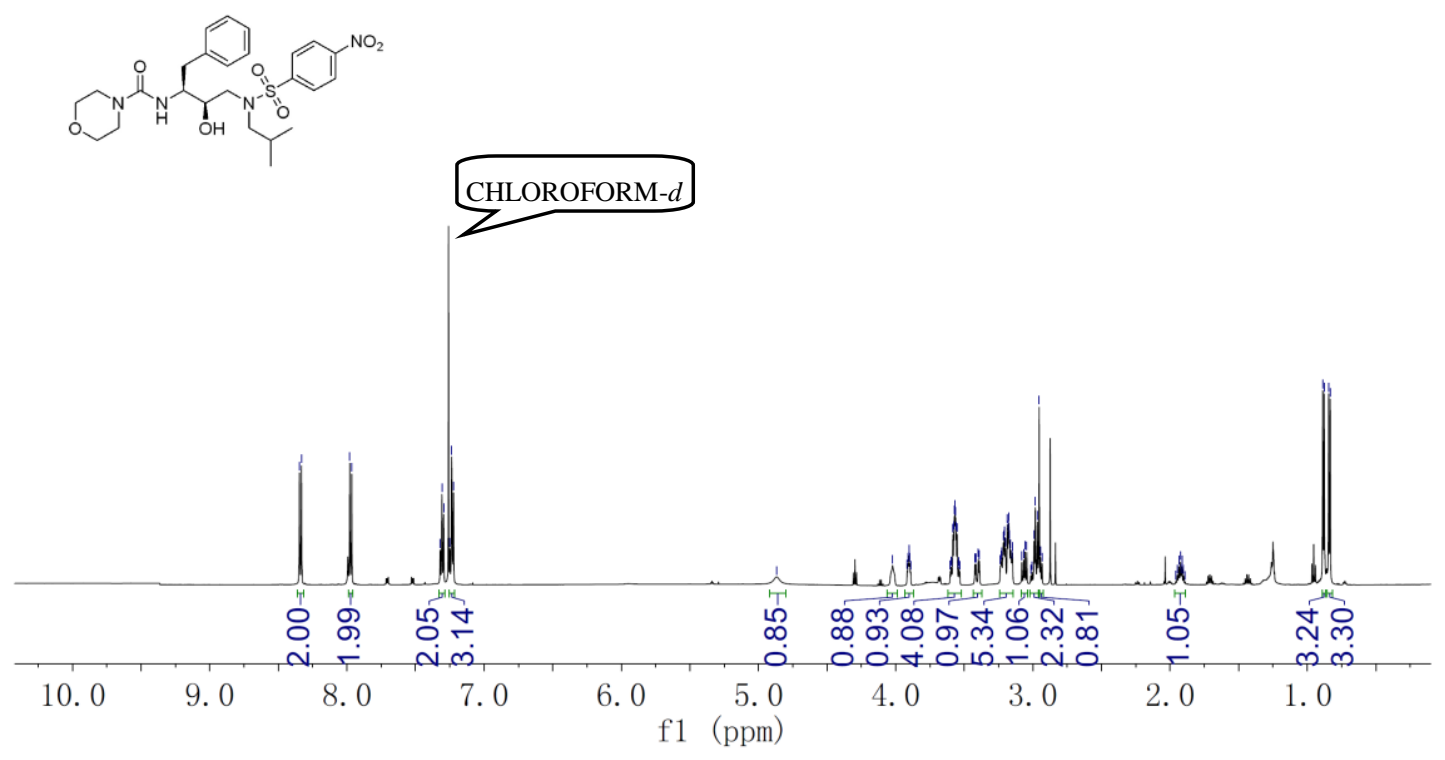

${ }^{1} \mathrm{H}$ NMR Spectrum of compound 27d

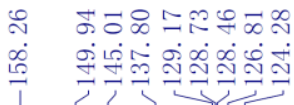

అ

î
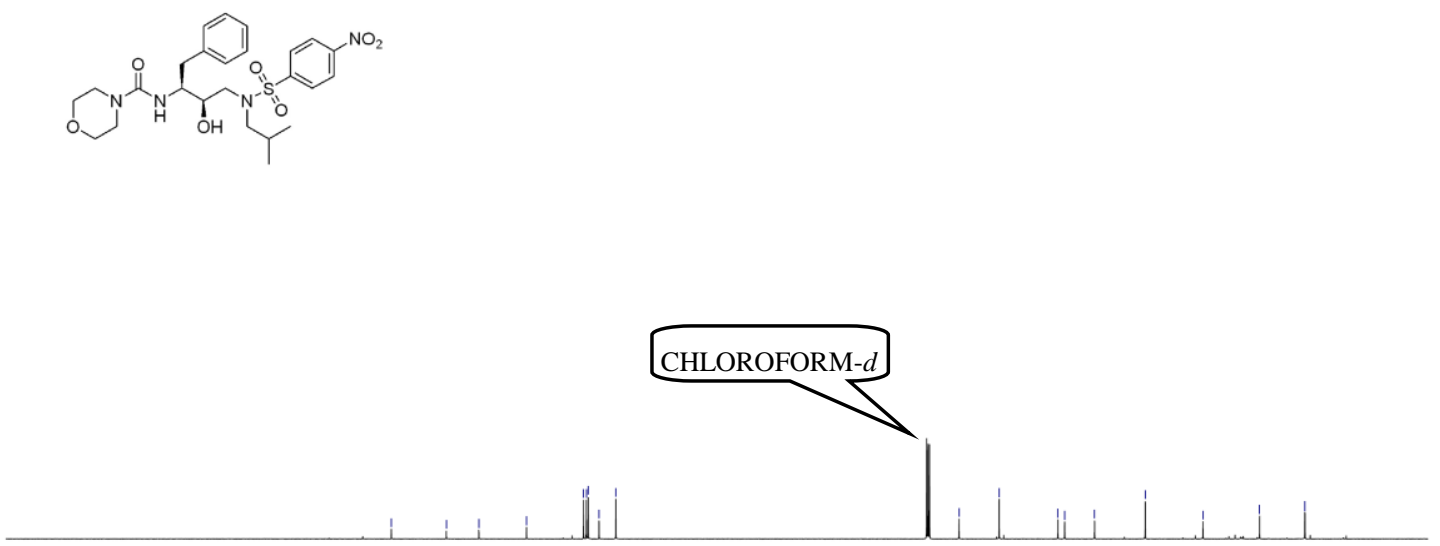


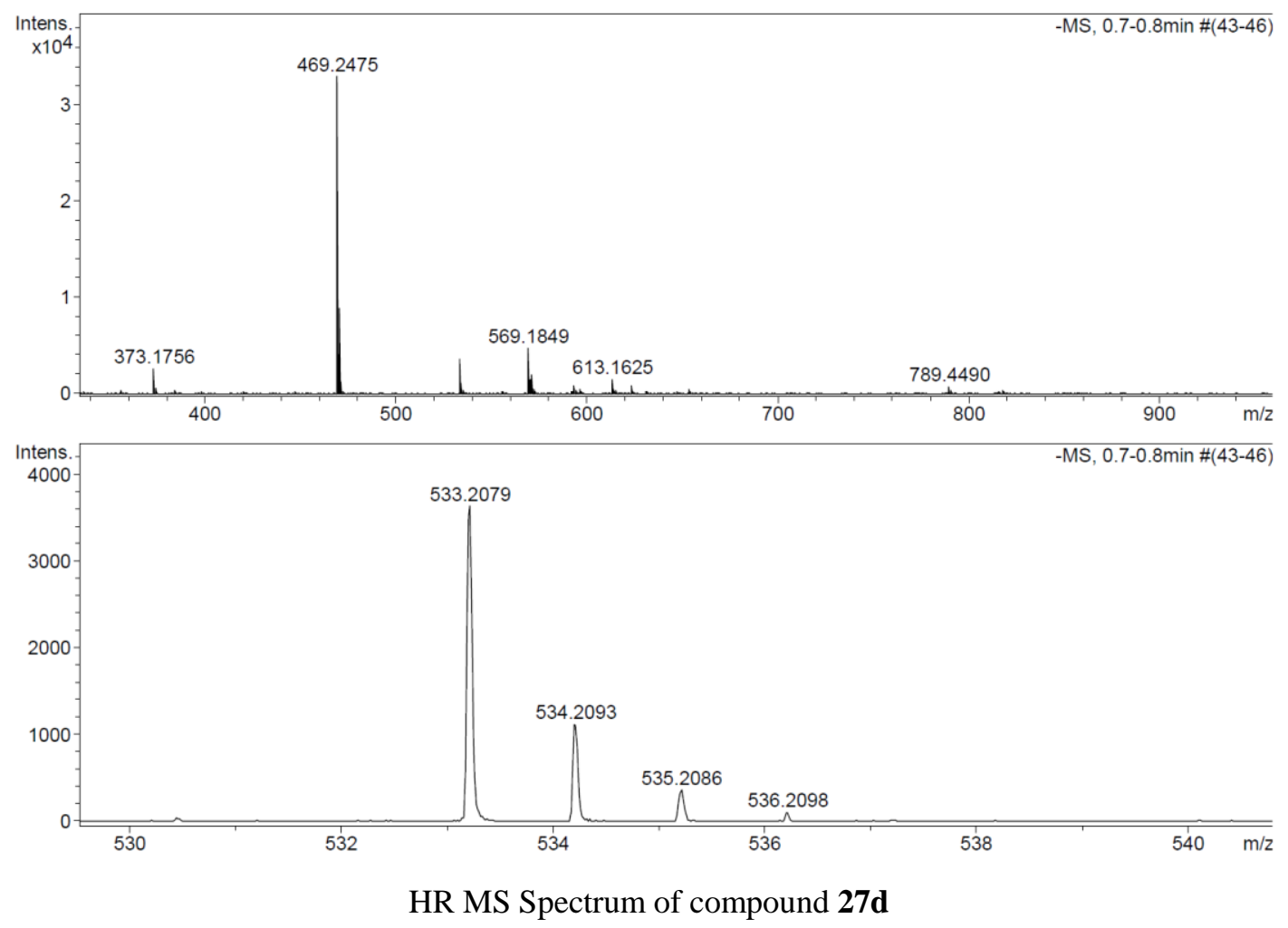

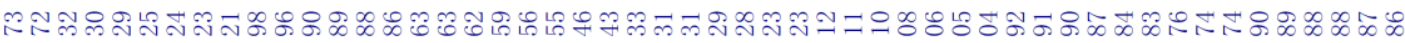
ن

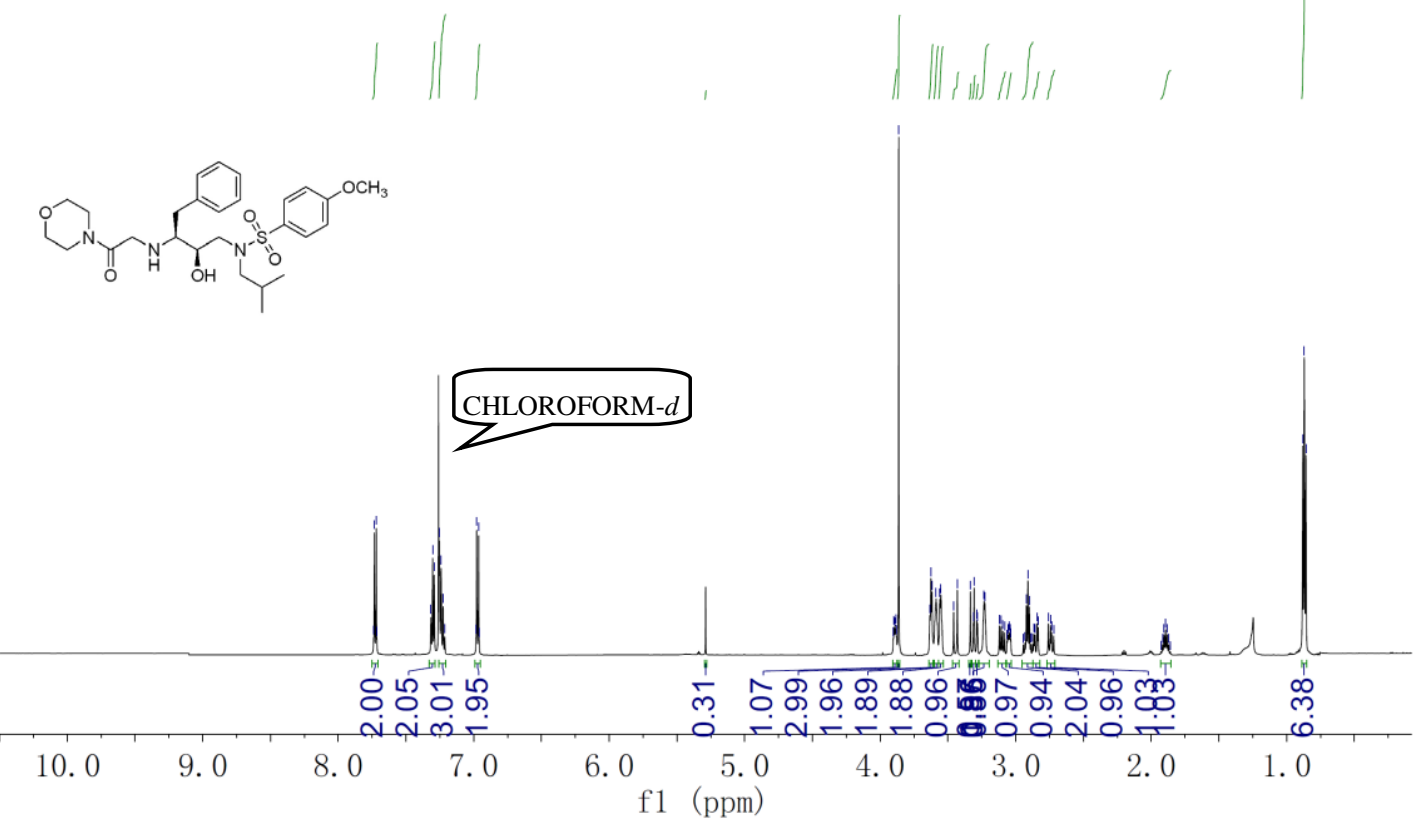

${ }^{1} \mathrm{H}$ NMR Spectrum of compound $\mathbf{2 8 a}$ 


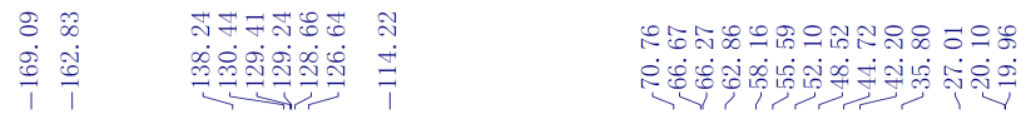

(2)

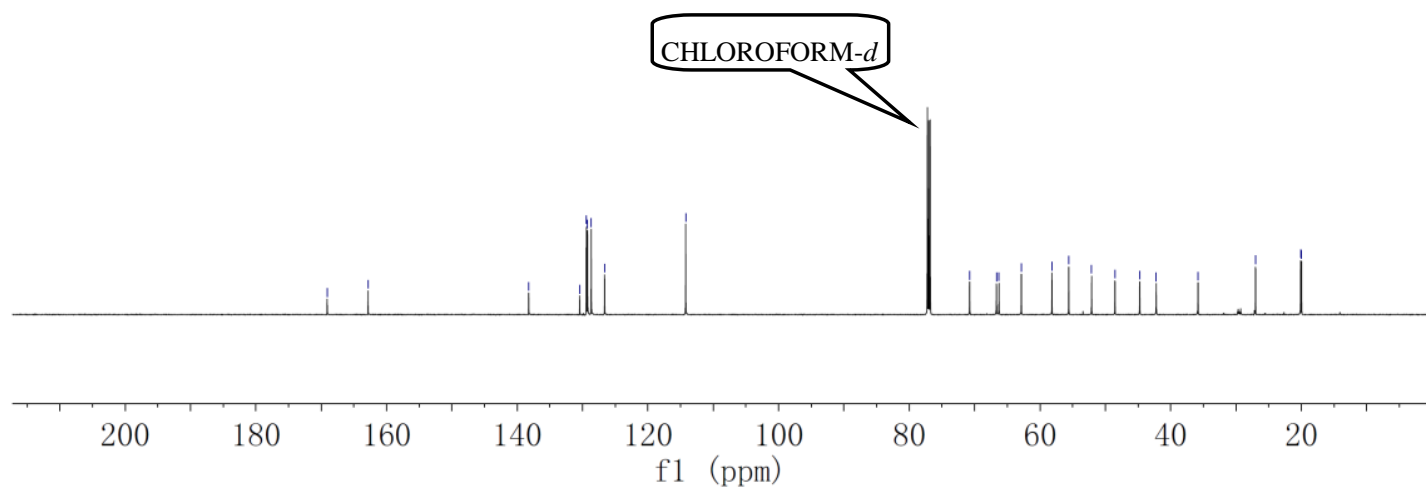

${ }^{13} \mathrm{C}$ NMR Spectrum of compound 28a
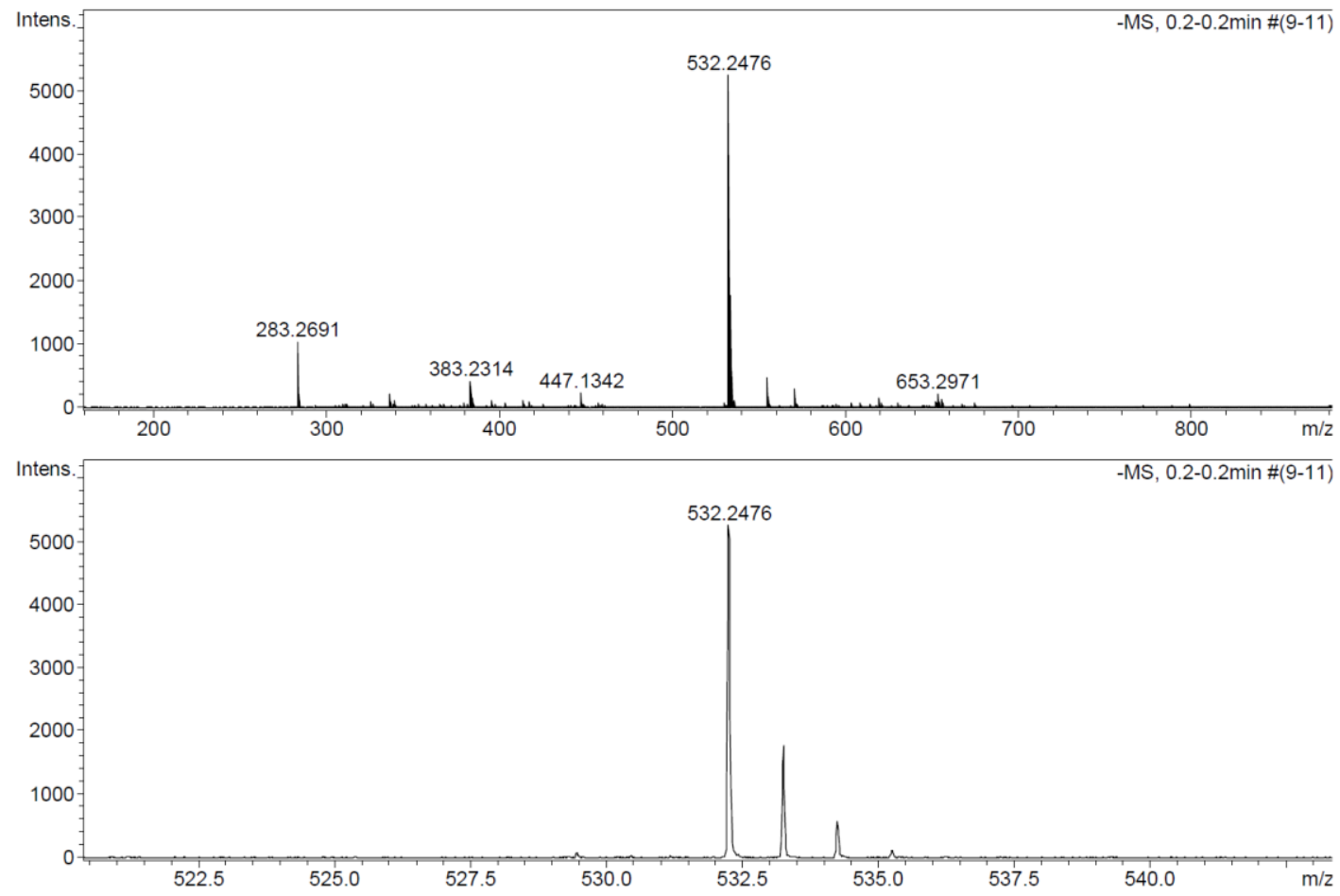

HR MS Spectrum of compound $\mathbf{2 8 a}$ 


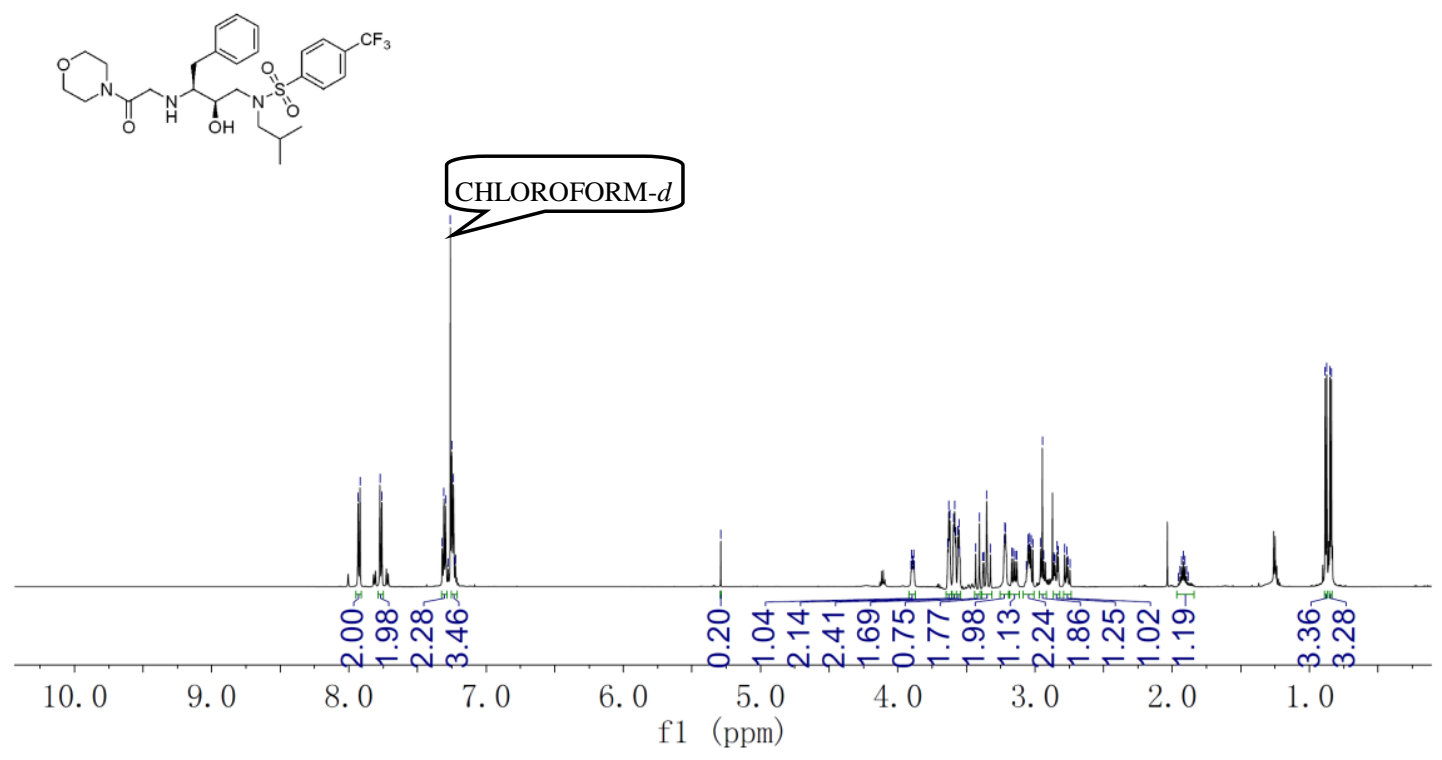

${ }^{1} \mathrm{H}$ NMR Spectrum of compound $\mathbf{2 8 b}$
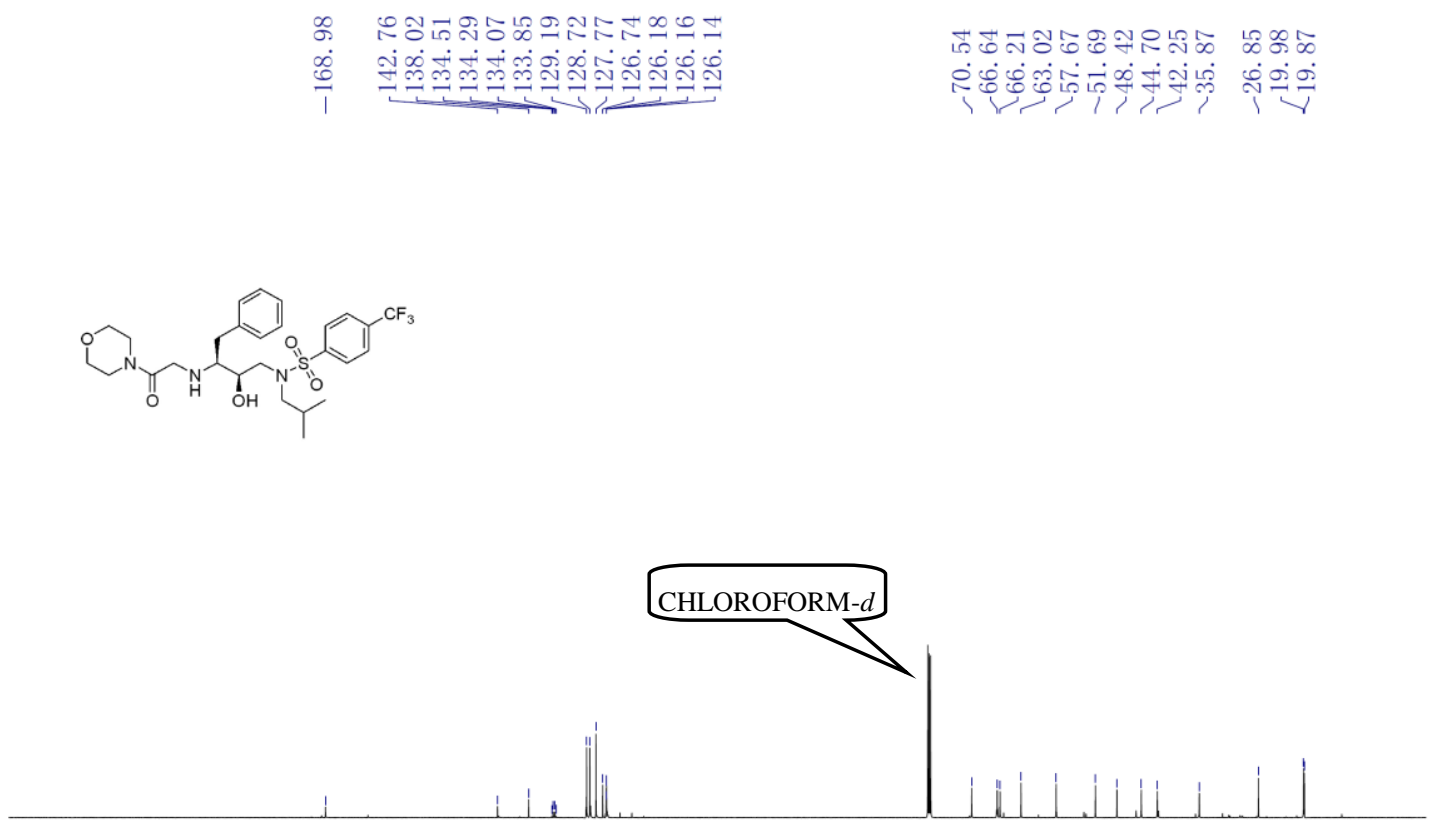

\begin{tabular}{|c|c|c|c|c|c|c|c|c|c|}
\hline 200 & 180 & 160 & 140 & $\begin{array}{r}120 \\
\text { f1 }\end{array}$ & $\begin{array}{c}100 \\
(\mathrm{ppm})\end{array}$ & 80 & 60 & 40 & 20 \\
\hline
\end{tabular}

${ }^{13} \mathrm{C}$ NMR Spectrum of compound $\mathbf{2 8 b}$ 

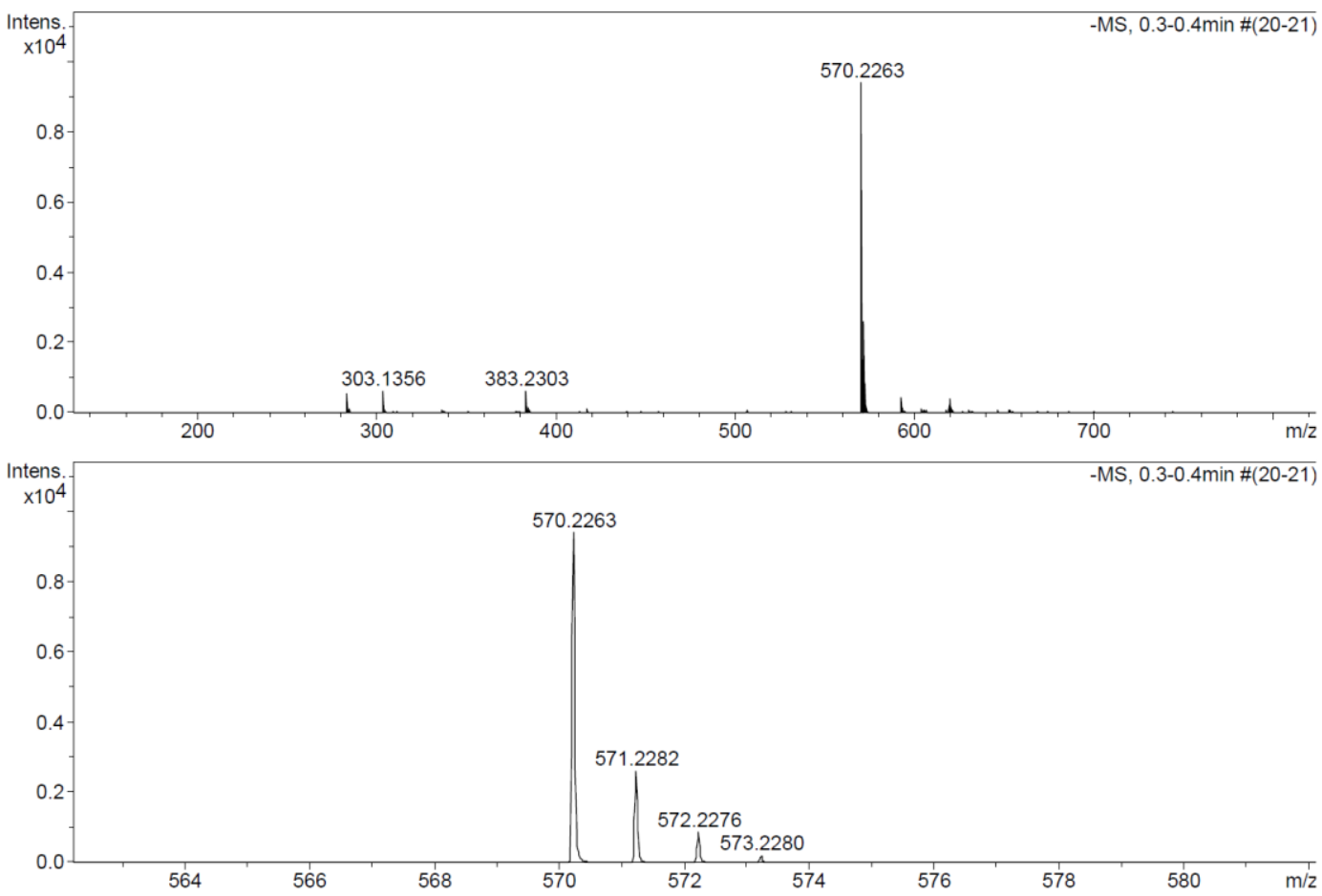

HR MS Spectrum of compound $\mathbf{2 8 b}$

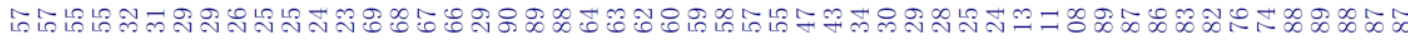

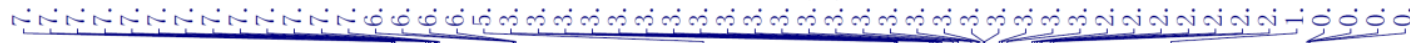

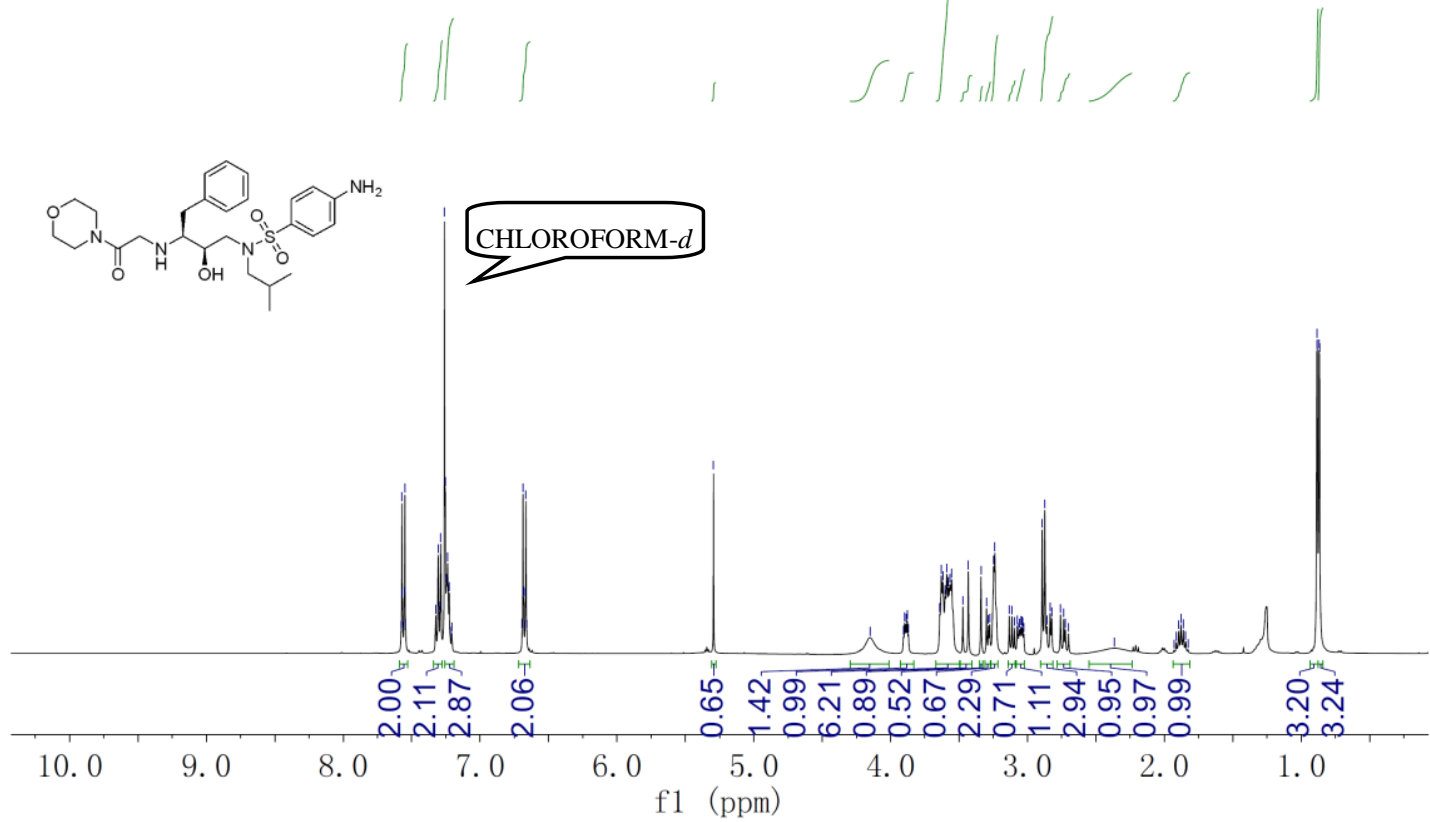

${ }^{1} \mathrm{H}$ NMR Spectrum of compound $\mathbf{2 8 c}$ 

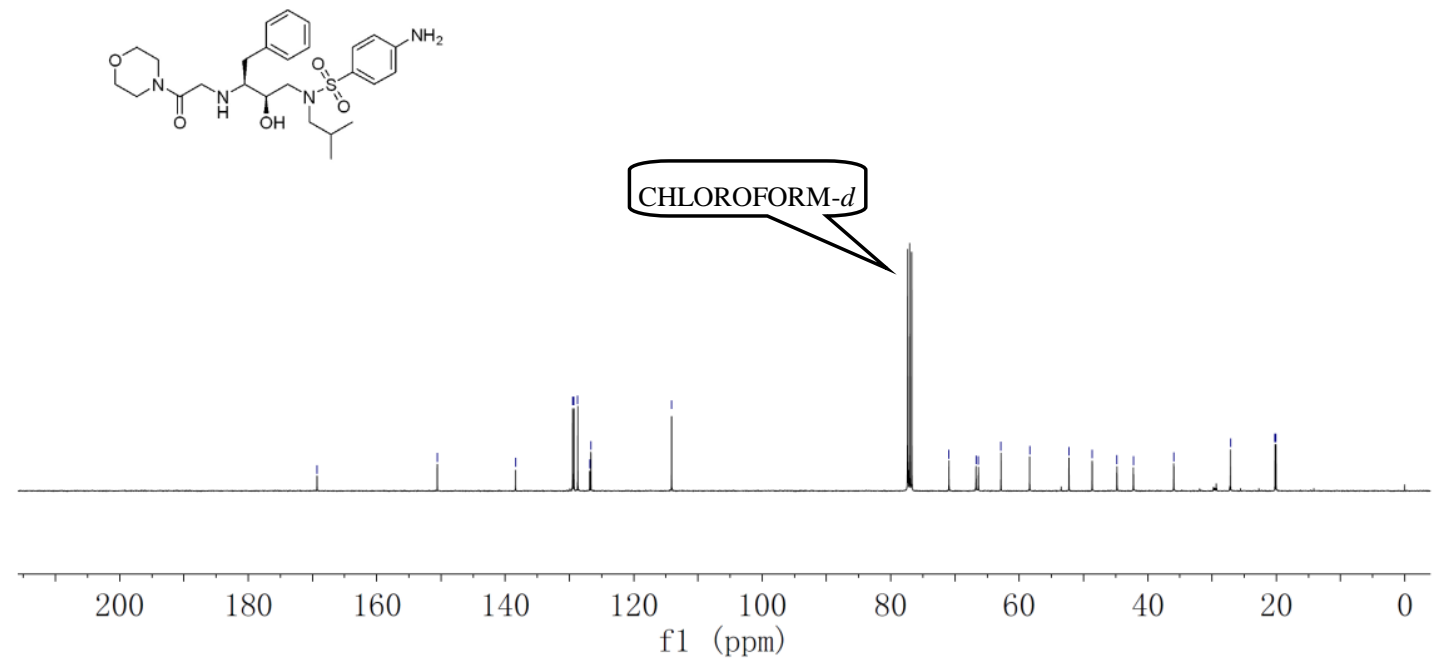

${ }^{13} \mathrm{C}$ NMR Spectrum of compound $\mathbf{2 8 c}$

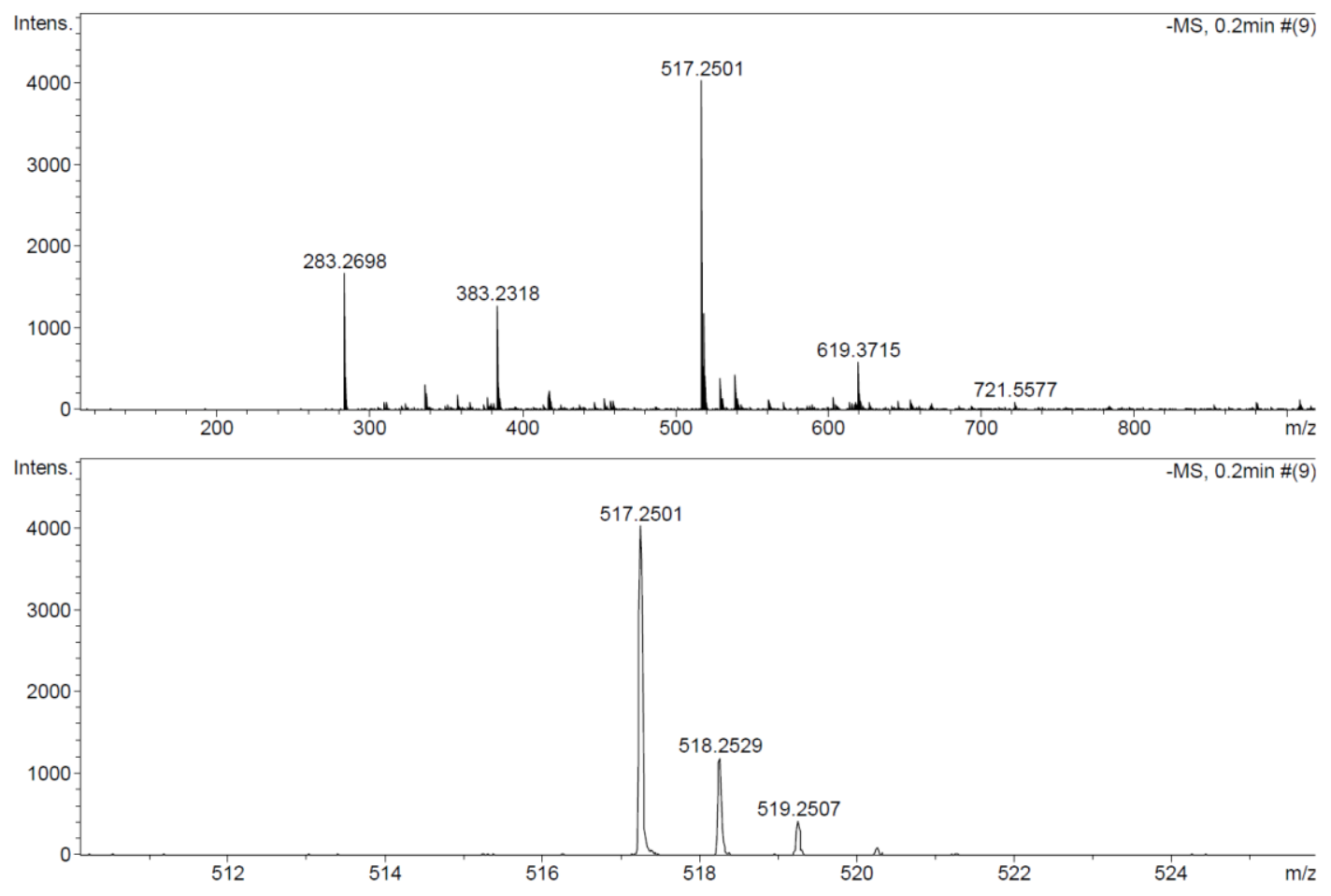

HR MS Spectrum of compound 28c 


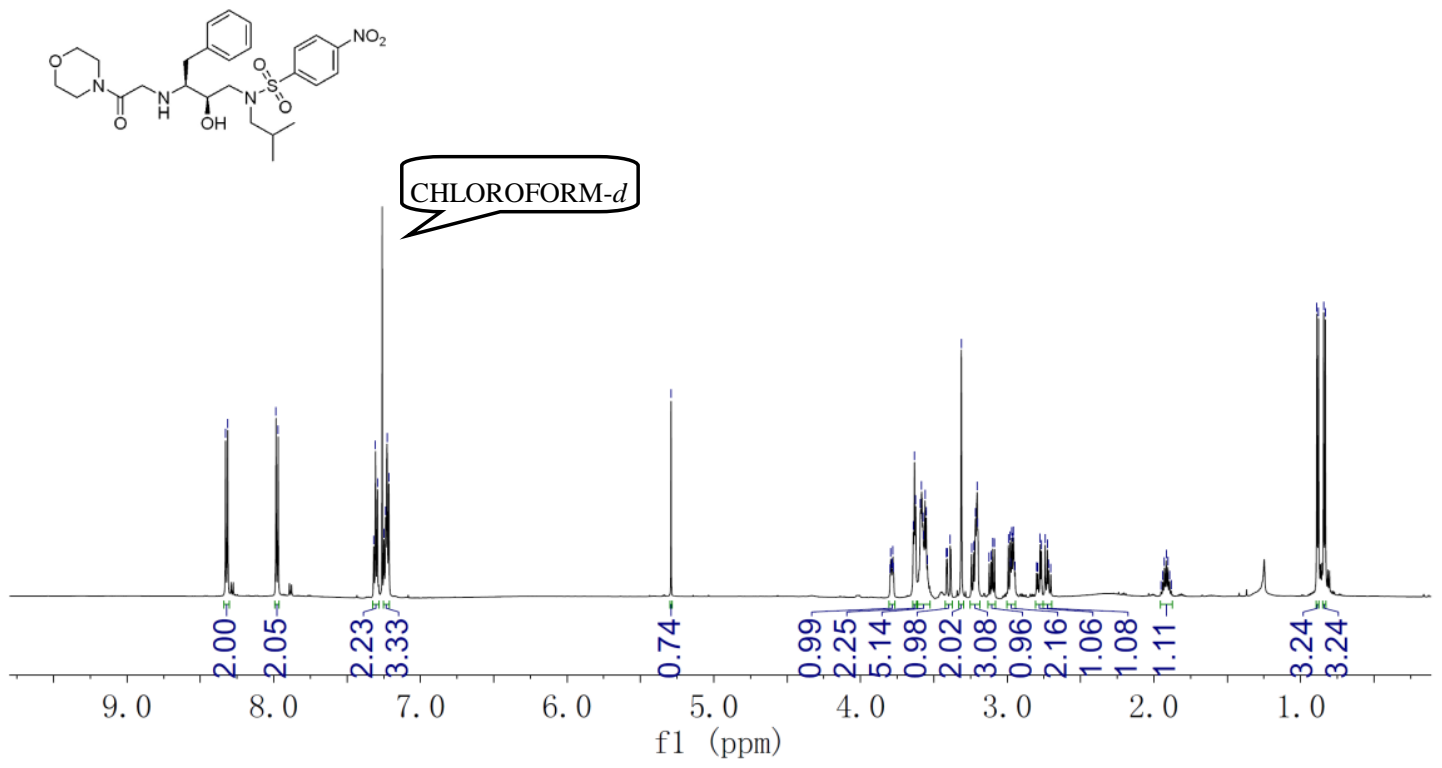

${ }^{1} \mathrm{H}$ NMR Spectrum of compound $\mathbf{2 8 d}$

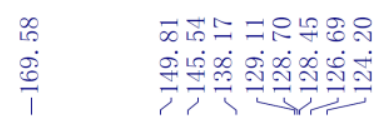

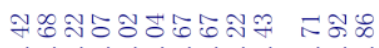

iी
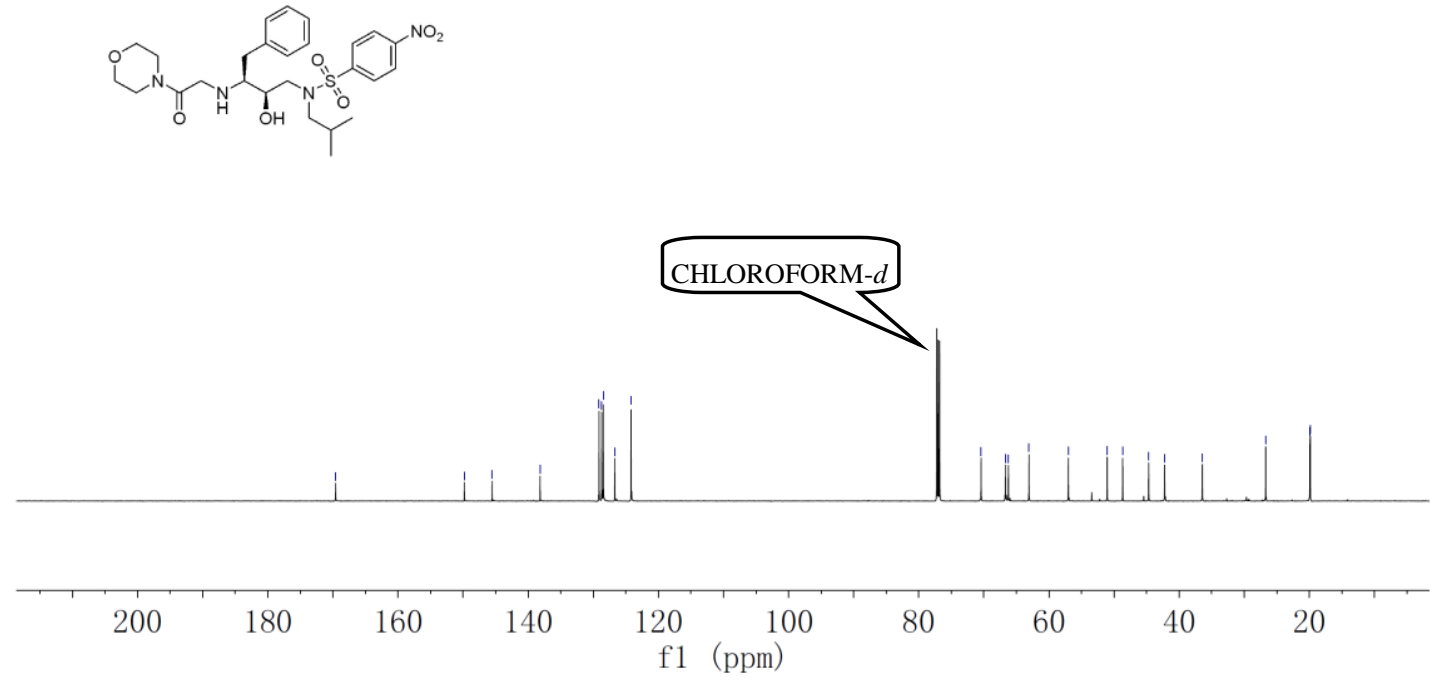

${ }^{13} \mathrm{C}$ NMR Spectrum of compound $\mathbf{2 8 d}$ 


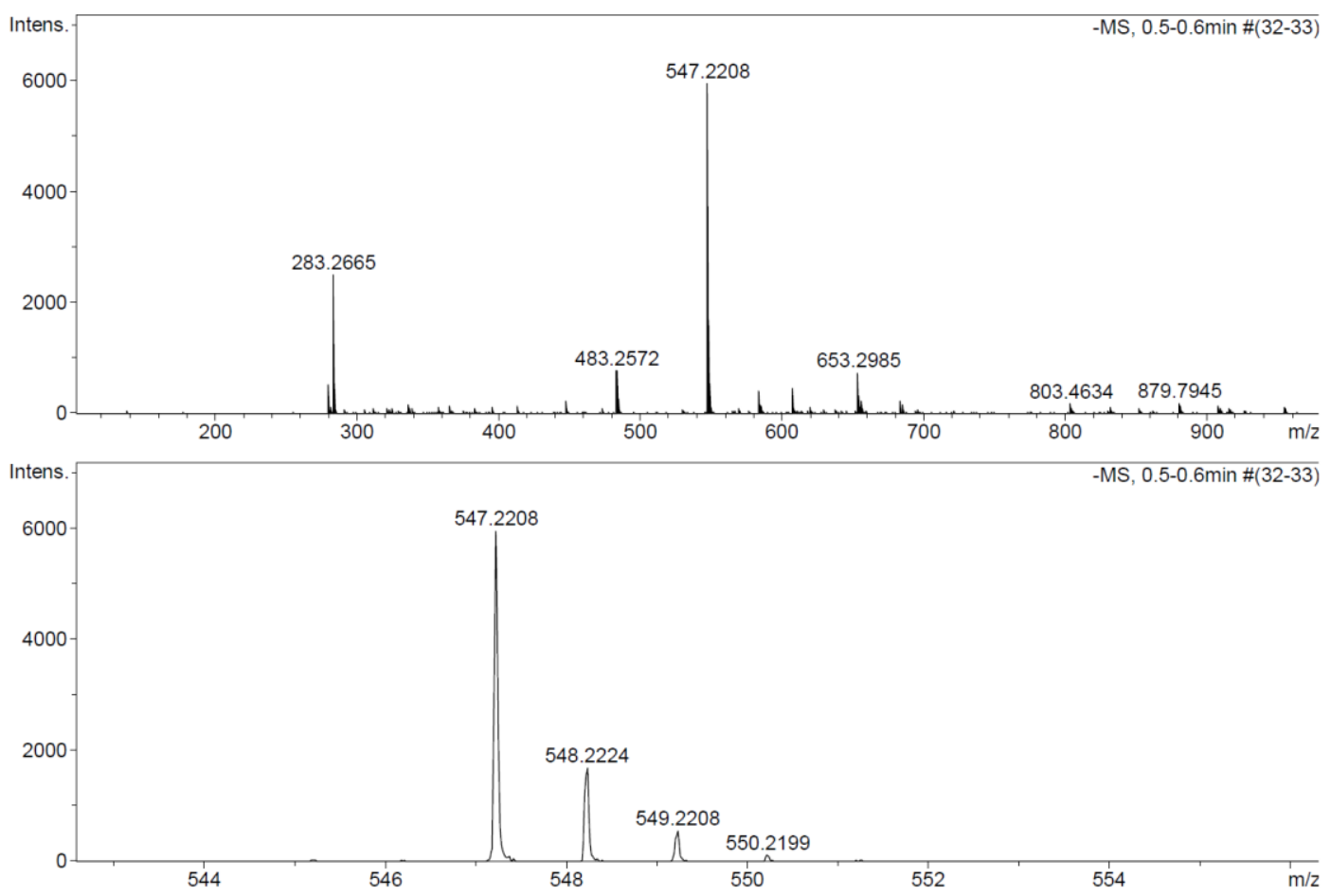

HR MS Spectrum of compound 28d

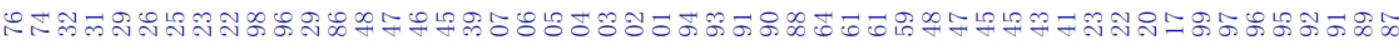

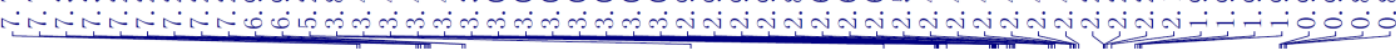

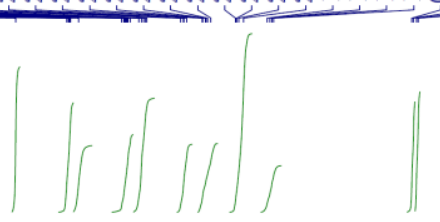

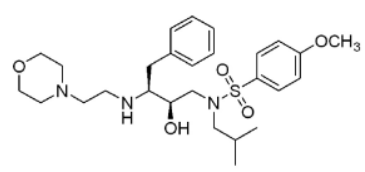

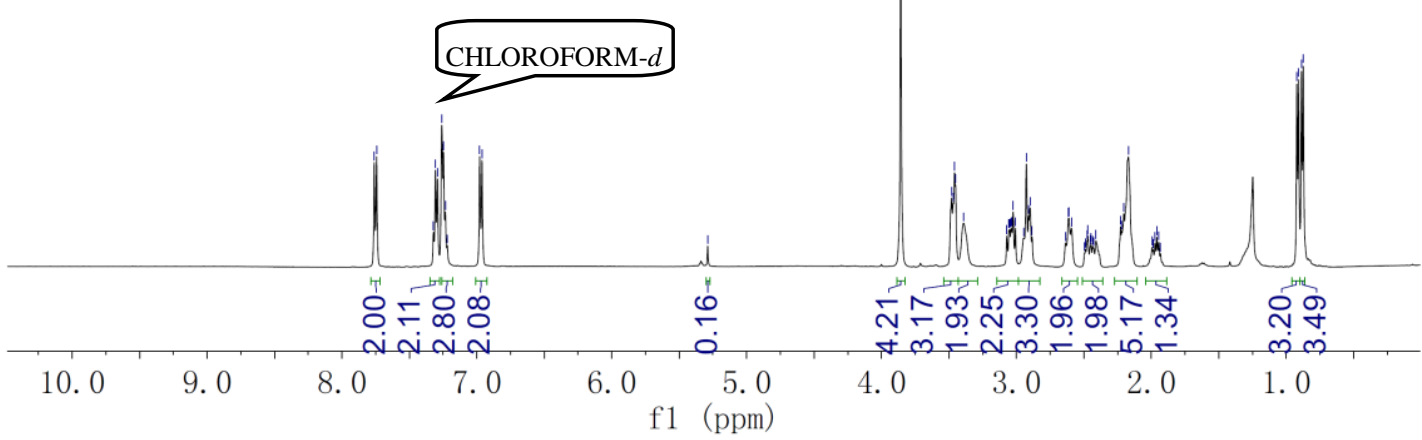

${ }^{1} \mathrm{H}$ NMR Spectrum of compound 29a 


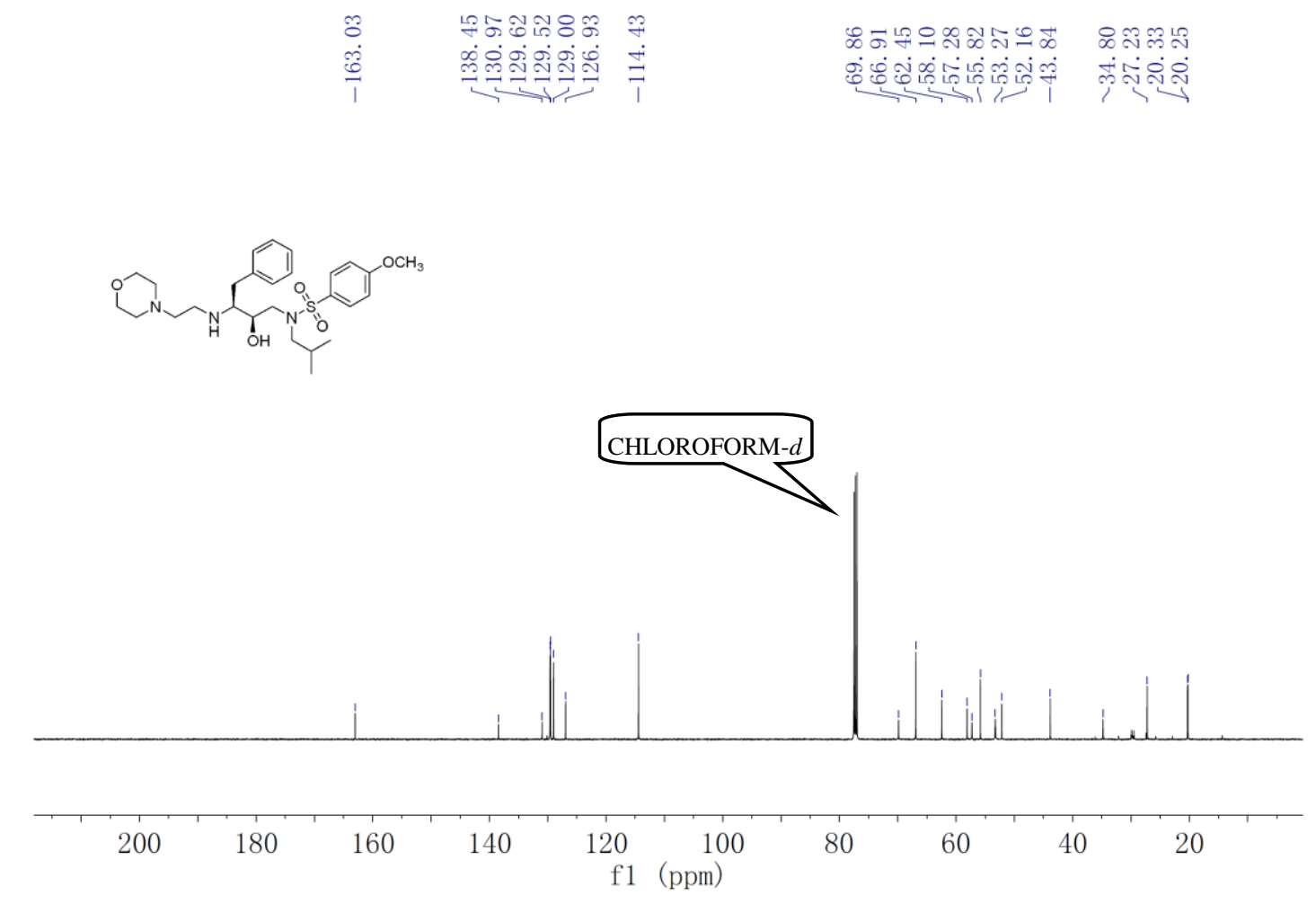

${ }^{13} \mathrm{C}$ NMR Spectrum of compound 29a
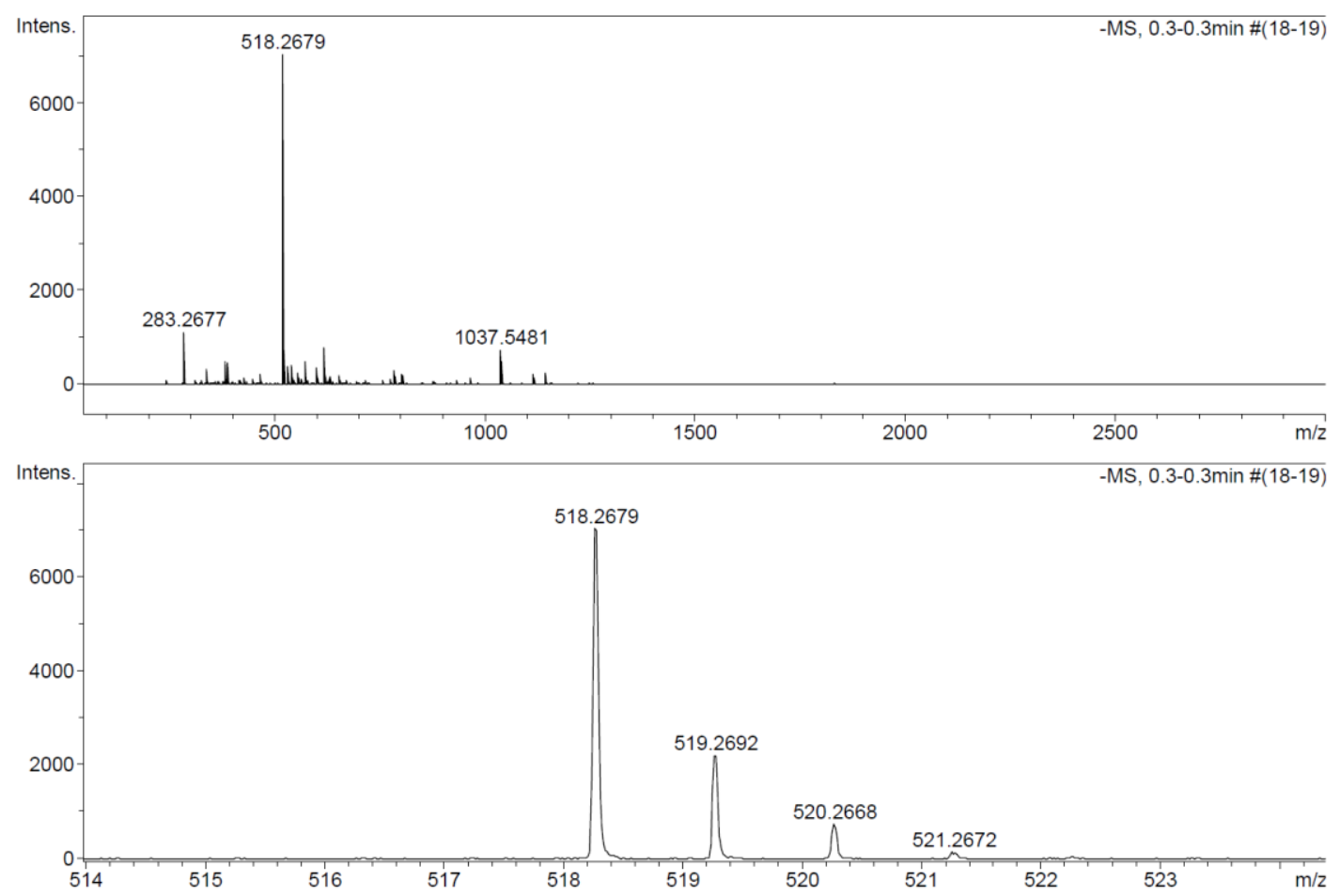

HR MS Spectrum of compound 29a 

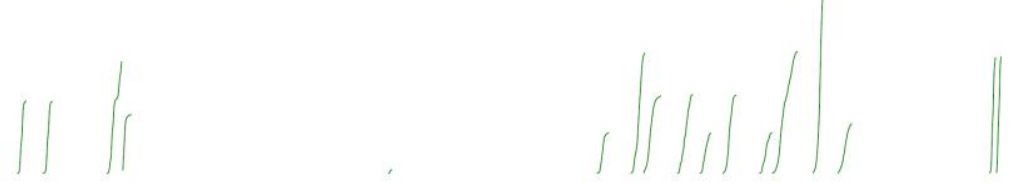<smiles>CC(C)CN(CC(O)CNCCN1CCOCC1)S(=O)(=O)c1ccc(C(F)(F)F)cc1</smiles>

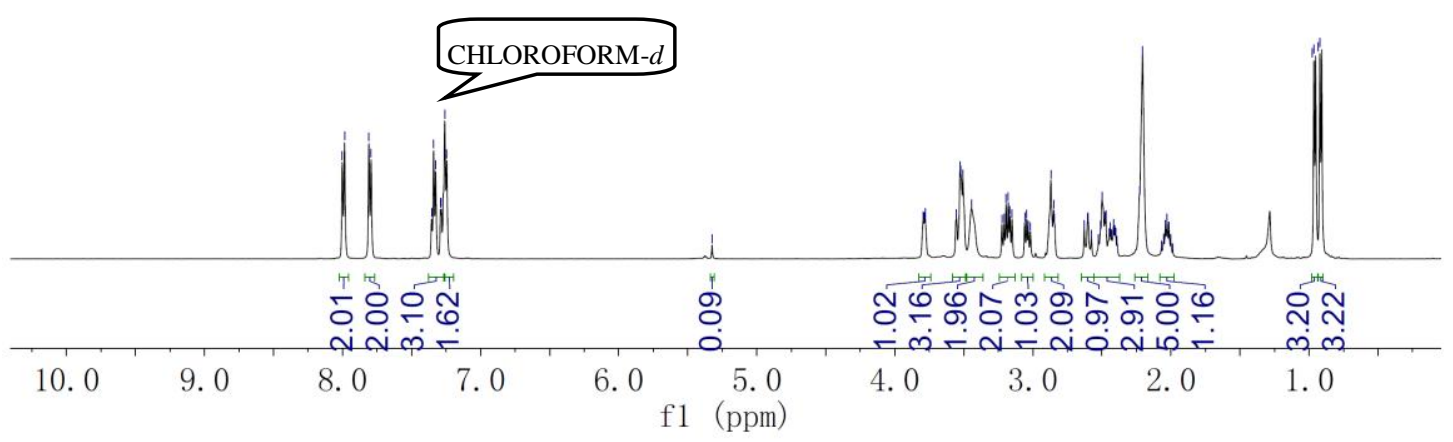

${ }^{1} \mathrm{H}$ NMR Spectrum of compound 29b
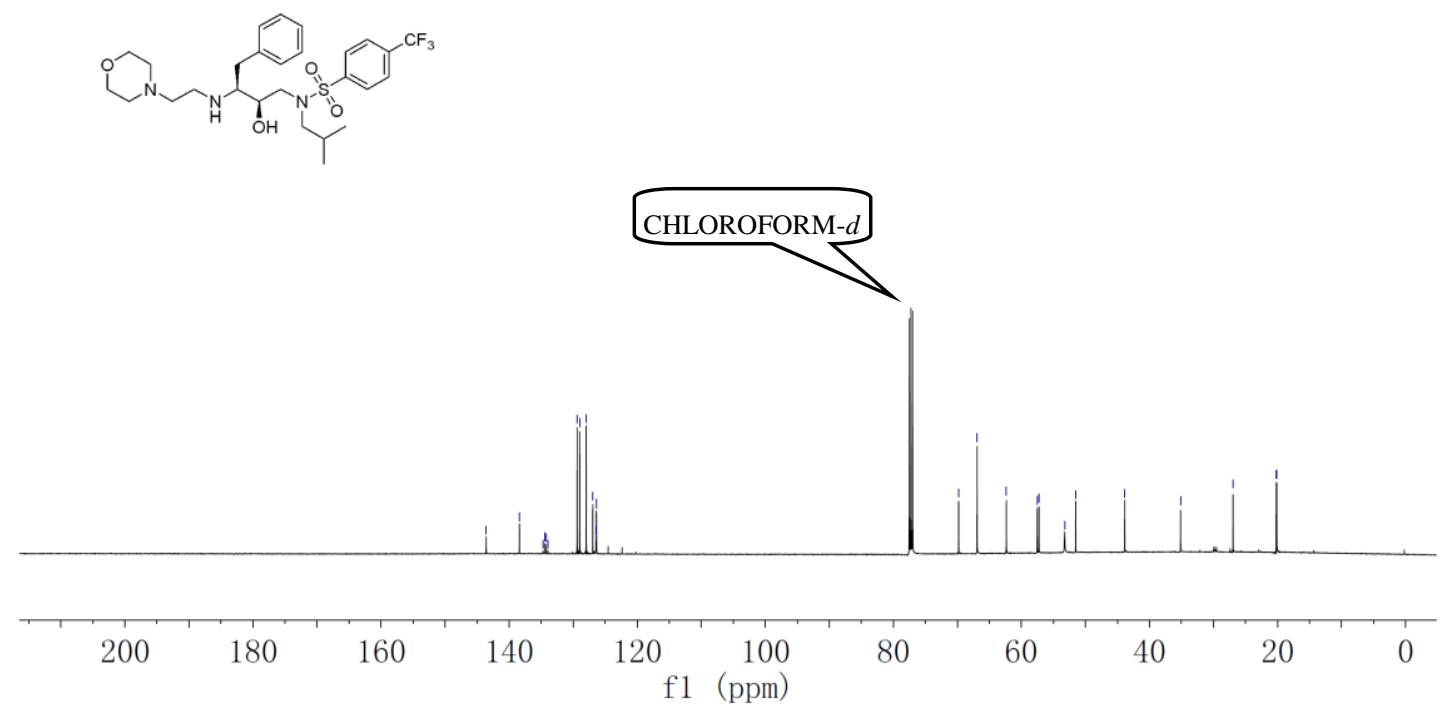

${ }^{13} \mathrm{C}$ NMR Spectrum of compound 29b 


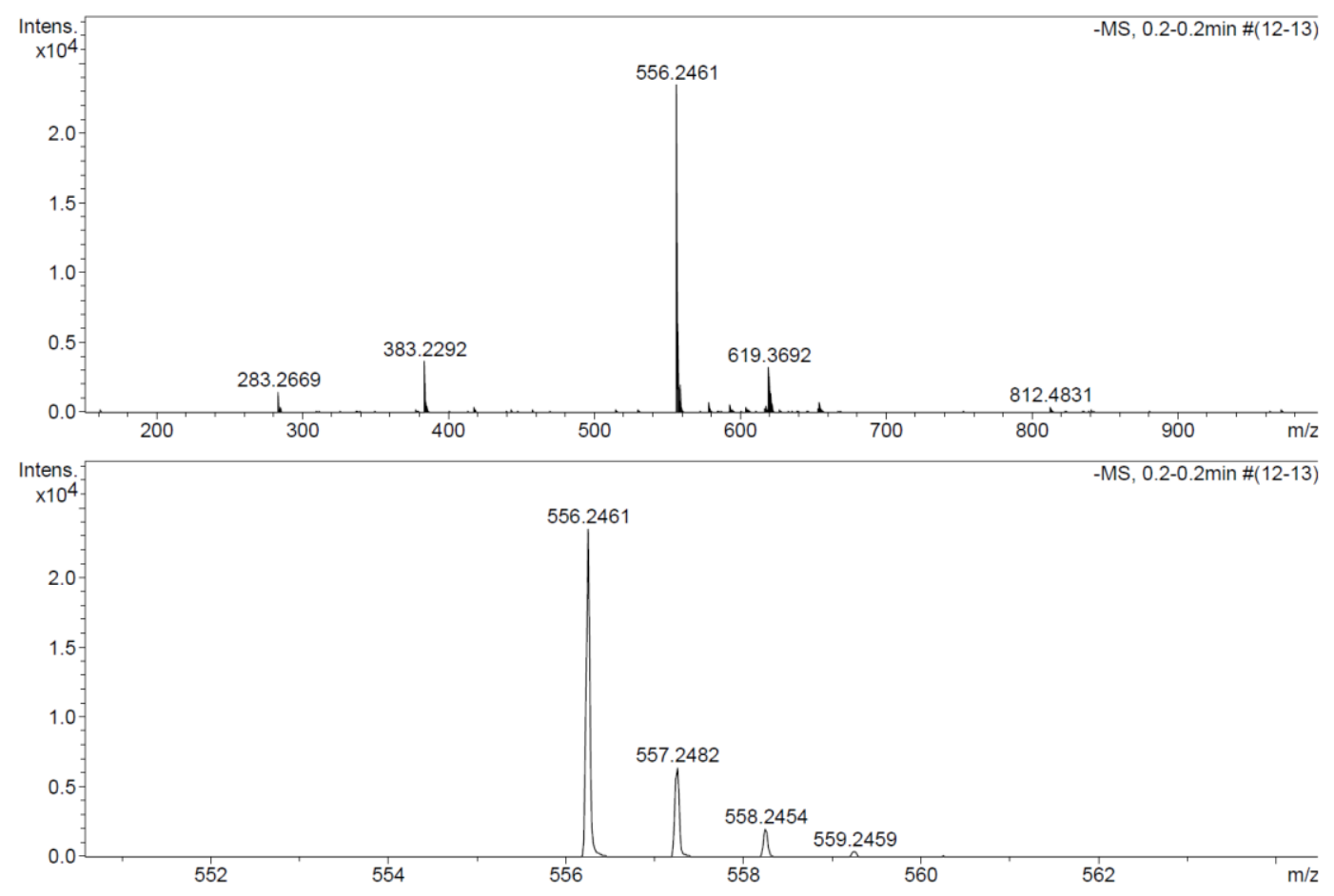

HR MS Spectrum of compound 29b

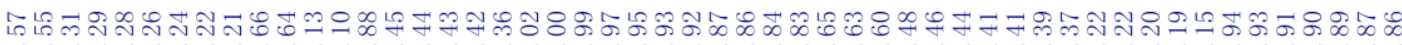

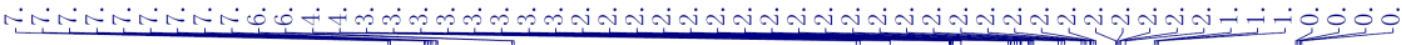

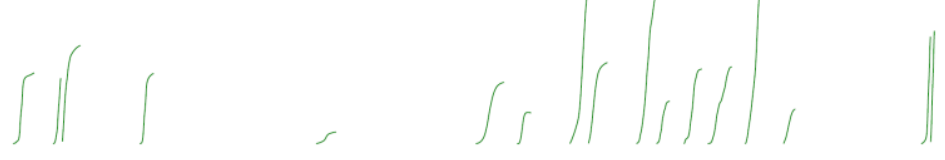<smiles>CC(C)CN(CC(O)C(Cc1ccccc1)NCCN1CCOCC1)S(=O)(=O)c1ccc(N)cc1</smiles>

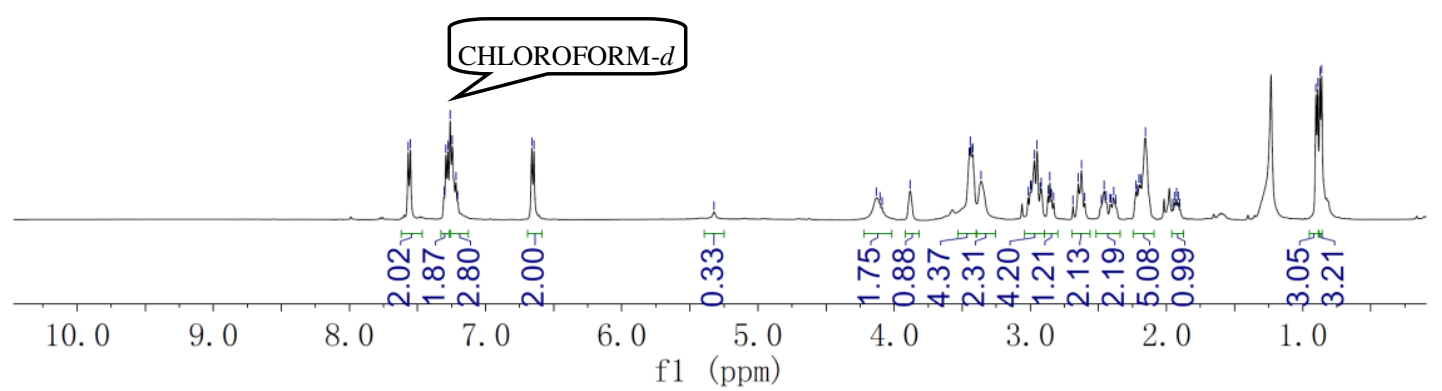

${ }^{1} \mathrm{H}$ NMR Spectrum of compound 29c 


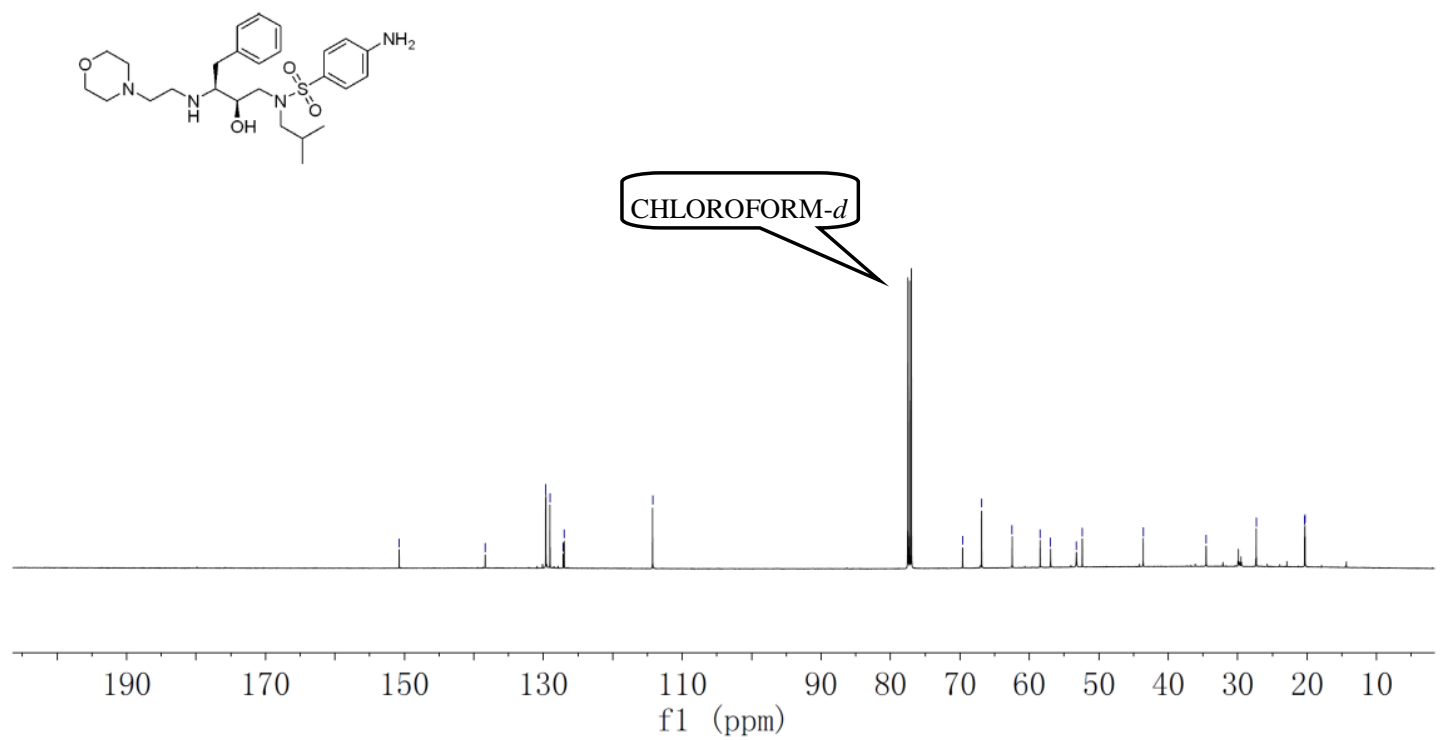

${ }^{13} \mathrm{C}$ NMR Spectrum of compound 29c

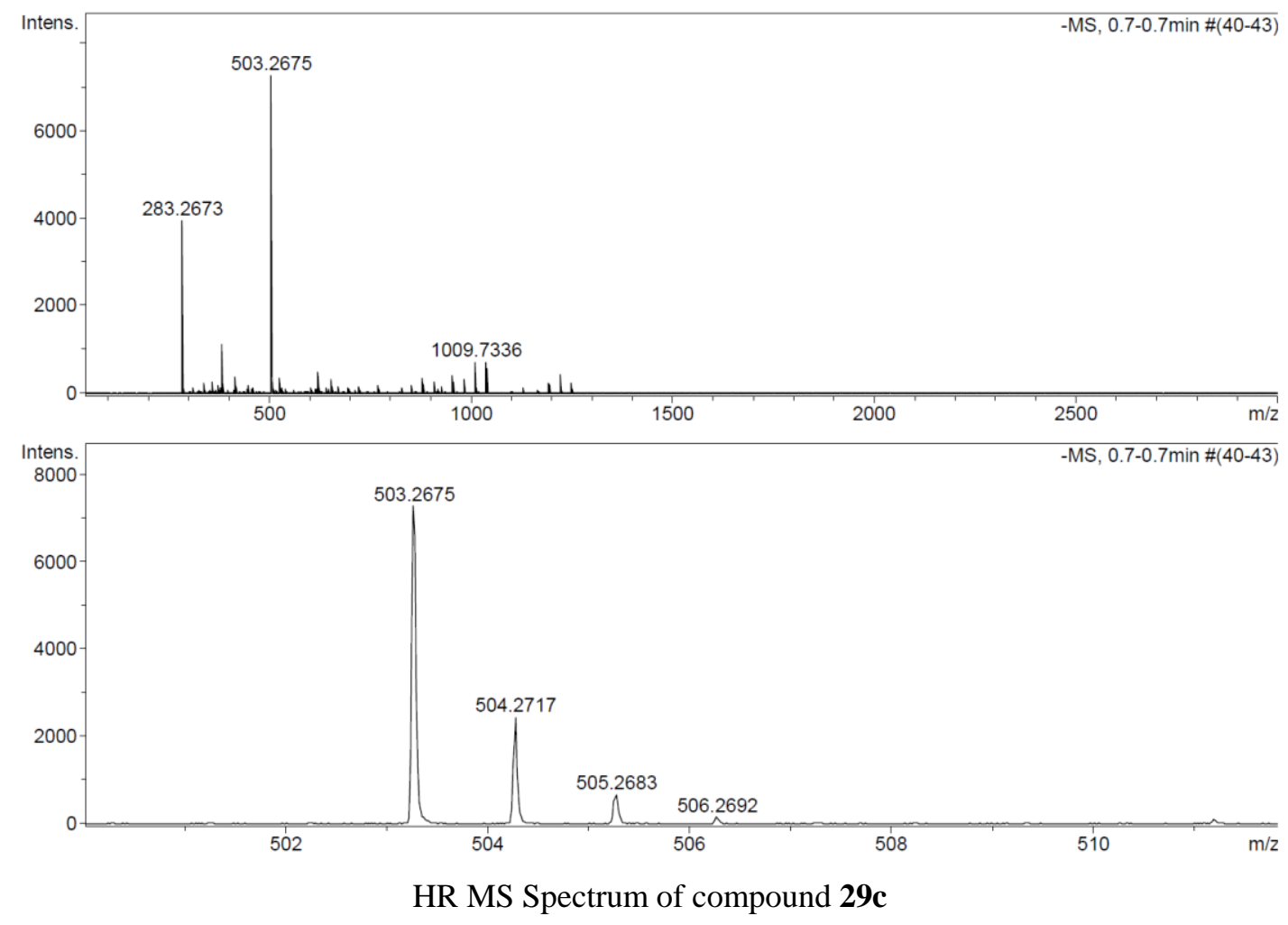




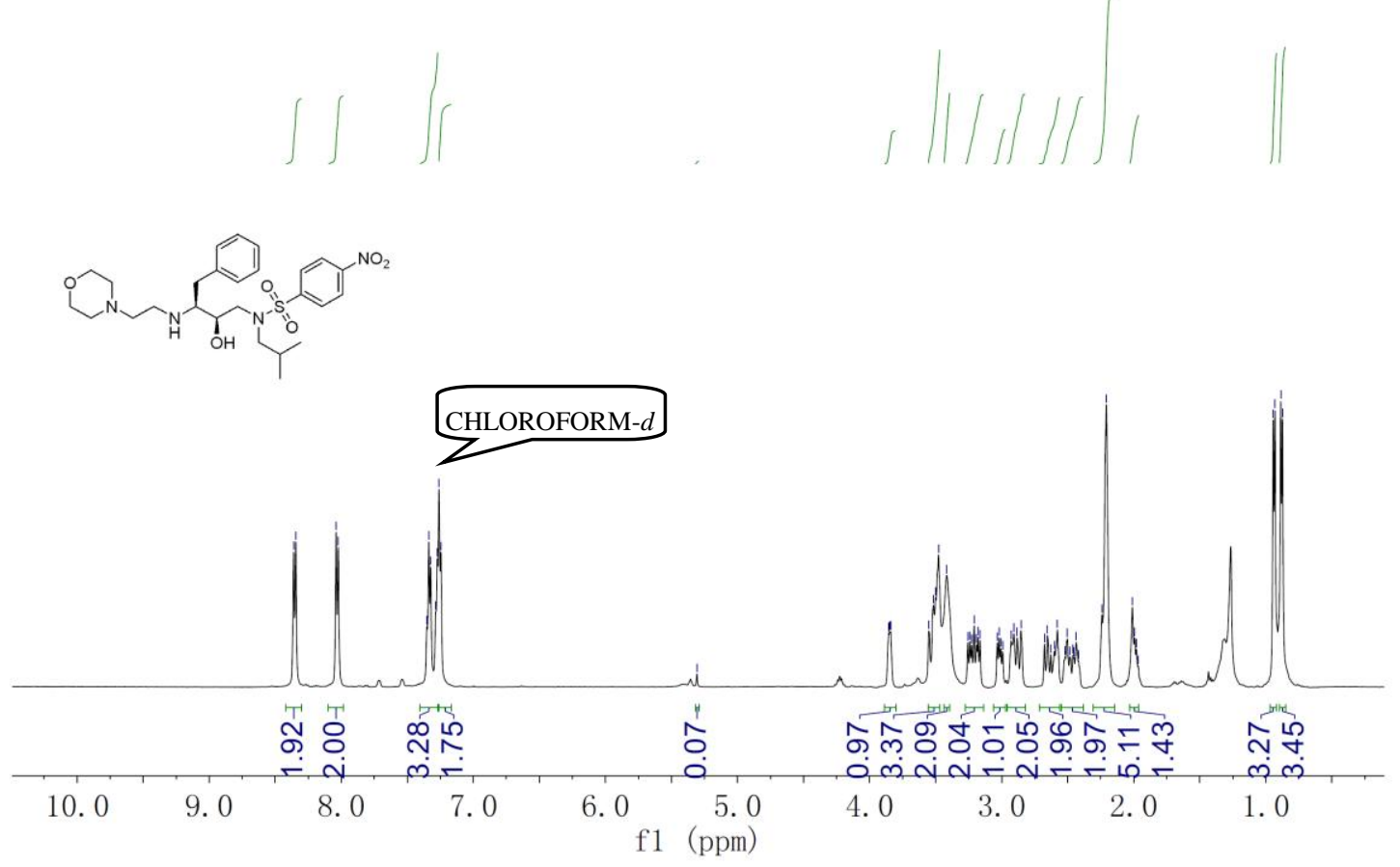

${ }^{1} \mathrm{H}$ NMR Spectrum of compound 29d

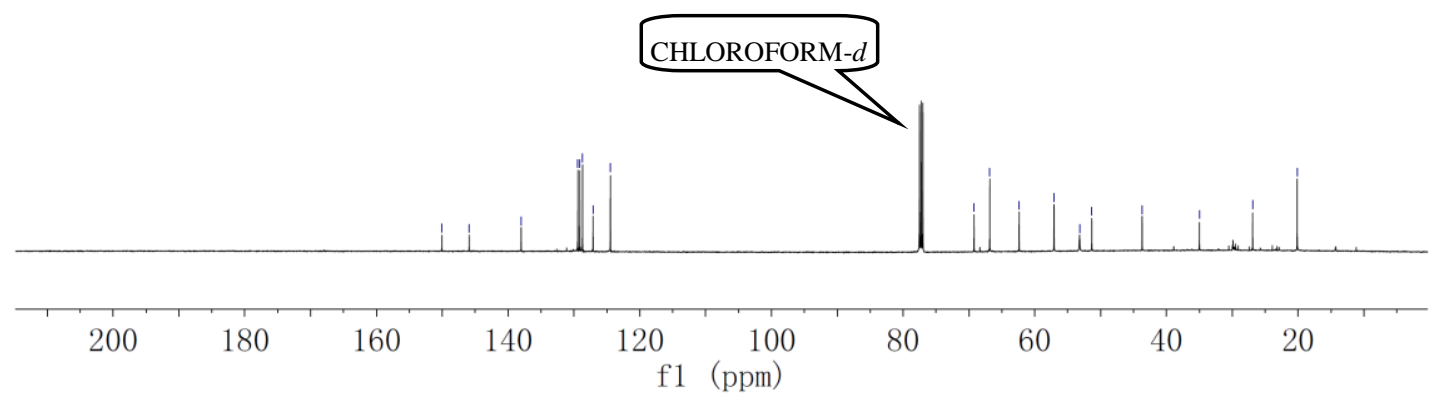

${ }^{13} \mathrm{C}$ NMR Spectrum of compound 29d 


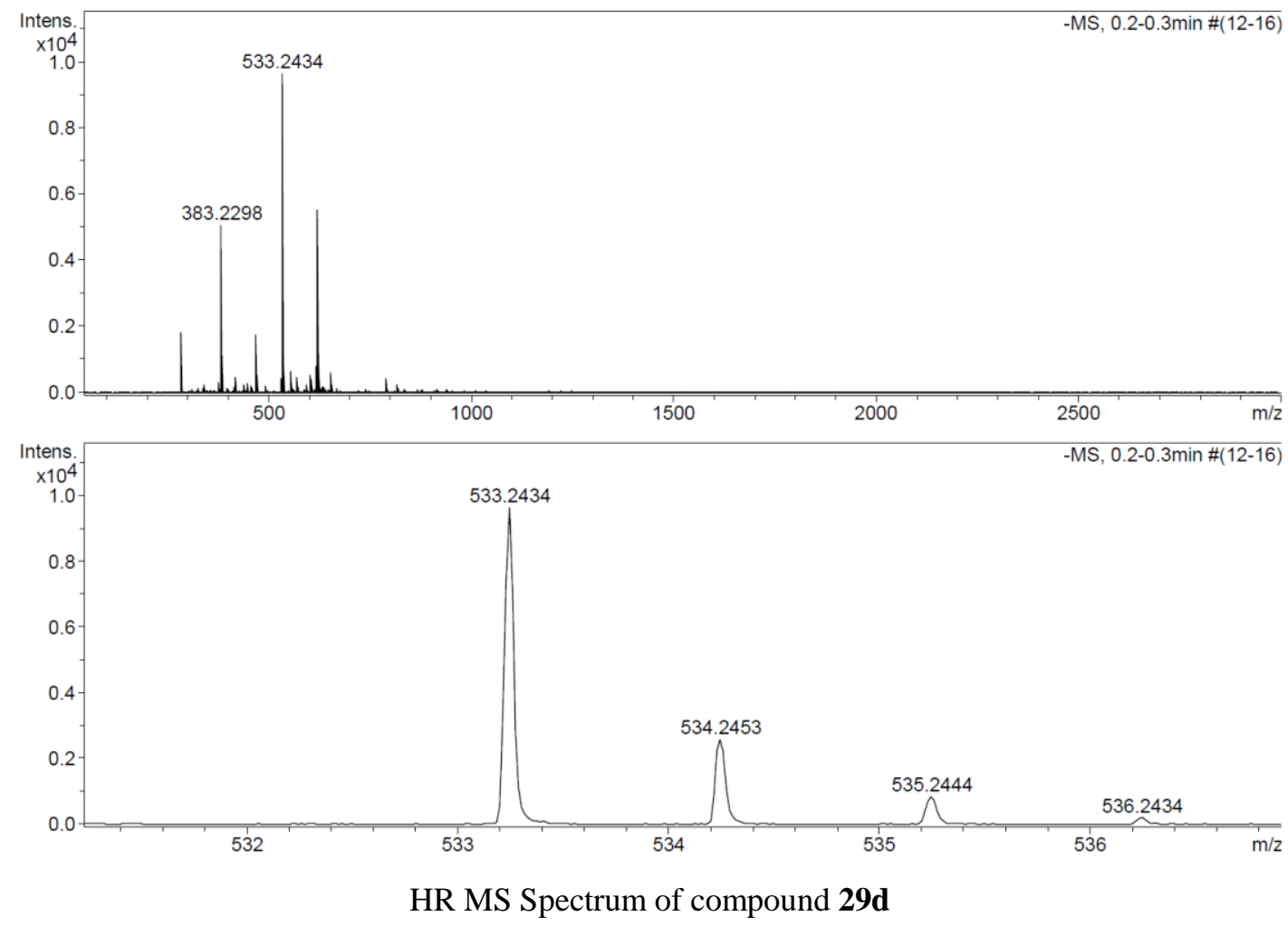

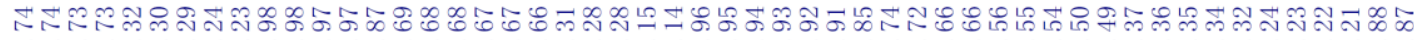
NiNNNN

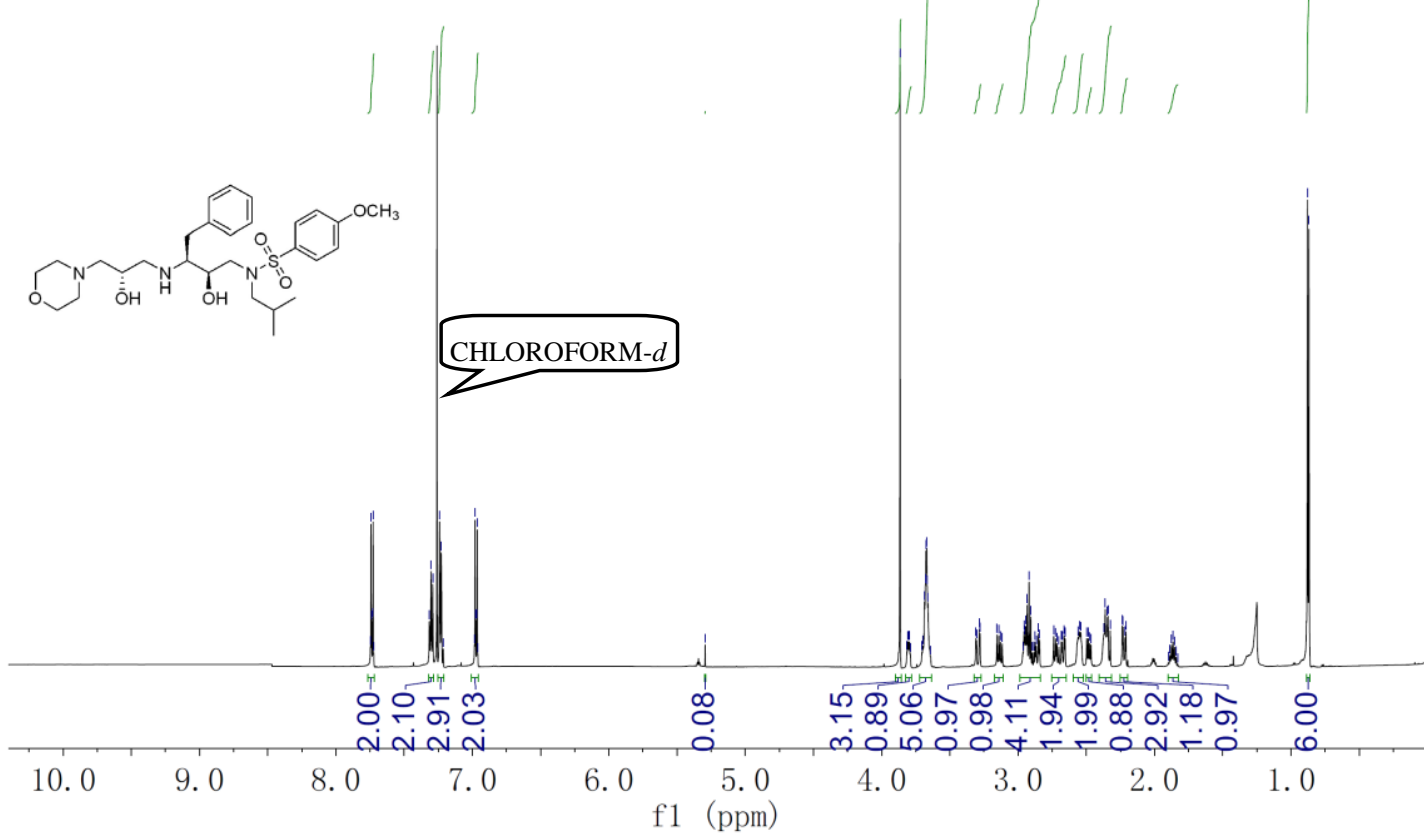

${ }^{1} \mathrm{H}$ NMR Spectrum of compound 30a 

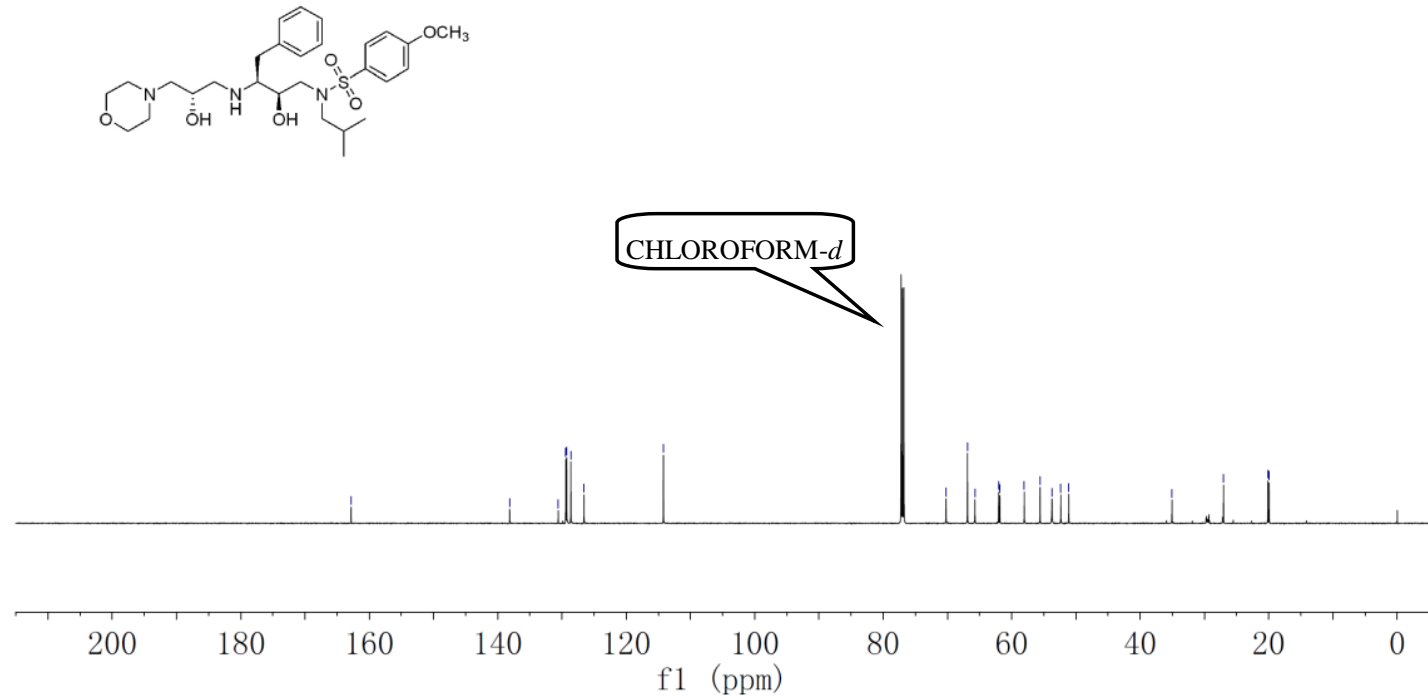

${ }^{13} \mathrm{C}$ NMR Spectrum of compound 30a
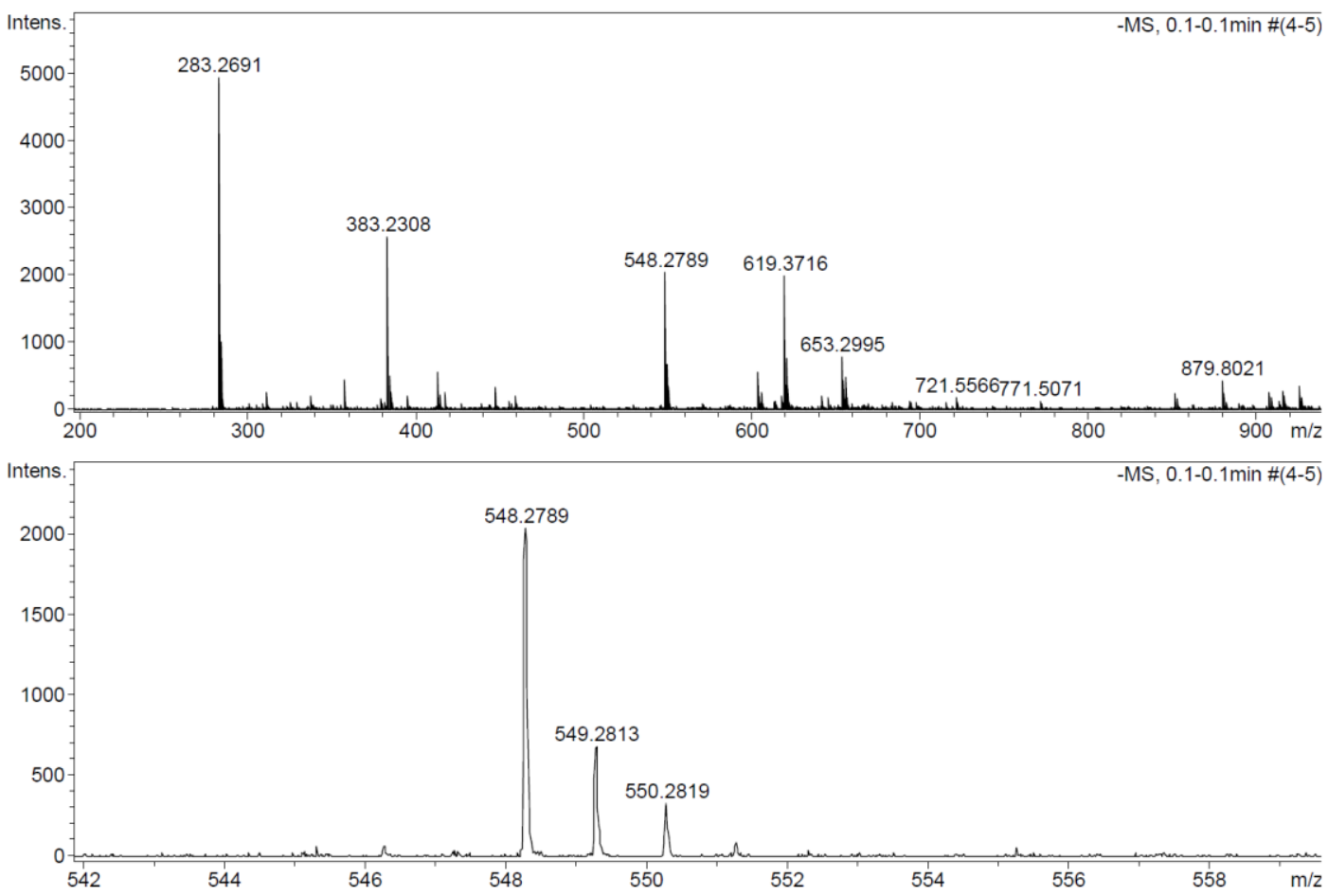

HR MS Spectrum of compound 30a 

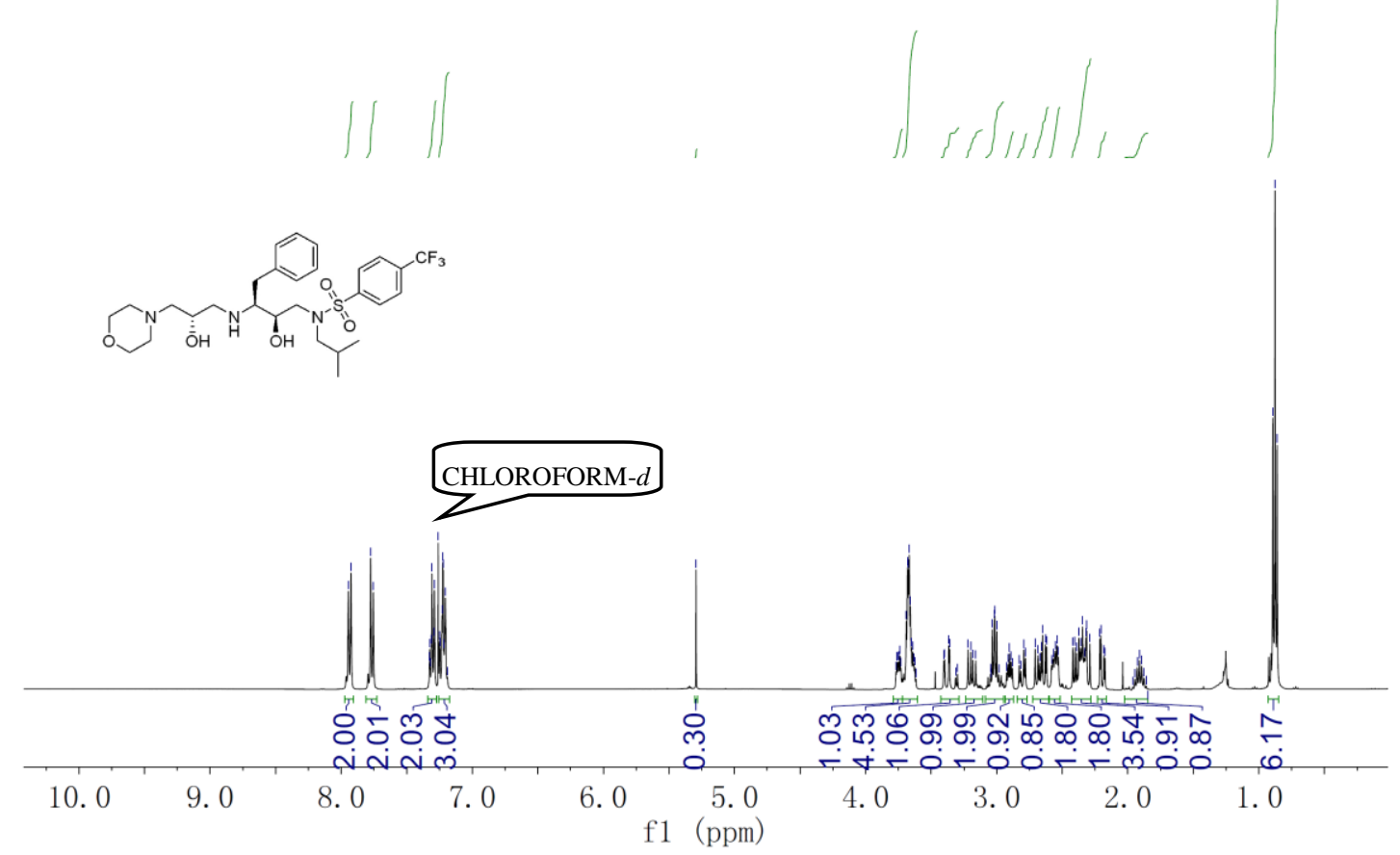

${ }^{1} \mathrm{H}$ NMR Spectrum of compound $\mathbf{3 0 b}$
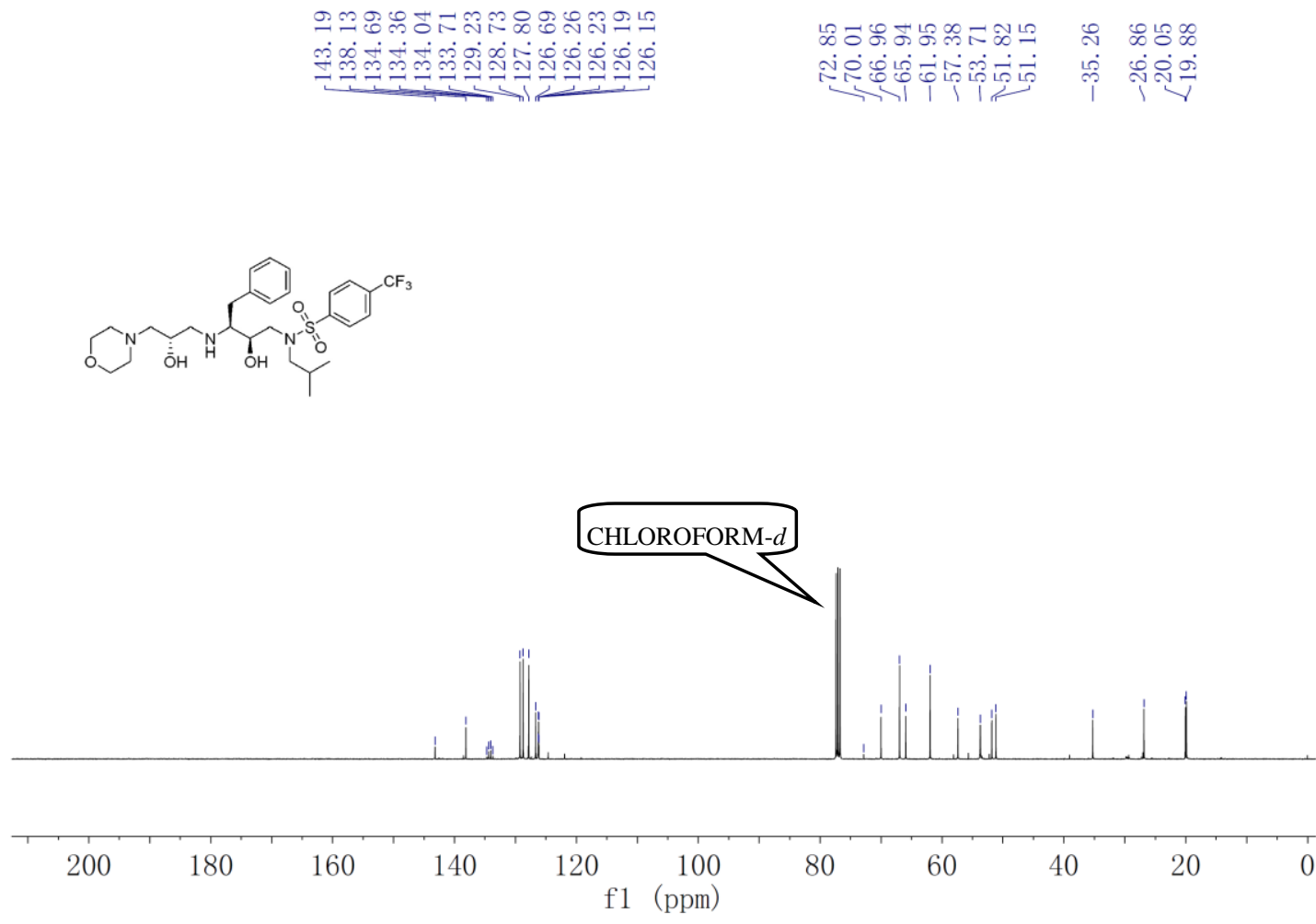

${ }^{13} \mathrm{C}$ NMR Spectrum of compound $\mathbf{3 0 b}$ 

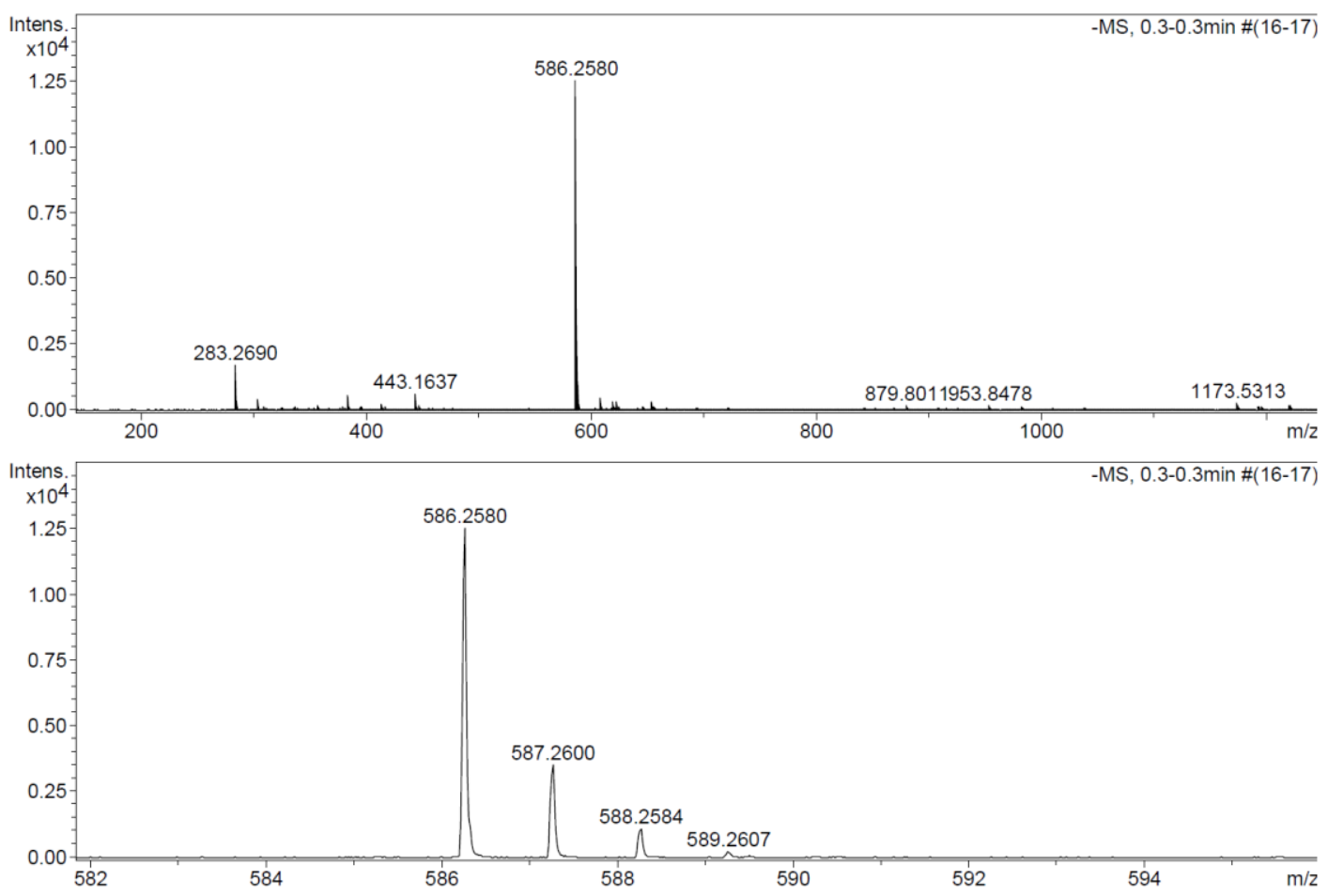

HR MS Spectrum of compound 30b

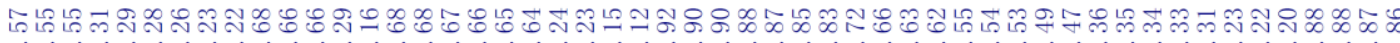

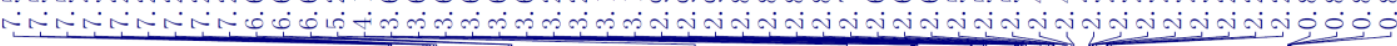
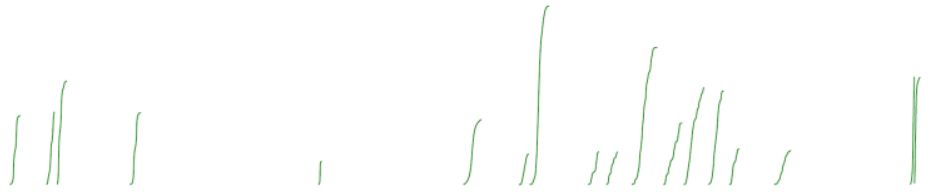<smiles>CC(C)CN(CC(O)C(Cc1ccccc1)NCC(O)CN1CCOCC1)S(=O)(=O)c1ccc(N)cc1</smiles>

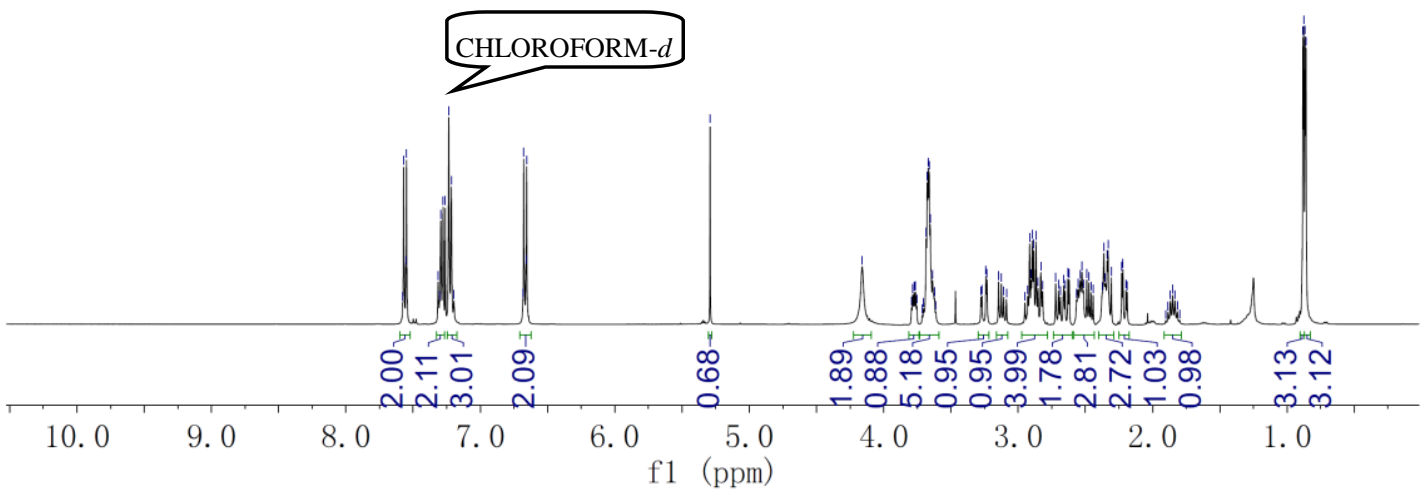

${ }^{1} \mathrm{H}$ NMR Spectrum of compound 30c 

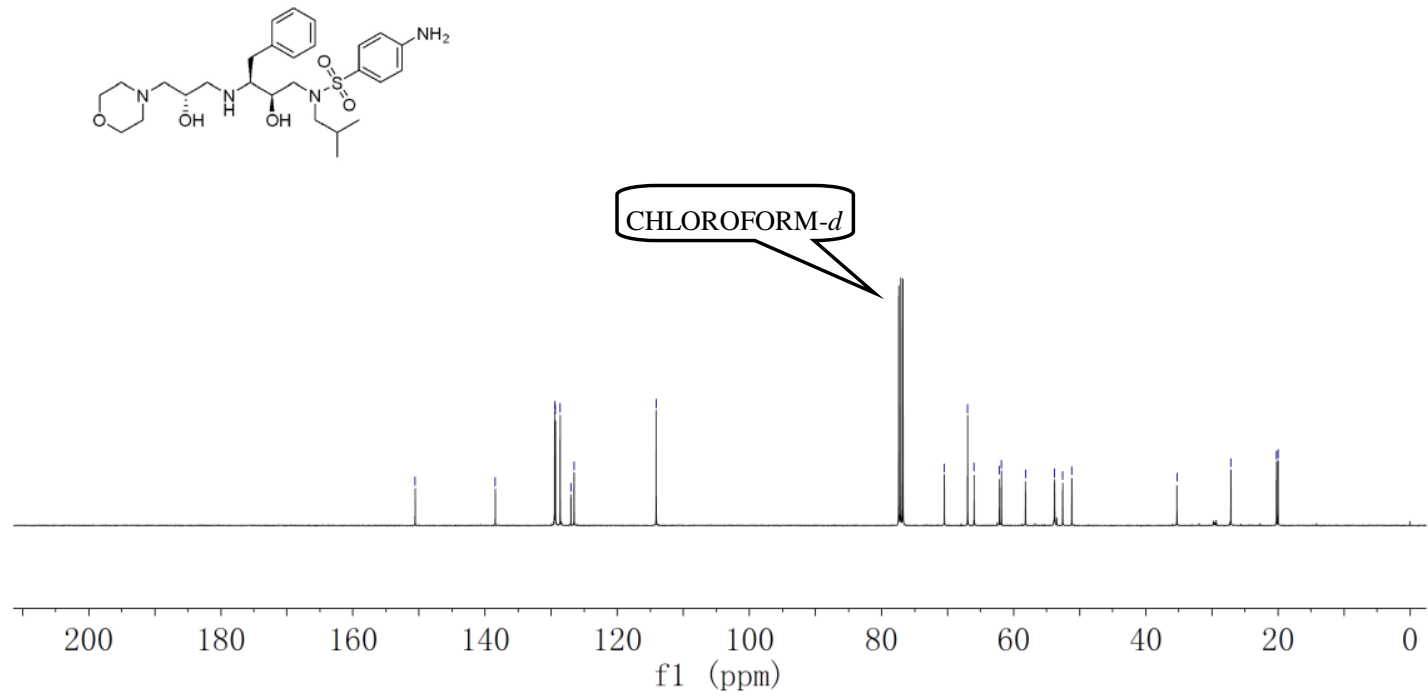

${ }^{13} \mathrm{C}$ NMR Spectrum of compound 30c
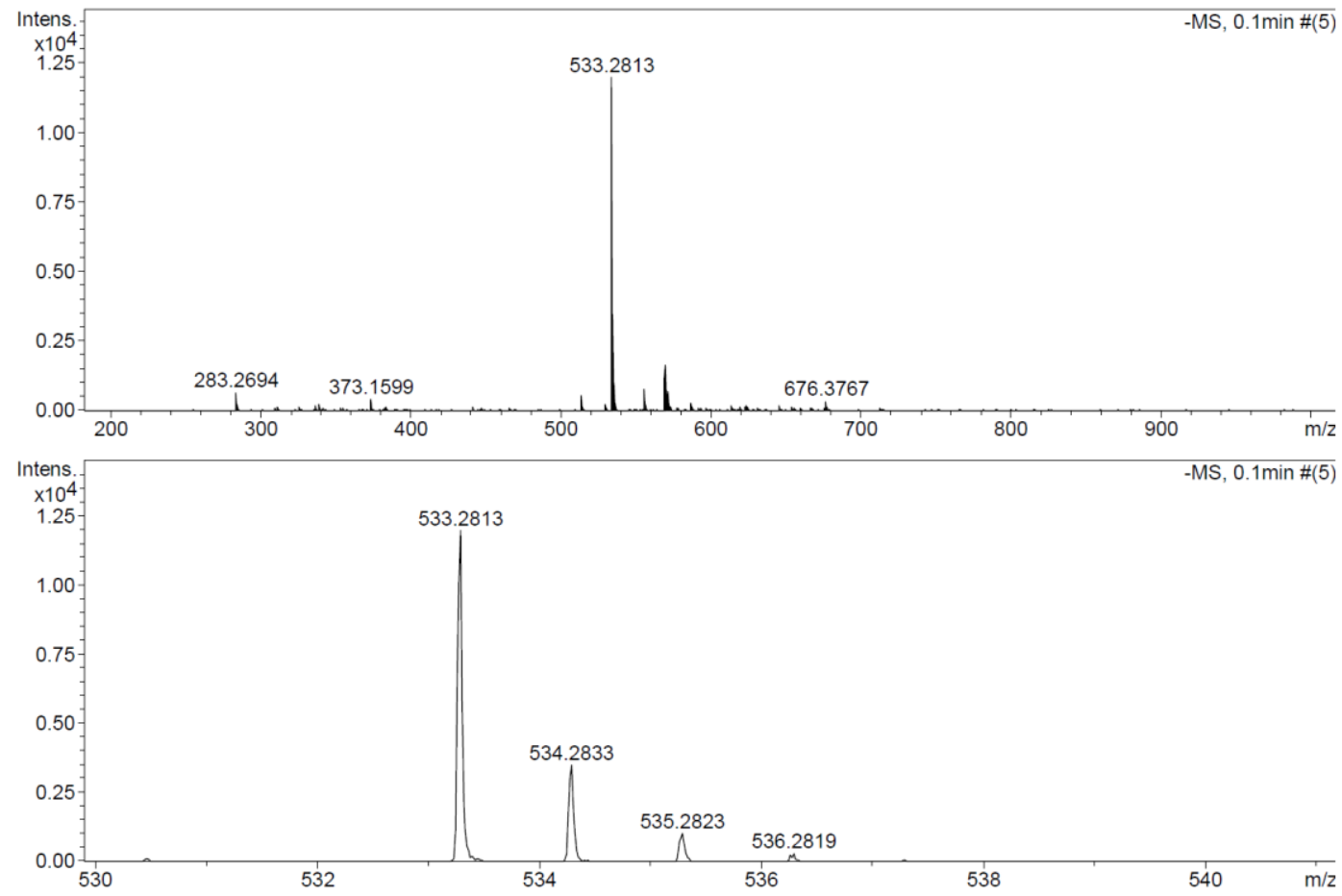

HR MS Spectrum of compound 30c 

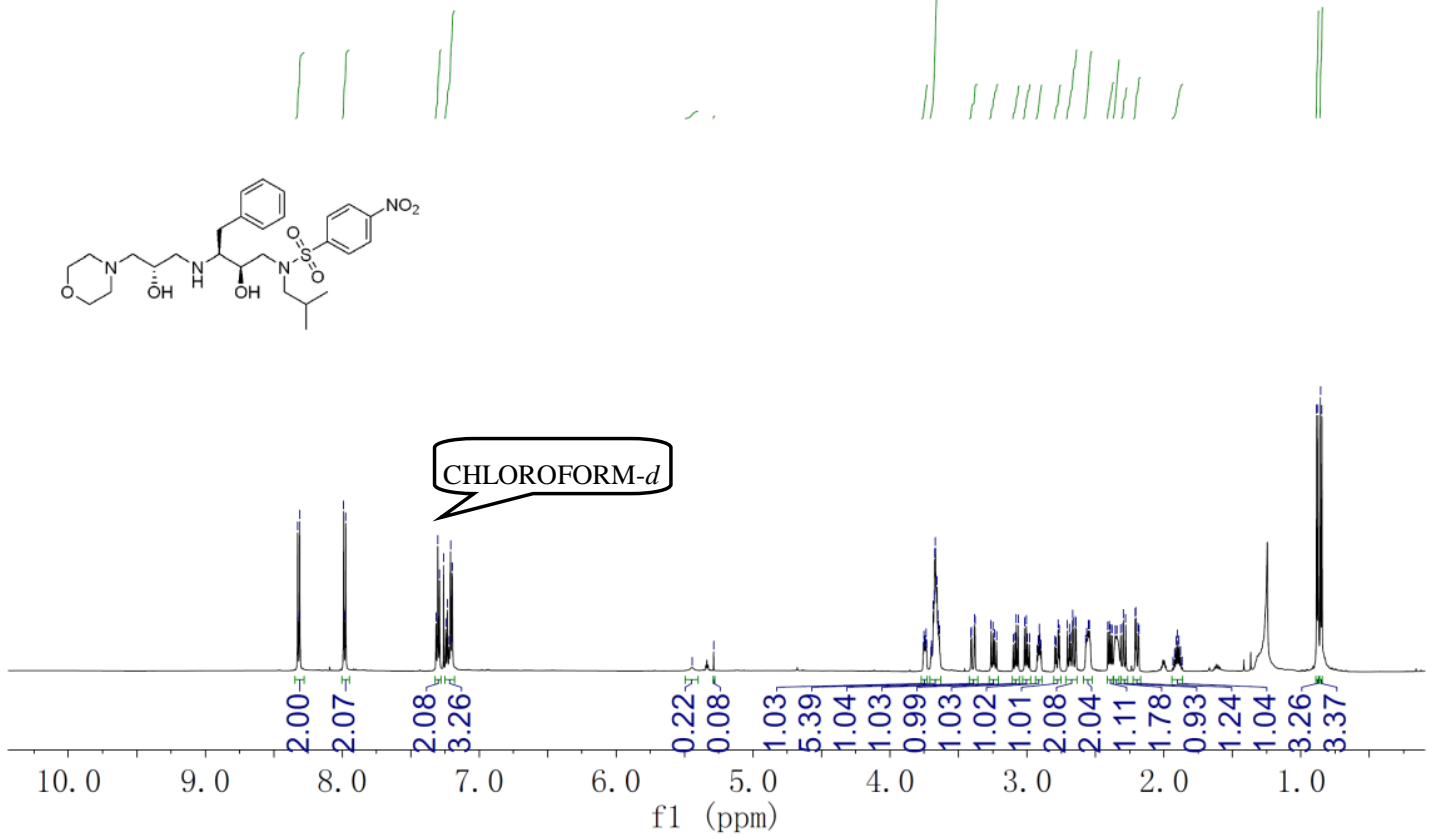

${ }^{1} \mathrm{H}$ NMR Spectrum of compound 30d
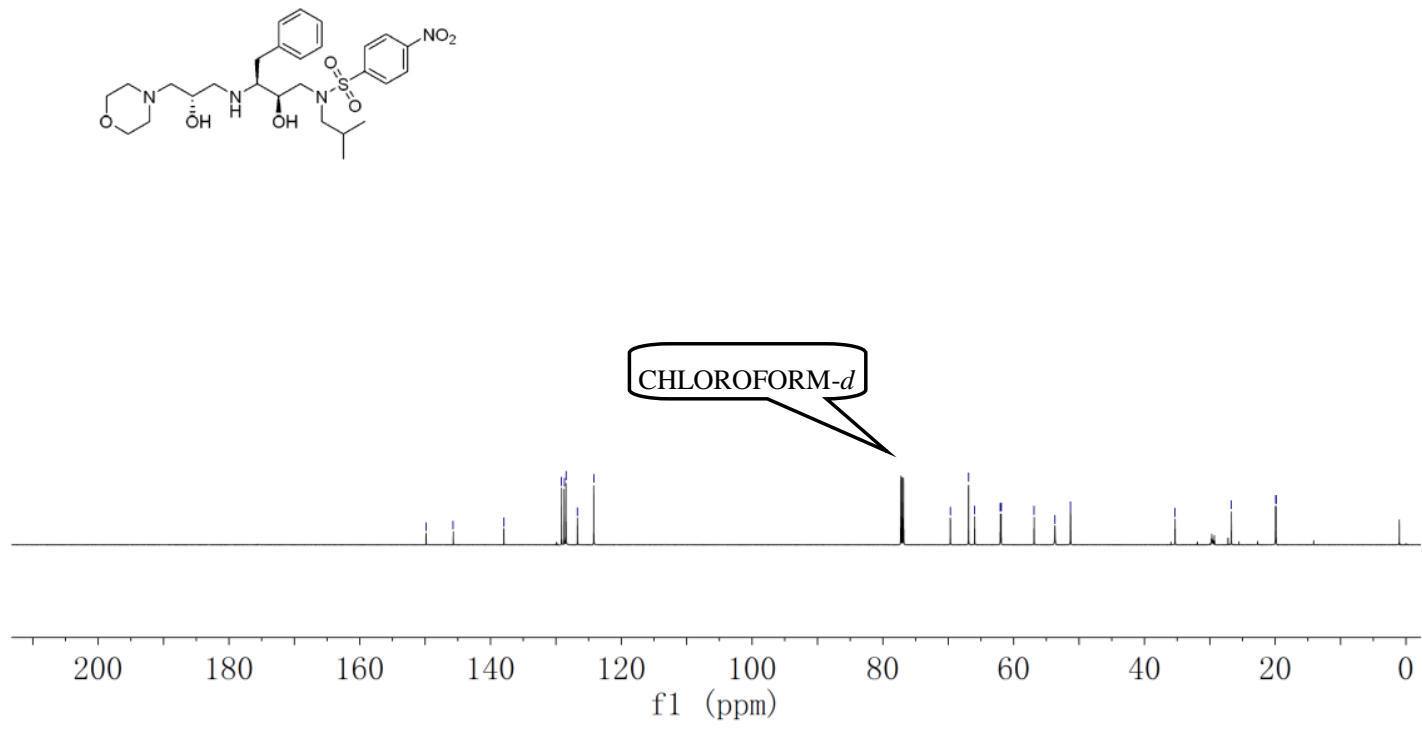

${ }^{13} \mathrm{C}$ NMR Spectrum of compound 30d 


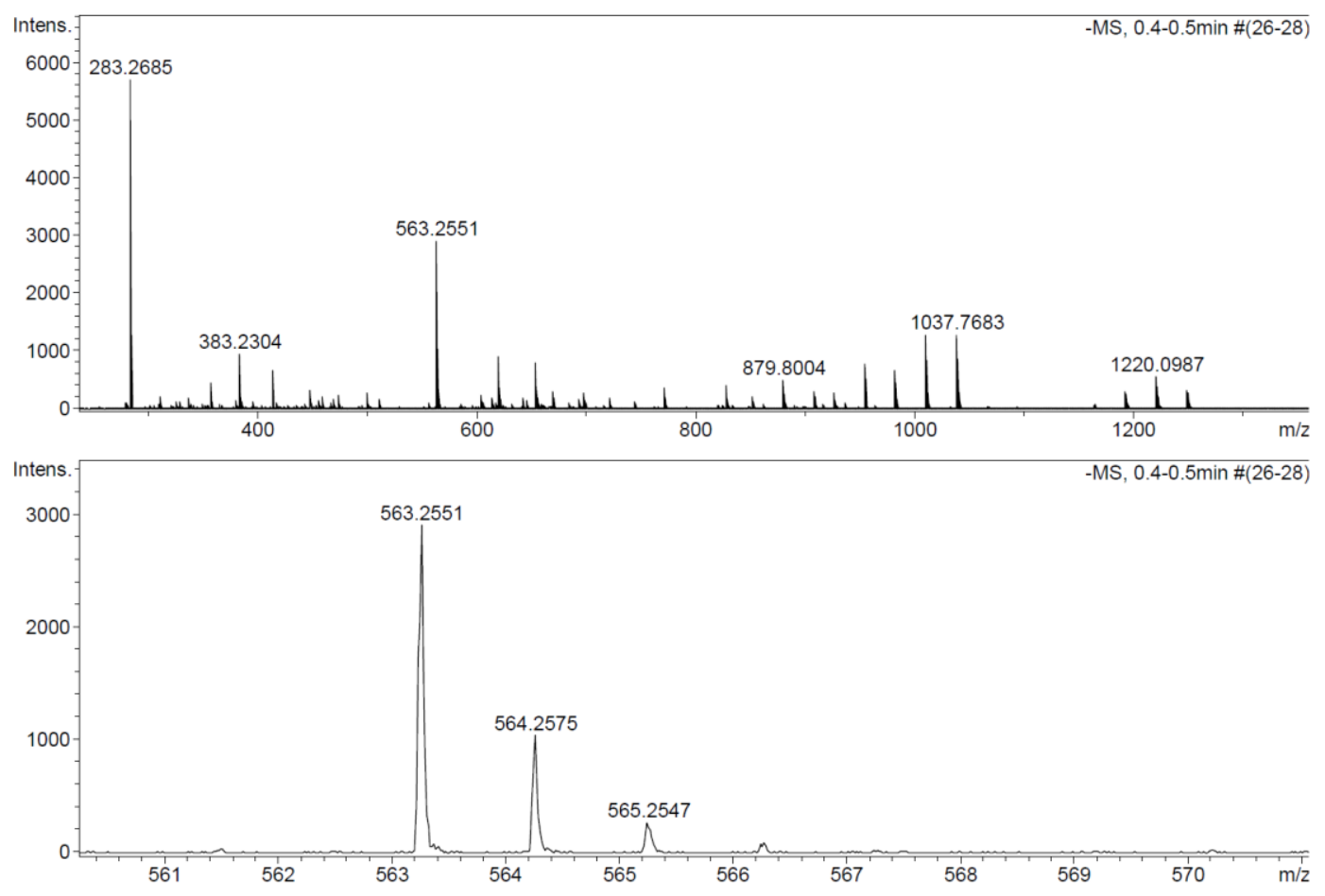

HR MS Spectrum of compound 30d 


\section{Chemistry section}

All experiments requiring anhydrous conditions were conducted in flame-dried glassware fitted with rubber septa under a positive pressure of dry argon, unless otherwise noted. THF was distilled under argon from sodium-benzophenone ketyl and $\mathrm{CH}_{2} \mathrm{Cl}_{2}$ was distilled under argon from calcium hydride. All reactions were monitored by thin-layer chromatography on silica gel plates (GF-254) and visualized with the UV light. Flash column chromatography was performed on a CombiFlash ${ }^{\circledR}$ Rf 200 system employing silica gel (50-75 $\mu \mathrm{m}$, Qingdao Haiyang Chemical Co.,Ltd). Melting points were taken on MP70 Melting Point System with revised. High resolution mass spectra were obtained on an Autospee Ultima-TOF spectrometer. ${ }^{1} \mathrm{H}$ NMR and ${ }^{13} \mathrm{C}$ NMR spectra were recorded in $\mathrm{CDCl}_{3}$ or $\mathrm{CD}_{3} \mathrm{OD}$ on a Bruker AVANCE III $400 \mathrm{MHz}$, $500 \mathrm{MHz}$ or $600 \mathrm{MHz}$ spectrometer (Bruker Inc) with tetramethylsilane (TMS) as an internal reference. The chemical shifts are given in $\delta(\mathrm{ppm})$ referenced to the respective solvent peak $\left(\mathrm{CDCl}_{3}:{ }^{1} \mathrm{H}, \delta=7.26 \mathrm{ppm},{ }^{13} \mathrm{C}, \delta=77.16 \mathrm{ppm} ; \mathrm{CD}_{3} \mathrm{OD}:{ }^{1} \mathrm{H}, \delta\right.$ $\left.=3.31 \mathrm{ppm},{ }^{13} \mathrm{C}, \delta=49.00 \mathrm{ppm}\right)$, and coupling constants are reported in Hz. All the target compounds were characterized by ${ }^{1} \mathrm{H}$ and ${ }^{13} \mathrm{C}$ NMRs and HRMS spectra.

\section{2-Morpholinoethyl (4-nitrophenyl) carbonate (12)}

To a stirred solution of 2-morpholinoethan-1-ol (11, $0.50 \mathrm{~g}, 3.8 \mathrm{mmol})$ in diethyl ether $(5.0 \mathrm{~mL})$ was added $p$-nitrophenyl chloroformate $(0.81 \mathrm{~g}, 4.0 \mathrm{mmol})$ slowly at $0{ }^{\circ} \mathrm{C}$ and stirred for $2 \mathrm{~h}$. The resulting mixture was then warmed to $25{ }^{\circ} \mathrm{C}$ and stirred overnight. Upon completion, the reaction mixture was filtered through a Celite $545^{\circledR}$ pad, and washed with $\mathrm{Et}_{2} \mathrm{O}(3 \times 10 \mathrm{~mL})$. The filtrate was concentrated under reduced pressure and afforded the crude product as white amorphous powder: yield $1.0 \mathrm{~g}$ (91\%); mp156.7-160.3 ${ }^{\circ} \mathrm{C} ;{ }^{1} \mathrm{H}$ NMR $\left(500 \mathrm{MHz}, \mathrm{CDCl}_{3}\right) \delta 8.32(\mathrm{dd}, J=24.5,8.2 \mathrm{~Hz}$, 2H), $7.48(\mathrm{dd}, J=24.5,8.1 \mathrm{~Hz}, 2 \mathrm{H}), 4.90(\mathrm{~s}, 1 \mathrm{H}), 4.41-4.21(\mathrm{~m}, 4 \mathrm{H}), 3.45(\mathrm{~s}, 1 \mathrm{H})$, $3.20(\mathrm{~s}, 2 \mathrm{H}), 3.12-2.85(\mathrm{~m}, 4 \mathrm{H}) ;{ }^{13} \mathrm{C} \mathrm{NMR}\left(101 \mathrm{MHz}, \mathrm{CDCl}_{3}\right) \delta 160.66,154.84$, $151.29,125.47,121.93,121.71,63.70,63.63,53.42,52.86$. 
To a stirred solution of $(R)$-2-methylmorpholine $(13,0.10 \mathrm{~g}, 0.73 \mathrm{mmol})$ and $\mathrm{K}_{2} \mathrm{CO}_{3}(0.40 \mathrm{~g}, 0.29 \mathrm{mmol})$ in anhydrous DMF $(1 \mathrm{~mL})$ was added bromoacetic acid (0.84 mmol in $2 \mathrm{~mL}$ dry DMF) dropwise under the protection of Argon. The resulting mixture was then warmed to $25^{\circ} \mathrm{C}$ and stirred overnight. Upon completion, the reaction mixture was quenched by addition of water $(2 \mathrm{~mL})$ and filtered through a Celite $545^{\circledR}$ pad. The filtrate was extracted with $\mathrm{CH}_{2} \mathrm{Cl}_{2}(3 \times 4 \mathrm{~mL})$ in order to take the low polarity impurities off. The aqueous phase was acidified to $\mathrm{pH} 4.0$ slowly by the addition of $4 \mathrm{M} \mathrm{HCl}$ solution, and the solvent was concentrated under reduced pressure. The precipitate was filtered and washed with $\mathrm{CH}_{3} \mathrm{OH}(3 \times 4 \mathrm{~mL})$. The filtrate was concentrated under reduced pressure and afforded the crude product as colorless oil: yield $0.10 \mathrm{~g}(85 \%) ; \operatorname{mp} 144.3-146.1{ }^{\circ} \mathrm{C} ;{ }^{1} \mathrm{H}$ NMR $\left(500 \mathrm{MHz}, \mathrm{CD}_{3} \mathrm{OD}\right) \delta$ $4.10-4.02(\mathrm{~m}, 1 \mathrm{H}), 3.98-3.85(\mathrm{~m}, 4 \mathrm{H}), 3.55(\mathrm{dd}, J=10.0,5.0 \mathrm{~Hz}, 2 \mathrm{H}), 3.17-3.09$ $(\mathrm{m}, 1 \mathrm{H}), 2.90-2.80(\mathrm{~m}, 1 \mathrm{H}), 1.22(\mathrm{~d}, J=5.0 \mathrm{~Hz}, 3 \mathrm{H}) ;{ }^{13} \mathrm{C} \mathrm{NMR}\left(151 \mathrm{MHz}, \mathrm{CD}_{3} \mathrm{OD}\right)$ $\delta 167.1,69.4,63.1,57.0,56.9,51.5,17.2$.

\section{(S)-2-(2-methylmorpholino)acetic acid (17)}

(S)-2-methylmorpholine (14) was treated with bromoacetic acid by following the same procedure outlined for $\mathbf{1 6}$ to give compound $\mathbf{1 7}$ as colorless oil with yield of $88 \%$ : mp133.0-134.7 ${ }^{\circ} \mathrm{C} ;{ }^{1} \mathrm{H}$ NMR $\left(500 \mathrm{MHz}, \mathrm{CD}_{3} \mathrm{OD}\right) \delta 4.10-4.01(\mathrm{~m}, 1 \mathrm{H}), 3.95-$ $3.85(\mathrm{~m}, 2 \mathrm{H}), 3.68(\mathrm{~s}, 2 \mathrm{H}), 3.53(\mathrm{~d}, J=15.0 \mathrm{~Hz}, 2 \mathrm{H}), 3.11-3.03(\mathrm{~m}, 1 \mathrm{H}), 2.83-2.75$ $(\mathrm{m}, 1 \mathrm{H}), 1.22(\mathrm{~d}, J=5.0 \mathrm{~Hz}, 3 \mathrm{H}) ;{ }^{13} \mathrm{C} \mathrm{NMR}\left(151 \mathrm{MHz}, \mathrm{CD}_{3} \mathrm{OD}\right) \delta$ 167.9, 69.5, 63.3, $58.4,57.0,51.4,17.3$.

\section{2-Morpholinoacetic acid (18)}

Methylmorpholine (15) was treated with bromoacetic acid by following the same procedure outlined for $\mathbf{1 6}$ to give compound $\mathbf{1 8}$ as colorless oil with yield of $88 \%$ : mp151.2-1153.4 ${ }^{\circ} \mathrm{C} ;{ }^{1} \mathrm{H}$ NMR (500 MHz, CD $\left.3 \mathrm{OD}\right) \delta 3.96-3.91(\mathrm{~m}, 4 \mathrm{H}), 3.73(\mathrm{~s}, 2 \mathrm{H})$, $3.36(\mathrm{~s}, 4 \mathrm{H}) ;{ }^{13} \mathrm{C} \mathrm{NMR}\left(126 \mathrm{MHz}, \mathrm{CD}_{3} \mathrm{OD}\right) \delta 168.0,63.8,58.3,52.4$. 
3R)-3-hydroxy-4-((N-isobutyl-4-methoxyphenyl)sulfonamido)-1-phenylbutan-2-yl)car bamate (23a)

DIEA (0.051 g, $0.39 \mathrm{mmol})$ was added dropwise to a stirred solution of 2-morpholinoethyl (4-nitrophenyl) carbonate $(\mathbf{1 2}, 0.070 \mathrm{~g}, 0.24 \mathrm{mmol})$ and $N-((2 R$, 3S)-3-amino-2-hydroxy-4-phenylbutyl)-N-isobutyl-4-methoxybenzenesulfonamide (8, $0.080 \mathrm{~g}, 0.20 \mathrm{mmol})$ in anhydrous DMF $(1 \mathrm{~mL})$ under the protection of Argon at $0{ }^{\circ} \mathrm{C}$ and stirred for $0.5 \mathrm{~h}$. The resulting mixture was then warmed to $25^{\circ} \mathrm{C}$ and stirred for $10 \mathrm{~h}$. Upon completion, the reaction mixture was quenched by the addition of saturated aqueous $\mathrm{NH}_{4} \mathrm{Cl}$ and extracted with EtOAc. The extracts were washed with $\mathrm{H}_{2} \mathrm{O}$, saturated aqueous $\mathrm{NaCl}$, dried over $\mathrm{Na}_{2} \mathrm{SO}_{4}$, and concentrated under reduced pressure. The crude product was purified by silica gel column chromatography $(65 \%$ EtOAc in n-hexane as the eluent) to afford 23a as pale yellow powder $(0.087 \mathrm{~g}, 80 \%)$. Mp 86.9-88.2 ${ }^{\circ} \mathrm{C} ;{ }^{1} \mathrm{H}$ NMR (400 MHz, $\left.\mathrm{CDCl}_{3}\right) \delta 7.73-7.66(\mathrm{~m}, 2 \mathrm{H}), 7.30$ - 7.27 (m, 1H), $7.26-7.18(\mathrm{~m}, 4 \mathrm{H}), 6.99-6.94(\mathrm{~m}, 2 \mathrm{H}), 5.28(\mathrm{~s}, 1 \mathrm{H}) 4.99(\mathrm{~d}, J=8.0 \mathrm{~Hz}, 1 \mathrm{H})$, $4.14-4.04(\mathrm{~m}, 2 \mathrm{H}), 3.89-3.79(\mathrm{~m}, 5 \mathrm{H}), 3.67(\mathrm{t}, J=4.0 \mathrm{~Hz}, 4 \mathrm{H}), 3.15-2.95(\mathrm{~m}, 3 \mathrm{H})$, $2.95-2.76(\mathrm{~m}, 3 \mathrm{H}), 2.52(\mathrm{t}, J=6.0 \mathrm{~Hz}, 2 \mathrm{H}), 2.44(\mathrm{t}, J=4.8 \mathrm{~Hz}, 4 \mathrm{H}), 1.88-1.74(\mathrm{~m}$, $1 \mathrm{H}), 0.89(\mathrm{~d}, J=6.6 \mathrm{~Hz}, 3 \mathrm{H}), 0.85(\mathrm{~d}, J=6.6 \mathrm{~Hz}, 3 \mathrm{H}) ;{ }^{13} \mathrm{C} \mathrm{NMR}\left(101 \mathrm{MHz}, \mathrm{CDCl}_{3}\right) \delta$ 163.0, 156.4, 137.7, 129.9, 129.5, 128.5, 126.5, 114.4, 72.5, 66.7, 61.7, 58.7, 57.4, 55.7, 55.1, 53.7, 35.4, 27.3, 20.2, 19.9; HRMS (ESI) m/z calcd. for $\mathrm{C}_{28} \mathrm{H}_{40} \mathrm{~N}_{3} \mathrm{O}_{7} \mathrm{~S}([\mathrm{M}$ $-\mathrm{H}]^{-}$): 562.2587 , found 562.2585 .

2-Morpholinoethyl

$((2 S$, 3R)-3-hydroxy-4-((N-isobutyl-4-(trifluoromethyl)phenyl)sulfonamido)-1-phenylbutan2-yl)carbamate $(\mathbf{2 3 b})$

2-Morpholinoethyl (4-nitrophenyl) carbonate (12) was treated with $N$-((2R, 3S)-3-amino-2-hydroxy-4-phenylbutyl)-N-isobutyl-4-(trifluoromethyl)benzenesulfona mide (9) by following the procedure outlined for $\mathbf{2 3 a}$ to give compound $\mathbf{2 3 b}$ as white amorphous powder (92\%). Mp 85.1-87.0 ${ }^{\circ} \mathrm{C} ;{ }^{1} \mathrm{H}$ NMR (400 MHz, $\left.\mathrm{CD}_{3} \mathrm{OD}\right) \delta 7.96$ (d, $J=8.0 \mathrm{~Hz}, 2 \mathrm{H}), 7.82(\mathrm{~d}, J=8.0 \mathrm{~Hz}, 2 \mathrm{H}), 7.23-7.05(\mathrm{~m}, 5 \mathrm{H}), 5.42(\mathrm{~s}, 1 \mathrm{H}) 4.07-3.88$ (m, 2H), $3.80-3.61(\mathrm{~m}, 2 \mathrm{H}), 3.57(\mathrm{t}, J=4.0 \mathrm{~Hz}, 4 \mathrm{H}), 3.42(\mathrm{dd}, J=15.0,2.4 \mathrm{~Hz}, 1 \mathrm{H})$, 
$3.16-2.97(\mathrm{~m}, 3 \mathrm{H}), 2.95-2.84(\mathrm{~m}, 1 \mathrm{H}), 2.56-2.41(\mathrm{~m}, 3 \mathrm{H}), 2.41-2.25(\mathrm{~m}, 4 \mathrm{H})$, $2.01-1.90(\mathrm{~m}, 1 \mathrm{H}), 0.85(\mathrm{~d}, J=6.6 \mathrm{~Hz}, 3 \mathrm{H}), 0.81(\mathrm{~d}, J=6.6 \mathrm{~Hz}, 3 \mathrm{H}) ;{ }^{13} \mathrm{C}$ NMR $(101$ $\left.\mathrm{MHz}, \mathrm{CD}_{3} \mathrm{OD}\right) \delta 158.7,145.4,140.5,135.9,135.5,135.2,134.9,130.8,129.7,129.7$, $127.8,127.7,74.0,68.0,63.4,58.8,58.4,57.7,55.3,53.6,37.4,28.2$, 20.8; HRMS (ESI) $\mathrm{m} / \mathrm{z}$ calcd. for $\mathrm{C}_{28} \mathrm{H}_{37} \mathrm{~F}_{3} \mathrm{~N}_{3} \mathrm{O}_{6} \mathrm{~S}\left([\mathrm{M}-\mathrm{H}]^{-}\right.$): 600.2355, found 600.2370.

\section{2-Morpholinoethyl}

$((2 S$ 3R)-3-hydroxy-4-((N-isobutyl-4-nitrophenyl)sulfonamido)-1-phenylbutan-2-yl)carbam ate $(23 d)$

2-Morpholinoethyl (4-nitrophenyl) carbonate (12) was treated with $N$-((2R, 3S)-3-amino-2-hydroxy-4-phenylbutyl)-N-isobutyl-4-nitrobenzenesulfonamide by following the procedure outlined for 23a to give compound $\mathbf{2 3 \mathbf { d }}$ as white amorphous powder (91\%). Mp 131.5-132.0 ${ }^{\circ} \mathrm{C} ;{ }^{1} \mathrm{H}$ NMR $\left(400 \mathrm{MHz}, \mathrm{CDCl}_{3}\right) \delta 8.36-$ $8.30(\mathrm{~m}, 2 \mathrm{H}), 7.98-7.92(\mathrm{~m}, 2 \mathrm{H}), 7.33-7.27(\mathrm{~m}, 2 \mathrm{H}), 7.26-7.20(\mathrm{~m}, 3 \mathrm{H}), 5.29(\mathrm{~s}$, $1 \mathrm{H}), 4.93(\mathrm{~d}, J=7.8 \mathrm{~Hz}, 1 \mathrm{H}), 4.11(\mathrm{t}, J=5.7 \mathrm{~Hz}, 2 \mathrm{H}), 3.89-3.79(\mathrm{~m}, 2 \mathrm{H}), 3.67(\mathrm{t}, J=$ $4.0 \mathrm{~Hz}, 4 \mathrm{H}), 3.24-3.13(\mathrm{~m}, 2 \mathrm{H}), 3.03-2.93(\mathrm{~m}, 3 \mathrm{H}), 2.93-2.82(\mathrm{~m}, 1 \mathrm{H}), 2.58-$ $2.50(\mathrm{~m}, 2 \mathrm{H}), 2.44(\mathrm{t}, J=4.0 \mathrm{~Hz}, 4 \mathrm{H}), 1.92-1.80(\mathrm{~m}, 1 \mathrm{H}), 0.87(\mathrm{t}, J=6.4 \mathrm{~Hz}, 6 \mathrm{H})$; ${ }^{13} \mathrm{C} \mathrm{NMR}\left(101 \mathrm{MHz}, \mathrm{CDCl}_{3}\right) \delta 156.6,150.1,144.8,137.4,129.4,128.7,128.6,126.8$, 124.4, 72.1, 66.8, 61.9, 57.8, 57.4, 55.4, 53.7, 52.7, 35.4, 27.0, 20.0, 19.9; HRMS (ESI) $\mathrm{m} / \mathrm{z}$ calcd. for $\mathrm{C}_{27} \mathrm{H}_{38} \mathrm{~N}_{4} \mathrm{NaO}_{8} \mathrm{~S} \quad\left([\mathrm{M}+\mathrm{Na}]^{+}\right): 601.2308$; found, 601.2329.

\section{2-Morpholinoethyl}

$((2 S$, 3R)-4-((4-amino-N-isobutylphenyl)sulfonamido)-3-hydroxy-1-phenylbutan-2-yl)carba mate $(23 c)$

To a solution of compound $23 \mathbf{d}(0.10 \mathrm{~g}, 0.17 \mathrm{mmol})$ in the mixture of $\mathrm{CH}_{3} \mathrm{OH}$ and EtOAc $(5 \mathrm{~mL})$ was added $5 \% \mathrm{Pd} / \mathrm{C}(0.10 \mathrm{~g})$. The resulting mixture was stirred at $25{ }^{\circ} \mathrm{C}$ under a $50 \mathrm{psi}_{2}$ pressure for $4 \mathrm{~h}$. The reaction mixture was filtered over Celite $545^{\circledR}$, and the filter cake was washed with $\mathrm{CH}_{3} \mathrm{OH}$. Removal of solvent under reduced pressure, followed by column chromatography on silica gel $\left(5 \% \mathrm{CH}_{3} \mathrm{OH}\right.$ in $\mathrm{CH}_{2} \mathrm{Cl}_{2}$ as the eluent) afforded the corresponding aromatic amine $(0.092 \mathrm{~g}, 97 \%)$ as white 
amorphous solid: mp 93.9-95.6 ${ }^{\circ} \mathrm{C} ;{ }^{1} \mathrm{H}$ NMR $\left(400 \mathrm{MHz}, \mathrm{CDCl}_{3}\right) \delta 7.55-7.49(\mathrm{~m}$, 2H), $7.31-7.26(\mathrm{~m}, 1 \mathrm{H}), 7.26-7.17(\mathrm{~m}, 4 \mathrm{H}), 6.68-6.63(\mathrm{~m}, 2 \mathrm{H}), 5.29(\mathrm{~s}, 1 \mathrm{H}), 4.97$ $(\mathrm{d}, J=8.0 \mathrm{~Hz}, 1 \mathrm{H}), 4.21(\mathrm{~s}, 2 \mathrm{H}), 4.13-4.04(\mathrm{~m}, 2 \mathrm{H}), 3.93-3.79(\mathrm{~m}, 2 \mathrm{H}), 3.66(\mathrm{t}, J=$ $4.8 \mathrm{~Hz}, 4 \mathrm{H}), 3.10(\mathrm{dd}, J=16.0,8.0 \mathrm{~Hz}, 1 \mathrm{H}), 3.04-2.95(\mathrm{~m}, 2 \mathrm{H}), 2.95-2.82(\mathrm{~m}, 2 \mathrm{H})$, $2.76(\mathrm{dd}, J=13.4,6.8 \mathrm{~Hz}, 1 \mathrm{H}), 2.51(\mathrm{t}, J=5.7 \mathrm{~Hz}, 2 \mathrm{H}), 2.46-2.37(\mathrm{~m}, 4 \mathrm{H}), 1.86-$ $1.74(\mathrm{~m}, 1 \mathrm{H}), 0.89$ (d, $J=6.6 \mathrm{~Hz}, 3 \mathrm{H}), 0.85$ (d, $J=6.6 \mathrm{~Hz}, 3 \mathrm{H}) ;{ }^{13} \mathrm{C} \mathrm{NMR}(101 \mathrm{MHz}$, $\left.\mathrm{CDCl}_{3}\right) \delta 156.4,150.8,137.8,129.5,129.5,128.5,126.5,126.1,114.1,72.5,66.8$, 61.8, 58.8, 57.5, 55.1, 53.7, 53.7, 35.4, 27.3, 20.2, 20.0; HRMS (ESI) m/z calcd. for $\mathrm{C}_{27} \mathrm{H}_{39} \mathrm{~N}_{4} \mathrm{O}_{6} \mathrm{~S}$ ( [M -H] $]^{-}$): 547.2590, found 547.2585.

$N-((2 S$,

3R)-3-hydroxy-4-((N-isobutyl-4-methoxyphenyl)sulfonamido)-1-phenylbutan-2-yl)-2-( (R)-2-methylmorpholino)acetamide (24a)

$N$-(3-Dimethylaminopropyl)- $N$ '-ethylcarbodiimide hydrochloride (EDCI, $0.058 \mathrm{~g}$, $0.30 \mathrm{mmol}$ ) and 1-hydroxybenzotriazole (HOBt, $0.030 \mathrm{~g}, 0.22 \mathrm{mmol}$ ) were sequentially added in batches to a stirred solution of (R)-2-(2-methylmorpholino)acetic acid $(\mathbf{1 6}, 0.041 \mathrm{~g}, 0.26 \mathrm{mmol})$ and $N-((2 R$, 3S)-3-amino-2-hydroxy-4-phenylbutyl)-N-isobutyl-4-methoxybenzenesulfonamide (8, $0.081 \mathrm{~g}, 0.20 \mathrm{mmol})$ in dry DMF $(1 \mathrm{~mL})$ at $0{ }^{\circ} \mathrm{C}$ under an argon atmosphere. The resulting mixture was stirred for $30 \mathrm{~min}$ at $0{ }^{\circ} \mathrm{C}$ and then warmed to $25^{\circ} \mathrm{C}$ and stirred for $1 \mathrm{~h}$. 4-Dimethylaminopyridine (DMAP, $0.005 \mathrm{~g}, 0.040 \mathrm{mmol}$ ) was added and the reaction mixture was stirred for another $5 \mathrm{~h}$ at $25^{\circ} \mathrm{C}$. The solvent was removed under reduced pressure. Water $(6 \mathrm{~mL})$ was added to the residue and extracted with EtOAc (3 $\times 6 \mathrm{~mL}$ ). The extracts were washed with saturated aqueous $\mathrm{NaCl}$, dried over $\mathrm{Na}_{2} \mathrm{SO}_{4}$, and concentrated under reduced pressure. The crude product was purified by silica gel column chromatography ( $1 \% \mathrm{CH}_{3} \mathrm{OH}$ in $\mathrm{CH}_{2} \mathrm{Cl}_{2}$ as the eluent) to afford $23 \mathrm{a}$ as pale yellow powder (0.078 g, 72\%). $\mathrm{Mp} 78.1-79.6{ }^{\circ} \mathrm{C} ;{ }^{1} \mathrm{H} \mathrm{NMR}\left(600 \mathrm{MHz}, \mathrm{CDCl}_{3}\right) \delta 7.78$ - $7.70(\mathrm{~m}, 2 \mathrm{H}), 7.43-7.27$ (m, 1H), 7.26 - 7.22 (m, 3H), 7.21 - 7.17 (m, 1H), 7.00 $6.96(\mathrm{~m}, 2 \mathrm{H}), 5.29(\mathrm{~s}, 1 \mathrm{H}), 4.36(\mathrm{~s}, 1 \mathrm{H}), 4.23(\mathrm{~s}, 1 \mathrm{H}), 3.95-3.90(\mathrm{~m}, 1 \mathrm{H}), 3.86(\mathrm{~s}, 3 \mathrm{H})$, $3.64(\mathrm{~d}, J=11.4 \mathrm{~Hz}, 1 \mathrm{H}), 3.54-3.38(\mathrm{~m}, 2 \mathrm{H}), 3.19(\mathrm{dd}, J=15.0,4.3 \mathrm{~Hz}, 1 \mathrm{H}), 3.15-$ 
$3.04(\mathrm{~m}, 2 \mathrm{H}), 3.00-2.78(\mathrm{~m}, 5 \mathrm{H}), 2.50(\mathrm{~s}, 1 \mathrm{H}) 2.13-1.92(\mathrm{~m}, 3 \mathrm{H}), 1.91-1.83(\mathrm{~m}$, 1H), $1.06(\mathrm{~d}, J=6.2 \mathrm{~Hz}, 3 \mathrm{H}), 0.88(\mathrm{dd}, J=9.5,6.6 \mathrm{~Hz}, 6 \mathrm{H}) ;{ }^{13} \mathrm{C} \mathrm{NMR}(151 \mathrm{MHz}$, $\left.\mathrm{CDCl}_{3}\right) \delta 170.5,163.0,137.8,130.0,129.4,129.2,128.5,126.6,114.3,72.9,71.6$, 66.3, 61.3, 59.8, 58.6, 55.6, 53.7, 53.1, 52.5, 34.5, 27.2, 20.1, 20.0, 18.8; HRMS (ESI) $\mathrm{m} / \mathrm{z}$ calcd. for $\mathrm{C}_{28} \mathrm{H}_{40} \mathrm{~N}_{3} \mathrm{O}_{6} \mathrm{~S}$ ( [M -H] $]^{-}$): 546.2638, found 546.2649.

$N-((2 S$,

3R)-3-hydroxy-4-((N-isobutyl-4-(trifluoromethyl)phenyl)sulfonamido)-1-phenylbutan2-yl)-2-((R)-2-methylmorpholino)acetamide (24b)

The target compound was obtained by $(R)$-2-(2-methylmorpholino)acetic acid (16) which was coupled with $N-((2 R$, 3S)-3-amino-2-hydroxy-4-phenylbutyl)-N-isobutyl-4-(trifluoromethyl)benzenesulfona mide (9) through EDCI/HOBt/DMAP coupling procedure in 79\% yield (white amorphous solid) as described for 24a: $\mathrm{mp} 76.9-78.5{ }^{\circ} \mathrm{C} ;{ }^{1} \mathrm{H} \mathrm{NMR}\left(600 \mathrm{MHz}, \mathrm{CDCl}_{3}\right)$ $\delta 7.94(\mathrm{~d}, J=8.2 \mathrm{~Hz}, 2 \mathrm{H}), 7.79(\mathrm{~d}, J=8.2 \mathrm{~Hz}, 2 \mathrm{H}), 7.37-7.28(\mathrm{~m}, 2 \mathrm{H}), 7.26-7.20$ (m, 3H), $5.29(\mathrm{~s}, 1 \mathrm{H}), 4.41(\mathrm{~s}, 1 \mathrm{H}), 4.23-4.16(\mathrm{~m}, 1 \mathrm{H}), 3.96-3.91(\mathrm{~m}, 1 \mathrm{H}), 3.67-$ $3.62(\mathrm{~m}, 1 \mathrm{H}), 3.45(\mathrm{t}, J=7.8 \mathrm{~Hz}, 1 \mathrm{H}), 3.41-3.35(\mathrm{~m}, 1 \mathrm{H}), 3.30(\mathrm{dd}, J=18.0,6.0 \mathrm{~Hz}$, 1H), $3.16(\mathrm{dd}, J=12.0,6.0, \mathrm{~Hz}, 1 \mathrm{H}), 3.08(\mathrm{dd}, J=12.0,6.0, \mathrm{~Hz}, 1 \mathrm{H}), 3.03-2.89(\mathrm{~m}$, 4H), $2.81(\mathrm{~d}, J=12.0 \mathrm{~Hz}, 1 \mathrm{H}), 2.46(\mathrm{~d}, J=12.0 \mathrm{~Hz}, 1 \mathrm{H}), 2.09-2.01(\mathrm{~m}, 2 \mathrm{H}), 1.95-$ $1.88(\mathrm{~m}, 2 \mathrm{H}), 1.07(\mathrm{~d}, J=6.2 \mathrm{~Hz}, 3 \mathrm{H}), 0.89$ (d, $J=1.4 \mathrm{~Hz}, 3 \mathrm{H}), 0.88$ (d, $J=1.4 \mathrm{~Hz}, 3 \mathrm{H})$; ${ }^{13} \mathrm{C} \mathrm{NMR}\left(151 \mathrm{MHz}, \mathrm{CDCl}_{3}\right) \delta 171.1,142.4,137.5,134.7,134.5,134.3,134.1,129.1$, 128.7, 127.8, 126.8, 126.3, 126.2, 72.7, 71.7, 66.5, 61.4, 60.0, 58.0, 54.1, 53.4, 52.6, 34.6, 27.0, 20.0, 19.9, 18.8; HRMS (ESI) m/z calcd. for $\mathrm{C}_{28} \mathrm{H}_{37} \mathrm{~F}_{3} \mathrm{~N}_{3} \mathrm{O}_{5} \mathrm{~S}$ ( [M -H] $]^{-}$): 584.2406, found 584.2433.

$N-((2 S$, 3R)-3-hydroxy-4-((N-isobutyl-4-nitrophenyl)sulfonamido)-1-phenylbutan-2-yl)-2-((R) -2-methylmorpholino)acetamide (24d)

The target compound was obtained by $(R)$-2-(2-methylmorpholino)acetic acid (16) which was coupled with $N-((2 R$, 
3S)-3-amino-2-hydroxy-4-phenylbutyl)-N-isobutyl-4-nitrobenzenesulfonamide

through EDCI/HOBt/DMAP coupling procedure in $80 \%$ yield (white amorphous solid) as described for 24a: $\mathrm{mp}$ 67.9-68.7 ${ }^{\circ} \mathrm{C} ;{ }^{1} \mathrm{H}$ NMR (400 MHz, $\left.\mathrm{CDCl}_{3}\right) \delta 8.38-8.31(\mathrm{~m}$, 2H), $8.02-7.94(\mathrm{~m}, 2 \mathrm{H}), 7.32-7.27(\mathrm{~m}, 2 \mathrm{H}), 7.24-7.19(\mathrm{~m}, 3 \mathrm{H}), 4.40(\mathrm{~d}, J=4.4 \mathrm{~Hz}$, $1 \mathrm{H}), 4.20-4.11(\mathrm{~m}, 1 \mathrm{H}), 3.95-3.88(\mathrm{~m}, 1 \mathrm{H}), 3.65-3.59(\mathrm{~m}, 1 \mathrm{H}), 3.48-3.39(\mathrm{~m}$, $1 \mathrm{H}), 3.38-3.33(\mathrm{~m}, 1 \mathrm{H}), 3.31(\mathrm{~d}, J=3.9 \mathrm{~Hz}, 1 \mathrm{H}), 3.21(\mathrm{~m}, 1 \mathrm{H}), 3.10-2.97(\mathrm{~m}, 3 \mathrm{H})$, $2.96-2.86(\mathrm{~m}, 2 \mathrm{H}), 2.80(\mathrm{~d}, J=16.6 \mathrm{~Hz}, 1 \mathrm{H}), 2.45(\mathrm{~d}, J=8.0 \mathrm{~Hz}, 1 \mathrm{H}), 2.09-1.98(\mathrm{~m}$, $2 \mathrm{H}), 1.97-1.84(\mathrm{~m}, 2 \mathrm{H}), 1.06(\mathrm{~d}, J=8.0 \mathrm{~Hz}, 3 \mathrm{H}), 0.87(\mathrm{dd}, J=6.6,5.4 \mathrm{~Hz}, 6 \mathrm{H}) ;{ }^{13} \mathrm{C}$ NMR $\left(101 \mathrm{MHz}, \mathrm{CDCl}_{3}\right) \delta 171.4,150.0,145.1,137.4,129.1,128.8,128.5,126.9$, $124.4,72.5,71.8,66.6,61.4,60.0,57.5,54.5,52.7,52.1,34.8,26.9,20.0,19.9$, 18.9; HRMS (ESI) m/z calcd. for $\mathrm{C}_{27} \mathrm{H}_{37} \mathrm{~N}_{4} \mathrm{O}_{7} \mathrm{~S}$ ( [M -H] $]^{-}$): 561.2383, found 561.2391.

$N-((2 S$,

3R)-4-((4-amino-N-isobutylphenyl)sulfonamido)-3-hydroxy-1-phenylbutan-2-yl)-2-((R )-2-methylmorpholino)acetamide (24c)

The target compound was obtained by hydrogenation of $\mathbf{2 4 d}$ by following the procedure outlined for $\mathbf{2 3 c}$ to afford compound $\mathbf{2 4 c}$ as white amorphous powder (88\%). Mp 120.3-122.5 ${ }^{\circ} \mathrm{C} ;{ }^{1} \mathrm{H}$ NMR (400 MHz, $\left.\mathrm{CDCl}_{3}\right) \delta 7.58-7.52$ (m, 2H), 7.37 - $7.27(\mathrm{~m}, 1 \mathrm{H}), 7.25-7.15(\mathrm{~m}, 4 \mathrm{H}), 6.71-6.63(\mathrm{~m}, 2 \mathrm{H}), 5.29(\mathrm{~s}, 1 \mathrm{H}), 4.38(\mathrm{~s}, 1 \mathrm{H})$, $4.26-4.08(\mathrm{~m}, 3 \mathrm{H}), 3.94-3.87(\mathrm{~m}, 1 \mathrm{H}), 3.66-3.59(\mathrm{~m}, 1 \mathrm{H}), 3.53-3.32(\mathrm{~m}, 2 \mathrm{H})$, $3.20-3.01(\mathrm{~m}, 3 \mathrm{H}), 3.00-2.73(\mathrm{~m}, 5 \mathrm{H}), 2.46(\mathrm{~d}, J=10.6 \mathrm{~Hz}, 1 \mathrm{H}), 2.08-1.96(\mathrm{~m}$, 2H), $1.95-1.79(\mathrm{~m}, 2 \mathrm{H}), 1.06(\mathrm{~d}, J=6.3 \mathrm{~Hz}, 3 \mathrm{H}), 0.89(\mathrm{t}, J=7.0 \mathrm{~Hz}, 6 \mathrm{H}) ;{ }^{13} \mathrm{C} \mathrm{NMR}$ $\left(101 \mathrm{MHz}, \mathrm{CDCl}_{3}\right) \delta 170.7,150.8,138.0,129.5,129.2$, 128.6, 126.6, 126.4, 114.1, 73.0, 71.8, 66.6, 61.5, 60.0, 58.8, 53.6, 53.4, 52.6, 34.5, 27.3, 20.2, 20.1, 18.9; HRMS (ESI) m/z calcd. for $\mathrm{C}_{27} \mathrm{H}_{39} \mathrm{~N}_{4} \mathrm{O}_{5} \mathrm{~S}\left([\mathrm{M}-\mathrm{H}]^{-}\right)$: 531.2641, found 531.2659.

$N-((2 S$,

3R)-3-hydroxy-4-((N-isobutyl-4-methoxyphenyl)sulfonamido)-1-phenylbutan-2-yl)-2-( (S)-2-methylmorpholino)acetamide (25a)

The target compound was obtained by (S)-2-(2-methylmorpholino)acetic acid (17) 
which

was

coupled

with

$N-((2 R$,

3S)-3-amino-2-hydroxy-4-phenylbutyl)-N-isobutyl-4-methoxybenzenesulfonamide (8) through EDCI/HOBt/DMAP coupling procedure in $68 \%$ yield (white amorphous solid) as described for $\mathbf{2 4 a}$ : $\mathrm{mp}$ 90.5-92.2 ${ }^{\circ} \mathrm{C} ;{ }^{1} \mathrm{H}$ NMR $\left(400 \mathrm{MHz}, \mathrm{CDCl}_{3}\right) \delta 7.76-7.71(\mathrm{~m}$, 2H), $7.51-7.27(\mathrm{~m}, 2 \mathrm{H}), 7.25-7.15(\mathrm{~m}, 3 \mathrm{H}), 7.01-6.96(\mathrm{~m}, 2 \mathrm{H}), 5.29(\mathrm{~s}, 1 \mathrm{H}), 4.42$ (s, 1H), $4.23(\mathrm{~s}, 1 \mathrm{H}), 3.95-3.88(\mathrm{~m}, 1 \mathrm{H}), 3.87(\mathrm{~s}, 3 \mathrm{H}), 3.74(\mathrm{~d}, J=11.0 \mathrm{~Hz}, 1 \mathrm{H}), 3.45$ (m, 2H), $3.19(\mathrm{dd}, J=15.0,4.4 \mathrm{~Hz}, 1 \mathrm{H}), 3.15-3.03(\mathrm{~m}, 2 \mathrm{H}), 3.02-2.71(\mathrm{~m}, 5 \mathrm{H})$, $2.40(\mathrm{~s}, 1 \mathrm{H}), 2.31-2.16(\mathrm{~m}, 2 \mathrm{H}), 1.92-1.75(\mathrm{~m}, 2 \mathrm{H}), 1.03(\mathrm{~d}, J=8.0 \mathrm{~Hz}, 3 \mathrm{H}), 0.88(\mathrm{t}$, $J=4.0 \mathrm{~Hz}, 6 \mathrm{H}) ;{ }^{13} \mathrm{C} \mathrm{NMR}\left(101 \mathrm{MHz}, \mathrm{CDCl}_{3}\right) \delta 170.9,163.1,137.9,130.1,129.5$, $129.2,128.6,126.7,114.4,72.8,71.5,66.4,61.4,59.6,58.7,55.7,53.8,53.2,52.9$, 34.5, 27.2, 20.2, 20.0, 18.8; HRMS (ESI) m/z calcd. for $\mathrm{C}_{28} \mathrm{H}_{40} \mathrm{~N}_{3} \mathrm{O}_{6} \mathrm{~S}\left([\mathrm{M}-\mathrm{H}]^{-}\right.$): 546.2638 , found 546.2654 .

$N-((2 S$,

3R)-3-hydroxy-4-((N-isobutyl-4-(trifluoromethyl)phenyl)sulfonamido)-1-phenylbutan2-yl)-2-((S)-2-methylmorpholino)acetamide (25b)

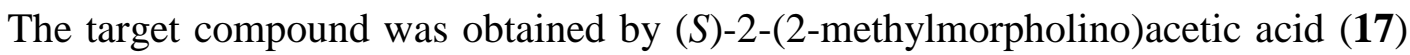
which was coupled with $N-((2 R$, 3S)-3-amino-2-hydroxy-4-phenylbutyl)-N-isobutyl-4-(trifluoromethyl)benzenesulfona mide (9) through EDCI/HOBt/DMAP coupling procedure in 76\% yield (white amorphous solid) as described for 24a: $\mathrm{mp} 71.5-72.9{ }^{\circ} \mathrm{C} ;{ }^{1} \mathrm{H} \mathrm{NMR}\left(600 \mathrm{MHz}, \mathrm{CDCl}_{3}\right)$ $\delta 7.94(\mathrm{~d}, J=8.2 \mathrm{~Hz}, 2 \mathrm{H}), 7.79(\mathrm{~d}, J=8.2 \mathrm{~Hz}, 2 \mathrm{H}), 7.29(\mathrm{t}, J=7.5 \mathrm{~Hz}, 2 \mathrm{H}), 7.25-$ $7.21(\mathrm{~m}, 3 \mathrm{H}), 5.29(\mathrm{~s}, 1 \mathrm{H}), 4.43(\mathrm{~s}, 1 \mathrm{H}), 4.20(\mathrm{~s}, 1 \mathrm{H}), 3.95-3.91(\mathrm{~m}, 1 \mathrm{H}), 3.74(\mathrm{~d}, J=$ $11.4 \mathrm{~Hz}, 1 \mathrm{H}), 3.52-3.31(\mathrm{~m}, 2 \mathrm{H}), 3.28(\mathrm{dd}, J=15.0,4.2 \mathrm{~Hz}, 1 \mathrm{H}), 3.17(\mathrm{~s}, 1 \mathrm{H}), 3.06$ (dd, $J=14.2,4.8 \mathrm{~Hz}, 1 \mathrm{H}), 3.00-2.92(\mathrm{~m}, 4 \mathrm{H}), 2.82(\mathrm{~s}, 1 \mathrm{H}), 2.49-2.11(\mathrm{~m}, 3 \mathrm{H})$, $1.90(\mathrm{~d}, J=6.8 \mathrm{~Hz}, 1 \mathrm{H}), 1.03(\mathrm{~d}, J=6.6 \mathrm{~Hz}, 3 \mathrm{H}), 0.89(\mathrm{~d}, J=2.4 \mathrm{~Hz}, 3 \mathrm{H}), 0.87$ (d, $J$ $=2.4 \mathrm{~Hz}, 3 \mathrm{H}) ;{ }^{13} \mathrm{C} \mathrm{NMR}\left(151 \mathrm{MHz}, \mathrm{CDCl}_{3}\right) \delta 171.2,142.4,137.5,134.5,134.3$, $129.1,128.7,127.8,126.8,126.3,72.6,71.5,66.3,61.4,59.7,58.0,54.2,52.9,52.6$, 34.6, 27.0, 20.0, 19.9, 18.8; HRMS (ESI) m/z calcd. for $\mathrm{C}_{28} \mathrm{H}_{37} \mathrm{~F}_{3} \mathrm{~N}_{3} \mathrm{O}_{5} \mathrm{~S}\left([\mathrm{M}-\mathrm{H}]^{-}\right.$): 584.2406, found 584.2411. 
$N-((2 S$,

3R)-3-hydroxy-4-((N-isobutyl-4-nitrophenyl)sulfonamido)-1-phenylbutan-2-yl)-2-((S)2-methylmorpholino)acetamide (25d)

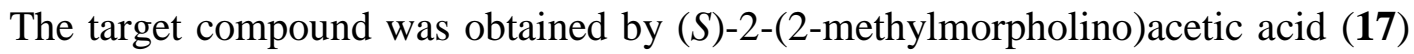
which was coupled with $N-((2 R$, 3S)-3-amino-2-hydroxy-4-phenylbutyl)-N-isobutyl-4-nitrobenzenesulfonamide (10) through EDCI/HOBt/DMAP coupling procedure in 70\% yield (white amorphous solid) as described for 24a: $\mathrm{mp}$ 138.4-140.3 ${ }^{\circ} \mathrm{C} ;{ }^{1} \mathrm{H}$ NMR (400 $\left.\mathrm{MHz}, \mathrm{CDCl}_{3}\right) \delta 8.38-8.32$ (m, 2H), $8.01-7.96(\mathrm{~m}, 2 \mathrm{H}), 7.32-7.27(\mathrm{~m}, 2 \mathrm{H}), 7.25-7.19(\mathrm{~m}, 3 \mathrm{H}), 5.29(\mathrm{~s}, 1 \mathrm{H})$, $4.46(\mathrm{~s}, 1 \mathrm{H}), 4.20-4.12(\mathrm{~m}, 1 \mathrm{H}), 3.96-3.89(\mathrm{~m}, 1 \mathrm{H}), 3.76-3.69(\mathrm{~m}, 1 \mathrm{H}), 3.44(\mathrm{t}$, $J=12.0 \mathrm{~Hz}, 1 \mathrm{H}), 3.33(\mathrm{dd}, J=15.0,4.0 \mathrm{~Hz}, 2 \mathrm{H}), 3.21(\mathrm{dd}, J=15.0,8.0 \mathrm{~Hz}, 1 \mathrm{H}), 3.09-$ $2.88(\mathrm{~m}, 5 \mathrm{H}), 2.80(\mathrm{~d}, J=16.0 \mathrm{~Hz}, 1 \mathrm{H}), 2.37$ (d, $J=9.2 \mathrm{~Hz}, 1 \mathrm{H}), 2.29-2.15(\mathrm{~m}, 2 \mathrm{H})$, $1.96-1.85(\mathrm{~m}, 1 \mathrm{H}), 1.79$ (t, $J=12.0 \mathrm{~Hz}, 1 \mathrm{H}), 1.01$ (d, J=8.0 Hz, 3H), 0.88 (d, J=4.0 $\mathrm{Hz}, 3 \mathrm{H}), 0.87$ (d, $J=4.0 \mathrm{~Hz}, 3 \mathrm{H}) ;{ }^{13} \mathrm{C} \mathrm{NMR}\left(101 \mathrm{MHz}, \mathrm{CDCl}_{3}\right) \delta 171.4,150.1,145.1$, $137.4,129.1,128.8,128.5,126.9,124.4,72.4,71.6,66.5,61.4,59.8,57.5,54.6,53.0$, 52.0, 34.8, 26.9, 20.0, 19.9, 18.8; HRMS (ESI) m/z calcd. for $\mathrm{C}_{27} \mathrm{H}_{37} \mathrm{~N}_{4} \mathrm{O}_{7} \mathrm{~S}$ ( [M $-\mathrm{H}]^{-}$): 561.2383, found 561.2386.

$N-((2 S$,

3R)-4-((4-amino-N-isobutylphenyl)sulfonamido)-3-hydroxy-1-phenylbutan-2-yl)-2-((S )-2-methylmorpholino)acetamide (25c)

The title compound was obtained by hydrogenation of $\mathbf{2 5 d}$ in $91 \%$ yield (white amorphous powder) by following the procedure outlined for $23 \mathrm{c}$ : $\operatorname{mp} 125.0-126.6{ }^{\circ} \mathrm{C}$; ${ }^{1} \mathrm{H}$ NMR (400 MHz, $\left.\mathrm{CDCl}_{3}\right) \delta 7.57-7.51(\mathrm{~m}, 2 \mathrm{H}), 7.35(\mathrm{~s}, 1 \mathrm{H}), 7.29-7.26(\mathrm{~m}, 1 \mathrm{H})$, $7.25-7.16(\mathrm{~m}, 4 \mathrm{H}), 6.71-6.62(\mathrm{~m}, 2 \mathrm{H}), 4.41(\mathrm{~s}, 1 \mathrm{H}), 4.30-4.07(\mathrm{~m}, 3 \mathrm{H}), 3.94-$ $3.88(\mathrm{~m}, 1 \mathrm{H}), 3.75-3.69(\mathrm{~m}, 1 \mathrm{H}), 3.52-3.43(\mathrm{~m}, 1 \mathrm{H}), 3.43-3.34(\mathrm{~m}, 1 \mathrm{H}), 3.18-$ $3.02(\mathrm{~m}, 3 \mathrm{H}), 2.99-2.75(\mathrm{~m}, 5 \mathrm{H}), 2.38(\mathrm{~d}, J=10.0 \mathrm{~Hz}, 1 \mathrm{H}), 2.27-2.15(\mathrm{~m}, 2 \mathrm{H}), 1.93$ - $1.70(\mathrm{~m}, 2 \mathrm{H}), 1.02(\mathrm{~d}, J=8.0 \mathrm{~Hz}, 3 \mathrm{H}), 0.89$ (d, $J=6.6 \mathrm{~Hz}, 3 \mathrm{H}), 0.87$ (d, J=6.6 Hz, $3 \mathrm{H}) ;{ }^{13} \mathrm{C} \mathrm{NMR}\left(101 \mathrm{MHz}, \mathrm{CDCl}_{3}\right) \delta 170.7,150.8,137.9,129.5,129.2,128.6,126.6$, 
$126.4,114.1,72.9,71.6,66.5,61.5,59.7,58.8,53.6,53.3,53.0,34.5,27.3,20.2,20.0$, 18.8; HRMS (ESI) $\mathrm{m} / \mathrm{z}$ calcd. for $\mathrm{C}_{27} \mathrm{H}_{39} \mathrm{~N}_{4} \mathrm{O}_{5} \mathrm{~S}$ ( $[\mathrm{M}-\mathrm{H}]^{-}$): 531.2641, found 531.2661 .

$N-((2 S$,

3R)-3-hydroxy-4-((N-isobutyl-4-methoxyphenyl)sulfonamido)-1-phenylbutan-2-yl)-2morpholinoacetamide (26a)

The target compound was obtained by 2-morpholinoacetic acid (18) which was coupled with $N-((2 R$, 3S)-3-amino-2-hydroxy-4-phenylbutyl)-N-isobutyl-4-methoxybenzenesulfonamide (8) through EDCI/HOBt/DMAP coupling procedure in $75 \%$ yield (white amorphous solid) as described for 24a: $\mathrm{mp} 115.2-116.7{ }^{\circ} \mathrm{C} ;{ }^{1} \mathrm{H}$ NMR (400 $\left.\mathrm{MHz}, \mathrm{CDCl}_{3}\right) \delta 7.77-7.70$ (m, 2H), $7.29-7.26(\mathrm{~m}, 1 \mathrm{H}), 7.25-7.18(\mathrm{~m}, 4 \mathrm{H}), 7.01-6.95(\mathrm{~m}, 2 \mathrm{H}), 5.29(\mathrm{~s}, 1 \mathrm{H})$, $4.36(\mathrm{~s}, 1 \mathrm{H}), 4.23(\mathrm{~s}, 1 \mathrm{H}), 3.96-3.89(\mathrm{~m}, 1 \mathrm{H}), 3.87(\mathrm{~s}, 3 \mathrm{H}), 3.53(\mathrm{~s}, 4 \mathrm{H}), 3.22-3.04$ $(\mathrm{m}, 3 \mathrm{H}), 3.00-2.74(\mathrm{~m}, 5 \mathrm{H}), 2.35-2.09(\mathrm{~m}, 4 \mathrm{H}), 1.92-1.81(\mathrm{~m}, 1 \mathrm{H}), 0.89(\mathrm{dd}, J=$ 8.4, 6.6 Hz, 6H); ${ }^{13} \mathrm{C}$ NMR (101 MHz, $\left.\mathrm{CDCl}_{3}\right) \delta 170.5,163.1,137.9,130.1,129.5$, 129.2, 128.6, 126.6, 114.4, 76.8, 72.9, 66.7, 61.7, 58.7, 55.7, 53.7, 53.5, 53.2, 34.5, 27.2, 20.2, 20.0; HRMS (ESI) $\mathrm{m} / \mathrm{z}$ calcd. for $\mathrm{C}_{27} \mathrm{H}_{38} \mathrm{~N}_{3} \mathrm{O}_{6} \mathrm{~S}$ ( [M - $\left.\mathrm{H}\right]^{-}$): 532.2481, found 532.2483 .

$N-((2 S$,

3R)-3-hydroxy-4-((N-isobutyl-4-(trifluoromethyl)phenyl)sulfonamido)-1-phenylbutan2-yl)-2-morpholinoacetamide (26b)

The target compound was obtained by 2-morpholinoacetic acid (18) which was coupled with $N-((2 R$, 3S)-3-amino-2-hydroxy-4-phenylbutyl)-N-isobutyl-4-(trifluoromethyl)benzenesulfona mide (9) through EDCI/HOBt/DMAP coupling procedure in $74 \%$ yield (white amorphous solid) as described for 24a: mp 114.3-116.1 ${ }^{\circ} \mathrm{C} ;{ }^{1} \mathrm{H}$ NMR (600 MHz, $\left.\mathrm{CDCl}_{3}\right) \delta 7.95(\mathrm{~d}, J=12.0 \mathrm{~Hz}, 2 \mathrm{H}), 7.79(\mathrm{~d}, J=8.4 \mathrm{~Hz}, 2 \mathrm{H}), 7.30-7.26(\mathrm{~m}, 2 \mathrm{H}), 7.25$ - $7.18(\mathrm{~m}, 3 \mathrm{H}), 4.33$ (s, 1H), $4.24(\mathrm{~s}, 1 \mathrm{H}), 3.96-3.91(\mathrm{~m}, 1 \mathrm{H}), 3.55(\mathrm{~s}, 4 \mathrm{H}), 3.31-$ 
$3.25(\mathrm{~m}, 1 \mathrm{H}), 3.21(\mathrm{~s}, 1 \mathrm{H}), 3.10-3.04(\mathrm{~m}, 1 \mathrm{H}), 3.03-2.79(\mathrm{~m}, 5 \mathrm{H}), 2.26(\mathrm{~s}, 3 \mathrm{H})$, $1.93-1.85(\mathrm{~m}, 1 \mathrm{H}), 0.89-0.87(\mathrm{~m}, 6 \mathrm{H}) ;{ }^{13} \mathrm{C} \mathrm{NMR}\left(151 \mathrm{MHz}, \mathrm{CDCl}_{3}\right) \delta 170.6,142.4$, $137.5,134.8,134.5,134.3,134.1,129.1,128.7,127.8,126.7,126.3,126.3,72.6,66.4$, 61.5, 58.1, 54.0, 53.3, 52.6, 34.6, 27.0, 20.0, 19.9; HRMS (ESI) m/z calcd. for $\mathrm{C}_{27} \mathrm{H}_{35} \mathrm{~F}_{3} \mathrm{~N}_{3} \mathrm{O}_{5} \mathrm{~S}\left([\mathrm{M}-\mathrm{H}]^{-}\right)$: 570.2250, found 570.2251.

$N-((2 S$,

3R)-3-hydroxy-4-((N-isobutyl-4-nitrophenyl)sulfonamido)-1-phenylbutan-2-yl)-2-mor pholinoacetamide (26d)

The target compound was obtained by 2-morpholinoacetic acid (18) which was coupled with $N-((2 R$,

3S)-3-amino-2-hydroxy-4-phenylbutyl)-N-isobutyl-4-nitrobenzenesulfonamide through EDCI/HOBt/DMAP coupling procedure in $80 \%$ yield (white amorphous solid) as described for 24a: $\mathrm{mp}$ 67.2-68.1 ${ }^{\circ} \mathrm{C} ;{ }^{1} \mathrm{H}$ NMR $\left(400 \mathrm{MHz}, \mathrm{CDCl}_{3}\right) \delta 8.38-8.30(\mathrm{~m}$, 2H), $8.02-7.92(\mathrm{~m}, 2 \mathrm{H}), 7.34-7.27(\mathrm{~m}, 2 \mathrm{H}), 7.24-7.18(\mathrm{~m}, 3 \mathrm{H}), 5.29(\mathrm{~s}, 1 \mathrm{H}), 4.40$ (d, J=4.2 Hz, 1H), $4.21-4.12(\mathrm{~m}, 1 \mathrm{H}), 3.95-3.88(\mathrm{~m}, 1 \mathrm{H}), 3.49$ (t, $J=4.6 \mathrm{~Hz}, 4 \mathrm{H})$, $3.33(\mathrm{dd}, J=16.0,4.0 \mathrm{~Hz}, 1 \mathrm{H}), 3.21(\mathrm{dd}, J=15.0,8.2 \mathrm{~Hz}, 1 \mathrm{H}), 3.11-2.86(\mathrm{~m}, 5 \mathrm{H})$, $2.81(\mathrm{~d}, J=20.0 \mathrm{~Hz}, 1 \mathrm{H}), 2.30-2.20(\mathrm{~m}, 2 \mathrm{H}), 2.20-2.10(\mathrm{~m}, 2 \mathrm{H}), 1.96-1.83(\mathrm{~m}$, $1 \mathrm{H}), 0.87(\mathrm{dd}, J=6.6,3.6 \mathrm{~Hz}, 6 \mathrm{H}) ;{ }^{13} \mathrm{C} \mathrm{NMR}\left(101 \mathrm{MHz}, \mathrm{CDCl}_{3}\right) \delta 171.2,150.1$, 145.0, 137.4, 129.1, 128.8, 128.5, 126.9, 124.4, 72.5, 66.8, 61.7, 57.5, 54.4, 53.6, 52.1, 34.8, 26.9, 20.0, 19.9; HRMS (ESI) m/z calcd. for $\mathrm{C}_{26} \mathrm{H}_{35} \mathrm{~N}_{4} \mathrm{O}_{7} \mathrm{~S}\left([\mathrm{M}-\mathrm{H}]^{-}\right)$: 547.2226, found 547.2211.

$N-((2 S$,

3R)-4-((4-amino-N-isobutylphenyl)sulfonamido)-3-hydroxy-1-phenylbutan-2-yl)-2-mo rpholinoacetamide (26c)

The title compound was obtained by hydrogenation of $\mathbf{2 6 d}$ in $81 \%$ yield (white amorphous powder) by following the procedure outlined for 23c: $\operatorname{mp} 164.0-165.5^{\circ} \mathrm{C}$; ${ }^{1} \mathrm{H}$ NMR (400 MHz, $\left.\mathrm{CDCl}_{3}\right) \delta 7.57-7.52(\mathrm{~m}, 2 \mathrm{H}), 7.34-7.27(\mathrm{~m}, 1 \mathrm{H}), 7.25-7.15$ (m, 4H), $6.70-6.64(\mathrm{~m}, 2 \mathrm{H}), 5.29(\mathrm{~s}, 1 \mathrm{H}), 4.37(\mathrm{~d}, J=4.0 \mathrm{~Hz}, 1 \mathrm{H}), 4.27-4.11(\mathrm{~m}$, 
3H), $3.94-3.87(\mathrm{~m}, 1 \mathrm{H}), 3.51(\mathrm{t}, J=4.0 \mathrm{~Hz}, 4 \mathrm{H}), 3.18-3.03(\mathrm{~m}, 3 \mathrm{H}), 3.00-2.74(\mathrm{~m}$, $5 \mathrm{H}), 2.29-2.19(\mathrm{~m}, 2 \mathrm{H}), 2.18-2.10(\mathrm{~m}, 2 \mathrm{H}), 1.90-1.79(\mathrm{~m}, 1 \mathrm{H}), 0.90(\mathrm{~d}, J=6.6 \mathrm{~Hz}$, $3 \mathrm{H}), 0.87(\mathrm{~d}, J=6.6 \mathrm{~Hz}, 3 \mathrm{H}) ;{ }^{13} \mathrm{C} \mathrm{NMR}\left(101 \mathrm{MHz}, \mathrm{CDCl}_{3}\right) \delta 170.6,150.8,137.9$, $129.5,129.2$, 128.6, 126.6, 126.4, 114.1, 73.0, 66.8, 61.7, 58.9, 53.5, 53.4, 34.5, 27.3, 20.2, 20.0; HRMS (ESI) m/z calcd. for $\mathrm{C}_{26} \mathrm{H}_{37} \mathrm{~N}_{4} \mathrm{O}_{5} \mathrm{~S}$ ( $\left.[\mathrm{M}-\mathrm{H}]^{-}\right)$: 517.2485, found 517.2496.

$N-((2 S$,

3R)-3-hydroxy-4-((N-isobutyl-4-methoxyphenyl)sulfonamido)-1-phenylbutan-2-yl)mor pholine-4-carboxamide (27a)

The target compound was obtained by morpholine-4-carbonyl chloride (19) which was coupled with $N-((2 R$, 3S)-3-amino-2-hydroxy-4-phenylbutyl)-N-isobutyl-4-methoxybenzenesulfonamide (8) through EDCI/HOBt/DMAP coupling procedure in 51\% yield (white amorphous solid) as described for 24a: mp 74.1-75.3 ${ }^{\circ} \mathrm{C} ;{ }^{1} \mathrm{H}$ NMR (600 MHz,CD $\left.{ }_{3} \mathrm{OD}\right) \delta 7.68(\mathrm{~d}, J=8.4$ $\mathrm{Hz}, 2 \mathrm{H}), 7.20-7.14(\mathrm{~m}, 4 \mathrm{H}), 7.12-7.08(\mathrm{~m}, 1 \mathrm{H}), 7.00$ (d, J=8.4 Hz, 2H), $3.87-$ $3.82(\mathrm{~m}, 1 \mathrm{H}), 3.80(\mathrm{~s}, 3 \mathrm{H}), 3.79-3.75(\mathrm{~m}, 1 \mathrm{H}), 3.47-3.40(\mathrm{~m}, 4 \mathrm{H}), 3.37(\mathrm{dd}, J=$ 12.0, $6.0 \mathrm{~Hz}, 1 \mathrm{H}), 3.21-3.16(\mathrm{~m}, 2 \mathrm{H}), 3.16-3.06$ (m, 3H), 3.00 (dd, J=13.6, 8.2 Hz, $1 \mathrm{H}), 2.90-2.84(\mathrm{~m}, 1 \mathrm{H}), 2.79-2.75(\mathrm{~m}, 1 \mathrm{H}), 2.64-2.58(\mathrm{~m}, 1 \mathrm{H}), 1.97-1.93(\mathrm{~m}$, $1 \mathrm{H}), 0.85(\mathrm{~d}, J=6.6 \mathrm{~Hz}, 3 \mathrm{H}), 0.79(\mathrm{~d}, J=6.6 \mathrm{~Hz}, 3 \mathrm{H}) ;{ }^{13} \mathrm{C} \mathrm{NMR}\left(151 \mathrm{MHz}, \mathrm{CD}_{3} \mathrm{OD}\right)$ $\delta 163.1,158.2$, 139.1, 130.6, 129.2, 129.0, 127.8, 125.7, 113.9, 73.5, 66.1, 57.5, 55.4, 54.8, 52.8, 44.0, 35.6, 26.6, 19.1, 19.0; HRMS (ESI) m/z calcd. for $\mathrm{C}_{26} \mathrm{H}_{36} \mathrm{~N}_{3} \mathrm{O}_{6} \mathrm{~S}$ ( [M $-\mathrm{H}]^{-}$): 518.2325, found 518.2345.

$N-((2 S$, 3R)-3-hydroxy-4-((N-isobutyl-4-(trifluoromethyl)phenyl)sulfonamido)-1-phenylbutan2-yl)morpholine-4-carboxamide (27b)

The target compound was obtained by morpholine-4-carbonyl chloride (19) which was coupled with $N-((2 R$, 3S)-3-amino-2-hydroxy-4-phenylbutyl)-N-isobutyl-4-(trifluoromethyl)benzenesulfona 
mide (9) through EDCI/HOBt/DMAP coupling procedure in 56\% yield (white amorphous solid) as described for 24a: $\mathrm{mp}$ 85.3-87.7 ${ }^{\circ} \mathrm{C} ;{ }^{1} \mathrm{H}$ NMR (600 MHz, $\mathrm{CDCl}_{3}$ ) $\delta 7.90(\mathrm{~d}, J=8.2 \mathrm{~Hz}, 2 \mathrm{H}), 7.77(\mathrm{~d}, J=8.2 \mathrm{~Hz}, 2 \mathrm{H}), 7.32-7.26(\mathrm{~m}, 2 \mathrm{H}), 7.25-7.20$ $(\mathrm{m}, 3 \mathrm{H}), 5.28(\mathrm{~s}, 1 \mathrm{H}), 4.96(\mathrm{~s}, 1 \mathrm{H}), 4.06(\mathrm{~s}, 1 \mathrm{H}), 3.94-3.89(\mathrm{~m}, 1 \mathrm{H}), 3.61-3.51(\mathrm{~m}$, 4H), $3.38(\mathrm{dd}, J=12.0,6.0 \mathrm{~Hz}, 1 \mathrm{H}), 3.25-3.14(\mathrm{~m}, 4 \mathrm{H}), 3.13-3.04(\mathrm{~m}, 1 \mathrm{H}), 3.03-$ $2.96(\mathrm{~m}, 3 \mathrm{H}), 2.91(\mathrm{dd}, J=13.6,7.4 \mathrm{~Hz}, 1 \mathrm{H}), 1.96-1.88(\mathrm{~m}, 1 \mathrm{H}), 0.87$ (d, $J=6.6 \mathrm{~Hz}$, $3 \mathrm{H}), 0.83(\mathrm{~d}, J=6.6 \mathrm{~Hz}, 3 \mathrm{H}) ;{ }^{13} \mathrm{C} \mathrm{NMR}\left(151 \mathrm{MHz}, \mathrm{CDCl}_{3}\right) \delta 158.2,142.4,138.0$, 134.7, 134.5, 134.3, 134.1, 129.2, 128.7, 127.8, 126.7, 126.3, 126.2, 72.7, 66.3, 58.1, 56.2, 52.4, 44.1, 35.3, 27.0, 20.0; HRMS (ESI) m/z calcd. for $\mathrm{C}_{26} \mathrm{H}_{33} \mathrm{~F}_{3} \mathrm{~N}_{3} \mathrm{O}_{5} \mathrm{~S}$ ( [M $-\mathrm{H}]^{-}$): 556.2093, found 556.2105.

$N-((2 S$,

3R)-3-hydroxy-4-((N-isobutyl-4-nitrophenyl)sulfonamido)-1-phenylbutan-2-yl)morph oline-4-carboxamide $(\mathbf{2 7 d})$

The target compound was obtained by morpholine-4-carbonyl chloride (19) which was coupled with $N-((2 R$, 3S)-3-amino-2-hydroxy-4-phenylbutyl)-N-isobutyl-4-nitrobenzenesulfonamide (10) through EDCI/HOBt/DMAP coupling procedure in 60\% yield (white amorphous solid) as described for 24a: $\mathrm{mp}$ 115.3-117.1 ${ }^{\circ} \mathrm{C}$; ${ }^{1} \mathrm{H}$ NMR (600 $\left.\mathrm{MHz}, \mathrm{CDCl}_{3}\right) \delta 8.36-8.32$ (m, 2H), $7.99-7.96(\mathrm{~m}, 2 \mathrm{H}), 7.33-7.29(\mathrm{~m}, 2 \mathrm{H}), 7.26-7.21(\mathrm{~m}, 3 \mathrm{H}), 5.29(\mathrm{~s}, 1 \mathrm{H})$, $4.87(\mathrm{~s}, 1 \mathrm{H}), 4.06-3.99(\mathrm{~m}, 1 \mathrm{H}), 3.93-3.87(\mathrm{~m}, 1 \mathrm{H}), 3.62-3.52(\mathrm{~m}, 4 \mathrm{H}), 3.41(\mathrm{dd}$, $J=12.0,6.0 \mathrm{~Hz}, 1 \mathrm{H}), 3.24-3.14(\mathrm{~m}, 5 \mathrm{H}), 3.06(\mathrm{dd}, J=13.6,7.8 \mathrm{~Hz}, 1 \mathrm{H}), 3.02-2.96$ (m, 2H), $2.95-2.93(\mathrm{~m}, 1 \mathrm{H}), 1.97-1.89(\mathrm{~m}, 1 \mathrm{H}), 0.88$ (d, J=6.6 Hz, 3H), 0.84 (d, $J=6.6 \mathrm{~Hz}, 3 \mathrm{H}) ;{ }^{13} \mathrm{C} \mathrm{NMR}\left(151 \mathrm{MHz}, \mathrm{CDCl}_{3}\right) \delta 158.3,149.9,145.0,137.8,129.2$, $128.7,128.5,126.8,124.3,72.3,66.2,57.4,56.3,51.8,44.1,35.4,26.8,20.0,19.9$; HRMS (ESI) m/z calcd. for $\mathrm{C}_{25} \mathrm{H}_{33} \mathrm{~N}_{4} \mathrm{O}_{7} \mathrm{~S}$ ( [M -H] $]^{-}$): 533.2070, found 533.2079.

$N-((2 S$, 3R)-4-((4-amino-N-isobutylphenyl)sulfonamido)-3-hydroxy-1-phenylbutan-2-yl)morp holine-4-carboxamide (27c) 
The title compound was obtained by hydrogenation of $\mathbf{2 7 d}$ in $91 \%$ yield (white amorphous powder) by following the procedure outlined for $23 \mathrm{c}: \operatorname{mp} 152.8-154.7^{\circ} \mathrm{C}$; ${ }^{1} \mathrm{H}$ NMR $\left(600 \mathrm{MHz}, \mathrm{CDCl}_{3}\right) \delta 7.53(\mathrm{~d}, J=8.2 \mathrm{~Hz}, 2 \mathrm{H}), 7.30-7.27(\mathrm{~m}, 2 \mathrm{H}), 7.26-$ $7.19(\mathrm{~m}, 3 \mathrm{H}), 6.67$ (d, J= 8.2 Hz, 2H), 4.98 (d, J=6.0 Hz, 1H), $4.15-4.08(\mathrm{~m}, 1 \mathrm{H})$, $3.93-3.86(\mathrm{~m}, 1 \mathrm{H}), 3.61-3.50(\mathrm{~m}, 4 \mathrm{H}), 3.46(\mathrm{~s}, 1 \mathrm{H}), 3.29$ (dd, $J=18.0,6.0 \mathrm{~Hz}, 1 \mathrm{H})$, $3.25-3.15(\mathrm{~m}, 4 \mathrm{H}), 3.08-2.93(\mathrm{~m}, 3 \mathrm{H}), 2.89(\mathrm{dd}, J=13.4,7.6 \mathrm{~Hz}, 1 \mathrm{H}), 2.81(\mathrm{dd}, J=$ 18.0, $12.0 \mathrm{~Hz}, 1 \mathrm{H}), 1.89(\mathrm{~m}, 1 \mathrm{H}), 0.88(\mathrm{~d}, J=6.6 \mathrm{~Hz}, 3 \mathrm{H}), 0.85(\mathrm{~d}, J=6.6 \mathrm{~Hz}, 3 \mathrm{H})$; ${ }^{13} \mathrm{C} \mathrm{NMR}\left(151 \mathrm{MHz}, \mathrm{CDCl}_{3}\right) \delta 158.2,150.5,138.4,129.4,128.5,126.5,126.4,114.2$, 73.0, 66.3, 58.9, 55.7, 53.1, 44.0, 35.4, 27.2, 20.1; HRMS (ESI) m/z calcd. for $\mathrm{C}_{25} \mathrm{H}_{35} \mathrm{~N}_{4} \mathrm{O}_{5} \mathrm{~S}$ ( [M -H] $]^{-}$): 503.2328, found 503.2304.

$N-((2 R$,

3S)-2-hydroxy-3-((2-morpholino-2-oxoethyl)amino)-4-phenylbutyl)-N-isobutyl-4-meth oxybenzenesulfonamide (28a)

The mixture of DIEA (0.076 g, $0.59 \mathrm{mmol})$ and DMAP (0.034 g, $0.21 \mathrm{mmol})$ was added slowly to a stirred solution of 2-chloro-1-morpholinoethan-1-one (20,0.034 g, $0.21 \mathrm{mmol})$ and $\mathrm{N}((2 R$, 3S)-3-amino-2-hydroxy-4-phenylbutyl)-N-isobutyl-4-methoxybenzenesulfonamide (8, $0.080 \mathrm{~g}, 0.20 \mathrm{mmol})$ in anhydrous DMF $(1 \mathrm{~mL})$ under the protection of Argon. The resulting mixture was then refluxed for $7 \mathrm{~h}$. Upon completion, the reaction mixture was cooled to $25^{\circ} \mathrm{C}$ and concentrated under reduced pressure. Water was added into the residue and extracted with $\mathrm{CH}_{2} \mathrm{Cl}_{2}$. The extracts were washed with saturated brine, dried over $\mathrm{Na}_{2} \mathrm{SO}_{4}$, and concentrated under reduced pressure. The crude product was purified by silica gel column chromatography $\left(3 \% \mathrm{CH}_{3} \mathrm{OH}\right.$ in $\mathrm{CH}_{2} \mathrm{Cl}_{2}$ as the eluent) to afford 28a as pale yellow powder (0.068 g, 65\%). Mp 84.1-86.6 ${ }^{\circ} \mathrm{C} ;{ }^{1} \mathrm{H}$ NMR (600 $\left.\mathrm{MHz}, \mathrm{CDCl}_{3}\right) \delta 7.75-7.71(\mathrm{~m}, 2 \mathrm{H}), 7.33-7.28(\mathrm{~m}, 2 \mathrm{H}), 7.26-7.21(\mathrm{~m}, 3 \mathrm{H}), 6.99-$ $6.95(\mathrm{~m}, 2 \mathrm{H}), 5.29(\mathrm{~s}, 1 \mathrm{H}), 3.91-3.88(\mathrm{~m}, 1 \mathrm{H}), 3.86(\mathrm{~s}, 3 \mathrm{H}), 3.64-3.61(\mathrm{~m}, 2 \mathrm{H})$, $3.59(\mathrm{~s}, 2 \mathrm{H}), 3.56(\mathrm{~d}, J=6.0 \mathrm{~Hz}, 2 \mathrm{H}), 3.44(\mathrm{~d}, J=12.0 \mathrm{~Hz}, 1 \mathrm{H}), 3.33(\mathrm{~s}, 1 \mathrm{H}), 3.31(\mathrm{~d}$, $J=3.1 \mathrm{~Hz}, 1 \mathrm{H}), 3.28(\mathrm{~d}, J=6.0 \mathrm{~Hz}, 1 \mathrm{H}), 3.27-3.20(\mathrm{~m}, 2 \mathrm{H}), 3.10(\mathrm{dd}, J=15.0,8.0$ $\mathrm{Hz}, 1 \mathrm{H}), 3.07-3.03(\mathrm{~m}, 1 \mathrm{H}), 2.95-2.87(\mathrm{~m}, 2 \mathrm{H}), 2.85(\mathrm{dd}, J=18.0,6.0 \mathrm{~Hz}, 1 \mathrm{H})$, 
$2.77-2.71(\mathrm{~m}, 1 \mathrm{H}), 1.93-1.85(\mathrm{~m}, 1 \mathrm{H}), 0.89-0.85(\mathrm{~m}, 6 \mathrm{H}) ;{ }^{13} \mathrm{C}$ NMR $(151 \mathrm{MHz}$, $\left.\mathrm{CDCl}_{3}\right) \delta 169.1,162.8,138.2,130.4,129.4,129.2,128.7,126.6,114.2,70.8,66.8$, 66.3, 62.9, 58.2, 55.6, 52.1, 48.5, 44.7, 42.2, 35.8, 27.0, 20.1, 20.0; HRMS (ESI) m/z calcd. for $\mathrm{C}_{27} \mathrm{H}_{38} \mathrm{~N}_{3} \mathrm{O}_{6} \mathrm{~S}$ ( [M -H] $]^{-}$): 532.2481, found 532.2476.

$N-((2 R$,

3S)-2-hydroxy-3-((2-morpholino-2-oxoethyl)amino)-4-phenylbutyl)-N-isobutyl-4-(trifl uoromethyl)benzenesulfonamide (28b)

2-Chloro-1-morpholinoethan-1-one (20) was treated with $N$ - $((2 R$, 3S)-3-amino-2-hydroxy-4-phenylbutyl)-N-isobutyl-4-(trifluoromethyl)benzenesulfona mide (9) by following the procedure outlined for $\mathbf{2 8 a}$ to give compound $\mathbf{2 8 b}$ as pale yellow powder (68\%). Mp 69.8-71.9 ${ }^{\circ} \mathrm{C} ;{ }^{1} \mathrm{H} \mathrm{NMR}\left(600 \mathrm{MHz}, \mathrm{CDCl}_{3}\right) \delta 7.93(\mathrm{~d}, J=$ $8.2 \mathrm{~Hz}, 2 \mathrm{H}), 7.77(\mathrm{~d}, J=8.2 \mathrm{~Hz}, 2 \mathrm{H}), 7.32-7.29(\mathrm{~m}, 2 \mathrm{H}), 7.26-7.21(\mathrm{~m}, 3 \mathrm{H}), 5.29$ (s, 1H), $3.92-3.87(\mathrm{~m}, 1 \mathrm{H}), 3.62(\mathrm{~d}, J=5.0 \mathrm{~Hz}, 2 \mathrm{H}), 3.61-3.57(\mathrm{~m}, 2 \mathrm{H}), 3.57-$ $3.54(\mathrm{~m}, 2 \mathrm{H}), 3.42(\mathrm{~d}, J=16.4 \mathrm{~Hz}, 1 \mathrm{H}), 3.39-3.31(\mathrm{~m}, 2 \mathrm{H}), 3.25-3.19(\mathrm{~m}, 2 \mathrm{H})$, $3.18-3.11(\mathrm{~m}, 1 \mathrm{H}), 3.08-3.01(\mathrm{~m}, 2 \mathrm{H}), 2.97-2.92(\mathrm{~m}, 2 \mathrm{H}), 2.87-2.82(\mathrm{~m}, 1 \mathrm{H})$, $2.79-2.73(\mathrm{~m}, 1 \mathrm{H}), 1.96-1.84(\mathrm{~m}, 1 \mathrm{H}), 0.88(\mathrm{~d}, J=6.6 \mathrm{~Hz}, 3 \mathrm{H}), 0.85(\mathrm{~d}, J=6.6 \mathrm{~Hz}$, $3 \mathrm{H}) ;{ }^{13} \mathrm{C} \mathrm{NMR}\left(151 \mathrm{MHz}, \mathrm{CDCl}_{3}\right) \delta 169.0,142.8,138.0,134.5,134.3,134.1,133.9$, 129.2, 128.7, 127.8, 126.7, 126.2, 126.1, 70.5, 66.6, 66.2, 63.0, 57.7, 51.7, 48.4, 44.7, 42.3, 35.9, 26.9, 20.0, 19.9; HRMS (ESI) m/z calcd. for $\mathrm{C}_{27} \mathrm{H}_{35} \mathrm{~F}_{3} \mathrm{~N}_{3} \mathrm{O}_{5} \mathrm{~S}\left([\mathrm{M}-\mathrm{H}]^{-}\right.$): 570.2250 , found 570.2263 .

$N-((2 R$,

3S)-2-hydroxy-3-((2-morpholino-2-oxoethyl)amino)-4-phenylbutyl)-N-isobutyl-4-nitro benzenesulfonamide (28d)

2-Chloro-1-morpholinoethan-1-one (20) was treated with $N$ - $((2 R$, 3S)-3-amino-2-hydroxy-4-phenylbutyl)-N-isobutyl-4-nitrobenzenesulfonamide (10)

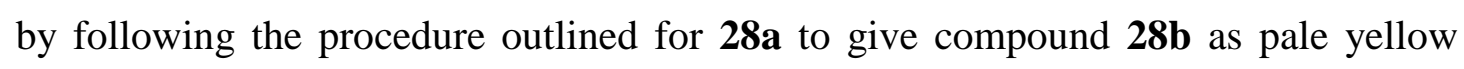
powder (69\%). $\mathrm{Mp} 82.1-84.7{ }^{\circ} \mathrm{C} ;{ }^{1} \mathrm{H}$ NMR (600 MHz, $\left.\mathrm{CDCl}_{3}\right) \delta 8.34-8.30(\mathrm{~m}, 2 \mathrm{H})$, $7.99-7.96(\mathrm{~m}, 2 \mathrm{H}), 7.32-7.28(\mathrm{~m}, 2 \mathrm{H}), 7.25-7.21(\mathrm{~m}, 3 \mathrm{H}), 5.29(\mathrm{~s}, 1 \mathrm{H}), 3.81-$ 
$3.76(\mathrm{~m}, 1 \mathrm{H}), 3.63(\mathrm{t}, J=6.0 \mathrm{~Hz}, 2 \mathrm{H}), 3.61-3.52(\mathrm{~m}, 5 \mathrm{H}), 3.40(\mathrm{dd}, J=12.0,3.0 \mathrm{~Hz}$, 1H), $3.31(\mathrm{~s}, 2 \mathrm{H}), 3.25-3.19(\mathrm{~m}, 3 \mathrm{H}), 3.10(\mathrm{dd}, J=13.6,7.8 \mathrm{~Hz}, 1 \mathrm{H}), 3.00-2.94(\mathrm{~m}$, 2H), $2.78(\mathrm{dd}, J=14.0,5.4 \mathrm{~Hz}, 1 \mathrm{H}), 2.72(\mathrm{dd}, J=14.0,9.0 \mathrm{~Hz}, 1 \mathrm{H}), 1.96-1.87(\mathrm{~m}$, $1 \mathrm{H}), 0.88(\mathrm{~d}, J=6.6 \mathrm{~Hz}, 3 \mathrm{H}), 0.84(\mathrm{~d}, J=6.6 \mathrm{~Hz}, 3 \mathrm{H}) ;{ }^{13} \mathrm{C} \mathrm{NMR}\left(151 \mathrm{MHz}, \mathrm{CDCl}_{3}\right) \delta$ 169.6, 149.8, 145.5, 138.2, 129.1, 128.7, 128.5, 126.7, 124.2, 70.4, 66.7, 66.2, 63.1, 57.0, 51.0, 48.7, 44.7, 42.2, 36.4, 26.7, 19.9, 19.8; HRMS (ESI) m/z calcd. for $\mathrm{C}_{26} \mathrm{H}_{35} \mathrm{~N}_{4} \mathrm{O}_{7} \mathrm{~S}$ ( [M -H] $]^{-}$): 547.2226, found 547.2208.

\section{4-Amino- $N-((2 R$,}

3S)-2-hydroxy-3-((2-morpholino-2-oxoethyl)amino)-4-phenylbutyl)-N-isobutylbenzen esulfonamide $(\mathbf{2 8 c})$

The title compound was obtained by hydrogenation of $\mathbf{2 8 d}$ in $92 \%$ yield (pale yellow powder) by following the procedure outlined for $23 \mathrm{c}: \mathrm{mp} 115.0-118.1{ }^{\circ} \mathrm{C} ;{ }^{1} \mathrm{H}$ NMR (400 MHz, $\left.\mathrm{CDCl}_{3}\right) \delta 7.59$ - $7.53(\mathrm{~m}, 2 \mathrm{H}), 7.34$ - $7.28(\mathrm{~m}, 2 \mathrm{H}), 7.26$ - $7.19(\mathrm{~m}$, $3 \mathrm{H}), 6.72-6.63(\mathrm{~m}, 2 \mathrm{H}), 5.29(\mathrm{~s}, 1 \mathrm{H}), 4.15(\mathrm{~s}, 1 \mathrm{H}), 3.93-3.83(\mathrm{~m}, 1 \mathrm{H}), 3.67-3.50$ (m, 6H), 3.45 (d, J= 16.0 Hz, 1H), $3.34(\mathrm{~s}, 1 \mathrm{H}), 3.31-3.27(\mathrm{~m}, 1 \mathrm{H}), 3.27-3.22(\mathrm{~m}$, $2 \mathrm{H}), 3.14-3.09(\mathrm{~m}, 1 \mathrm{H}), 3.08-3.02(\mathrm{~m}, 1 \mathrm{H}), 2.91-2.81(\mathrm{~m}, 3 \mathrm{H}), 2.78-2.69(\mathrm{~m}$, 1H), $2.30(\mathrm{~s}, 1 \mathrm{H}), 1.94-1.81(\mathrm{~m}, 1 \mathrm{H}), 0.88(\mathrm{~d}, J=1.6 \mathrm{~Hz}, 3 \mathrm{H}), 0.87$ (d, J= $1.6 \mathrm{~Hz}$, $3 \mathrm{H}) ;{ }^{13} \mathrm{C} \mathrm{NMR}\left(101 \mathrm{MHz}, \mathrm{CDCl}_{3}\right) \delta 169.3,150.6,138.4,129.5,129.3,128.7,126.9$, 126.7, 114.1, 70.9, 66.7, 66.4, 62.8, 58.4, 52.3, 48.7, 44.8, 42.2, 36.0, 27.1, 20.2, 20.0; HRMS (ESI) m/z calcd. for $\mathrm{C}_{26} \mathrm{H}_{37} \mathrm{~N}_{4} \mathrm{O}_{5} \mathrm{~S}$ ( [M -H] $]^{-}$): 517.2485, found 517.2501.

$N-((2 R$,

3S)-2-hydroxy-3-((2-morpholinoethyl)amino)-4-phenylbutyl)-N-isobutyl-4-methoxybe nzenesulfonamide (29a)

To a stirred

solution

of $N-((2 R$, 3S)-3-amino-2-hydroxy-4-phenylbutyl)-N-isobutyl-4-methoxybenzenesulfonamide (8, $0.10 \mathrm{~g}, 0.25 \mathrm{mmol})$ and $\mathrm{K}_{2} \mathrm{CO}_{3}(0.068 \mathrm{~g}, 0.49 \mathrm{mmol})$ in $\mathrm{CH}_{3} \mathrm{CN}(1 \mathrm{~mL})$ was added 4-(2-bromoethyl)morpholine $(\mathbf{2 1}, 0.057 \mathrm{~g}, 0.30 \mathrm{mmol})$ slowly and stirred for $30 \mathrm{~min}$. The resulting mixture was then warmed to $60{ }^{\circ} \mathrm{C}$ and stirred for another $1 \mathrm{~h}$. Upon 
completion, the reaction mixture was cooled to $25^{\circ} \mathrm{C}$ and filtered through a Celite $545^{\circledR}$ pad. The filtrate was concentrated under reduced pressure. The crude product was purified by silica gel column chromatography $\left(1 \% \mathrm{CH}_{3} \mathrm{OH}\right.$ in $\mathrm{CH}_{2} \mathrm{Cl}_{2}$ as the eluent) to afford 29a as pale yellow powder: yield 0.079 $\mathrm{g}(62 \%)$; mp60.0-61.9 ${ }^{\circ} \mathrm{C}$; ${ }^{1} \mathrm{H}$ NMR $\left(500 \mathrm{MHz}, \mathrm{CDCl}_{3}\right) \delta 7.75(\mathrm{~d}, J=8.5 \mathrm{~Hz}, 2 \mathrm{H}), 7.35-7.28(\mathrm{~m}, 2 \mathrm{H}), 7.26-$ $7.18(\mathrm{~m}, 3 \mathrm{H}), 6.97(\mathrm{~d}, J=8.5 \mathrm{~Hz}, 2 \mathrm{H}), 5.29(\mathrm{~s}, 1 \mathrm{H}), 3.86(\mathrm{~s}, 4 \mathrm{H}), 3.54-3.43(\mathrm{~m}, 3 \mathrm{H})$, $3.43-3.29(\mathrm{~m}, 2 \mathrm{H}), 3.15-2.99(\mathrm{~m}, 2 \mathrm{H}), 2.99-2.83(\mathrm{~m}, 3 \mathrm{H}), 2.66-2.55(\mathrm{~m}, 2 \mathrm{H})$, $2.51-2.36(\mathrm{~m}, 2 \mathrm{H}), 2.27-2.10(\mathrm{~m}, 5 \mathrm{H}), 2.04-1.89(\mathrm{~m}, 1 \mathrm{H}), 0.92(\mathrm{~d}, J=6.5 \mathrm{~Hz}, 3 \mathrm{H})$, $0.88(\mathrm{~d}, J=6.5 \mathrm{~Hz}, 3 \mathrm{H}) ;{ }^{13} \mathrm{C} \mathrm{NMR}\left(126 \mathrm{MHz}, \mathrm{CDCl}_{3}\right) \delta 163.0,138.5,131.0,129.6$, $129.5,129.0,126.9,114.4,69.9,66.9,62.5,58.1,57.3,55.8,53.3,52.2,43.8,34.8$, 27.2, 20.3; HRMS (ESI) $\mathrm{m} / \mathrm{z}$ calcd. for $\mathrm{C}_{27} \mathrm{H}_{40} \mathrm{~N}_{3} \mathrm{O}_{5} \mathrm{~S}$ ( [M -H $]^{-}$): 518.2689, found 518.2679 .

$N-((2 R$,

3S)-2-hydroxy-3-((2-morpholinoethyl)amino)-4-phenylbutyl)-N-isobutyl-4-(trifluorom ethyl)benzenesulfonamide (29b)

4-(2-Bromoethyl)morpholine (21) was treated with $N$ - ((2R, 3S)-3-amino-2-hydroxy-4-phenylbutyl)-N-isobutyl-4-(trifluoromethyl)benzenesulfona mide (9) by following the procedure outlined for $29 \mathbf{a}$ to give compound $29 \mathbf{b}$ as pale yellow powder $(71 \%)$. Mp 50.2-51.6 ${ }^{\circ} \mathrm{C} ;{ }^{1} \mathrm{H}$ NMR $\left(500 \mathrm{MHz}, \mathrm{CDCl}_{3}\right) \delta 7.99$ (d, J= $5.0 \mathrm{~Hz}, 2 \mathrm{H}), 7.80(\mathrm{~d}, J=10.0 \mathrm{~Hz}, 2 \mathrm{H}), 7.38-7.27(\mathrm{~m}, 3 \mathrm{H}), 7.26-7.20(\mathrm{~m}, 2 \mathrm{H}), 5.29$ $(\mathrm{s}, 1 \mathrm{H}), 3.83-3.74(\mathrm{~m}, 1 \mathrm{H}), 3.58-3.48(\mathrm{~m}, 3 \mathrm{H}), 3.49-3.36(\mathrm{~m}, 2 \mathrm{H}), 3.24-3.13(\mathrm{~m}$, $2 \mathrm{H}), 3.08-3.00(\mathrm{~m}, 1 \mathrm{H}), 2.91-2.82(\mathrm{~m}, 2 \mathrm{H}), 2.65-2.56(\mathrm{~m}, 1 \mathrm{H}), 2.56-2.37(\mathrm{~m}$, $3 \mathrm{H}), 2.26-2.17(\mathrm{~m}, 5 \mathrm{H}), 2.08-1.98(\mathrm{~m}, 1 \mathrm{H}), 0.96(\mathrm{~d}, J=10.0 \mathrm{~Hz}, 3 \mathrm{H}), 0.93-0.90$ $(\mathrm{d}, \mathrm{J}=5.0 \mathrm{~Hz}, 3 \mathrm{H}) ;{ }^{13} \mathrm{C} \mathrm{NMR}\left(126 \mathrm{MHz}, \mathrm{CDCl}_{3}\right) \delta 143.6,138.4,134.7,134.5,134.2$, 133.9, 129.4, 129.0, 128.0, 126.9, 126.4, 126.3, 69.8, 66.9, 62.4, 57.5, 57.3, 53.3, 51.5, 43.9, 35.2, 27.0, 20.2, 20.1; HRMS (ESI) m/z calcd. for $\mathrm{C}_{27} \mathrm{H}_{37} \mathrm{~F}_{3} \mathrm{~N}_{3} \mathrm{O}_{4} \mathrm{~S}\left([\mathrm{M}-\mathrm{H}]^{-}\right.$): 556.2457, found 556.2461.

$N-((2 R$, 
3S)-2-hydroxy-3-((2-morpholinoethyl)amino)-4-phenylbutyl)-N-isobutyl-4-nitrobenze nesulfonamide (29d)

4-(2-Bromoethyl)morpholine (21) was treated with $N$ - $((2 R$, 3S)-3-amino-2-hydroxy-4-phenylbutyl)-N-isobutyl-4-nitrobenzenesulfonamide (10) by following the procedure outlined for 29a to give compound 29d as pale yellow powder (73\%). Mp 98.5-100.8 ${ }^{\circ} \mathrm{C} ;{ }^{1} \mathrm{H}$ NMR $\left(500 \mathrm{MHz}, \mathrm{CDCl}_{3}\right) \delta 8.35(\mathrm{~d}, J=10.0 \mathrm{~Hz}$, 2H), $8.03(\mathrm{~d}, J=10.0 \mathrm{~Hz}, 2 \mathrm{H}), 7.40-7.27(\mathrm{~m}, 3 \mathrm{H}), 7.26-7.17(\mathrm{~m}, 2 \mathrm{H}), 5.29(\mathrm{~s}, 1 \mathrm{H})$, $3.89-3.80(\mathrm{~m}, 1 \mathrm{H}), 3.55-3.47(\mathrm{~m}, 3 \mathrm{H}), 3.42(\mathrm{~s}, 2 \mathrm{H}), 3.27-3.14(\mathrm{~m}, 2 \mathrm{H}), 3.01(\mathrm{~m}$, $1 \mathrm{H}), 2.96-2.82(\mathrm{~m}, 2 \mathrm{H}), 2.72-2.56(\mathrm{~m}, 2 \mathrm{H}), 2.55-2.38(\mathrm{~m}, 2 \mathrm{H}), 2.31-2.15(\mathrm{~m}$, $5 \mathrm{H}), 1.99-1.90(\mathrm{~m}, 1 \mathrm{H}), 0.94(\mathrm{~d}, J=10.0 \mathrm{~Hz}, 3 \mathrm{H}), 0.88$ (d, J=10.0 Hz, 3H); ${ }^{13} \mathrm{C} \mathrm{NMR}$ $\left(126 \mathrm{MHz}, \mathrm{CDCl}_{3}\right) \delta 150.1,145.9,138.0,129.4,129.1,128.7,127.1,124.5,69.2,66.8$, 62.4, 57.1, 53.2, 51.3, 43.7, 35.0, 26.9, 20.2; HRMS (ESI) $\mathrm{m} / \mathrm{z}$ calcd. for $\mathrm{C}_{26} \mathrm{H}_{37} \mathrm{~N}_{4} \mathrm{O}_{6} \mathrm{~S}$ ( [M - $]^{-}$): 533.2434, found 533.2434.

4-Amino-N-((2R,

3S)-2-hydroxy-3-((2-morpholinoethyl)amino)-4-phenylbutyl)- $N$-isobutylbenzenesulfon amide (29c)

The title compound was obtained by hydrogenation of $\mathbf{2 9 d}$ in $91 \%$ yield (pale yellow powder) by following the procedure outlined for $23 \mathrm{c}$ : $\mathrm{mp} 111.2-113.3{ }^{\circ} \mathrm{C} ;{ }^{1} \mathrm{H}$ NMR (500 MHz, $\left.\mathrm{CDCl}_{3}\right) \delta 7.56(\mathrm{~d}, J=8.0 \mathrm{~Hz}, 2 \mathrm{H}), 7.33-7.27(\mathrm{~m}, 2 \mathrm{H}), 7.26-7.13$ (m, 3H), $6.65(\mathrm{~d}, J=8.0 \mathrm{~Hz}, 2 \mathrm{H}), 5.32(\mathrm{~s}, 1 \mathrm{H}), 4.13(\mathrm{~s}, 2 \mathrm{H}), 3.92-3.82(\mathrm{~m}, 1 \mathrm{H}), 3.53$ $-3.40(\mathrm{~m}, 4 \mathrm{H}), 3.36(\mathrm{~s}, 2 \mathrm{H}), 3.04-2.90(\mathrm{~m}, 4 \mathrm{H}), 2.90-2.80(\mathrm{~m}, 1 \mathrm{H}), 2.69-2.56(\mathrm{~m}$, 2H), $2.52-2.34(\mathrm{~m}, 2 \mathrm{H}), 2.25-2.09(\mathrm{~m}, 5 \mathrm{H}), 1.96-1.88(\mathrm{~m}, 1 \mathrm{H}), 0.90(\mathrm{~d}, J=5.0 \mathrm{~Hz}$, $3 \mathrm{H}), 0.87(\mathrm{~d}, J=5.0 \mathrm{~Hz}, 3 \mathrm{H}) ;{ }^{13} \mathrm{C} \mathrm{NMR}\left(126 \mathrm{MHz}, \mathrm{CDCl}_{3}\right) \delta 150.8,138.4,129.7$, 129.6, 129.1, 127.1, 127.0, 114.3, 69.6, 66.9, 62.5, 58.5, 57.0, 53.2, 52.4, 43.6, 34.6, 27.3, 20.4, 20.3; HRMS (ESI) $\mathrm{m} / \mathrm{z}$ calcd. for $\mathrm{C}_{26} \mathrm{H}_{39} \mathrm{~N}_{4} \mathrm{O}_{4} \mathrm{~S}$ ( [M -H] $]^{-}$): 503.2692, found 503.2675.

$N-((2 R$, 3S)-2-hydroxy-3-(((S)-2-hydroxy-3-morpholinopropyl)amino)-4-phenylbutyl)-N-isobut 


\section{yl-4-methoxybenzenesulfonamide (30a)}

To a stirred solution of (R)-4-(oxiran-2-ylmethyl)morpholine (22, $0.034 \mathrm{~g}, 0.16$ mmol) in anhydrous EtOH (5 mL) was added DIEA (0.011 g, $0.82 \mathrm{mmol})$ dropwise under the protection of Argon. After stirring for $1 \mathrm{~h}, \quad N-((2 R$, 3S)-3-amino-2-hydroxy-4-phenylbutyl)-N-isobutyl-4-methoxybenzenesulfonamide (8, $0.80 \mathrm{~g}, 0.20 \mathrm{mmol}$ ) was added into the resulting mixture and then warmed to refluxing for $30 \mathrm{~h}$. Upon completion, the reaction mixture was concentrated under reduced pressure. Water was added into the residue and extracted with EtOAc. The extracts were washed with saturated brine, dried over $\mathrm{Na}_{2} \mathrm{SO}_{4}$, and concentrated under reduced pressure. The crude product was purified by silica gel column chromatography (1\% $\mathrm{CH}_{3} \mathrm{OH}$ in $\mathrm{CH}_{2} \mathrm{Cl}_{2}$ as the eluent) to afford 30a as white amorphous powder $(0.037 \mathrm{~g}$, 41\%). Mp 65.5-66.4 ${ }^{\circ} \mathrm{C} ;{ }^{1} \mathrm{H}$ NMR $\left(600 \mathrm{MHz}, \mathrm{CDCl}_{3}\right) \delta 7.77-7.72(\mathrm{~m}, 2 \mathrm{H}), 7.32-$ $7.28(\mathrm{~m}, 2 \mathrm{H}), 7.25-7.21(\mathrm{~m}, 3 \mathrm{H}), 7.01-6.96(\mathrm{~m}, 2 \mathrm{H}), 5.29(\mathrm{~s}, 1 \mathrm{H}), 3.87(\mathrm{~s}, 3 \mathrm{H})$, $3.82-3.78(\mathrm{~m}, 1 \mathrm{H}), 3.72-3.64(\mathrm{~m}, 5 \mathrm{H}), 3.29(\mathrm{dd}, J=18.0,6.0 \mathrm{~Hz}, 1 \mathrm{H}), 3.14(\mathrm{dd}, J=$ 15.0, $8.4 \mathrm{~Hz}, 1 \mathrm{H}), 2.99-2.84(\mathrm{~m}, 4 \mathrm{H}), 2.76-2.65(\mathrm{~m}, 2 \mathrm{H}), 2.60-2.52(\mathrm{~m}, 2 \mathrm{H}), 2.48$ $(\mathrm{dd}, J=12.0,6.0 \mathrm{~Hz}, 1 \mathrm{H}), 2.41-2.31(\mathrm{~m}, 3 \mathrm{H}), 2.25-2.20(\mathrm{~m}, 1 \mathrm{H}), 1.90-1.83(\mathrm{~m}$,

$1 \mathrm{H}), 0.87(\mathrm{~d}, J=6.6 \mathrm{~Hz}, 6 \mathrm{H}) ;{ }^{13} \mathrm{C} \mathrm{NMR}\left(151 \mathrm{MHz}, \mathrm{CDCl}_{3}\right) \delta 162.8,138.2,130.6$, 129.4, 129.3, 128.6, 126.6, 114.2, 70.2, 66.9, 65.7, 62.0, 61.8, 58.0, 55.6, 53.7, 52.4, 51.1, 35.1, 27.0, 20.1, 19.9; HRMS (ESI) m/z calcd. for $\mathrm{C}_{28} \mathrm{H}_{42} \mathrm{~N}_{3} \mathrm{O}_{6} \mathrm{~S}\left([\mathrm{M}-\mathrm{H}]^{-}\right.$): 548.2794, found 548.2789.

$N-((2 R$,

3S)-2-hydroxy-3-(((S)-2-hydroxy-3-morpholinopropyl)amino)-4-phenylbutyl)-N-isobut yl-4-(trifluoromethyl)benzenesulfonamide (30b)

(R)-4-(oxiran-2-ylmethyl)morpholine (22) was treated with $N$ - $((2 R$, 3S)-3-amino-2-hydroxy-4-phenylbutyl)-N-isobutyl-4-(trifluoromethyl)benzenesulfona mide (9) by following the procedure outlined for 30a to give compound $\mathbf{3 0 b}$ as white amorphous powder (59\%). $\mathrm{Mp} 52.1-54.2{ }^{\circ} \mathrm{C} ;{ }^{1} \mathrm{H} \mathrm{NMR}\left(400 \mathrm{MHz}, \mathrm{CDCl}_{3}\right) \delta 7.97-$ $7.91(\mathrm{~m}, 2 \mathrm{H}), 7.81-7.73(\mathrm{~m}, 2 \mathrm{H}), 7.34-7.27$ (m, 2H), $7.26-7.17$ (m, 3H), 5.29 (s, $1 \mathrm{H}), 3.79-3.72(\mathrm{~m}, 1 \mathrm{H}), 3.72-3.61(\mathrm{~m}, 5 \mathrm{H}), 3.42-3.29(\mathrm{~m}, 1 \mathrm{H}), 3.23-3.11(\mathrm{~m}$, 
1H), $3.09-2.95(\mathrm{~m}, 2 \mathrm{H}), 2.94-2.87(\mathrm{~m}, 1 \mathrm{H}), 2.80(\mathrm{dd},=16.0,4.0 \mathrm{~Hz}, 1 \mathrm{H}), 2.73-$ $2.60(\mathrm{~m}, 2 \mathrm{H}), 2.60-2.52(\mathrm{~m}, 2 \mathrm{H}), 2.43-2.28(\mathrm{~m}, 4 \mathrm{H}), 2.19(\mathrm{dd}, J=12.0,4.0 \mathrm{~Hz}$, $1 \mathrm{H}), 2.02-1.85(\mathrm{~m}, 1 \mathrm{H}), 0.88(\mathrm{t},=6.6 \mathrm{~Hz}, 6 \mathrm{H}) ;{ }^{13} \mathrm{C} \mathrm{NMR}\left(101 \mathrm{MHz}, \mathrm{CDCl}_{3}\right) \delta$ 143.2 , 138.1, 134.7, 134.4, 134.0, 133.7, 129.2, 128.7, 127.8, 126.7, 126.3, 126.2, 126.1, 72.9, 70.0, 67.0, 65.9, 62.0, 57.4, 53.7, 51.8, 51.2, 35.3, 26.9, 20.1, 19.9; HRMS (ESI) m/z calcd. for $\mathrm{C}_{28} \mathrm{H}_{39} \mathrm{~F}_{3} \mathrm{~N}_{3} \mathrm{O}_{5} \mathrm{~S}$ ( [M -H] $]^{-}$): 586.2563, found 586.2580.

$N-((2 R$,

3S)-2-hydroxy-3-(((S)-2-hydroxy-3-morpholinopropyl)amino)-4-phenylbutyl)-N-isobut yl-4-nitrobenzenesulfonamide (30d)

$(R)-4-(o x i r a n-2-y l m e t h y l) m o r p h o l i n e \quad(22) \quad$ was treated with $N$ - $((2 R$, 3S)-3-amino-2-hydroxy-4-phenylbutyl)-N-isobutyl-4-nitrobenzenesulfonamide (10) by following the procedure outlined for 30a to give compound 30d as white amorphous powder (61\%). $\mathrm{Mp} 81.2-83.9{ }^{\circ} \mathrm{C} ;{ }^{1} \mathrm{H} \mathrm{NMR}\left(600 \mathrm{MHz}, \mathrm{CDCl}_{3}\right) \delta 8.34-$ $8.28(\mathrm{~m}, 2 \mathrm{H}), 8.00-7.95(\mathrm{~m}, 2 \mathrm{H}), 7.32-7.28(\mathrm{~m}, 2 \mathrm{H}), 7.25-7.18(\mathrm{~m}, 3 \mathrm{H}), 3.77-$ $3.73(\mathrm{~m}, 1 \mathrm{H}), 5.45(\mathrm{~s}, 1 \mathrm{H}), 5.29(\mathrm{~s}, 1 \mathrm{H}), 3.71-3.63(\mathrm{~m}, 5 \mathrm{H}), 3.39(\mathrm{dd}, J=15.0,2.6$ $\mathrm{Hz}, 1 \mathrm{H}), 3.24(\mathrm{dd}, J=15.0,6.0 \mathrm{~Hz}, 1 \mathrm{H}), 3.08(\mathrm{dd}, J=13.6,7.6 \mathrm{~Hz}, 1 \mathrm{H}), 3.00(\mathrm{dd}, J=$ 13.6, 7.6 Hz, 1H), $2.94-2.89(\mathrm{~m}, 1 \mathrm{H}), 2.78(\mathrm{dd}, J=14.0,6.0 \mathrm{~Hz}, 1 \mathrm{H}), 2.72-2.63(\mathrm{~m}$, $2 \mathrm{H}), 2.59-2.53(\mathrm{~m}, 2 \mathrm{H}), 2.39(\mathrm{dd}, J=12.0,6.6 \mathrm{~Hz}, 1 \mathrm{H}), 2.37-2.33(\mathrm{~m}, 2 \mathrm{H}), 2.31-$ $2.27(\mathrm{~m}, 1 \mathrm{H}), 2.20(\mathrm{dd}, J=12.4,6.0 \mathrm{~Hz}, 1 \mathrm{H}), 1.94-1.86(\mathrm{~m}, 1 \mathrm{H}), 0.88(\mathrm{~d}, J=6.6 \mathrm{~Hz}$, $3 \mathrm{H}), 0.85(\mathrm{~d}, J=6.6 \mathrm{~Hz}, 3 \mathrm{H}) ;{ }^{13} \mathrm{C} \mathrm{NMR}\left(151 \mathrm{MHz}, \mathrm{CDCl}_{3}\right) \delta 149.8,145.7,137.9$, 129.1, 128.7, 128.4, 126.7, 124.2, 69.7, 66.9, 65.9, 62.0, 61.9, 56.8, 53.7, 51.3, 51.2, 35.3, 26.7, 19.9, 19.8; HRMS (ESI) m/z calcd. for $\mathrm{C}_{27} \mathrm{H}_{39} \mathrm{~N}_{4} \mathrm{O}_{7} \mathrm{~S}\left([\mathrm{M}-\mathrm{H}]^{-}\right)$: 563.2539, found 563.2551 .

4-Amino- $N-((2 R$,

3S)-2-hydroxy-3-(((S)-2-hydroxy-3-morpholinopropyl)amino)-4-phenylbutyl)-N-isobut ylbenzenesulfonamide $(\mathbf{3 0 c})$

The title compound was obtained by hydrogenation of $30 d$ in $95 \%$ yield (white amorphous powder) by following the procedure outlined for $23 \mathrm{c}$ : $\mathrm{mp} 74.3-76.2{ }^{\circ} \mathrm{C} ;{ }^{1} \mathrm{H}$ 
NMR (400 MHz, $\left.\mathrm{CDCl}_{3}\right) \delta 7.60$ - $7.52(\mathrm{~m}, 2 \mathrm{H}), 7.33$ - $7.27(\mathrm{~m}, 2 \mathrm{H}), 7.25$ - $7.17(\mathrm{~m}$, $3 \mathrm{H}), 6.71-6.62(\mathrm{~m}, 2 \mathrm{H}), 5.29(\mathrm{~m}, 1 \mathrm{H}) 4.16(\mathrm{~s}, 2 \mathrm{H}), 3.81-3.74(\mathrm{~m}, 1 \mathrm{H}), 3.73-3.59$ (m, 5H), $3.25(\mathrm{dd}, J=16.0,4.0 \mathrm{~Hz}, 1 \mathrm{H}), 3.12(\mathrm{dd}, J=16.0,8.0 \mathrm{~Hz}, 1 \mathrm{H}), 2.97-2.78$ (m, 4H), $2.74-2.60(\mathrm{~m}, 2 \mathrm{H}), 2.59-2.43(\mathrm{~m}, 3 \mathrm{H}), 2.40-2.29(\mathrm{~m}, 3 \mathrm{H}), 2.21(\mathrm{dd}, J=$ 12.4, 3.6 Hz, 1H), $1.91-1.79(\mathrm{~m}, 1 \mathrm{H}), 0.88(\mathrm{~d}, J=2.4 \mathrm{~Hz}, 3 \mathrm{H}), 0.86(\mathrm{~d}, J=2.4 \mathrm{~Hz}$, $3 \mathrm{H}) ;{ }^{13} \mathrm{C} \mathrm{NMR}\left(101 \mathrm{MHz}, \mathrm{CDCl}_{3}\right) \delta 150.6,138.5,129.5,129.4,128.6,127.0,126.5$, $114.1,70.5,67.0,66.0,62.2,61.9,58.2,53.8,52.6,51.2,35.3,27.1,20.2,20.0$; HRMS (ESI) m/z calcd. for $\mathrm{C}_{27} \mathrm{H}_{41} \mathrm{~N}_{4} \mathrm{O}_{5} \mathrm{~S}\left([\mathrm{M}-\mathrm{H}]^{-}\right.$): 533.2798, found 533.2813.

\section{In vitro assay for HIV-1 Protease}

The HIV-1 protease inhibitory activities of all new designed inhibitors were measured using fluorescence resonance energy transfer (FRET) method. Peptide (Arg-Glu (EDANS)-Ser-Gln-Asn-Tyr-Pro-Ile-Val-Gln-Lys(DABCYL)-Arg) purchased from AnaSpec was selected as the substrate. The energy transfer donor (EDANS) and acceptor (DABCYL) dyes are labeled at two ends of the peptide to perform FRET. Excitation and emission wavelengths were set at $340 \mathrm{~nm}$ and $490 \mathrm{~nm}$. Inhibitors were dissolved in dimethylsulfoxide (DMSO) and diluted to appropriate concentrations. HIV-1 protease was cloned and heterologously expressed in Escherichia coli and purified. The experiment was carried out in 96-well plates. The FRET assay reaction buffer contained $0.1 \mathrm{M}$ sodium acetate, $1 \mathrm{M}$ sodium chloride, 1 $\mathrm{mM}$ ethylenediaminetetraacetic acid (EDTA), $1 \mathrm{mM}$ dithiothreitol (DTT), 2\% DMSO and $1 \mathrm{mg} / \mathrm{mL}$ bovine serum albumin (BSA) with an adjusted $\mathrm{pH}$ 4.7. Protease and inhibitor were mixed and incubated for 20-30 mins at room temperature and then the substrate was added. Each reaction was recorded for about 10 mins.

\section{Converting $\mathrm{IC}_{50}$ to $\mathrm{K}_{\mathrm{i}}$ values}

The $\mathrm{IC}_{50}$ value depends on concentrations of the enzyme HIV-1 PR, the inhibitor, and the substrate along with other experimental conditions. While, comparisons of $\mathrm{K}_{\mathrm{i}}$ values can be more readily made among different laboratories to characterize the inhibitors. What is required is an accurate determination of the $\mathrm{K}_{\mathrm{i}}$ value, an intrinsic, 
thermodynamic quantity that is independent of the substrate but depends on the enzyme and inhibitor. For competitive inhibition, the equation for $\mathrm{K}_{\mathrm{i}}$ is used to take into account the concentration of the substrate, the $\mathrm{K}_{\mathrm{m}}$ of the enzyme-substrate reaction and the $\mathrm{IC}_{50}$ value. The expression is

$$
\mathrm{K}_{\mathrm{i}}=\mathrm{IC}_{50} /\left(\mathrm{S} / \mathrm{K}_{\mathrm{m}}+1\right)
$$

The concentration of the substrate in the assay is $6.20 \mu \mathrm{M}$, and the $\mathrm{K}_{\mathrm{m}}$ of the enzyme-substrate reaction is $1.79 \mu \mathrm{M}$.

\section{Infectivity assay on HIV-1 late stage}

The inhibitory effect of compounds on HIV-1 infectivity were determined using a single-round HIV-1 infectivity assay. 293T cells were co-transfected with either plasmid pNL4-3-E-R $\quad$ (pHIV-1 $\left.{ }_{\mathrm{NL4}-3}\right)$ or DRV-resistant pNL4-3-E-R ${ }^{-}$variants $\left(\mathrm{pHIV}^{-1} 1_{\mathrm{DRV}}{ }_{\mathrm{s}}\right.$ ) and $\mathrm{pHCMV}-\mathrm{G}(\mathrm{VSV}-\mathrm{G})$ to produce VSV-G pseudotyped HIV-1. Inhibitors dissolved in dimethylsulfoxide (DMSO) and diluted to appropriate concentrations, were added into culture medium at 5 hours of post-transfection. After incubating for 48 hours at temperature $37{ }^{\circ} \mathrm{C}$, pseudotyped viruses in $10 \mu \mathrm{L}$ of supernatant were used to infect SupT1 cells for 48 hours, followed by measuring luciferase activity of newly infected cells using Centro LB960 (Berthold).

For the assay using wild type HIV $-1,1 \times 10^{6}$ SupT1 cells were infected with $100 \mu \mathrm{L}$ HIV-1 NL4-3 in the presence of $100 \mathrm{nM}$ chemicals and $10 \mu \mathrm{g} / \mathrm{mL}$ polybrene, keeping a total volume of $500 \mu \mathrm{L}$ (Spin infection at 1800rpm, 45min). Cells were washed once in the next morning and medium were replaced with fresh medium containing $100 \mathrm{nM}$ chemicals. At $48 \mathrm{hpi}$, viruses were harvested and $50 \mu \mathrm{L}$ of viruses were used to infect TZM-bl cells, followed by measuring luciferase activity in the infected cells.

\section{Infectivity assay on HIV-1 early stage}

To assess the effect of the compounds on HIV-1 infectivity, the experiments were carried out using VSVG-pseudotyped HIV-1. SupT1 cells $\left(1 \times 10^{5} / \mathrm{ml}\right)$ were infected with VSVG-pseudotyped HIV-1(NL4-3) in 96-well plates, and then the compounds were added at the concentration of $10 \mu \mathrm{M}$. Equal volumes of DMSO were added into 
the culture medium, in order to keep constant final DMSO concentration as $1 \%(\mathrm{v} / \mathrm{v})$. 48 hours later, SupT1 cells were lysed and firefly luciferase activities were determined using a firefly Luciferase Assay System (Promega).

\section{Construction of DRV-resistant pNL4-3-E-R- cloning $\left(\mathrm{pHIV}-1_{\mathrm{DRV}} \mathrm{R}_{\mathrm{s}}\right)$}

To generate HIV-1 clones carrying the intended mutations, site-directed mutagenesis kit (SBS Genetech) was used. V32I, L33F, I54M, and I84V in the protease were introduced into pNL4-3-E-R- according to the manual from the manufacturer. The primers used for mutations were 32/33 (F'-ACAGGAGCA GATGATACAATATTTGAAGAAAT GAATTTGCCA, R'-TGGCAAATTCATTTC TTCAAATATTGTATCATCTGC TCCTGT), 54(F'-GGGAATtGGAGGTtTTATG AAAGTAAGACAGTATGAT, R'ATCATACTGTCTTACTTTCATAAAACCTCCAATTCCC) and 84(F’- GGA CCTACACCTGTCAACGTAATTGGAAGAA ATCTGT, R'- ATCATACTG TCTTACTTTCATAAAACCTCCAATTCCC). Determination of the nucleotide sequences of plasmids confirmed that each clone had the desired mutations but no unintended mutations (BBI Life Sciences Corporation).

\section{Molecular modeling}

In general, the docking was performed through "DOCK" module in the Molecular Operating Environment (MOE) using the alpha triangle placement method. Refinement of the docked poses was carried out using the Forcefield refinement scheme and scored using both the affinity $\mathrm{dG}$ and london $\mathrm{dG}$ scoring system. The pose with the higher docking negative score implied better binding. 